\title{
Catalogue of Tombs
}

\author{
Transcribed by Vanessa Davies
}

The tomb types listed below, when supplied, are taken from Reisner (1932), where he mentions a few of the $\mathrm{N} 2000$ tombs. The types are as follows:

rock-cut chamber with sloping entrance ( $\mathrm{N} 2 \mathrm{O} 71)$.

vi a = Open pit with crude-brick well, roofed with stone slabs, plastered with mud (N 2096).

vi $\mathrm{b}=$ Open pit with rubble well, or sunk well, roofed with stone slabs (N 2103).

vi $\mathrm{c}=$ Open pit with burial rectangle, packed with rubble or stone slabs and covered with stones or stone slabs and mud plaster ( $\mathrm{N} 2042)$.

vi $\mathrm{d}=$ Open pit with side chamber, blocked with crude-brick or rubble (N 2075).

For each tomb, there are one or two abbreviations indicating the source of that tomb data.

$\mathrm{TC}=\mathrm{Tomb}$ Card (field notes in the MFA, with copies at the Hearst Museum). MM = Mace Manuscript (manuscript draft in the MFA, with a copy at the Hearst Museum).

Where MM is crossed out (MM), it indicates that Mace had included the record in his manuscript and subsequently crossed it out.

The photograph numbers as listed below reflect the original excavator's numbering system. That system is slightly different from the current numbering systems used by the Phoebe A. Hearst Museum of Anthropology and the Museum of Fine Arts, Boston. The original glass negatives were numbered sequentially with a letter prefix (A, B, or C), which indicates the plate size. The Hearst Museum's current numbering system, which is used in this book except in the text reproduced from the original excavator's records, is NED-letter prefixphotograph number. The numbering system at The Museum of Fine Arts, Boston includes the suffix_os (for "Old Series") after the photograph number.

The drawings reproduced below accompanied the field notes. They do not always appear here in numerical order due to the constraints of the layout of this book.

Plates that illustrate the catalogue follow at the end. They were not inserted into the catalogue text because they are not a part of that original text. 

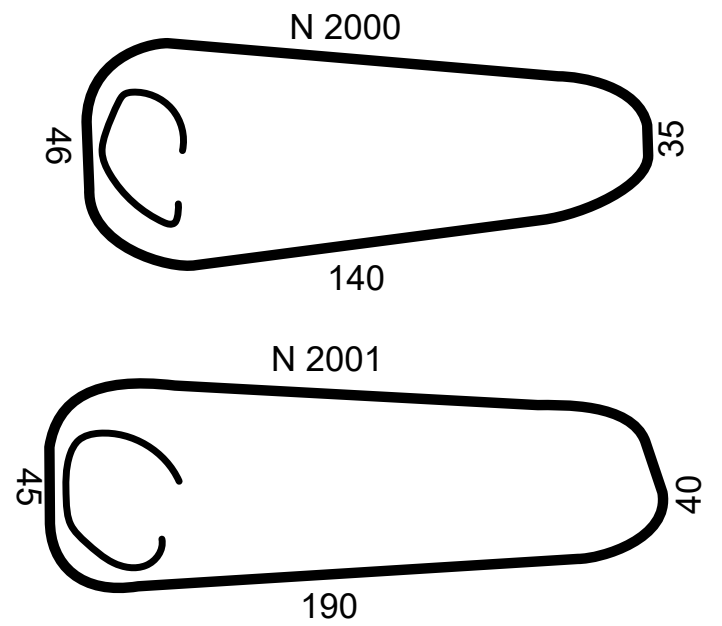

(i)
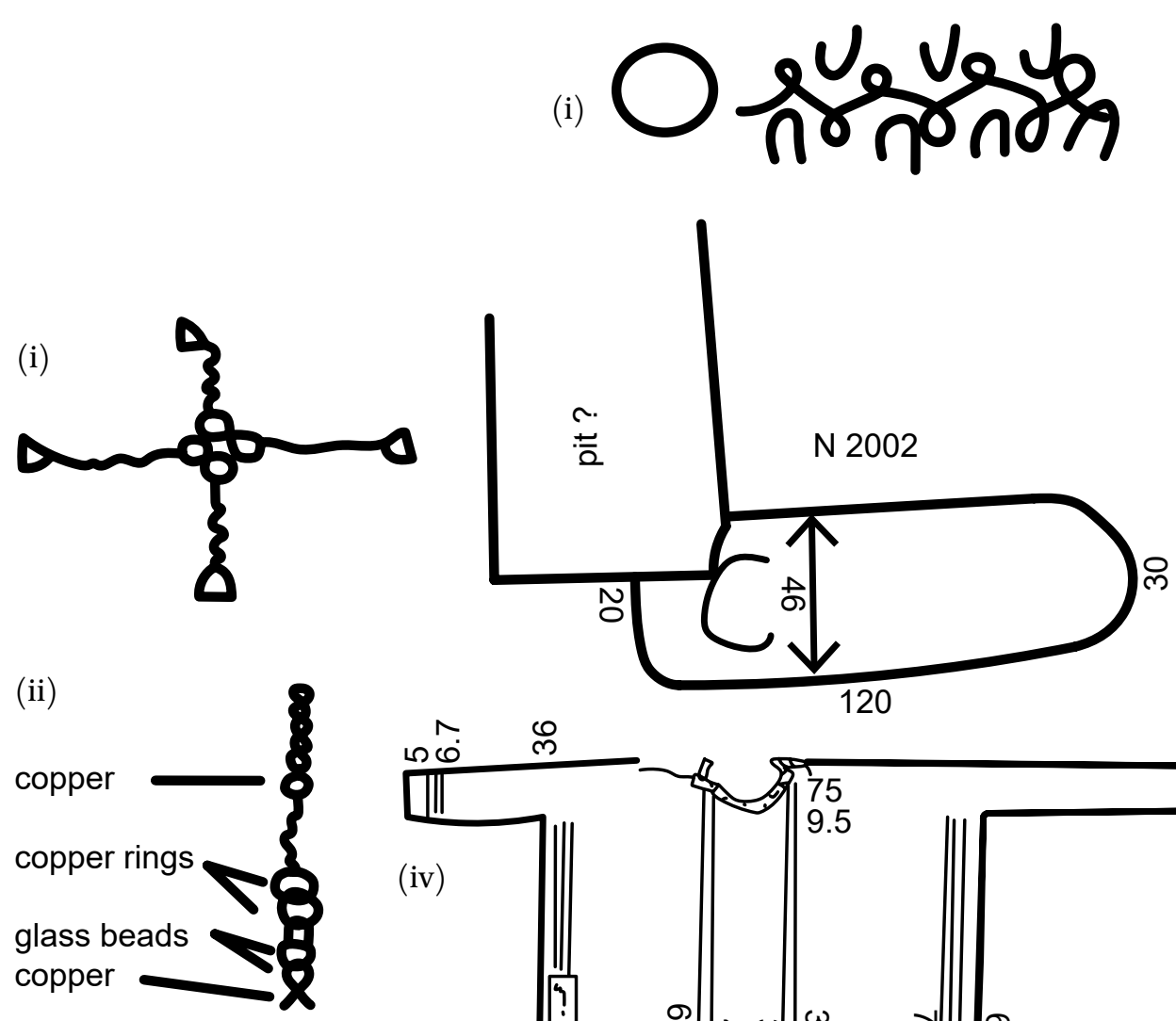

(iii)
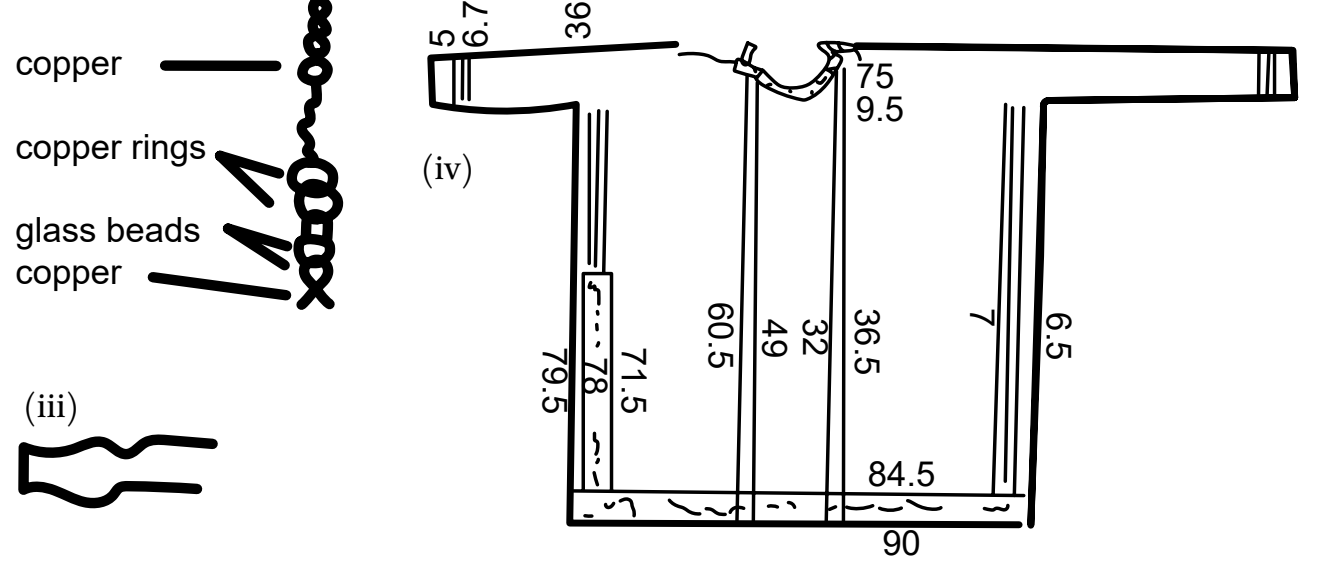


\section{N 2000 (TC; MM) Map E3; photo C 8004}

75 down. Copt. Shallow grave running east-west. Adult. Sex? On back, head west. The outside wrapping was a shawl of yellow cloth with fringed edges, and 7 lines of white thread inwoven at either end. This was laid above the body at the head end, and there was a slight excess of cloth. Here, the sides of the cloth were turned down and sewn together. At the feet end, there was a larger excess that was turned back under the feet and apparently left loose. The shawl next below showed traces of elaborate work in colored wool. This mummy was not unwrapped, but was packed and sent away whole. We have therefore no research of the inner wrappings.

N 2001 (TC) Map N/A [ed.: This record is Reisner's note of preliminary work that was done in 1901.]

Rotten wooden box empty.

[ed.: No image. This tomb card also contained brief notes about N 2021 and $\mathrm{N} 2041$, referring not to Mace's tombs of those numbers, but reflecting an earlier numbering system.]

N 2001 (TC; MM) Map D3 [ed.: Map location given in excavation records; perhaps adjacent to $\mathrm{N} 2433$, mostly in the tear in the map]; photo $\mathrm{C} 8194$ 100 down. Copt. Shallow grave running east-west. Adult male. On back, head west, arms by side. Remains of linen shirt with embroidered rosettes round sleeves, reaching apparently to halfway between knee and ankle. 3 woven ridges down each breast and over shoulder. Sides of shirt and bottom of sleeves corded. Shirt made in 1 piece. Nether arm was in sleeve. Sleeves were sewn up to above elbow at any rate. There were 2 wrapping shawls, both of sackcloth. These were folded over the body in the usual way, and ends of both were sewn together with fine cord. Between the 2 shawls, there were a few cords bound round the neck. On the outside, the bindings were of type 4 (i), but mostly gone. Quantity of salt. Under body, there were 3 palm sticks and 1 of sesaban, fastened together, and on the body there was a quantity of salt. Round the neck, there was a small shawl of coarse cloth, with lines of green and blue thread inwoven at either end. Over face, an enormous pad of cloth, consisting of an old shirt, much darned and patched.

N 2002 (TC; Mм) Map D3 [ed.: according to excavation records, tomb is lo-

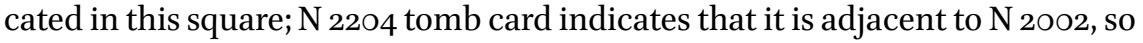
partially in the tear in the map]; photo C 8451, C 8455

70 down. Copt. Shallow grave running east-west. Child aged approx. 8, probably a girl. On back, head west, arms by side. Traces of straight, dark hair. Round neck 2 or 3 strings of glass beads, blue, green, yellow, and red, with a few shells. 

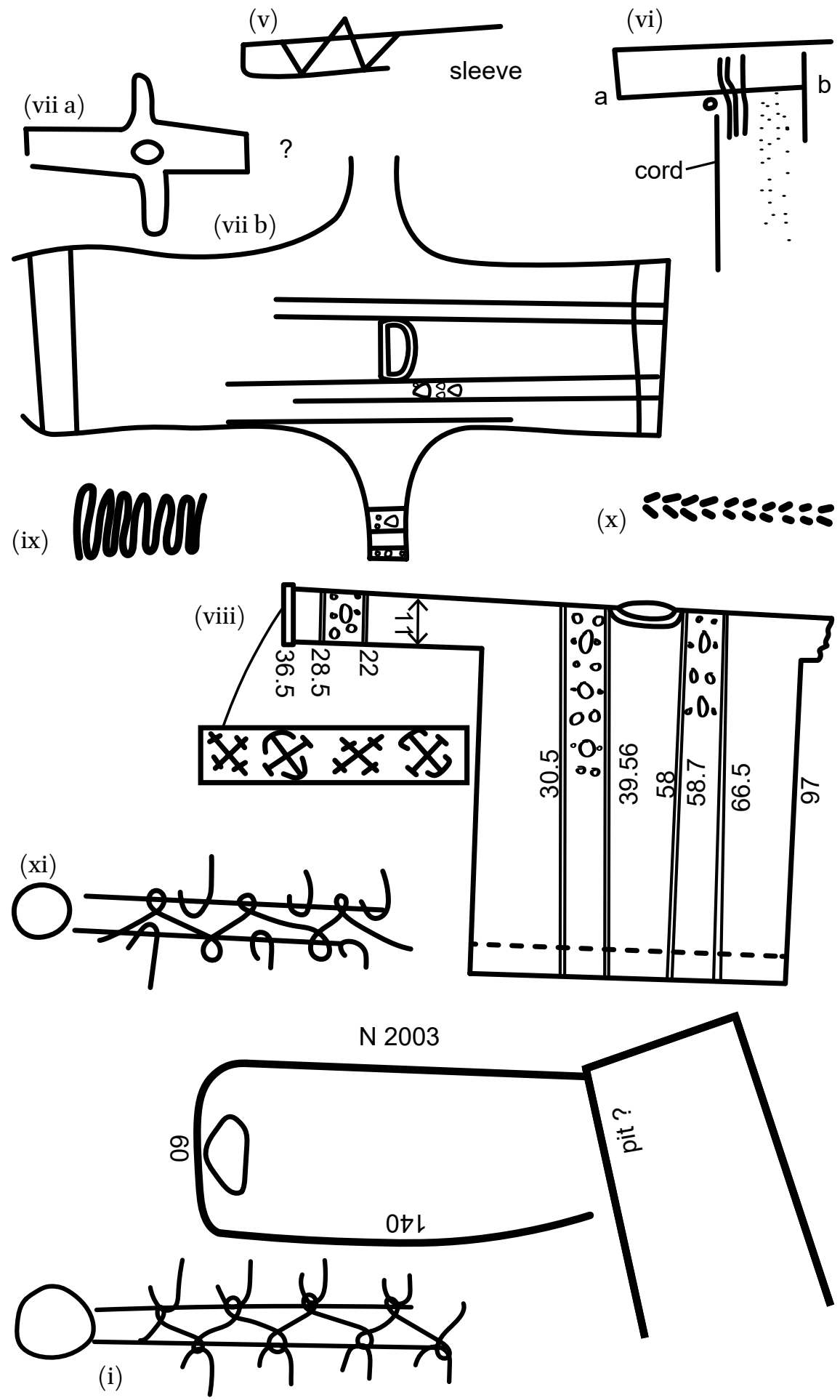
On the breast, probably attached to one of these strings, a cross composed of glass beads and copper wire. 4 beads in center, 3 red and 1 blue (i). On right ear, earring of copper with glass bead pendants (ii). On left, remains of a similar one. On the right and left wrists, a copper bracelet of type (iii), and also on the left, a broken one of bone. On a finger of the left hand, a copper ring. The body was dressed in a single linen shirt (iv) of a dark reddish color. 2 narrow lines down each breast and 3 at each side. 3 on each sleeve. Sides of shirt and ends of sleeves corded (v). Neck plain. Bottom of shirt selvage (vi) with linen ridges left in weaving (a...b). Both edges of sleeves were selvage, and thin edge [illegible] into body of shirt. Shirt cut from one piece of cloth. Sleeves originally sewn to armpit. On the head, there were remains of a net hood or cap of blue, yellow, and red thread. This was covered by a piece of cloth. Between last wrapping and shirt, under the body, a layer of salt and 2 palm sticks. These had been tied together. A few plant seeds on body. The first wrapping shawl consisted of a coarse cloth that was folded over in the usual way, but the right side was thrown over before the left. Above this, the body was wrapped in the shirt that had been unpicked at the sides and opened out to its fullest extent (vii a, vi b). Sleeves wrapped round over middle of body. Elaborate embroidery (viii): Remains of white and blue strip sewn around neck, 2 wide, and around bottom of sleeves. Around bottom of shirt, remains of a strip approx. 7 wide. On this bottom strip at any rate, white and blue were put on separately. White was sewn on so (ix), and blue thread was afterwards worked in in such a way as to leave geometrical patterns in white. From shoulder to below armpit, a line of red wool was sewn in so (x). Lines of embroidery of rosettes (flower designs) in red, yellow, blue, and green wools down front and round sleeves were enclosed by narrow lines of dark blue or heliotrope thread worked into warp. The shirt was cut from a single piece of cloth. In the weaving, there were occasional lines of thicker thread in the woof. Embroidery in blue, yellow, red, and green wool, sewn on to the warp, the woof in many cases being left undernearth. The binding of horizontal 2-strand fiber cords came next above this and was of type 4 (xi).

\section{N 2003 (тс; мм) Map D3; photo C 7979, C 7980, C 7981, C 7982, C 8003} 100 down from hard gebel. Copt. Shallow grave running east-west. Adult male. On back, head west, arms by side. Remains of beard, almost red in color. Pubic hair dark brown in color. Right ear still preserved. The body was clothed in 3 linen shirts, all plain except middle one, which had a decoration of 2 inwoven blue lines of thread. Under the body, there were 2 sticks, on the left, an acacia, and on the right, a palm. The first and second wrapping shawls were of coarse cloth, folded over in the usual way. Next came the binding, 2-strand fiber cords, which was of type 4 (i), and above this, there was a shawl of finer 

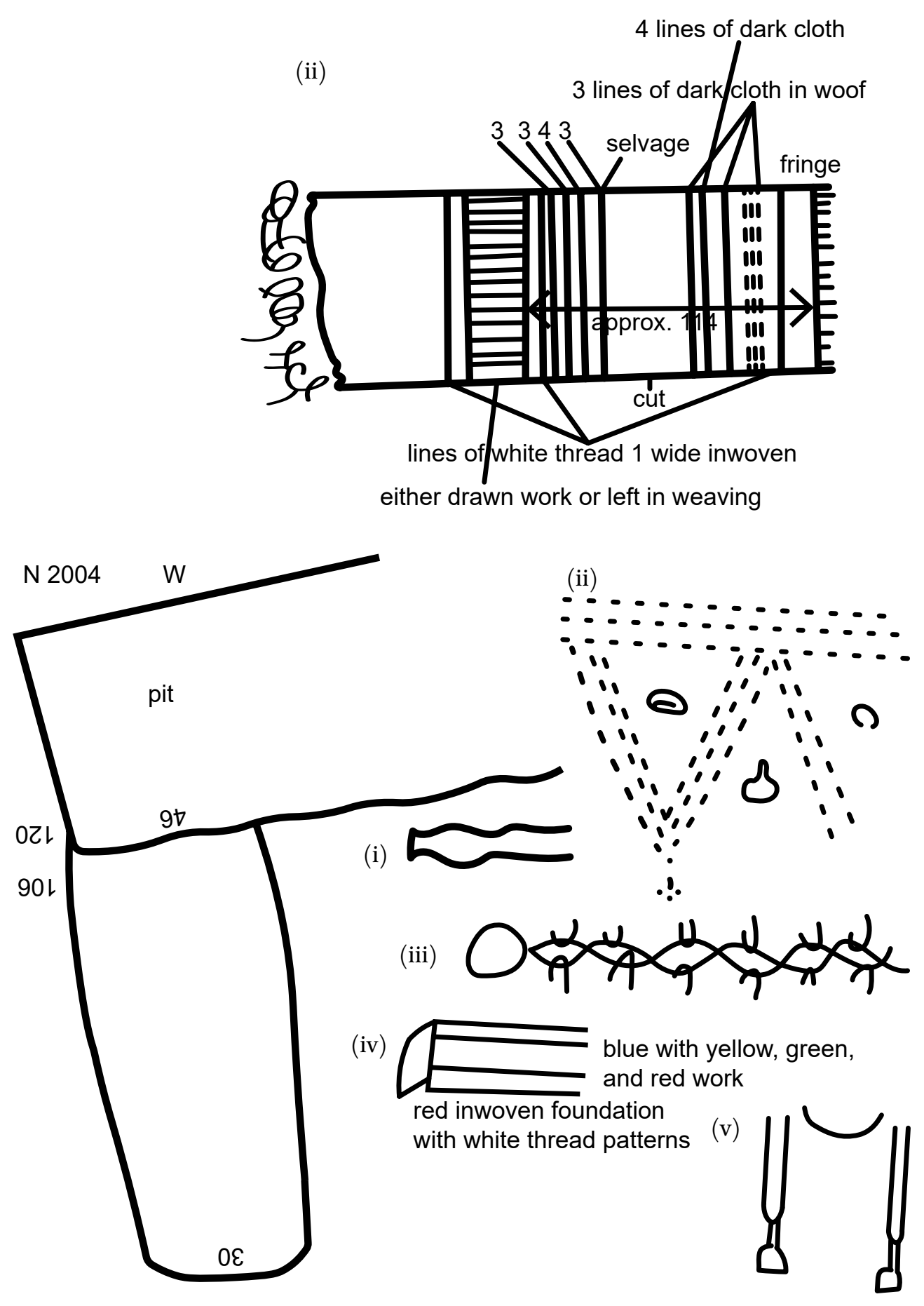
cloth, apparently laid loosely on top. This outer shawl (ii) had apparently been taken from the loom in an unfinished state, as at one end, the threads were tangled and unravelled. In the grave, under the feet at any rate, there was a layer of palm leaves.

N 2004 (TC; MM) Map D4 [ed.: Map location given in excavation records; probably adjacent to $\mathrm{N} 2838$, in tear on map.]; photo $\mathrm{C} 8480$

8 o down. Copt. Shallow grave running east-west, west end projecting over early pit. Adult female. On back, head west, arms by side. Skull gone. Left femur broken anciently. On the right forearm, 4 iron bracelets. On the right wrist, a copper bracelet of type (i). On left wrist, copper bracelet of type (i). On the right hand, 8 rings of bone, 6 on the third finger and 2 on the little finger. On the left hand, 6 or 7 rings of bone. Wrapped on outside in a shawl of dark heliotrope color with a fringed end and white inwoven lines near end (ii). This was merely laid on top of body versus being tied round feet. Near end, there was a pattern in dark red wool. Small designs in angles in light red, blue, green, and yellow wool. Underneath, tied with 2-strand fiber cord (iii). Under this, additional horizontal bindings. Below, wrapped in 2 thicknesses of sackcloth, both with sides sewn together. Upper, left over right. In lower, right over left. Outer shirt had bands of embroidery down front and over shoulder (iv). Neither arm in sleeve. Under this, there was a shawl, which completely covered body. Below, another shirt, left arm in sleeve. First shirt: neck gone, sides corded, bottom of sleeves corded. Sleeves similar to chest bands, but double row of blue. Chest design (v) apparently not on shoulder. Sewn on to bottom, a strip of blue cloth with white thread designs, 5 wide. Similar pointed endof sleeve 1.7 wide. Second shirt: round bottom, a strip of red cloth sewn on 6 wide with designs in sewn white thread. This was apparently sewn on back and front and went a distance of 38 up sides. The cloth of shirt was brown with occasional lines of green bounded by white thread. Down the chest?, there were bands of designs in red wool. Round sleeves, a narrow band of red cloth with white thread designs. A quantity of salt and a few plant seeds were sprinkled over the body. Under body between sackcloth and shirt, 3 palm sticks. These were tied together with fiber cords at either end. 


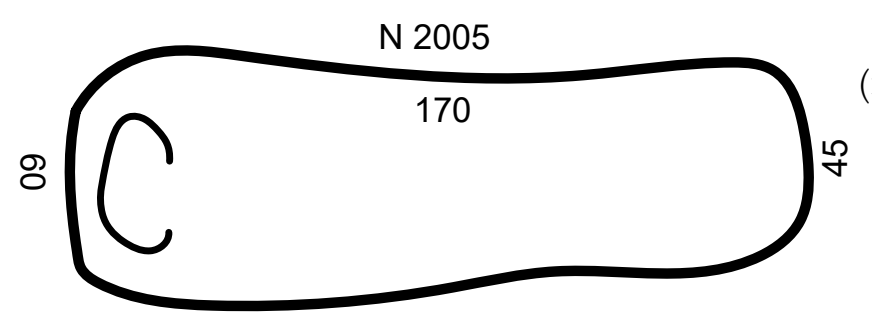

(iii)

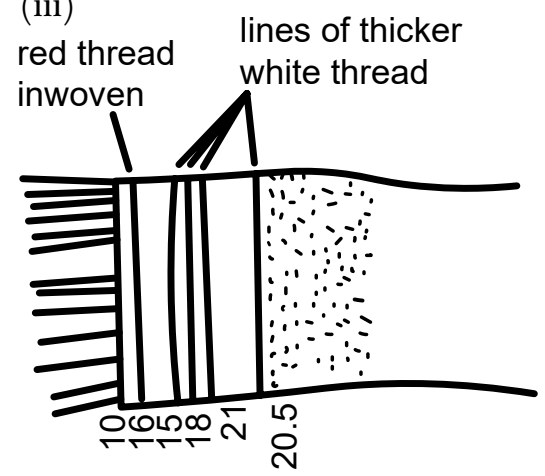

(iv)

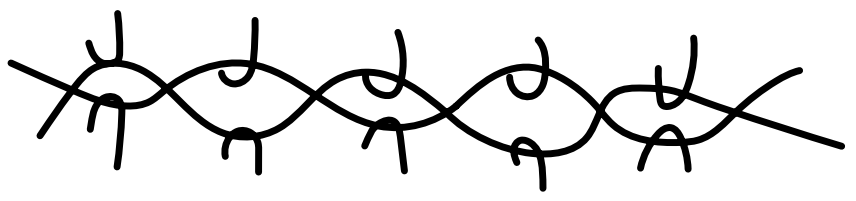

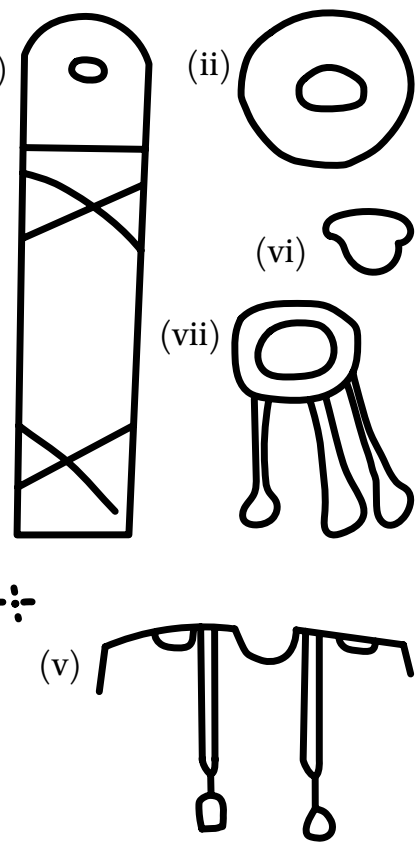

0

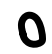

N 2006

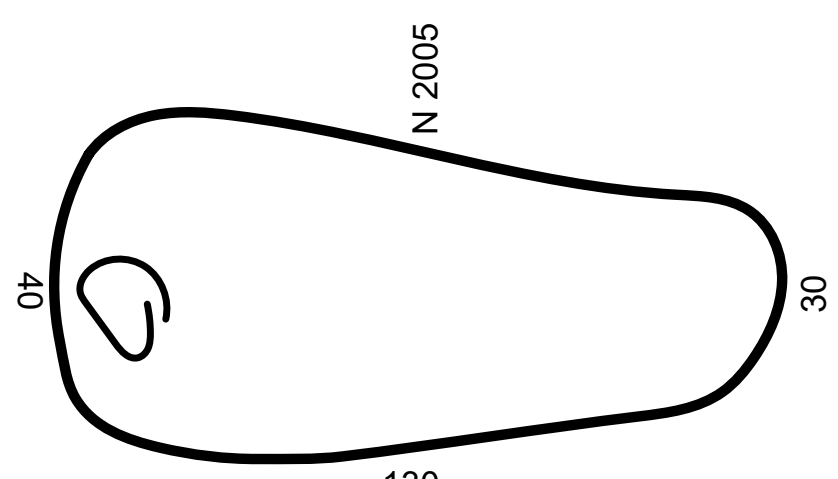

130

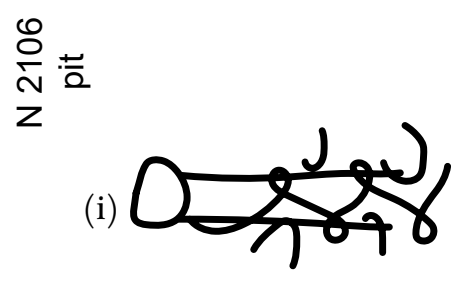




\section{$\mathrm{N}_{2005}$ (TC) Map D4}

8 o down. Copt. Male? Head west, aged 22-23. In filling, on. Also, a wooden? pierced (i). Also, a wooden disc (ii), and a piece of fiber rope. Laid on top of body outside, not wrapped round, a shawl approx. $15^{2} \times 5^{2}$ (iii). Had fringed edges. Color almost all gone. In angles, trees of green boughs with red trunks (wool). Colors all needle work. Remains of binding of 2 straw fiber cords, type (iv). Below, a single binding of sackcloth, left side over right. Below, a wrapping of cloth with 2 rows of 3 inwoven lines of green thread near each end and a wrapping of coarse cloth. These two were folded over together. Very curly dark brown hair. Shirt (v) reached almost to ankle. Bottom of shirt plain, top turned over and hemmed. Neck (vi) type. Sleeves? Left arm at any rate not in sleeve. Right arm probably not either. Decoration of scroll flower type. Work in lines: figures? in rosettes. Background, inwoven red, green, yellow, and blue wool sewn in afterwards. A small round pad sewn on to back of neck on outside. Quantity of salt under body. Few plant ends on body. Under body, 1 "sont" [i.e., acacia] and 1 palm stick outside innermost wrappings. These had been tied together. Inside shirt by left arm, remains of an iron? (vii).

\section{N 2006 (TC) Map D4; photo C 8002}

9o down. Coptic child. Head west, aged approx. 10. Remains of binding of type (i). On right shoulder, small ball of fiber cord and 2 or 3 skeins of fiber fastened together. Wrapped first in a cloth shawl with embroidered ends, then in a shawl of bright red. Quantity of salt on body. Over head, at any rate, under red shawl, remains of woolen wrapping with embroidery. This was almost all gone, but there remained several little bunches of wool that had been sewn on. Quantity of reddish brown short hair preserved on head. Also, on right eye, eyelashes and eyebrows preserved. Round head, a circlet of palm leaf 3 wide. This was wound inside and out with red wool that was wound round? and into this wool were stuck bits of straw to form patterns. Remains of shirt, showing small red border sewn on round neck. On right arm, remains of an iron bracelet. Outer shawl had fringed ends (ii). Near fringe, a line of open work. All traces of color gone. Red shawl: piece of a shirt (iii). Near sides, lines of white thread (inwoven). Patterns bounded by lines of white thread. Ground of patterns blue: decoration in white thread with red and yellow wool insertion. 

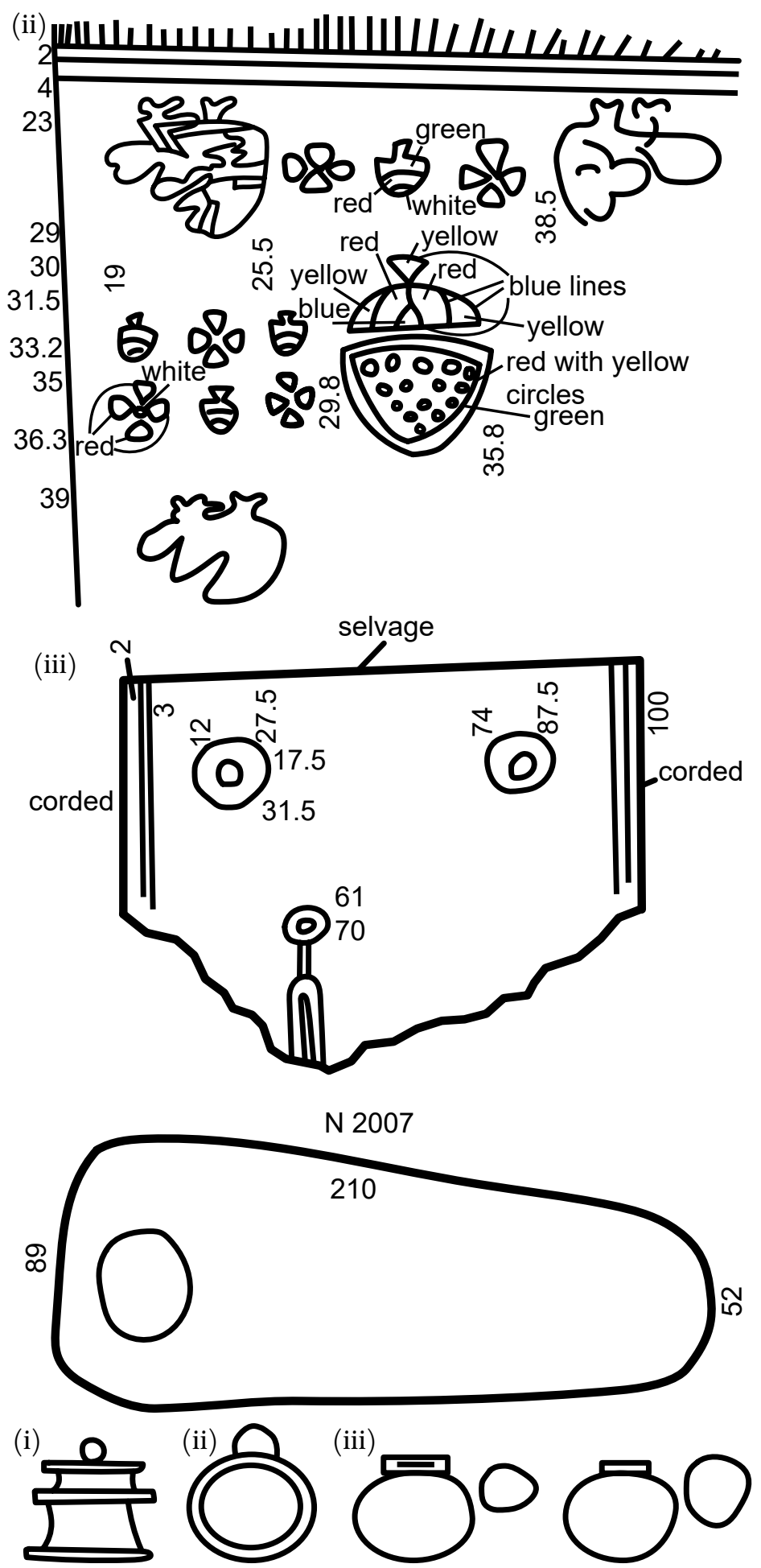

(iii)

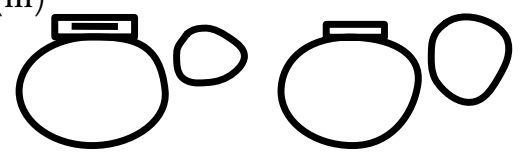




\section{N 2007 (TC) Map D4; photo C 8463}

95 down. Copt. Adult male. Head west. In filling on west side, wooden box (i). Usual position. Cloth almost all gone except from above head. On finger of left hand, silver ring (ii). On one finger of right hand, 2 copper rings (iii). These had animal figures? engraved on bezel. Skull was standing straight up so that it faced towards feet. Over skull, there was certainly 1 thickness of sackcloth, 2 of cloth. Under body, one on each side, a palm stick. By right side of body, too small for bracelet, too large for ring, a copper circlet.

\section{N 2008 (TC) Map D4 (red)}

Coptic. Burial of a small Coptic child aged 1-2 at end in filling of pit. Tied on outside with double strand fiber cord. Wrapped first in a shawl with fringed ends with, originally, lines of red, blue, and yellow wool [illegible] all over. 80 wide. Underneath, feet were wrapped in remains of a tiny plain shirt. Under body, inside wrappings, 3 palm sticks tied together at ends. Quantity of salt with body. Over head, remains of a shawl with green lines inwoven. No trace of shirt. On left arm, remains of 2 or 3 iron bracelets.

\section{N 2009 (TC) Map E3}

75 down. Copt. Head west. First tied with horizontal double strand fiber cord with style (i). Outside, a wrapping of sackcloth, ends fringed, line of open work near ends. Left side folded over right. Below, 3 wrappings of cloth, outer being of fairly rough texture, middle medium, and inner fine. They all had left side folded over right. They reached to just below feet, but there was a large excess, $40-5$ o, beyond head. The ends of the 3 cloths were turned over head together and twisted up to form a large circular pad. The outer shawl was plain with fringed ends. Middle had tasselled ends and near ends, starting at approx. 20, a line of embroidery 45 wide, between 2 narrow lines of unwoven green thread. The embroidery consisted of geometrical patterns of yellow, green, red, and blue wool. Length approx. 230, width approx. 115. The inner shawl had plain ends turned over and hemmed, starting at 5 from end. There were 2 lines of dark red and blue cloth inwoven, 2-3 wide. Between them, there were occasional small crosses, etc., in same color (sewn in). Length 130-140, width approx. 120. This shawl was darned in several places. Between this shawl and the body, there was a quantity of salt. Over face, an extra pad of cloth. Quantity of long artificially curled hair? Remains of beard? Straight. Round neck, inside shirt, a strip of palm leaf. Body in very good condition. Most of skin left. On right leg, bottom of fibula joined both to tibia and heel bone. 3 shirts. The 2 outer ones at any rate were inside out. Remains of reddish brown pubic hair. Under body, between shirts and shawls, 2 thick "sont" sticks. These were tied together at ends. Arms were outside all sleeves. Headpad consisted of a 


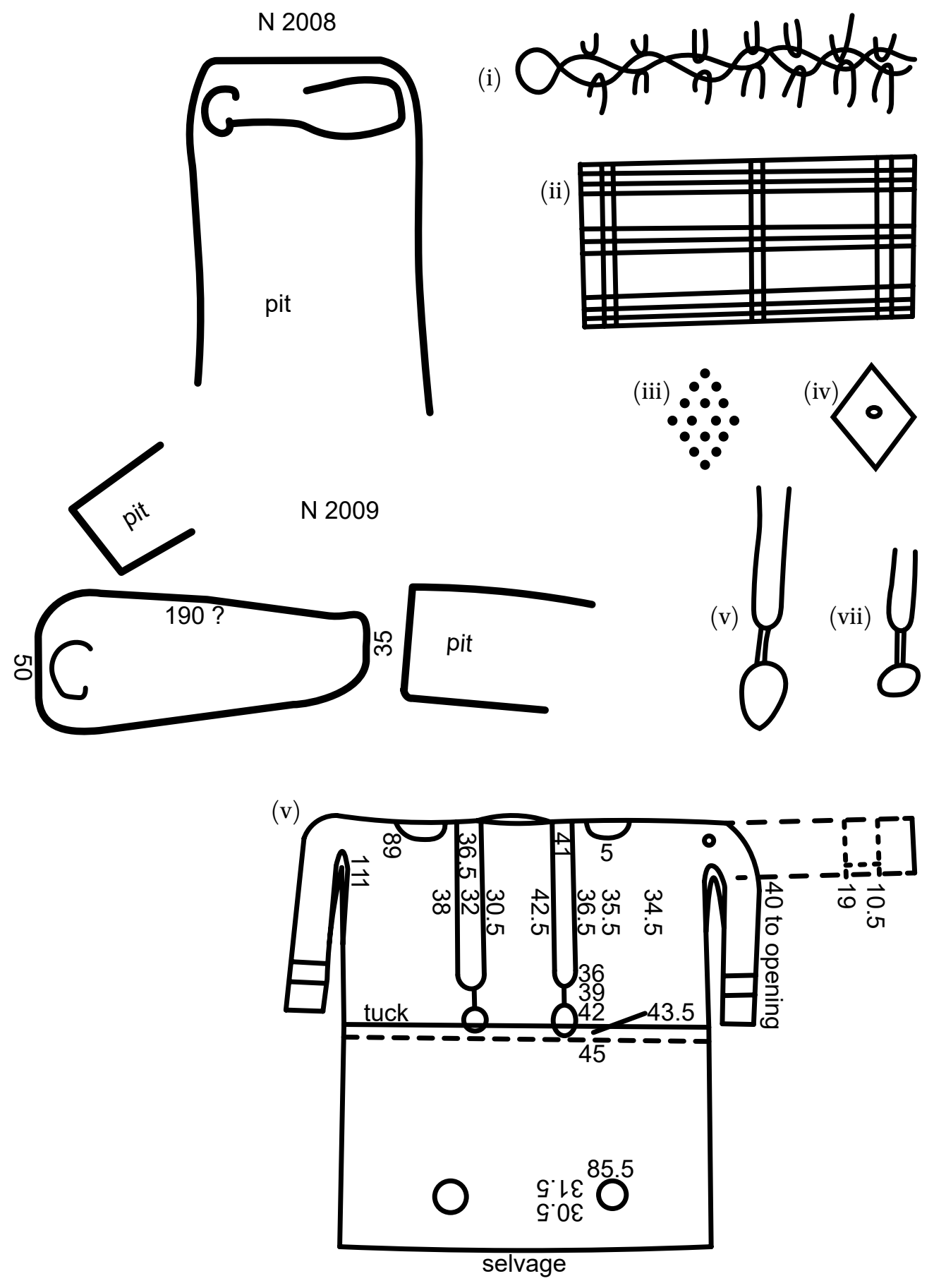


shawl 64 wide, ? long. Sides were strengthend by an ending of colored wools (ii). Lines of blue and green inwoven in cloth. Near one corner, (iii) in colored wools (needlework). Near another corner, (iv) in red wool with a green center. Put in with a needle. Probably there were 2 of each of these patterns, 1 at each of the 4 corners. Outer shirt (v): of coarse flax? Sleeve open from shoulder to neck. Made of 1 piece of cloth. Bottom of skirt plain, selvage edge of cloth ? Sides strengthened with cording, not a single cord sewn on, but a double cord worked into edge of cloth, sewn together. Bottom of sleeve similarly corded. Sleeves sewn up nearly to shoulder, left open under armpit. Sleeves were not inside out. Therefore, the arms were not in them. Tuck 3 wide, lower part of shirt gathered over upper. Sleeve panels did not go all round. There was a space 1.5 of plain cloth on each side of join. 6 lines of ribbing on each side of shirt from shoulder to end of opening. Also, 2 lines of ribbing inside breast panels. Rough tags of cloth left inside shirt at ends of ribbing and round circles of color. Second shirt: Also inside out except sleeves. Same style as outer shirt. Length 140, width ? Sleeves sewn up almost to shoulder. Neck and bottom of shirt plain. Down breast back and front, (vi) in red with decoration in original thread. Round sleeves, a panel of similar design. These were inwoven. In shoulder and near bottom of skirt, 4 medallions similar in style, but with medallion sewn on. Shirt made of 2 pieces of cloth, the join being 62 from top. Below join, a small crack. Inner shirt in very bad condition. Worn right side out. Neck finished off with sewn cording. Length 106+, width ? At 32 from top, a double tuck 10 wide, sewn at top and bottom, i.e., length of shirt was decreased by 20. (vii) down breasts back and front. Not distinct panels like second shirt, but patterns worked in red on original cloth. Similar bands round sleeves. Panels on shoulders and bottom of skirt. Those on shoulders were worked in like the panels, whereas those at the bottom were sewn on. This shirt was roughly darned in several places. 


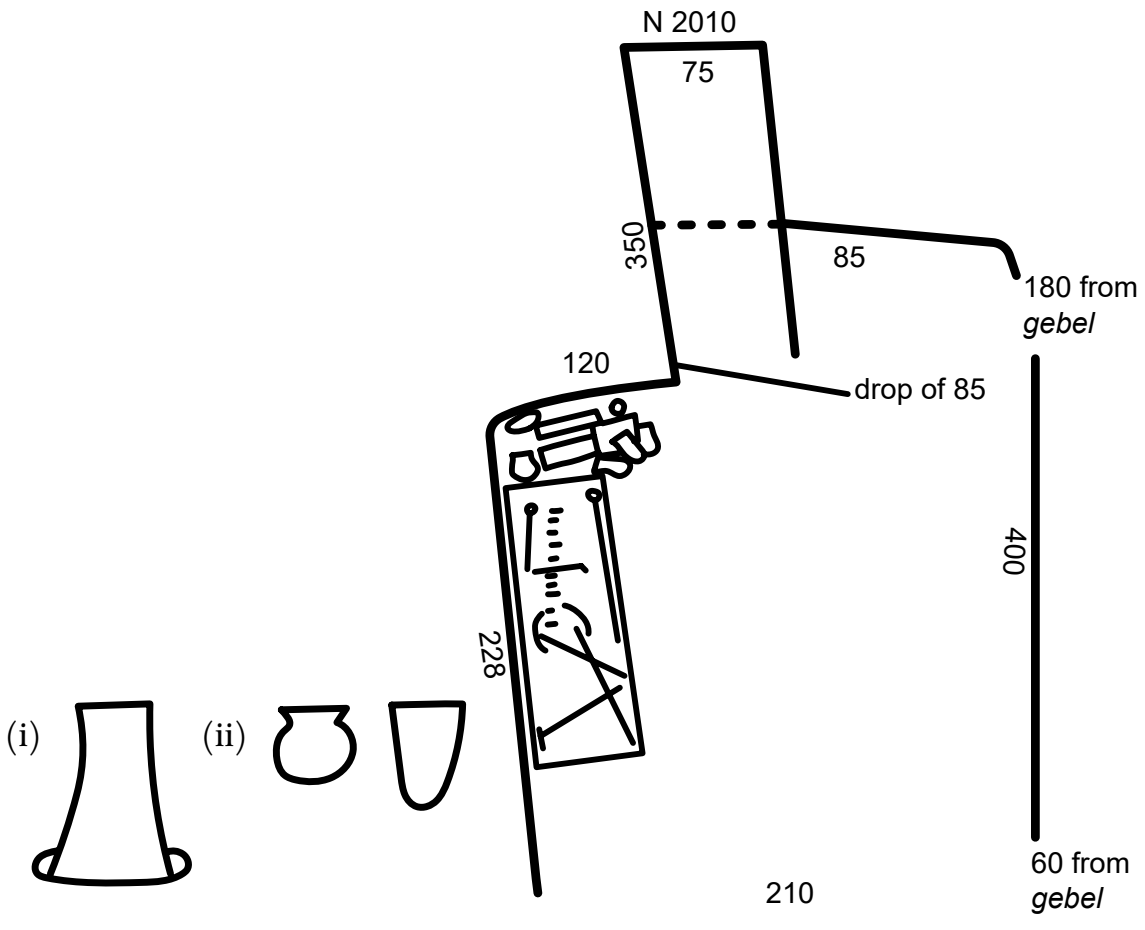

N 2014

N 2015

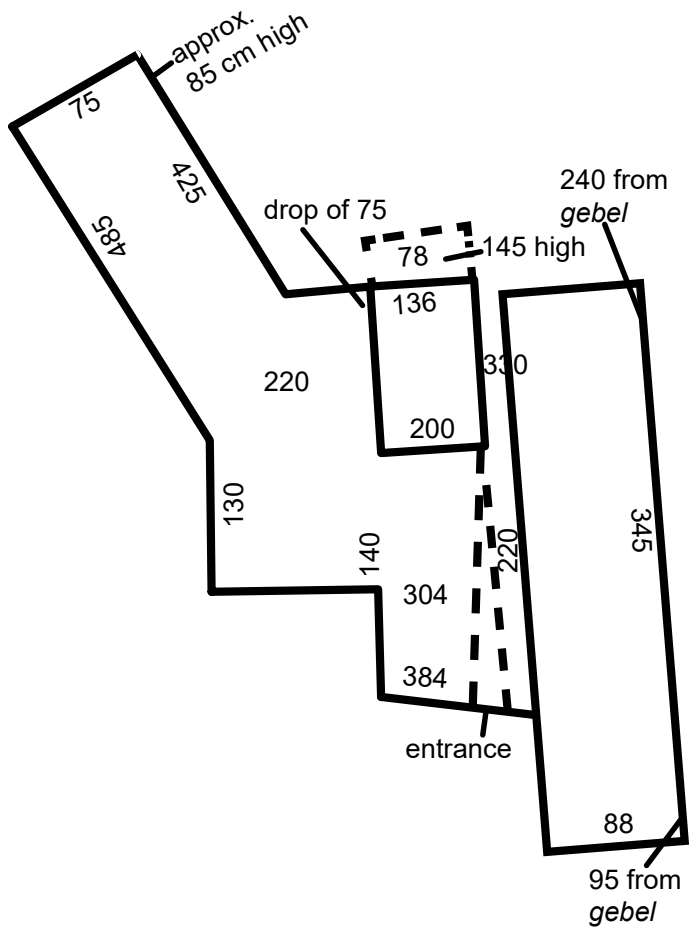


N 2010 (TC) Map D4; photo B 7129

Irregular chamber, sides broken away, gebel much broken away. Remains of bottom of coffin. Burial on 6 o of radim. ? shape of tomb. Possibly two tombs. In pit, few broken bones. In large chamber, number of A pots, (i) $\cdot M$, (ii). Few dark and light glass disc beads (6-14302).

N 2011 (TC) Map D4 (red)

140 to 100 from gebel. Contained absolutely nothing.

$\mathrm{N} 2012$ (TC) Map D4

145 from gebel running down to nothing. Contained absolutely nothing. Was probably a pit and chamber, but roof absolutely disappeared.

N 2013 (TC) Map D5 (red)

9o from gebel. Contained nothing. Half tomb broken away when roof of lower moghar collapsed.

N 2014, N 2015 (TC) Map D4 (red), D5 (red) 2015 was chamber and pit. Portion of roof at north end shows that chamber was about 95 high. Was 60 lower than level of 2014. Chamber of 2014 had been 140 high, but almost all broken away. In large chamber, several pots (i) A, M, two skulls. In 2015, few pieces of wood showing that there had been a coffin.

N 2016 (TC) Map D4; photos A 8267, B 8251, C 8193, C 8464, C 8465 270 from gebel. 130 high. 80 of radim above. Sides and roof of chamber and pit fairly accurately cut, but floor of chamber left very rough. Larger stones from gebel projecting. Burial utterly plundered. Scattered three gold brooches (6-14304a-c) and stone beads, cylindrical (6-14303). In filling at top of pit, small glass bottle (MFA 47.1684?), piece of a large dish with Coptic inscription scratched on it, and broken pottery (i).

$\mathrm{N}_{2017}$ (TC) Map D4

8 o to gebel. Coptic burial. Male. Body originally wrapped round with rough cloth. Inside in the burial at any rate finer cloth. In front of face, circle of worked cloth. Under body, 3 palm sticks. Head raised slightly above body, resting on a small heap of sand.

N 2018 (TC) Map D4

Absolutely plundered out. Floor broken away by cutting of next tomb. Contained two or three bones and two or three fragments of Coptic? pottery. 

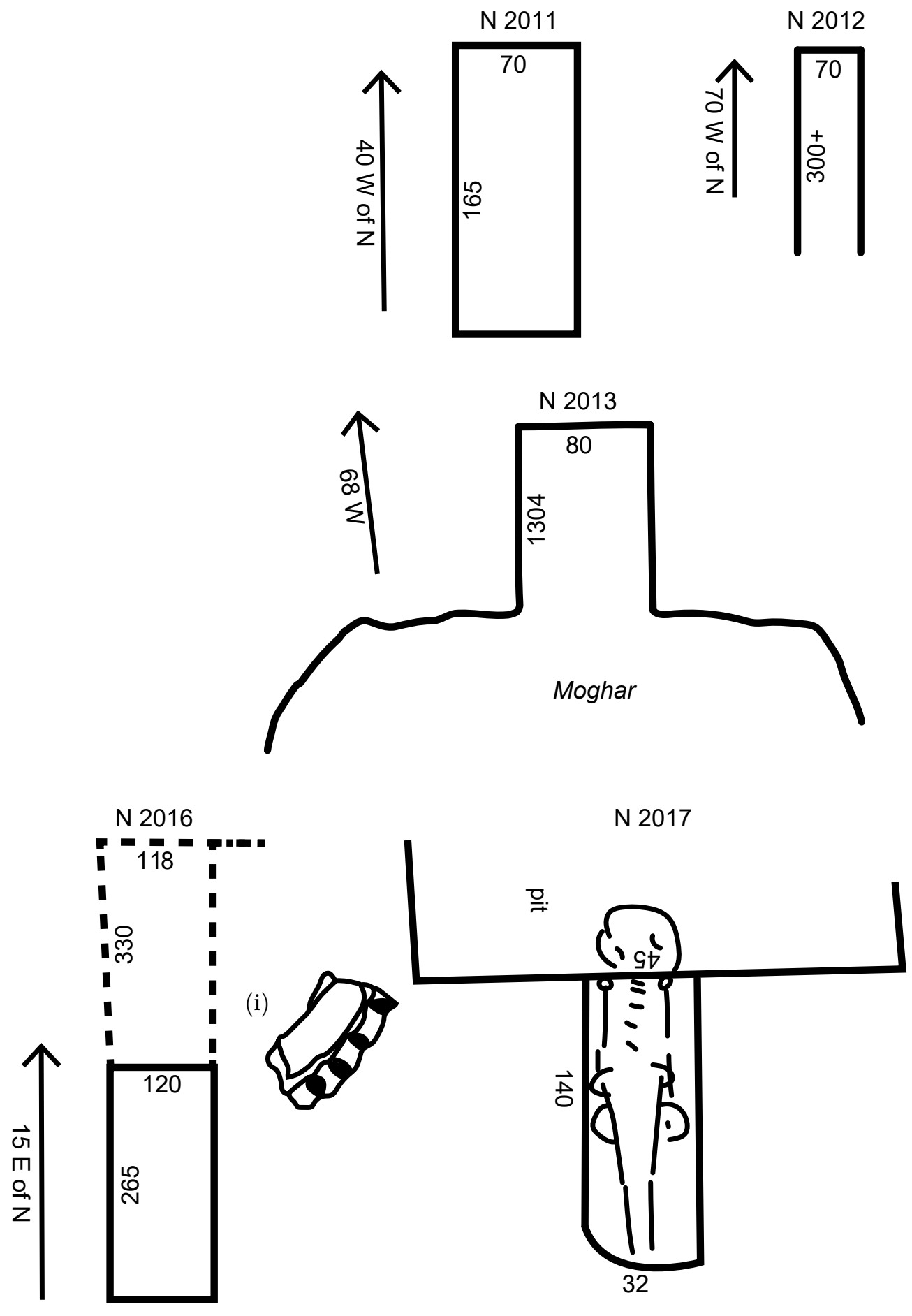
N 2019, N 2210 (TC) Map D4 (red); photo C 7074 (N 2210)

$5^{\circ}$ from gebel. Ends of two graves. Rest cut away. About 30 between floor of 2210 and roof of 2019 .

N 2021 (TC) Map N/A [ed.: This record is Reisner's note of preliminary work that was done in 1901.]; photos A 4943, B 8247, C 9628, C 9629

Empty pits. Rectangular cloth. Shells, etc.

[ed.: No image. This tomb card also contained brief notes about N 2001 and $\mathrm{N}$ 2041, referring not to Mace's tombs of those numbers, but reflecting an earlier numbering system.] [ed.: According to museum records, the following objects are also from this burial: Hearst Museum: 6-14305 (metal beads), 6-14306 (carnelian amulets), 6-14307 (beads and amulets); MFA: 47.1694 (jar with pointed base), 47.1695 (tall shouldered jar with projecting rim), 47.1696 and 47.1697 (collared jars).]

N 203 o (TC) Map E4; photos B ०885, C 7001

Cut away by next tomb. Head of outside burial gone. Buried on stomach. Pottery A, M, (i). Small pottery, kohl pot. (6-14301, 6-14308, 6-14309) Stela in niche in bad condition. Name gone (ii) (6-14551). Colors in red, yellow, and black. Figures in half relief, hieroglyphs incised. In inner chamber, remains of a burial. Only one femur, a tibia, and a few small bones left.

\section{N 2031 (TC) Map E3; photo C o983, C 7178, C 7179}

About 200 down from gebel level. Chamber was about 155 high, but almost all broken away. Stela face down and on top of coffin (i). Figure in sunk relief, hieroglyphs incised. Colors black, red, and yellow. Burial underneath, male. Right arm bent up. Left arm under body. Two ribs broken. Coffin had angled corner. Measurement [ed.: not given]. a. Remains of burial. Lower leg bones, broken skull, and some of vertebrae and ribs left. Had apparently been buried on back. By neck, quantity of gold foil (6-14310) had been upon something made of wood. Traces of coffin under feet, and apparently under coffin, few bones of a calf or some other small animal. Scattered about upper part of body, number of small glaze disc beads, green stone (iii) amulet, (iv) with gold lining inside, carnelian (v), white stone (vi) and (vii), green stone (viii), carnelian (viii), glaze (viii), soapstone? (ix), blue stone (x) (6-14317). Under coffin, pottery. Quantity of A, M with white inside rim (6-14313, 6-14318, 6-14321), and (ii) (6-14311, 6-14314, 6-14315, 6-14319, 6-14320). Slight groove and knife mark (6-14312). Broken clay jar stopper (xi). Also ordinary stoppers (xii). 
46

DAVIES

(i)

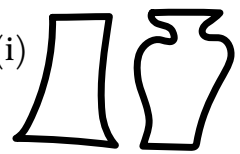

(ii)

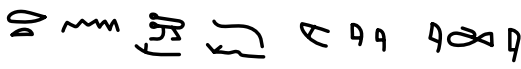

$$
\begin{aligned}
& \text { 至区993还 }
\end{aligned}
$$

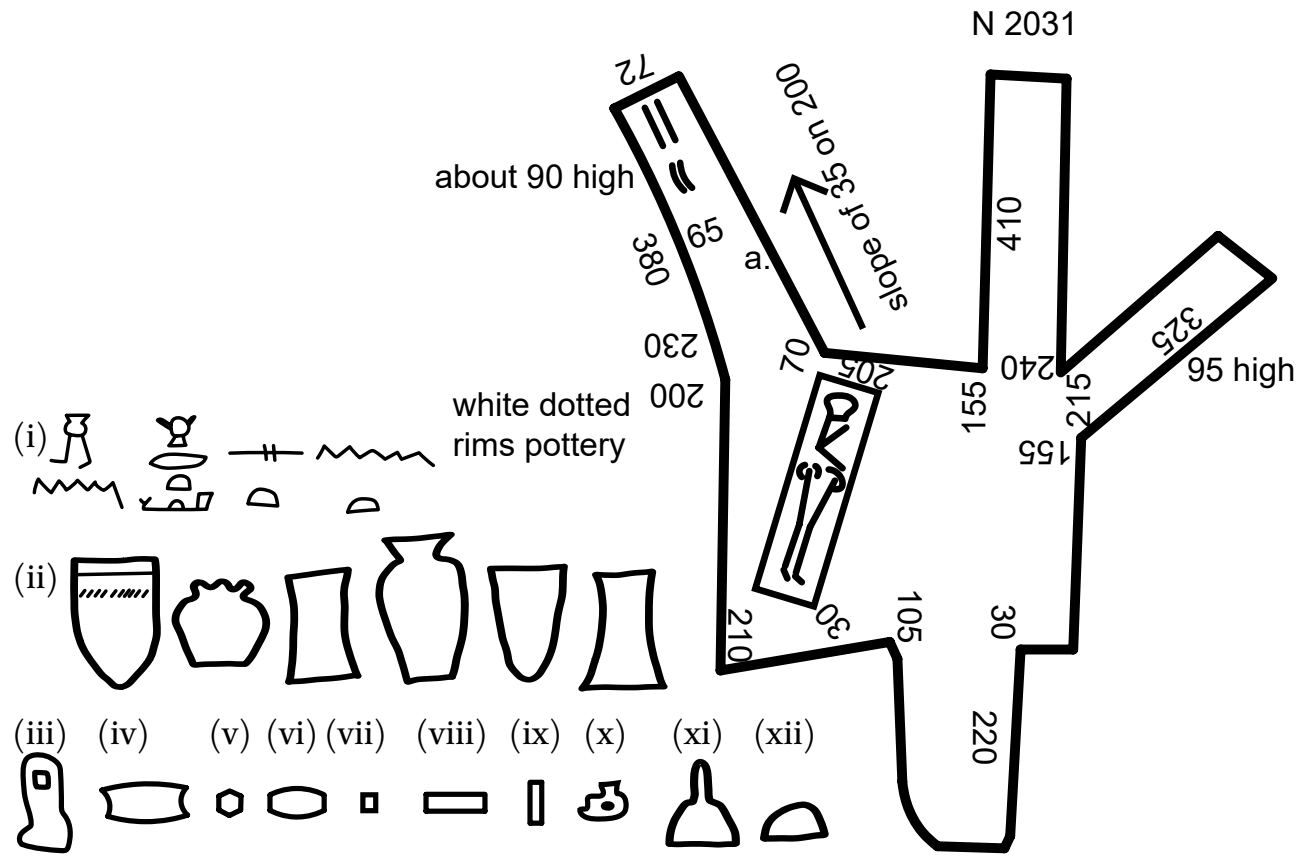

Vanessa Davies - 9789004396906

Downloaded from Brill. com $04 / 26 / 202301: 37: 56 \mathrm{PM}$
via free access 


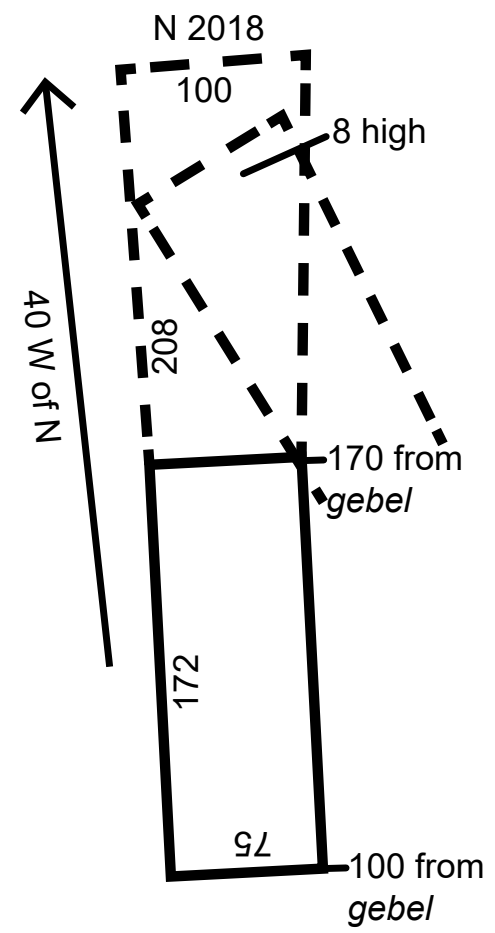

N 2019, N 2210
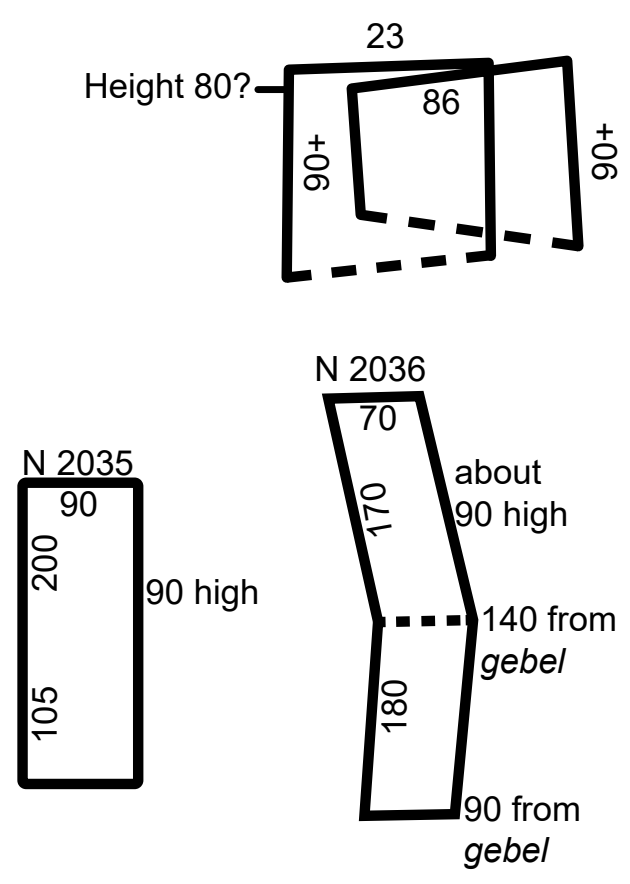

N 2037

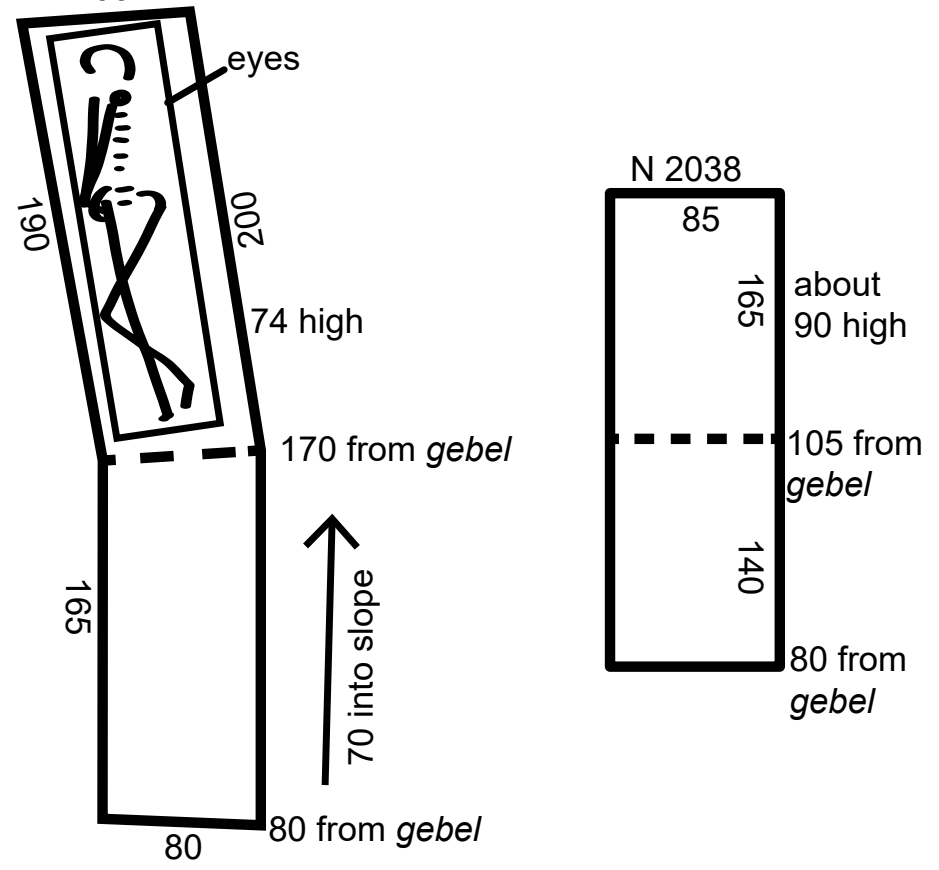



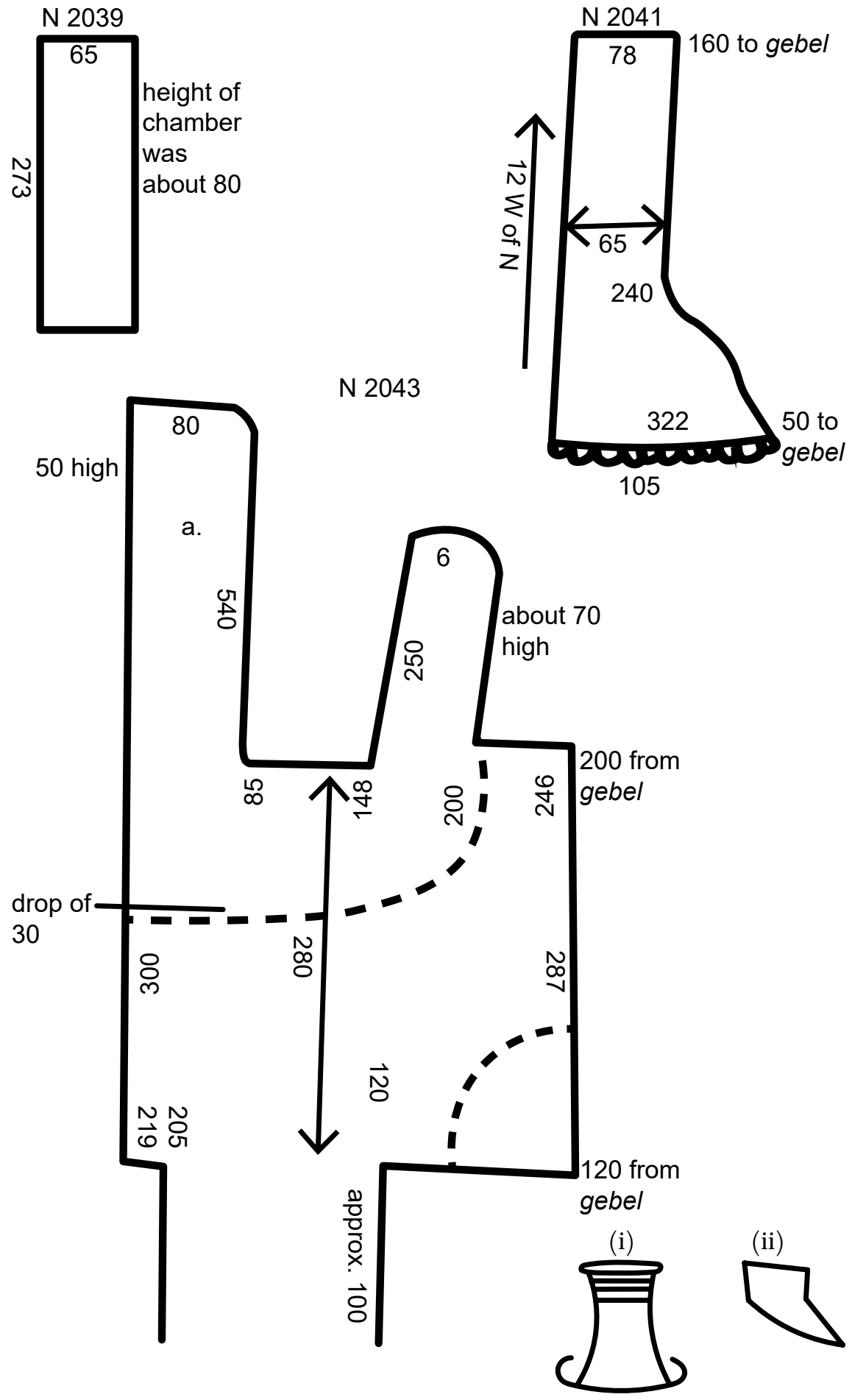
N 2044

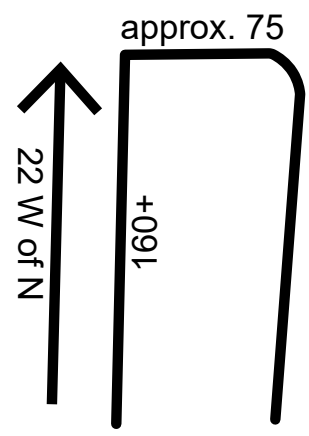

N $2045 \quad$ N 2046

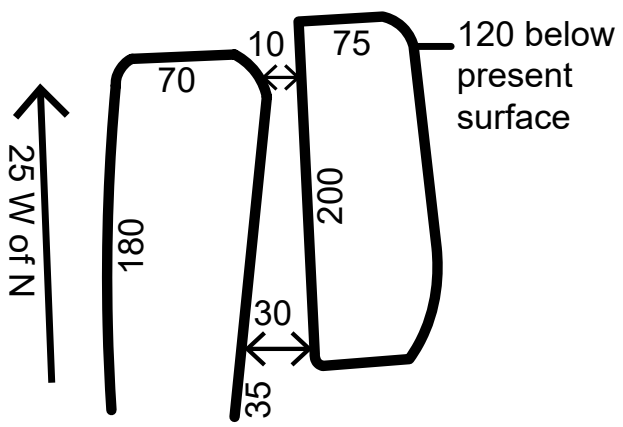

N 2047
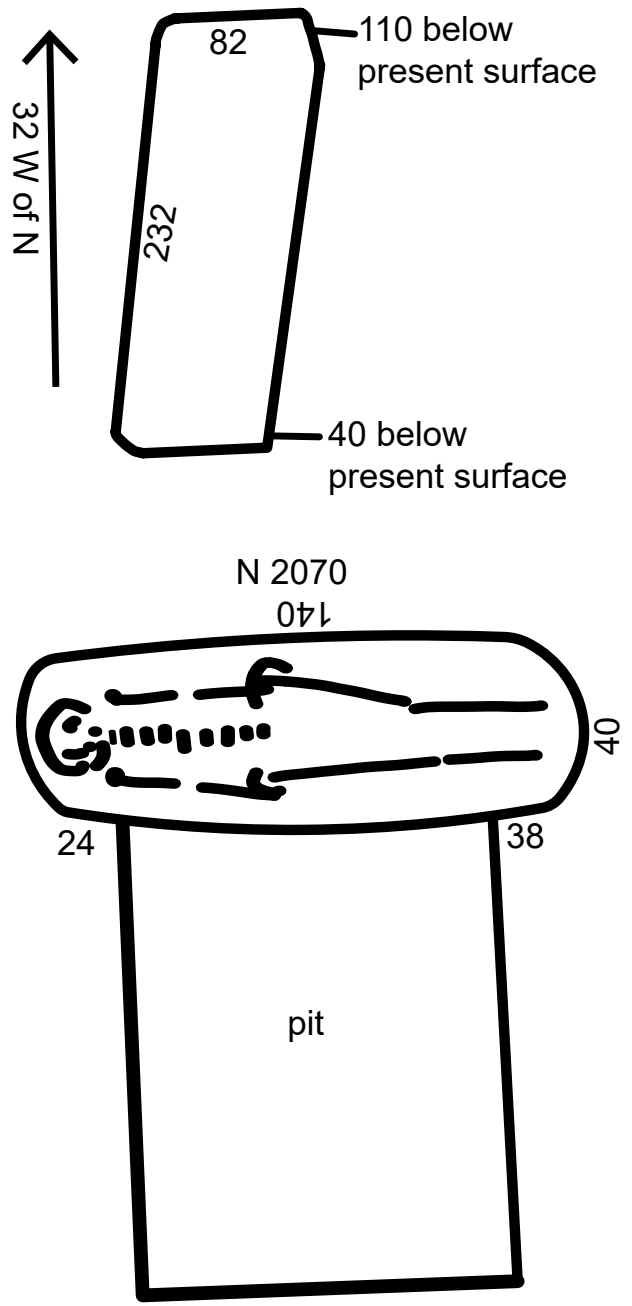


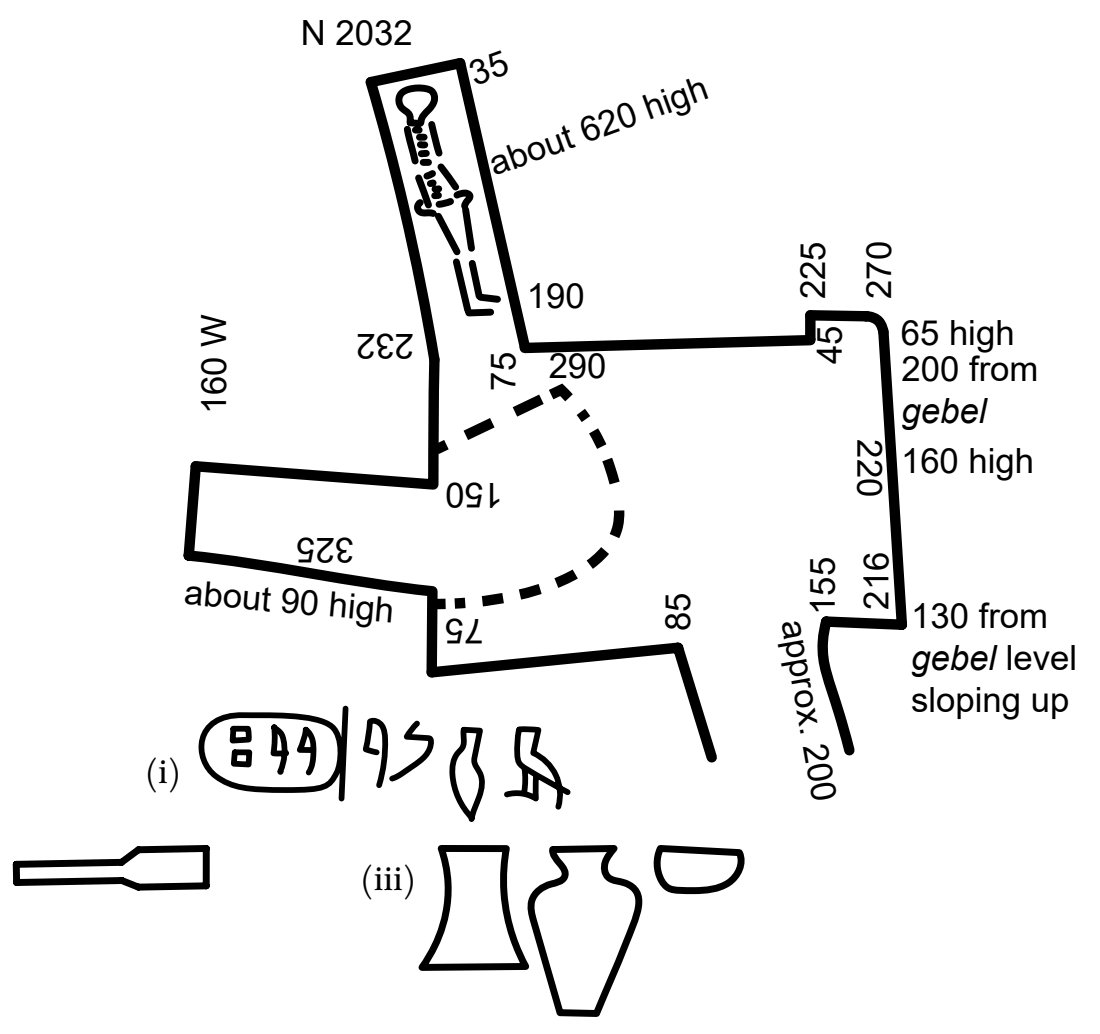

(ii)

N 2033

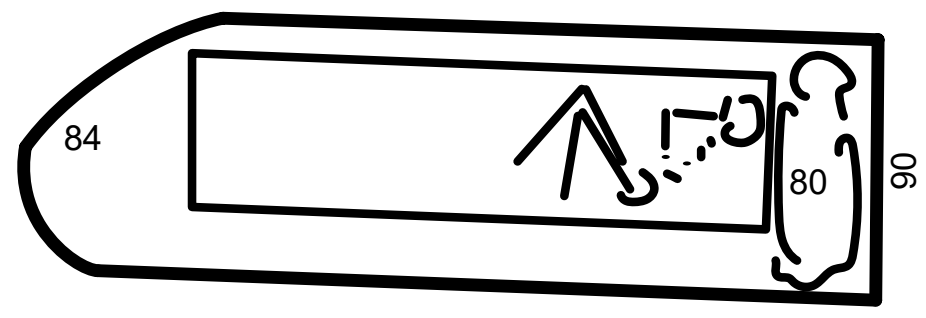

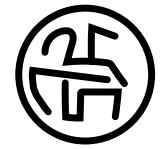

(i)

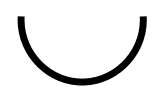

(ii) 
$\mathrm{N}_{2032}$ (TC) Map E4

200 to 130 from gebel, sloping up. Traces of mud show that shaft had been blocked. In dotted lines, pottery and above them, thrown down carelessly, stela of (i) (6-14552). Figure slightly cut in half relief. Colored red. Lines: two top, paint is yellow (not cut). Second two, paint is red. Hieroglyphs cut and painted green with blue. Nabut [i.e., staff] and (ii) yellow. Green bracelets and alternate yellow and red necklaces. Burial in small chamber in back. Remains of decayed coffin. Traces of cloth over body had been several thicknesses under body. Pottery: A, M, (iii) (6-14322, 6-14323, 6-14324, 6-14325, 6-14326, 6-14327, 6-14329, 6-14548), small white clay kohl pot, shell wand for kohl.

\section{N 2033 (TC) Map E3 (red)}

Burial of small child in long coffin. Upper bones scattered by falling apart of body. By legs, round faience rosette backed seal (i). Outside head of coffin, two small Coptic burials, one directly on top of the other. Inside measurement $185 \times$ $31 \times 40$. Thickness of wood 6 . Corners as usual, Round pegs. White stucco inside and out. Copts: Usual position head N. Upper A: Small child covered with four thicknesses of rough cloth, probably all one piece wrapped round. Between layers, over head, quantity of soft fiber. Over face, apparently a pad of colored cloth. Under body, inside wrappings, 4 palm sticks, bound together with fiber. Rope at either end and in middle. Few scraps of skin left, one piece showing navel. B: Usual position, head N, small child. Wrapped in 2 coarse cloth wrappings, with fringed ends with 3 narrow lines of blue approx. 10 from fringes. Body was laid on those. Sides were thrown over and corners turned back over head and feet. Tied round on outside with fiber cords. Next inside, a quantity of dried twigs and branches. Below, wrapped round body and covering face, a covering of very wide meshed cloth. Under body, inside outer wrappings, 4 palm sticks, tied together at any rate at one end. Underneath, a plain shirt, neck (ii). Underneath, rucked right up to small of back.

\section{N 2034 (TC) Map E4; photo B 7129, C o993, C 8285}

In large chamber, small faience plaque (6-14328). In a., burial disturbed. Had been in back. Position of lower arm bones? All upper bones disturbed. Right tibia and fibula gone. In large chamber, number of A pots, (i) M, (ii) M. Several round clay jar stoppers. Broken bronze needle. Two pieces of burnt wood. Remains of burial. Adult. Sex? On back. Arms by side? Remains of wood from coffin. [ed.: According to Hearst Museum records, 6-14316 (dish, broken) is from this burial.] 

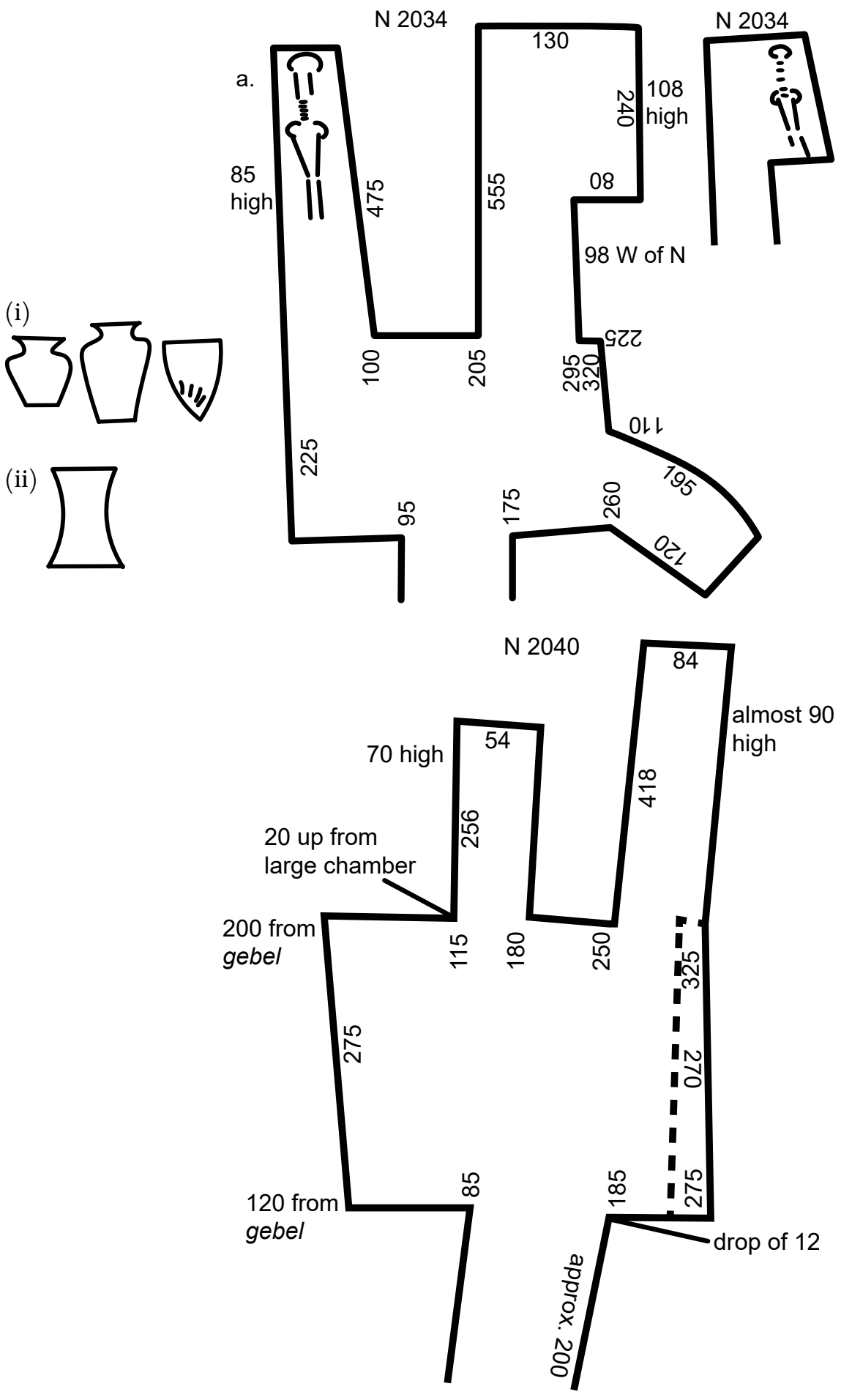
N 2035 (TC) Map E4

Contained absolutely nothing.

$\mathrm{N}_{2036}$ (TC) Map E4

Contained only two or three broken bones and scraps of coffin.

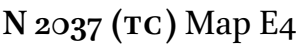

Male. Body covered with much decayed cloth. On left side. Left leg straight down. Right bend under, but pelvis had probably fallen into this position. Inside measurement of coffin $178 \times 42 \times 42$. Thickness of wood 3.5. Corners as usual. Round pegs all through coffin. Coffin white inside and out. Eyes on coffin of black, black pupils, white irises. [ed.: According to Hearst Museum records, 6-14330 (dish) is from this burial.]

$\mathrm{N} 2038$ (тC) Map E4

Contained absolutely nothing.

$\mathrm{N}_{2} \mathrm{O} 39$ (TC) Map E4 (red)

100 from gebel. Contained nothing. Side of tomb cut away in the making of 2030.

N 2040 (TC) Map B5; photo B 8619

200 to 120 from gebel. Sharp slope of 32 from large chamber. Roof of large chamber completely gone. Within dotted lines, several A pots, 2 or 3 (i), 1 (ii), and 1 (iii). Also in filling, quantity of A, (iv), M. (v) with a dull yellowish unpolished surface. ? date. Also, granite (vi), (vii) worked out with a drill.

N 2041 (TC) Map N/A [ed.: This record is Reisner's note of preliminary work that was done in 1901.]

Ditto. [ed.: In reference to the N 2021 record: "Empty pits. Rectangular cloth. Shells, etc." No image. This tomb card also contained brief notes about N 2001 and $\mathrm{N}$ 2021, referring not to Mace's tombs of those numbers, but reflecting an earlier numbering system.]

N 2041 (TC) Map B5

Absolutely plundered out. On gebel at SW end, wall of stones built 30 high, 20 wide. Probably originally pit and chamber. 
(i) (ii) (iii)

$\nabla$ ॠ
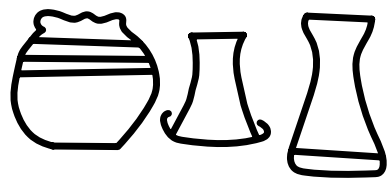

(iv)
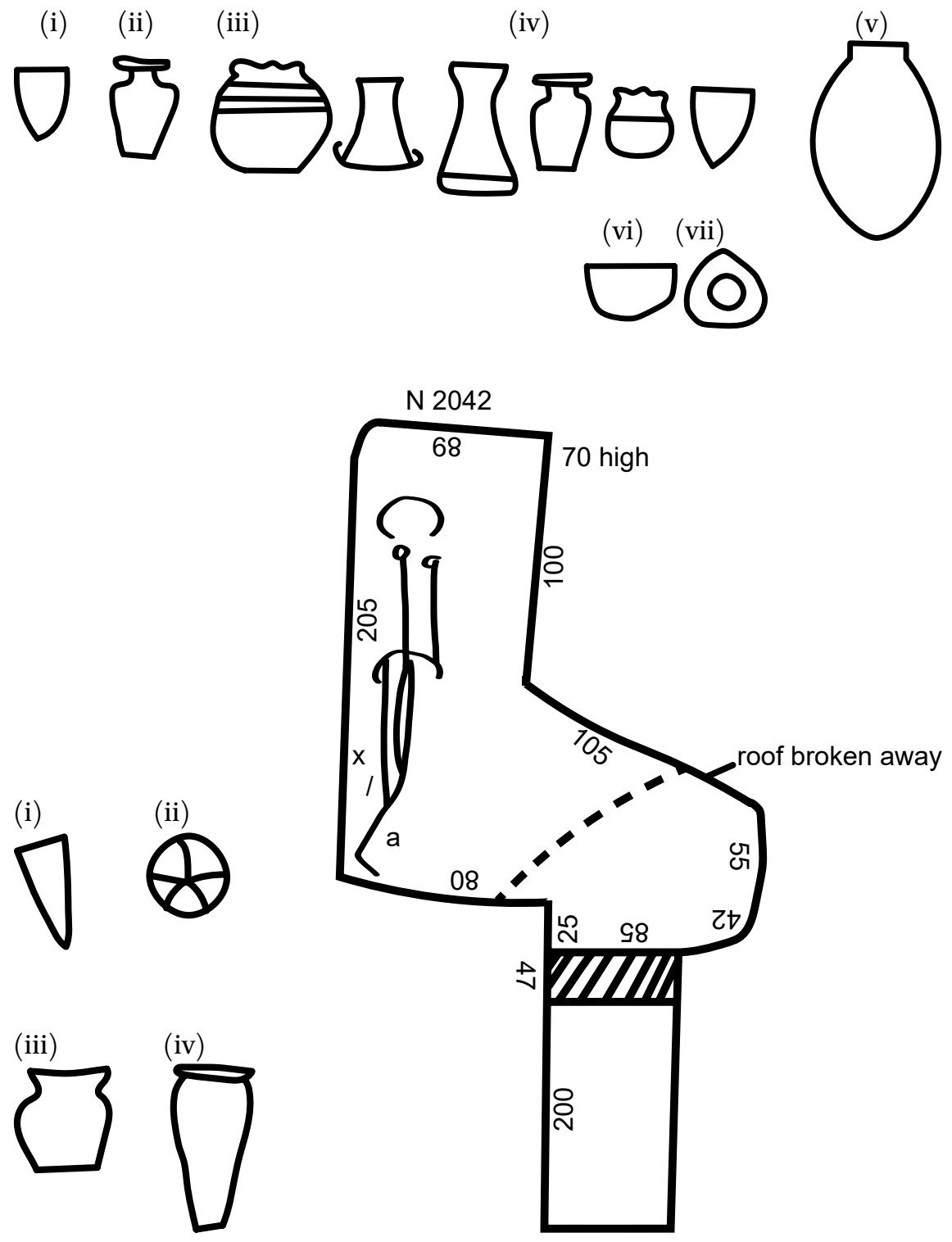

N 2048

(i)

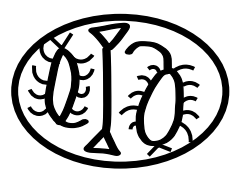

(ii)

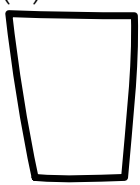

190

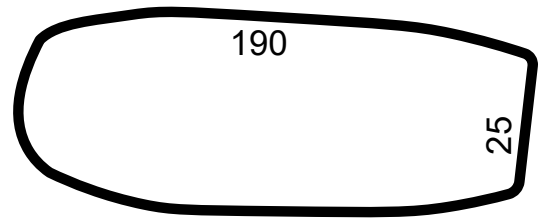


N 2042 (тC) Map B5; type vi c; photo A 8265, C 7496, C 7498, C 7499, C 7500, C 7501, C 7502 , C 7503 , C 7504 , C 7505

Brick and a half thick. 70 high inside, i.e., full brick height. 76 high outside, i.e., half brick height. At /, 2 alabaster (i) (6-14342). At x, granite paint grinder, shell wand for kohl, and bone kohl spatula. At a, 1 alabaster kohl pot (6-14331). On left side. Pelvis out of position, but this might have come through falling apart of body. Skull broken and turned right over on upper vertebrae. Skull upwards, facing NE. Round pelvis girdle of 15 strings of shell and black and green glaze beads (6-14332, 6-14341, 6-14343). Order from below: 1. all green, 2. all white, 3. black and white, 4 . black and white, 5 . all white, 6 . black and white, 7 . black and white with few green, 8. black and white, 10. white, 11. black and white, 12. black and white. Strings were under both arms. All upper part broken owing to falling apart of pelvis. Underneath, 8 strings in position. Strings join at intervals of about an inch. Both upper and lower layers of girdle were underneath pelvis. Possibly it was a double girdle as all upper part was disturbed. There were extra strings; 1 of tiny glaze disc, and 1 of carnelian disc (6-14333, 6-14335) and tiny glaze amulets (6-14334, 6-14340). In filling, fossil (ii), bronze needle. 2 alabaster at 8194 1/4 (iii) (6-14331) and 8194 2/4 (iv) (6-14342). [ed.: According to Hearst Museum records, 6-14336 (loose beads), 6-14337 (travertine bead), 6-14338 (carnelian ball beads), 6-14339 (faience ball beads) are from this burial.]

\section{N 2043 (TC) Map B5}

Tomb fairly accurately cut. In a., 1 skull. In large chamber, several A1, broken (i), broken $\mathrm{M}$, (ii) in white pottery.

N 2044 (TC) Map B5 (red)

100 below present surface, running down 17 within. Had contained a coffin. Absolutely plundered out. [ed.: According to Hearst Museum records, 6-14344 (hes vase) is from this burial or from $\mathrm{N}$ 2048.]

N 2045, N 2046 (TC) Map B4 (both red)

Neither contained anything.

$\mathrm{N}_{2} \mathrm{O} 47$ (TC) Map C4 (red)

Contained absolutely nothing. May have been pit and chamber.

N 2048 (тC) Map B3; photo C 8285

In radim, scarab (i) (6-14348). Also, half a wooden[ed.:?] vase, originally with lid (ii). A few bones. Cut bottom of grave. Coptic burial? [ed.: According to Hearst Museum records, 6-14344 (ceramic jar), 6-14345 (bent wire), 6-14346 (copper fragments), 6-14347 (glass fragment) are from this burial.] 


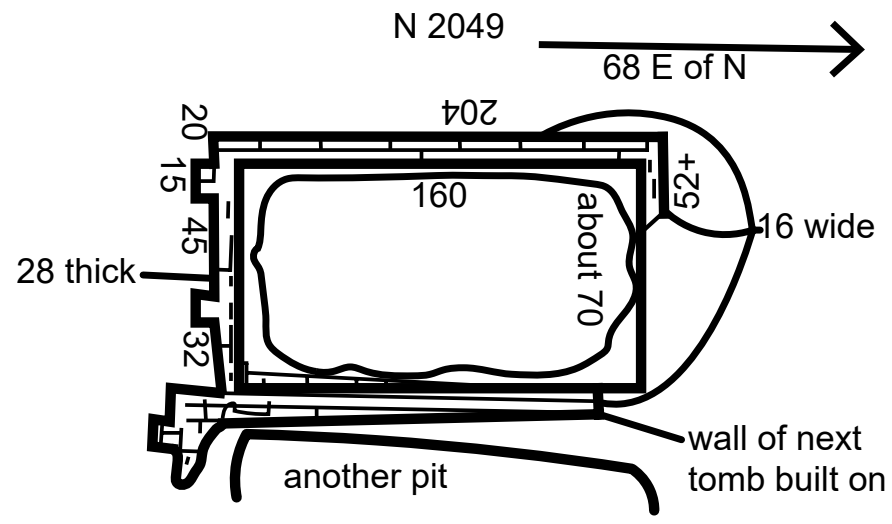

31

(i)

broken off
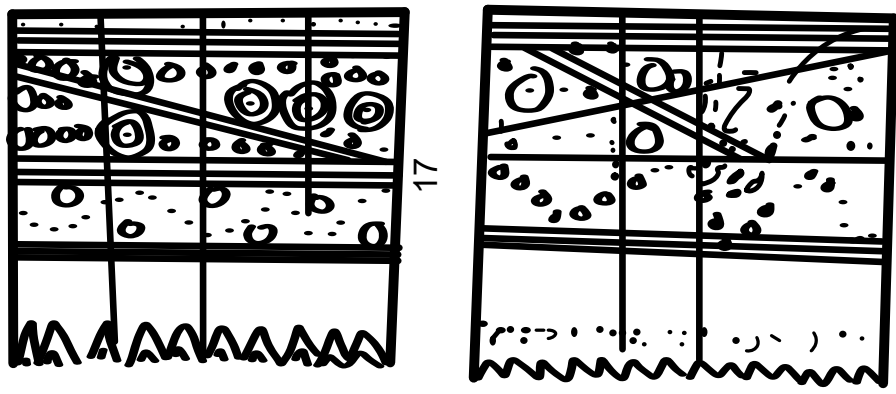

broken off

(ii)
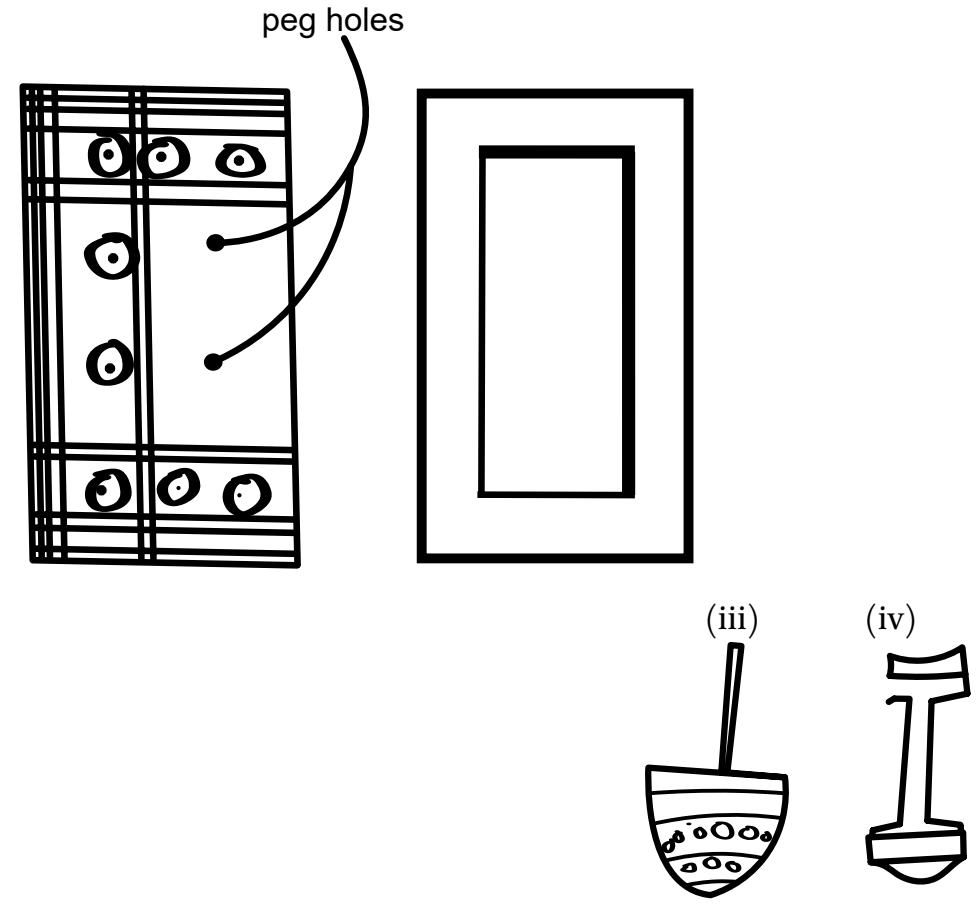

(v)

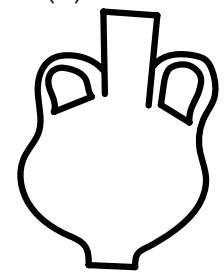




\section{N 2049 (TC) Map B3; photos C 846o, C 8461, C 8462, C 8506}

Walls built on gebel. 140 to bottom. Walls 25 high. At bottom, irregular hole. No chamber. No bones of any kind. Halfway down, Coptic decorated wood. Pieces pegged in 2 round pegs. Pegs ran right through (i). Pieces joined by small round pegs (ii). Whorl (iii). 14 high into stick. 8 across. And several pieces (iv) similar to (ii). Small piece of glass. Pottery (v).

\section{N 2070 (TC) Map B4 (red)}

100 from surface. Coptic burial above early burial.

N 2071 (TC) Map B4; type rock-cut chamber with sloping entrance; photos A 8267, A 8268, B 825o, C 8074, C 8194, C 8285, C 8567

Each body had originally a wooden coffin, but these had almost entirely disappeared. (a) Body of a child. Leg bones and right arm disturbed. Head broken. By pelvis, glaze (i) of striped black and white faience. Round neck, string of small brown faience disc beads (6-14372). 1 carnelian (ii) 1 (iii), 10o[ed..?] (ii), 2 carnelian (ii), and a small scaraboid (iv) (6-14372). (b) Arm bones disturbed. Round neck string of green faience disc beads (6-14365?, 6-14368?). Also, a small faience scarab (v) (6-14374). (c) Bones much disturbed and broken. Round neck strings of carnelian short cylindrical beads and tiny faience discs (6-14373?, 6-14378?, 6-14379?). Behind head number of faience amulets (6-14375). By left arm, there had been a small wooden box containing 4 faience scarabs, and a number of faience amulets, and beads (iii) and disc also scattered above body (6-14373?, 6-14378?, 6-14379?). Number of shells pierced for threading (6-14355, 6-14356). Stone pendant with black rings (6-14359). Two faience (vi) beads, white with black continuous ring decoration (6-14358). Green faience (vii) and disc beads and small amulets (6-14357?, 6-14364?, 6-14367?). 1 carnelian (viii) and 1 disc (6-14377?). Small shell disc beads (6-14362?). Pottery kohl pot. 2 pieces of an alabaster jar, one of which had been used as a scraper (6-14353, 6-14354). Pieces of 2 or 3 ivory needles. 1 mussel shell. In radim above, 2 pieces of a pot (ix), which had been broken and mended anciently. Below, a second layer of burials. (a) Adult male. On back. Position of arms ? (b) Sex? Aged approx. 20. On side, but exact position of legs and arms? Head rested on a brick. (c) Remains of burial of a young child. $(d+e)$ Remains of burials of 2 women? Bones of these 2 last considerably displaced. (e) was over on stomach. By neck of (e), a quantity of beads: blue and black glaze and light stone disc (ii, viii, iii, x) (6-14364?), 1 crumb (ii) (6-1436o?, 6-14364?), 1 (i), 1 glaze scaraboid (xi) (6-14363). Door partly blocked with bricks. 40 of radim below, then 50 of roughly burnt brick. Alabaster at 8194: (xii) 2071a, (xiii) 2071a, (xiv) 2071: really 2093. [ed.: For the alabaster jar (xiv), see 6-14412 in N 2093. According to Hearst Museum records, 6-14351, 6-14352 (alabaster jars), and 6-14361 (bead 
N 2071
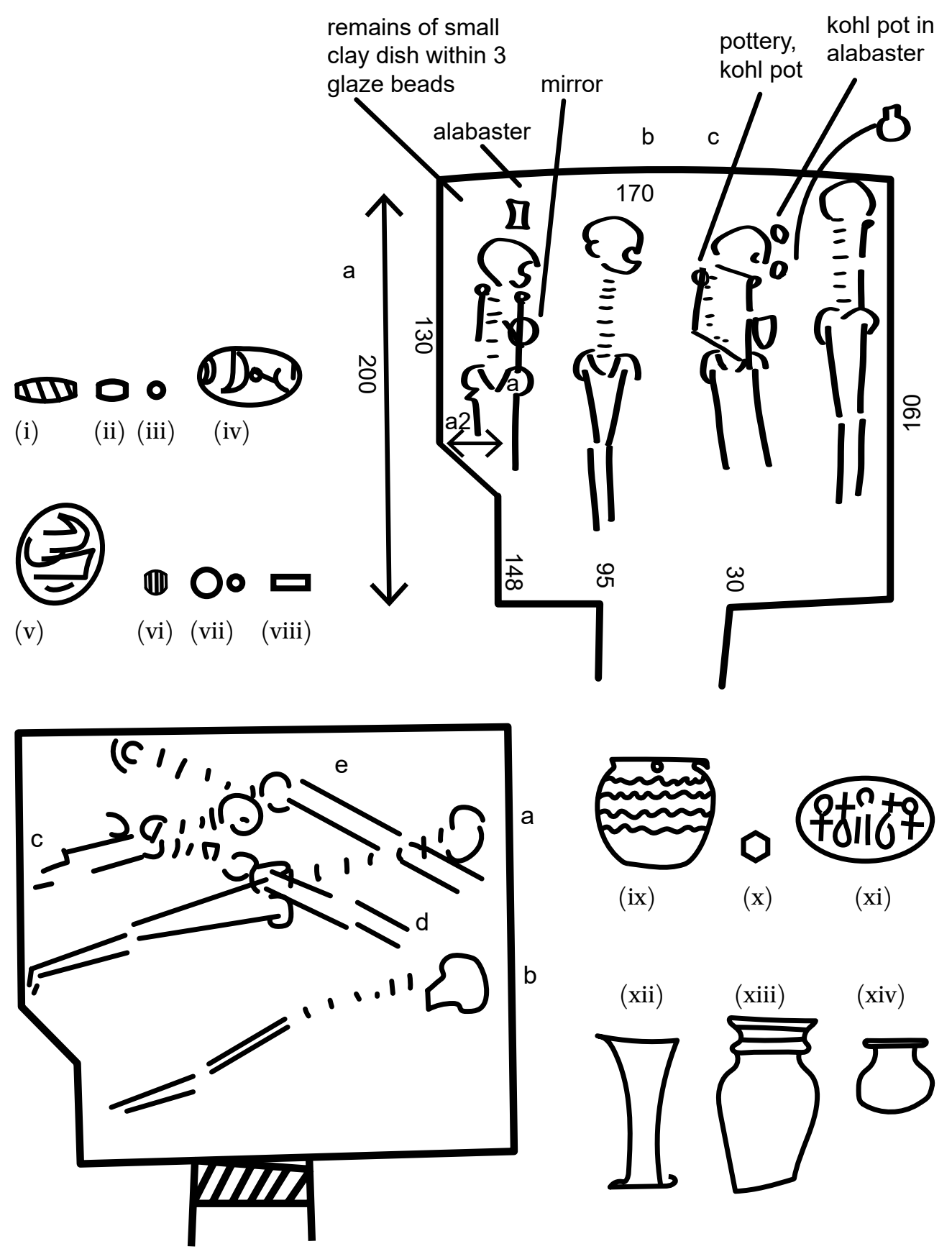

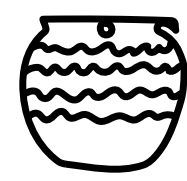

(ix)

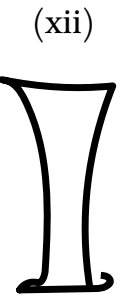

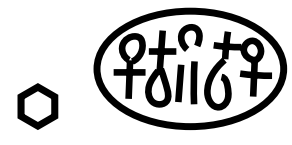

(x)

(xi)

(xiv)

(xiii)

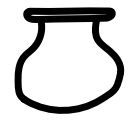


fragments and rocks) are from this burial. 6-14366 (mirror) is labeled as potentially coming from this burial. 6-14369 (alabaster jar) and 6-14370, 6-14371 (mud beads and decorations) are from N 2071a. 6-14373 (beads) are from N 2071b. 6-14376 (pendant) is from $\mathrm{N}$ 2071c.]

\section{N 2072 (TC) Map A5; photo C 8235}

Roof of large chamber entirely gone. Present height 120 from gebel. In large chamber, head and shoulders of a burial. Round neck, several strings of glaze beads sizes apparently strung separately. In front, probably on shell necklace, lion plaque in limestone (6-14381; Reisner 1932, fig. 5o:19) and 1 carnelian (i) bead (6-14381). Also, string of black glaze beads. In front, apparently on black string, carnelian (ii) and (i), limestone (iii), and quartzite (i) (6-1438o, 6-14381). Several broken As, 1 (iv).

$\mathrm{N}_{2} \mathrm{O} 73$ (TC) Map B4

40 from gebel. Coptic grave? Contained nothing.

\section{N 2074 (TC) Map A5}

35 from black clay deposit. Coptic burial. Remains of sackcloth under body.

N 2075 (TC) Map A4; type vi d; photo B 8248, C 8074, C 8194, C 8285 16o down from gebel level. $100 \mathrm{E}$ of N. In an upper part of plundered burial. By neck, quantity of carnelian beads scattered. Barrel carnelian strung with black glaze disc between; in one place, a lazuli disc in place of glaze (6-1438ga, 6-14389b, 6-1439o). Small carnelian (i) strung together (6-14385). Layer of same shape either together or with black glaze between. Also, a string of tiny shell (6-14385). In large chamber, few shell disc beads. In main chamber, a few pots, mostly broken (ii). Piece of a drab (iii)? 2 alabaster C 8194 1/5 (iv) and 2/5 (v) [ed.: According to Hearst Museum records, 6-14382 (glass bead/plug), 6-14383 (scarab), 6-14384 (assorted beads, including a striped faience bead similar to the drawing in 2071), 6-14384.1 (metal beads), 6-14386 (jar fragment), 6-14387 (metal wire), 6-14388 (needle), 6-14391, 6-14392 (alabaster vessel), 6-14393, 6-14394, 6-14395 (mirrors), 6-14396 (ceramic jar) are from this burial.]

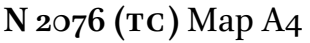

7 o down. Coptic burial. Usual position. Head gone.

N 2077 (TC) Map A4

On black ash level. Coptic. Child. usual position. By ankles, 4 more anklets. 


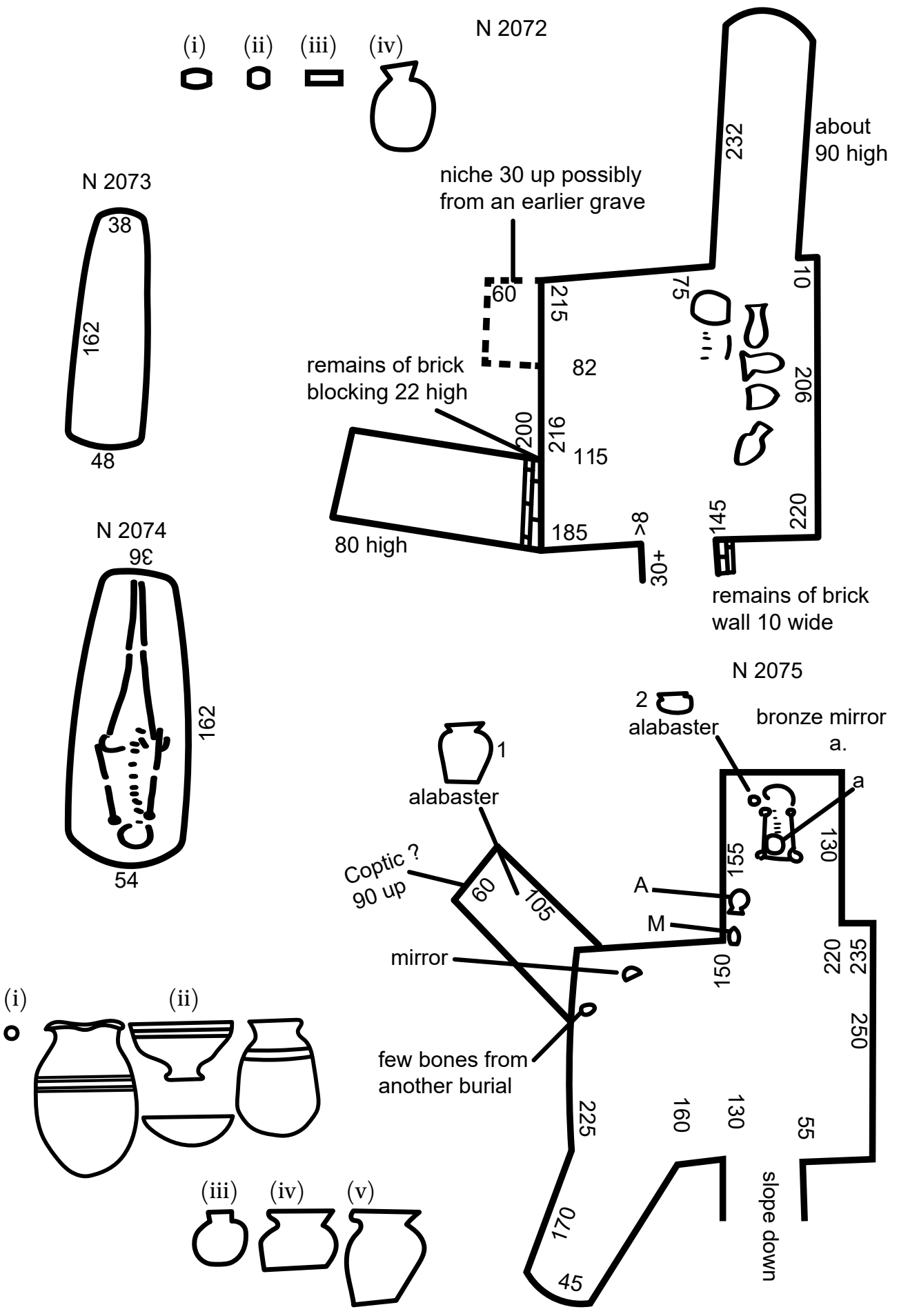




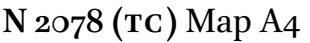

On black ash level. Coptic burial. Usual position.

$\mathrm{N} 2079$ (TC) Map A4

20 below black level. Coptic burial. Lower leg bones gone. Had protruded over 2071.

N 209o (TC) Map C5; photo B 7146

Few traces of decayed cord showed that there had been a coffin. Bead girdle 8 strings. Behind back, order from above was white shell (1), white and black (2), white shell (3), white shell (5), white and black (4), white and black (7), green (8), white (6). 7 and 8 did not go over left ilium. 7 came round underneath into position next to 4.8 went over 6 and under 7 and 4 and came up between 7 and 6. Under right ilium, order from above was 12345678 . All strings went over right ilium. Strings were not fastened together in any way as strings crossed especially at sides where they kept no sort of order. By right arm, few strings[ed.:?] green glaze and shell beads and 1 carnelian possibly bracelet. Round neck, string of tiny glaze disc beads. Also, a few of the beads by neck, but these may have come from girdle as beads were much scattered (6-14397, 6-14398, 6-14399, 6-14400, 6-14401, 6-14402, 6-14403, 6-14404, 6-14405, 6-14407). Remains of coffin, but measurements [ed.:?]. [ed.: According to Hearst Museum records, 6-14406 (djed pendant) and 6-14408 (pot stand) are from this burial.]

N 2091 (TC) Map C5 (red)

Bottom of coffin and lower leg bones gone. Curious dent on skull. Skull had been wrapped in cloth. No trace of cloth anywhere else. Coffin almost entirely destroyed by worms. [ed.: According to Hearst Museum records, 6-14409 (mirror) is from this burial.]

N 2092 (тC) Map C5; photo B 8251

90 from surface running down to nothing. Plundered body of a small child. Fragments of cloth under body. Round neck, double string of small blue faience disc beads (6-14410).

N 2093 (тC) Map C5; photo B 7129, B 7144

Slope of 50 from outside into large chamber. South side of tomb cut away where tomb 2094 was made. Sides of doorway mudded. Outside brick walls. On south side, outside, remains of a wall of stones and mud continuing out to level of outside wall of 2094: brick wall 40 high; stone wall 18 high. In b, $2 \mathrm{~A}$ pots. Half chamber a cut away by chamber of 2094. In large chamber, broken 
N 2076

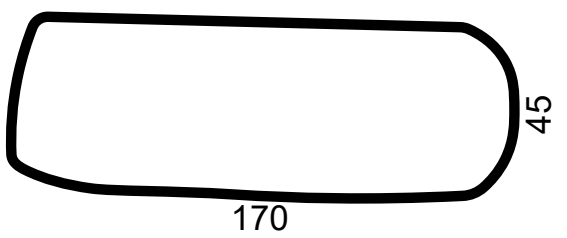

N 2078
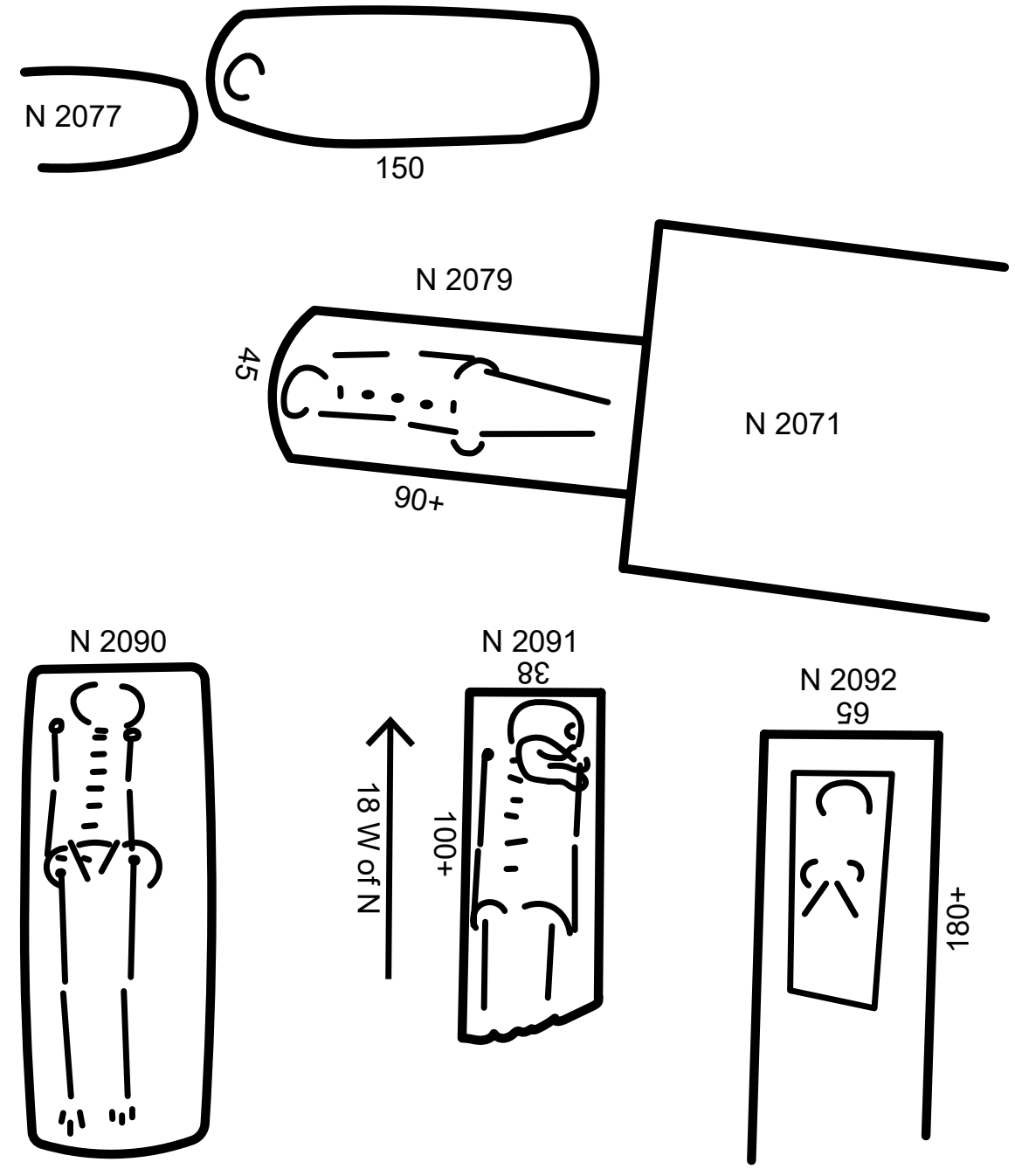

N 2077

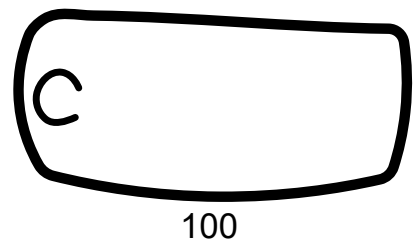


(i)

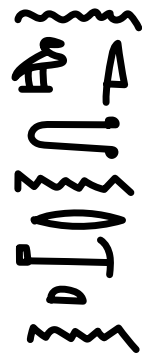

10 remains of

stone and brick

blocking 60 thick

(iii)

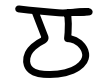

(iv)

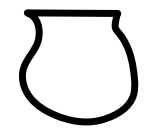

(ii)

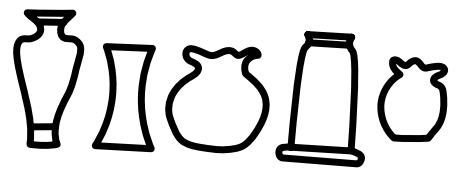

30 from gebel

N 2093

stand pot

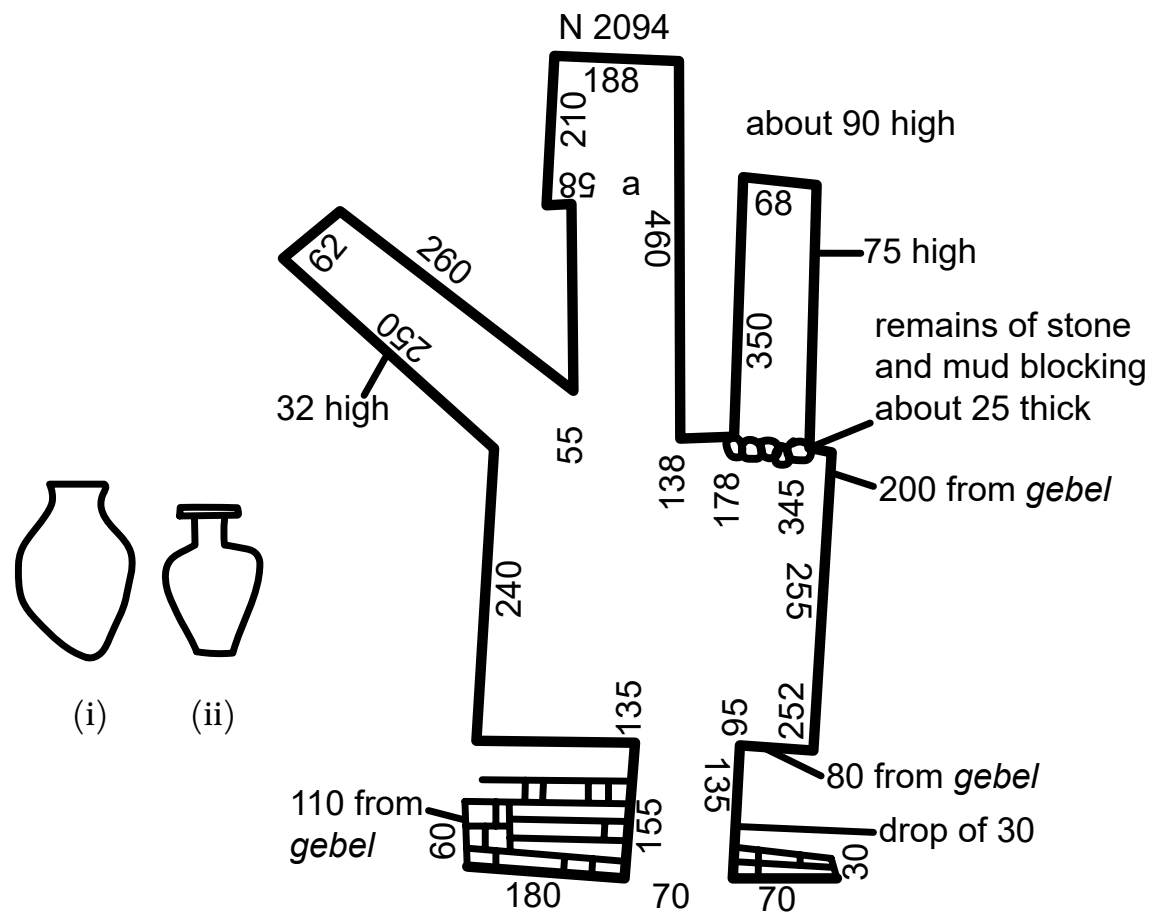



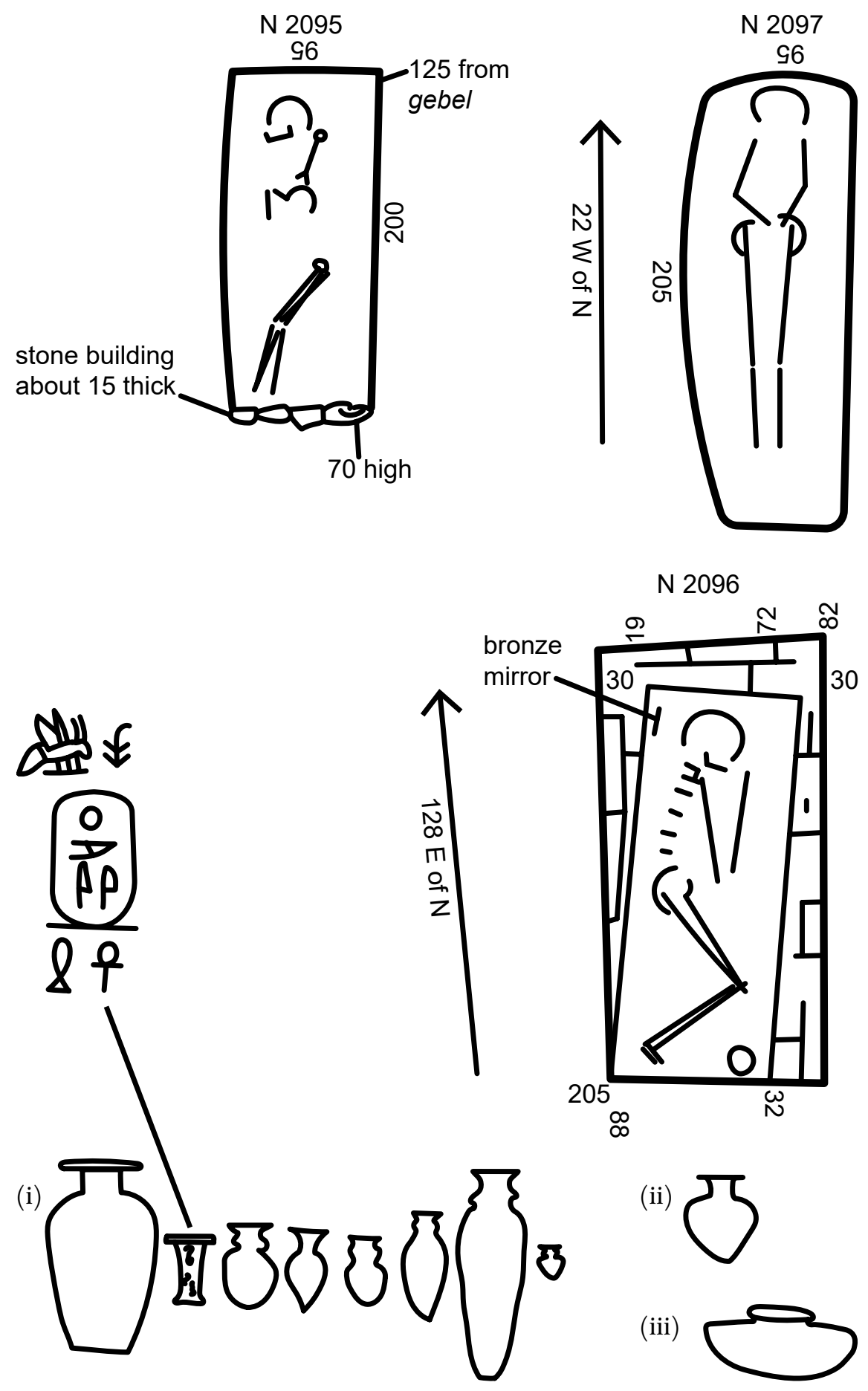
stela man and wife (i). Several As, M, (ii) (6-14411, 6-14416), small clay kohl pot (iii) (6-14418), broken stem of an alabaster vase (6-14417), shell which had been painted (6-14413). Granite paint grinder and pebble (6-14414). Small alabaster (iv) (6-14412). [ed.: For a drawing of 6-14412, see image (xiv) in N 2071. According to Hearst Museum records, 6-14415 (flint knife) is from the large chamber in this burial.]

\section{$\mathrm{N}_{2} 094$ (TC) Map $\mathrm{C}_{5}$}

a [ed.: the center shaft, labeled "a" on diagram] contained remains of 1 burial, 1 A pot, and pieces of a (i) in rough red. Large chamber contained several broken As, 2 large (ii), and 1 small M. Sides of doorway plastered. At outside, remains of brick building on top of gebel, which had run down almost to nothing.

$\mathrm{N} 2095$ (тC) Map C5

125 from gebel. Plundered. Upper bones scattered and hiatus between them and leg bones, which had remained more or less in position. At end, built with stones. This may have been blocking of door with a pit outside, but the latter had disappeared altogether.

N 2096 (TC) Map C4; type vi a; photo C 2165, C 76o9, C 8o67, C 8o68, C 8o69, C 8070, C 9630

About 170 from gebel level. Brick 40 high. By feet, (i) in alabaster (6-14419, 6-14421, 6-14422, 6-14423, 6-14424, 6-14425, 6-14426). (ii) in limestone? (6-14427) (iii) in black veined limestone (6-14420). Traces of wooden coffin, which apparently fitted exactly inside bricking. On left side, position of left arm doubtful. Body disarrayed slightly before coffin decayed as 1 tooth and upper vertebra below pelvis. Coffin was apparently put in position.

N 2097 (TC) Map $\mathrm{C}_{5}$

65 deep. Male? Body on back. Head turned to northeast. No traces of coffin.

\section{N 2098 (TC) Map C5}

Height [of large chamber] had been about 140, but roof had practically all gone. a. Plundered bones scattered. b. Plundered from hole at side. [ed.: No "b" in drawing.] Both doors had been blocked with stones and outsides mudded. Both had been covered with rough fantasia scrawlings. In large chamber, number of A pots (i) (6-1298, 6-1299). 


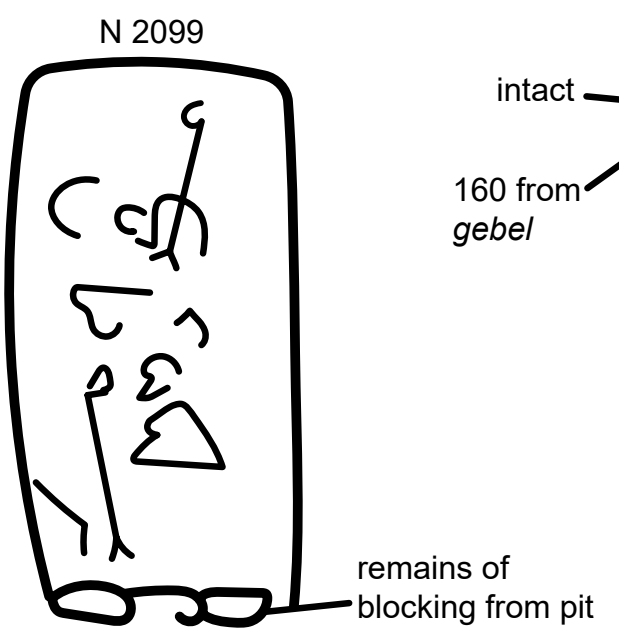

N 2100

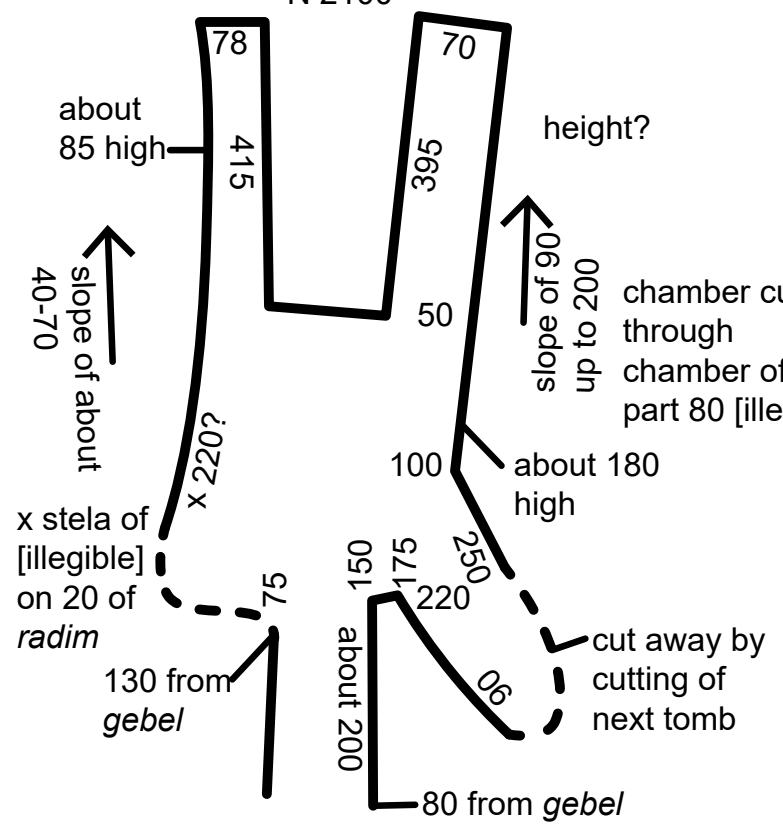

N 2098

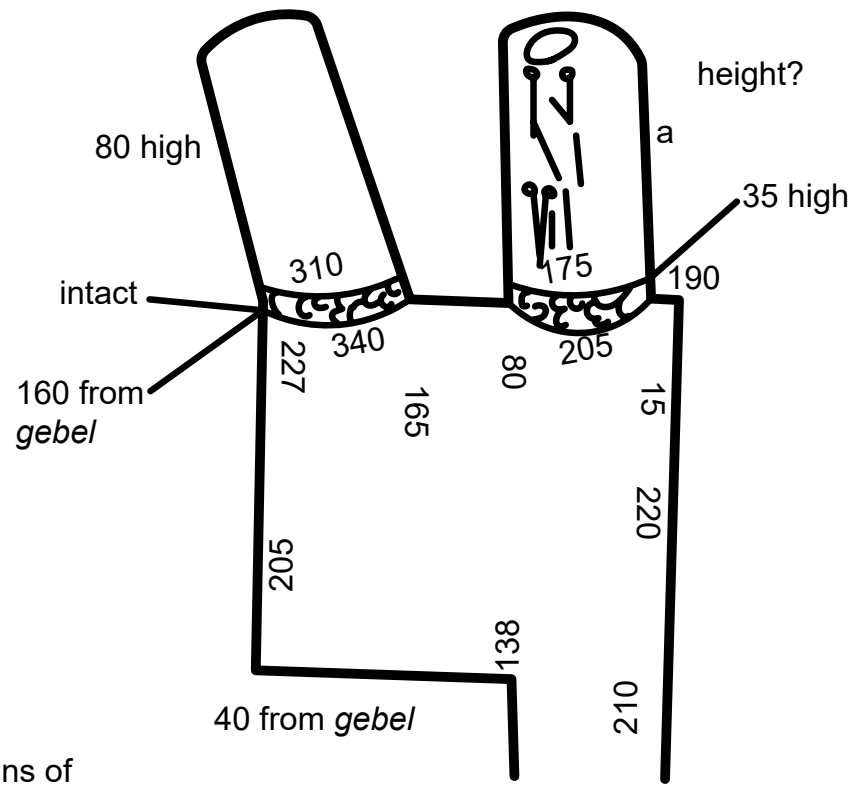

(i)

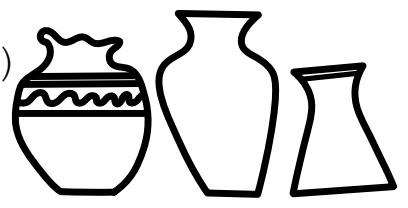

(i)

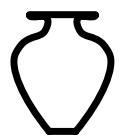

(ii)

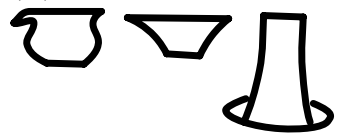


N 2099 (тC) Map C4; photo B 7471

Pottery (see photographs). Dish on ring stand (6-14428, 6-14429, 6-2799). 4 saucers, in a nest. Pieces of charcoal. Burial plundered. Bones scattered all over grave. Had been pit and chamber, but pit gone.

$\mathrm{N} 2100$ (TC) Map C5

Most of roof of large chamber standing. From outside, slight slope up to door and step[ed.:?] down into chamber. In big chamber, 1 broken skull. Several A pots (i) (6-14430), M (ii). First (ii) with spout, in firm dark red pottery, slightly polished (6-14431). Stela.

\section{$\mathrm{N}_{2101}$ (TC) Map C4 (red)}

Square hole cut to top of door, then continued down breadth of chamber only. Contained absolutely nothing.

\section{N 2102 (TC) Map C4; photos B 8447, C 8472}

70 down. Both bodies were originally wrapped in cloth. a. Female, young: bones not fully ossified. Bronze ring on third finger of left hand. Bronze bracelet just above elbow. Bracelet on right arm above wrist. Head gone. In place of it, bronze circlet. Round neck, number of strings of beads, most irregularly strung of colored glass, gilt glass, carnelian, and stone, and shells. There were traces of bronze work also. The beads probably all came from one collar that had a bronze framework. Possibly though the bronze fragments were from earrings. Under chin, small bronze cross. Also, small fragment of iron. By each ear, remains of elaborate bronze earrings with plain bead pendants. b. (i) ? Coptic cross. Both bodies had 3 palm sticks beneath them.

N 2103 (TC) Map C4; type vi b; photo C 8074, C 8194

315 down from gebel. Chamber 140 high. Burial on back. Skull wrought away from from upper vertebrae, but may have fallen apart so. 3 alabasters: (i) (6-14432, 6-14433, 6-14435). No trace of wooden coffin. Remains of burial from superstructure visible. No measures possible. [ed.: According to Hearst Museum records, 6-14434 (mirror) is from this burial.]

N 2104 (TC) Map D5

About 5 o below gebel level. Burial in front of moghar. All trace of its pit or chamber had disappeared. Remains of stucco showed that there had been a coffin, but all wood was gone. 
N 2104

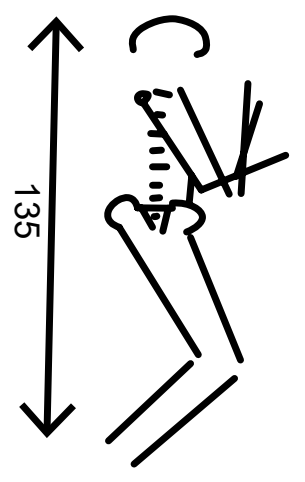

N 2101

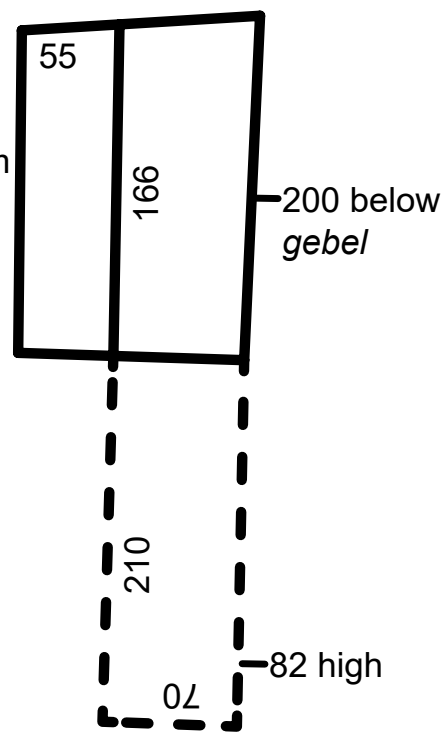

open bronze circlet, ends overlapping and twisting round

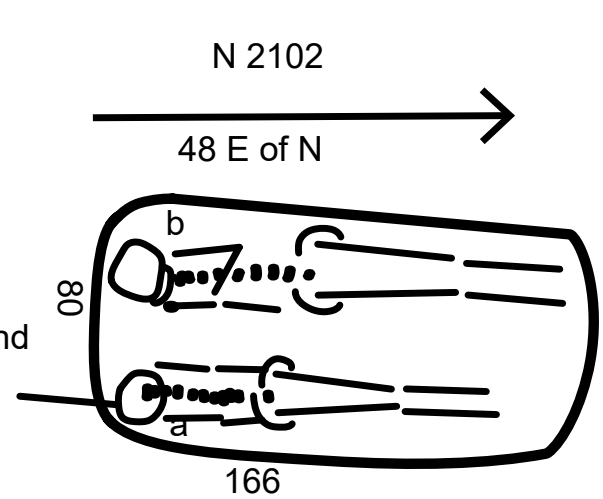

N 2103

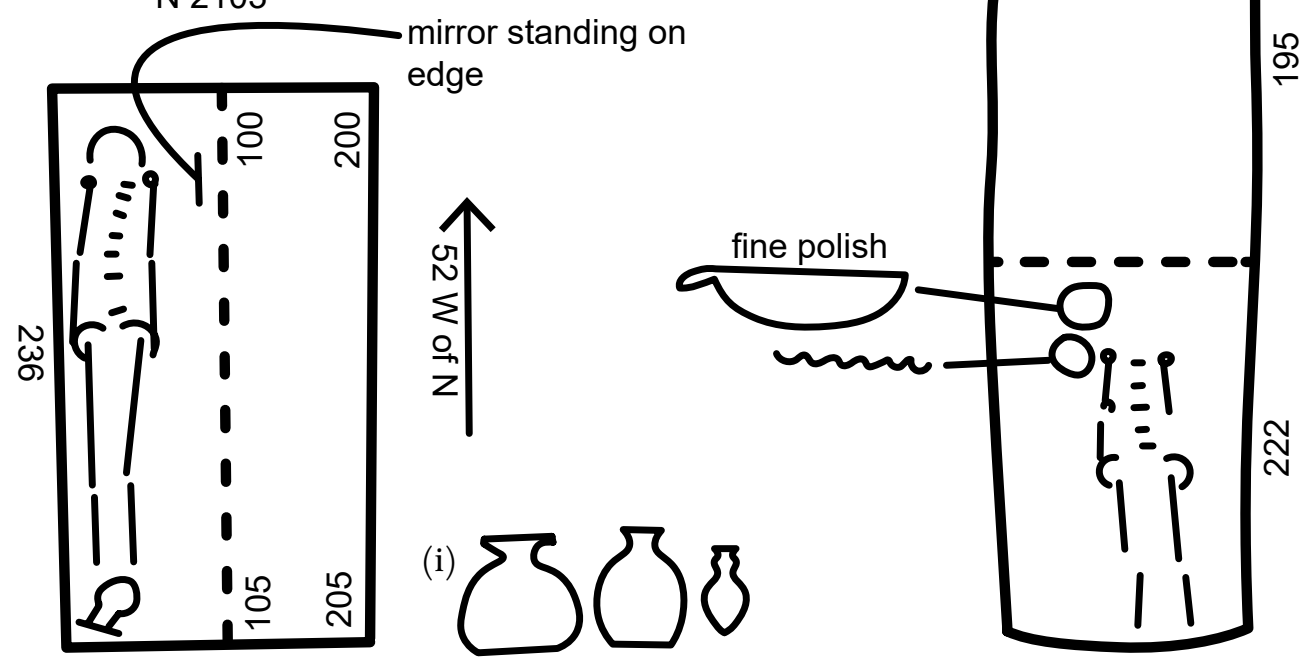


$\mathrm{N}_{2105}$ (TC) Map D4

270 down. About 100 down. On underside of mirror, remains of cloth (6-14436). Burial plundered. Head gone. Traces of decayed coffin. Position on back. Quantity of rotten cloth by body. [ed.: According to Hearst Museum records, 6-1411 (broken ceramic dish) and 6-14437 (beads) are from this burial.]

\section{N 2106 (тс) Map D4}

70 deep. Copt. Adult. Male? Head west. Wrapped first in a fairly fine cloth and tied round. This cloth was ornamented with broad lines of blue thread at intervals. Underneath, a second covering, probably shirt, with traces of ornamentation in colored wool. Dried twigs on body. Wrappings were tied up tight in a bunch over feet: over head, a quantity of extra cloth rolled up. Under body, 2 palm sticks and 1 "sont."

$\mathrm{N}_{2107}$ (TC) Map D4

Copt. Child of about 3. Head west. Cloth almost entirely gone. 3 palm sticks under body. [ed.: According to Hearst Museum records, 6-14438 (broken jar) is from this burial.]

\section{N 2108 (TC) Map D4; photo C 8468}

2 Coptic burials. a. Child. Female. 2 palm sticks under body. By head, roll of cloth, part of which was elaborately worked with colored wools. By right hand, small bone ring. (Rings on fingers were placed in front of pudenda. Necklace of beads and shells with copper ornaments, and a copper cross. Earrings. Brown, wavy, almost straight hair.) S. b. Adult female. Head west. Usual position. By sides of body, a palm stick and a sesban stick. Remains of 2 or 3 thicknesses of cloth, but almost all decomposed Remains of dark, straight hair. From a?: With body (see Smith), bronze cross. Remains of twisted bronze work, 2 small bronze rings, and a quantity of coarse beads: carnelian, amethyst, beryl(?), shell, and various kinds of glass. (Large number of beads and shells with a cross.) S.

$\mathrm{N}_{2109}$ (тс) Map C4

Copt. See Smith. Under body, 2 strong pieces of wood, sawn $5_{1 / 2} \times 8$.

N 2110 (Green) (TC) Map D3

(Green) 16o deep from hard gebel. Contained _ pieces of veneer from coffin. Pieces of $A$ and (i). 
N 2106

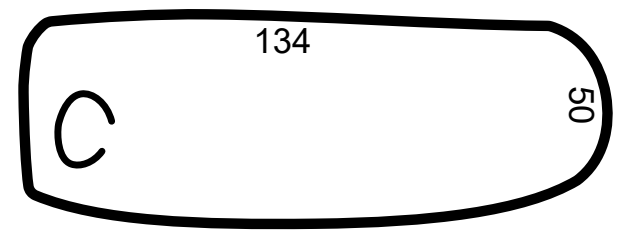

N 2108
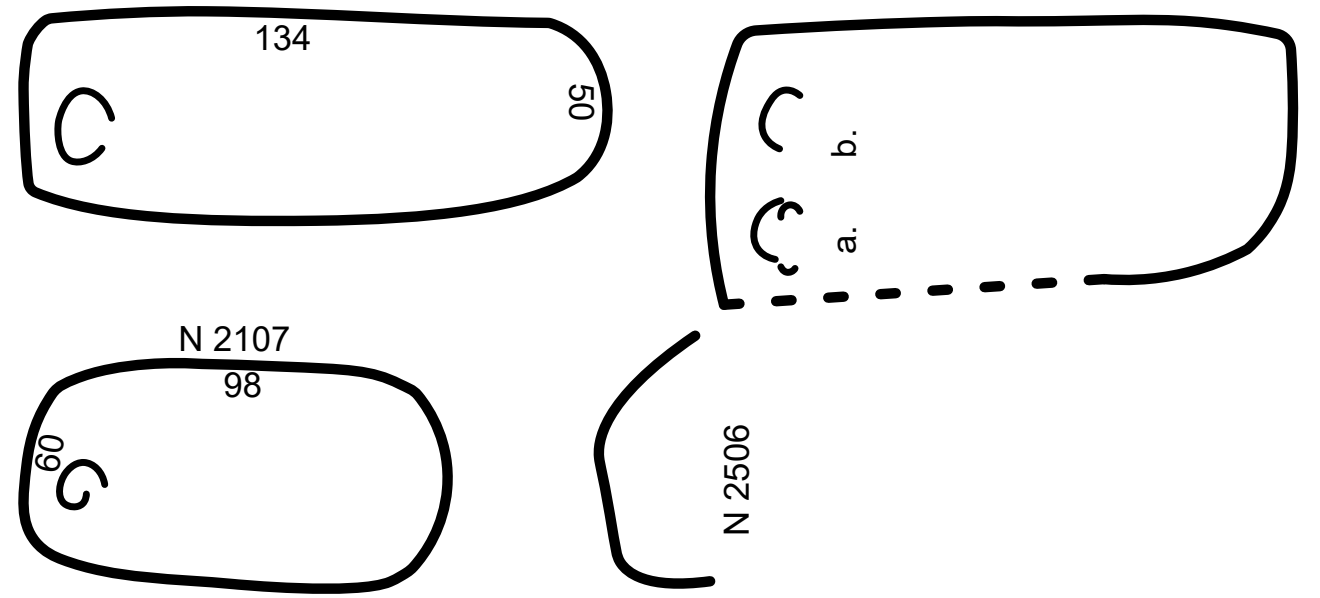

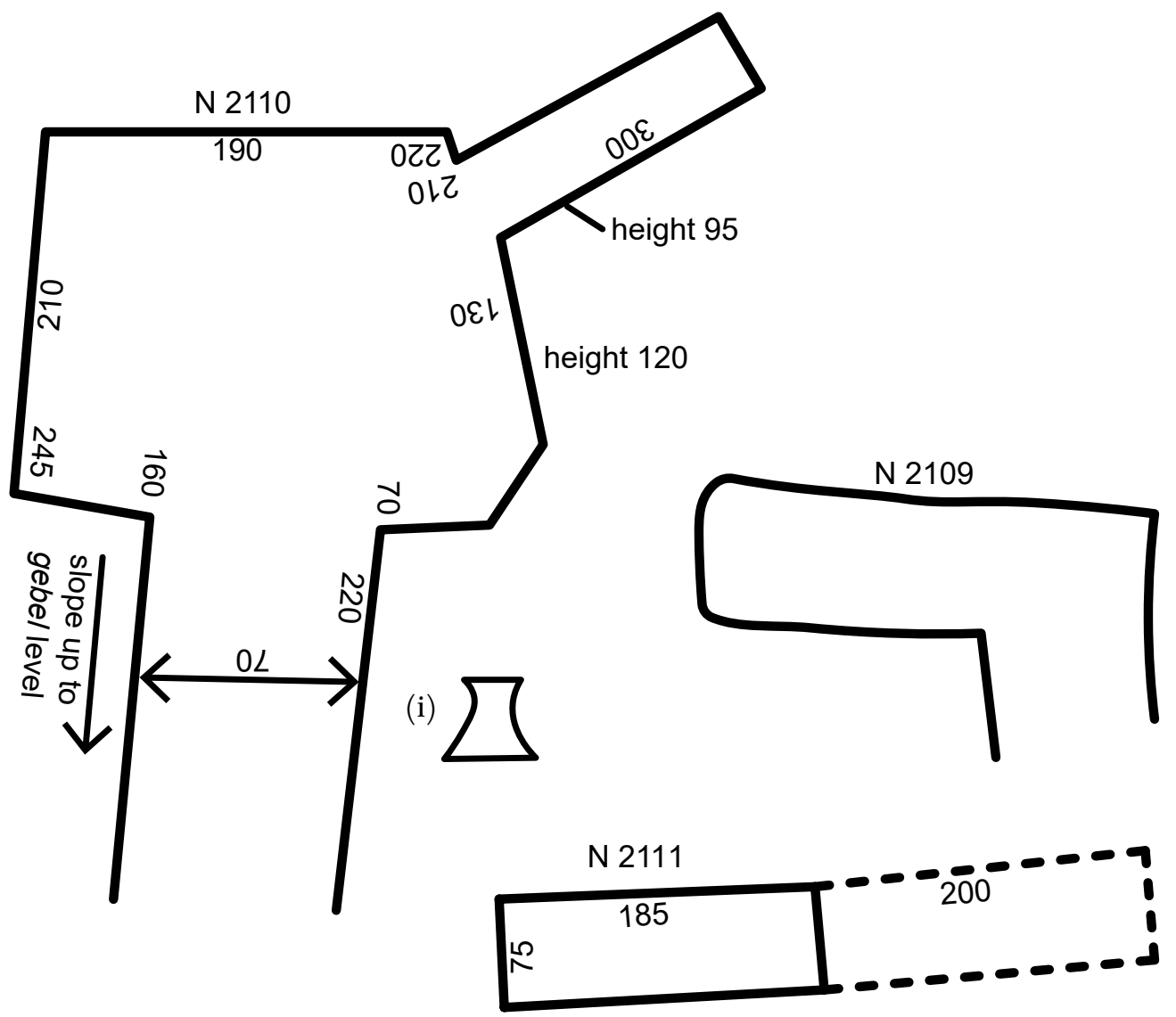


N 211 (TC) Map D3

200 down. Contained nothing.

N 2112 (TC) Map D3

No chamber. Contained fragments of a wooden coffin. Wooden headrest (i) (6-14439). [ed.: Hearst Museum records had erroneously assigned 6-14440 (beads) to this burial, but they are from $\mathrm{N} 2212$.

N 2114 = N 2051? (TC) Map D5; photo C 8518

Height was 130. Nearly all broken away. Door blocked with rough stones faced with mud. This blocking went in 18o. Adult. Sex? Burial on back. Bones in very bad condition.

$\mathrm{N}_{2115}$ (TC) Map D5

65 high. Remains of chamber, half broken away when roof of 2114 fell in. Contained nothing.

$\mathrm{N} 2116$ (TC) Map D4

185 drop from gebel level. 95 high. Contained nothing.

$\mathrm{N} 2117$ (TC) Map D4

75 down from gebel level. $47 \mathrm{~W}$ of N. Early grave with much broken away by Copts. Remains of wooden coffin.

$\mathrm{N} 2118$ (TC) Map D4 (red)

8 o W. Floor of chamber broken through to chamber beneath.

N 2119 (TC) Map D5; photo C 8516, C 8538

$42 \mathrm{~W}$. Height of chamber? In main chamber, burial on back. Adult male. Also, several pots, A? (i) (6-14442, 6-14443, 6-14444, M (ii) (6-14441). Glazed amulet (iii). Chamber blocked with rough stones faced with mud. On mud face, a few rough scratches. This stone blocking went in a distance of 130. Burial in chamber. Male? adult. Bones in very bad condition. On right side. Position given approximate. Apparently, both hands to face. Traces of wood from coffin. 

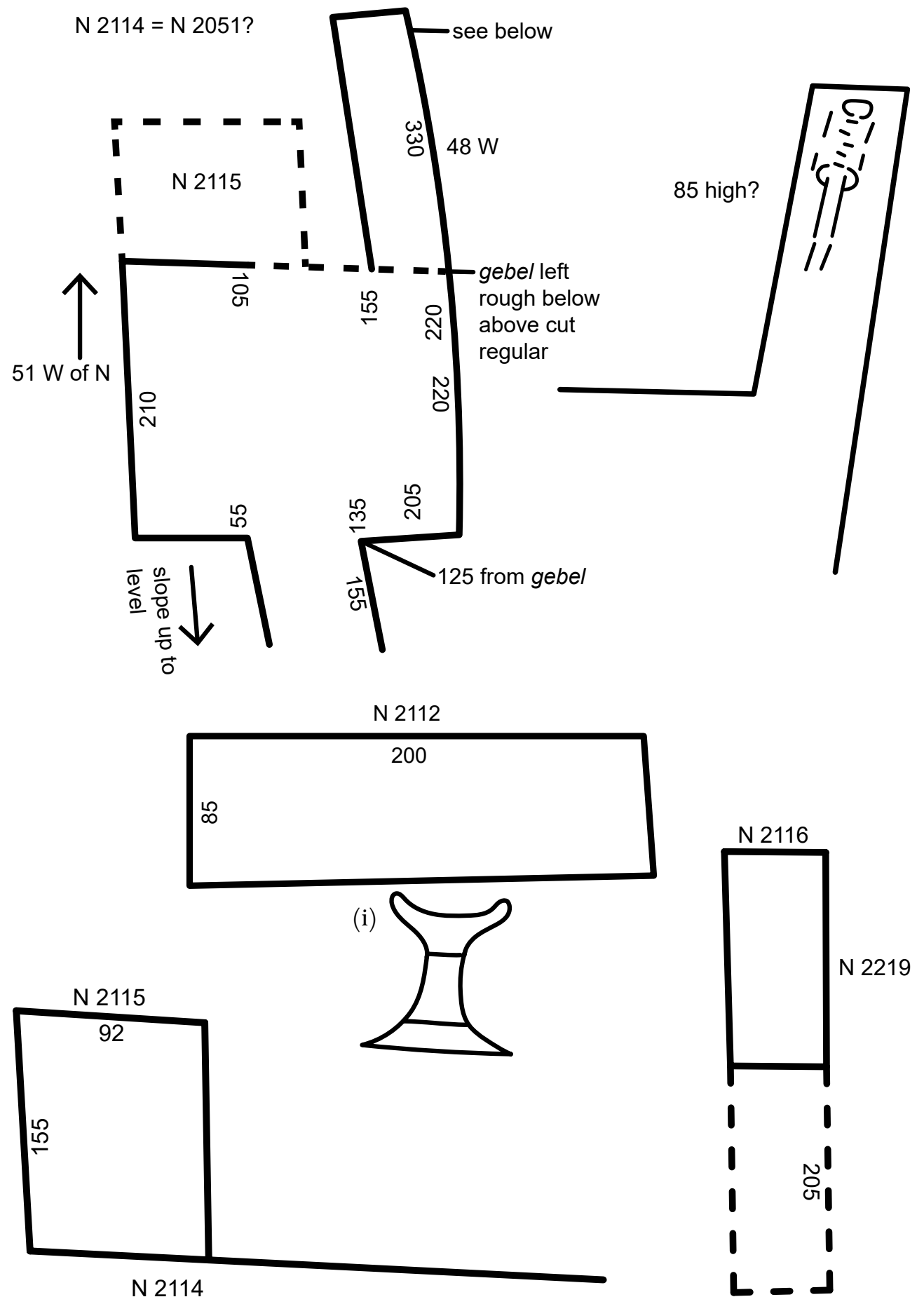

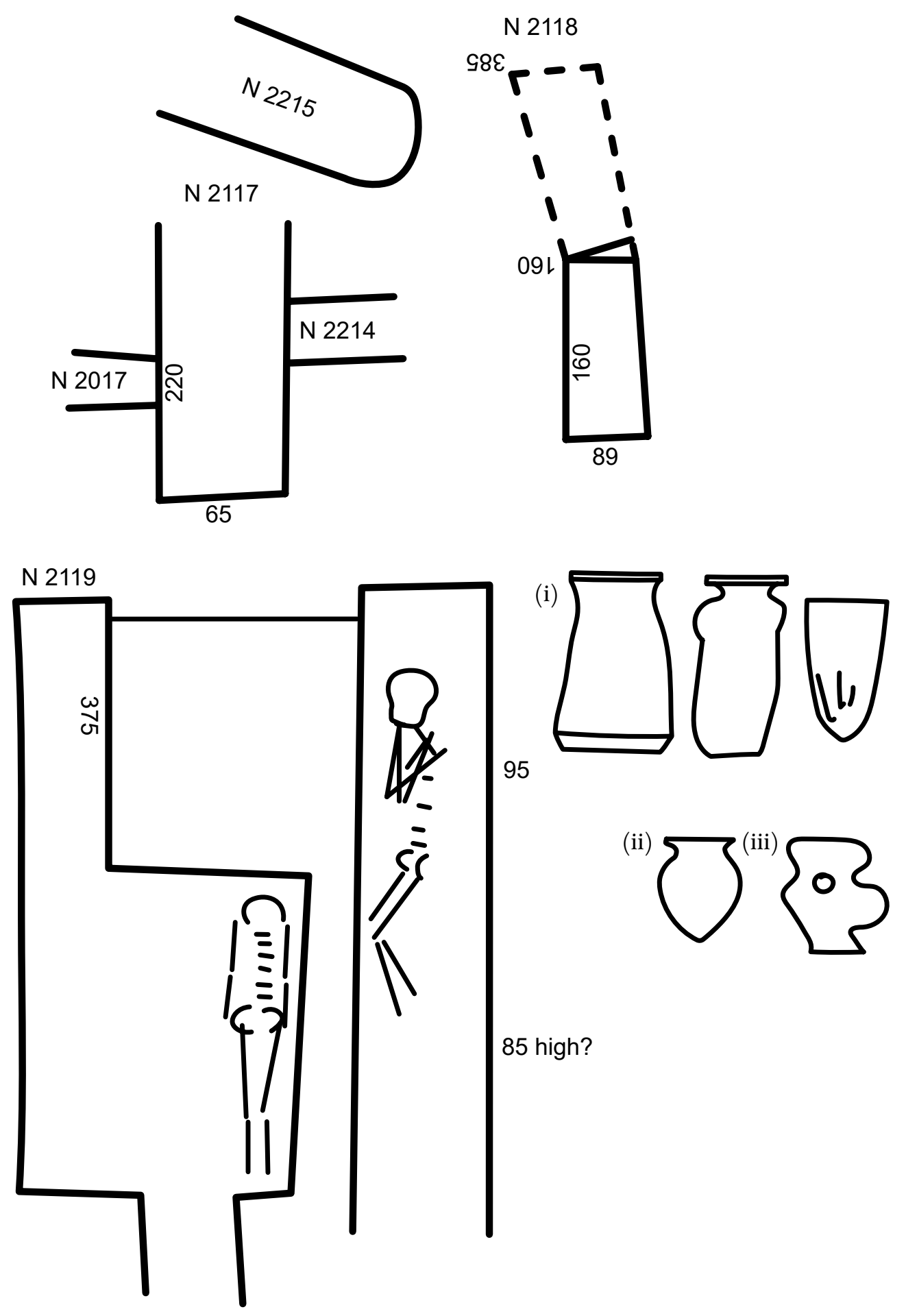


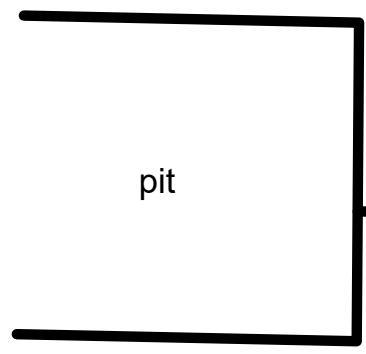

N 2130

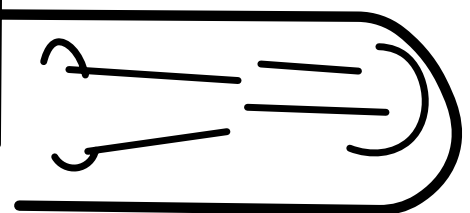

(i)

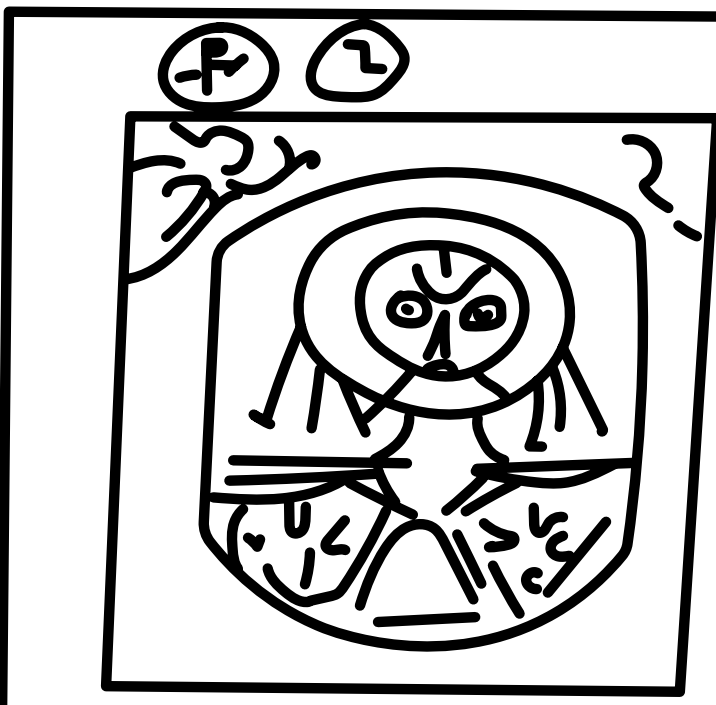

(ii)

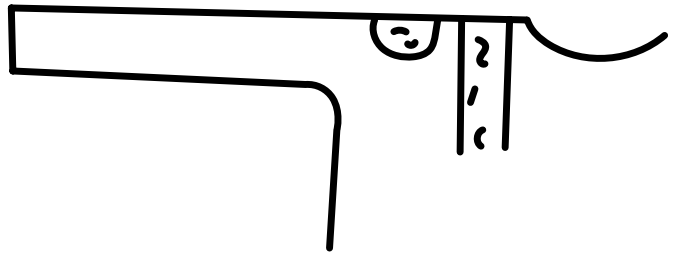

(iii)

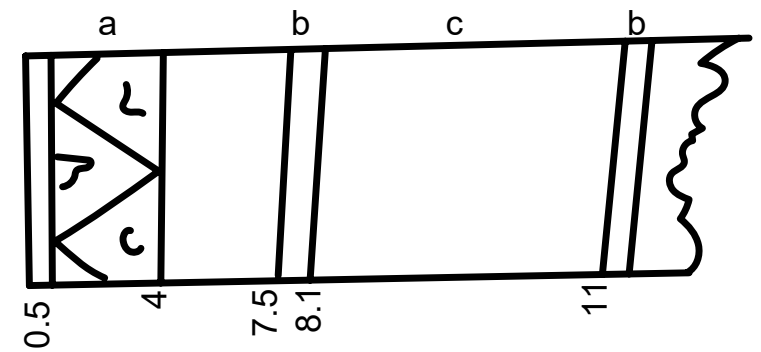

(iv)

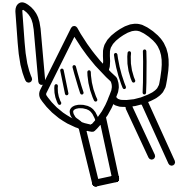




\section{N 2130 (TC) Map E3}

Mate ? (S) Lower part of Coptic burial. Wrapped in coarse sackcloth. Outside this, there had been a thin wrapping of pink cloth with white bands. Inside, wrapped in 2 or 3 thicknesses of finer cloth, by feet, a square of fine drawn work. Over feet, a roll of apparently odds and ends of colored cloth, worked in various colors with wool. Just below knees, a panel of wool work in red, blue, green, and yellow. Under body, inside wrappings, remains of palm sticks. Remains of a shawl and 2 shirts. Shawl: with fringed edges. Near each corner?, a large square panel sewn on (i). This was elaborately embroidered, and was certainly all drawn and needle worked?? Pattern, a human figure?, was worked in red, blue, yellow, and green wools. Outsides of patterns were strengthened by binding thick yellow thread round and round 2 or 3 threads of the warp. First shirt: a whole sleeve remained. This shirt was worn inside out. Arm was sewn up for a distance of 37 with red wool. At the top, the edges met, but as it went lower, tuck of increasing size was left. Round the hole in the sleeve at arm pit, a cord of blue wool was sewn. On breast, there had been the usual bands and circles of embroidery in red, blue, yellow, and green ?inwoven or put in with needle (ii). Designs floral. Round cuff, an applied band of usual blue and yellow. Second shirt: Lower part of sleeve remaining (iii). a. Applied band of usual blue and yellow. b. Narrow bands of red triangles on a blue ground. c. Drawn work, filled in with needlework? of red, green, yellow, and blue. Other fragments showed remains of breast bands with floral designs of similar work. One piece with design (iv) showed very clearly that wool had been applied with the needle?

\section{N 2131 (TC) Map E4}

About 5 o high. Gebel ran down to level at end of wall. Male? Position of arms? Remains of cloth under body. Remains of wooden coffin, too much broken to measure.

\section{$\mathrm{N}_{2132}$ (TC) Map E3 (red)}

130 down. Broken away by falling in of roof of moghar. Adult male. Burial disturbed. Legs bent back sharp from the knee. Had been wrapped in cloth. Inside, traces of coffin $138 \times 38 \times 29$. Thickness of wood $21 / 2$. Corners as usual. Whitened inside and out. A part of the coffin had at some time been burnt.

\section{N 2133 (TC) Map D4}

100 down. Adult female. Lower part of Coptic burial. Head west. Upper part broken away by pit. Wrapped first with a fine cloth (very little remaining) one 

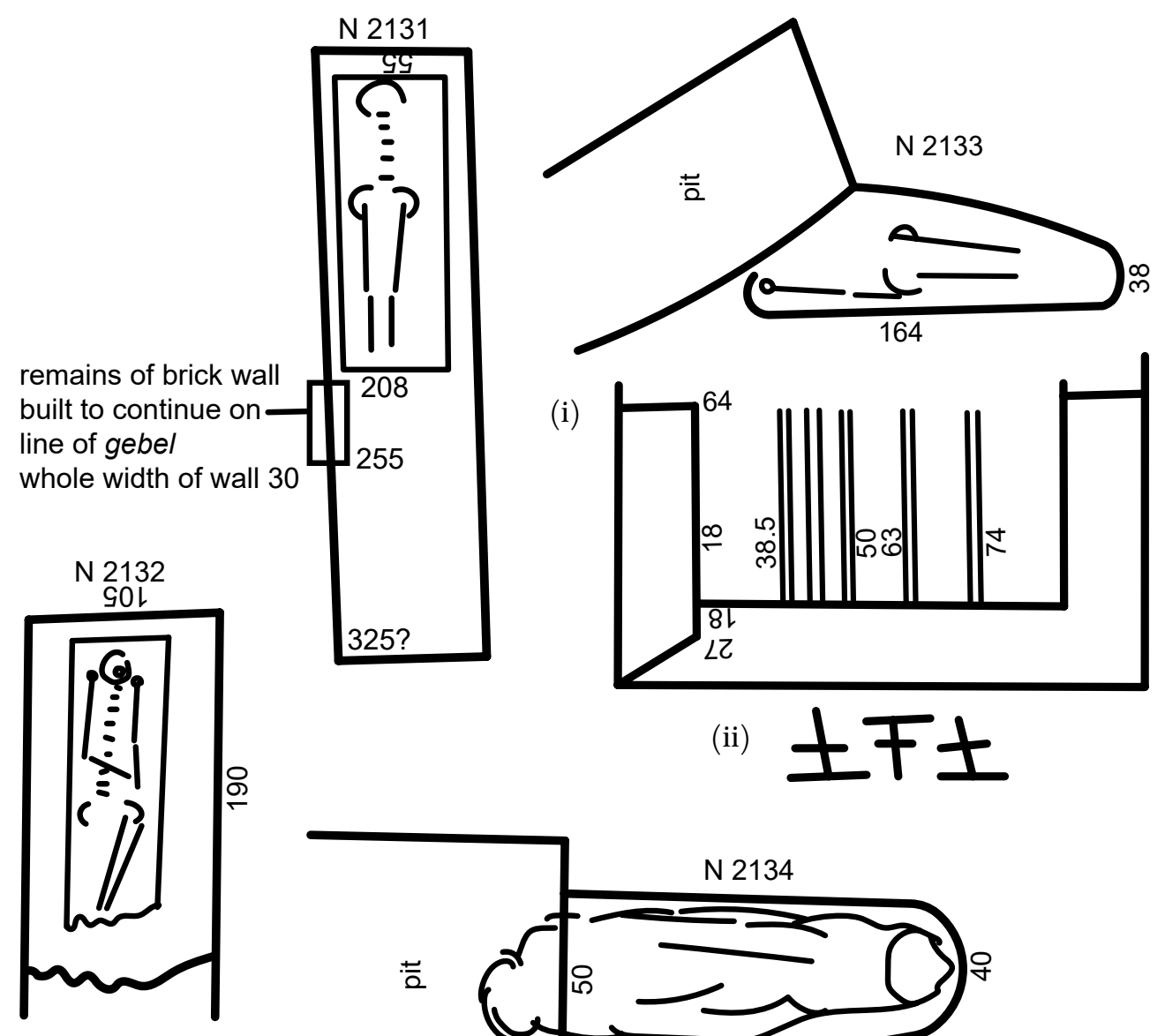

(i)
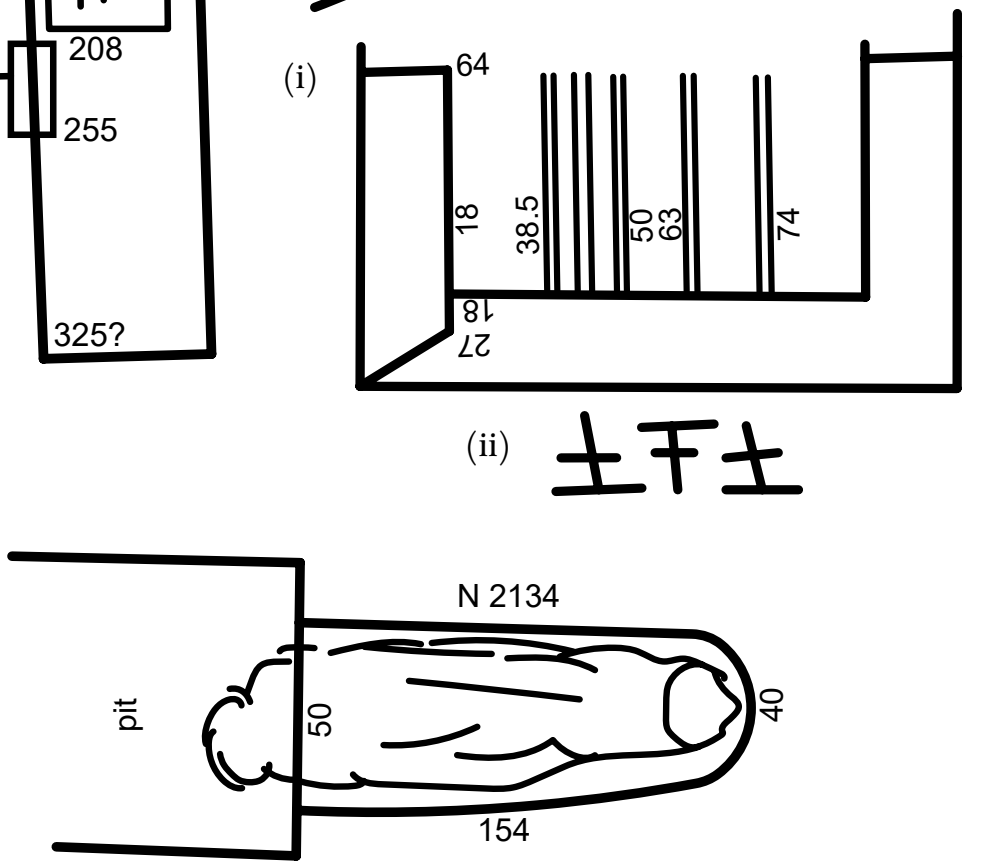

(iii)

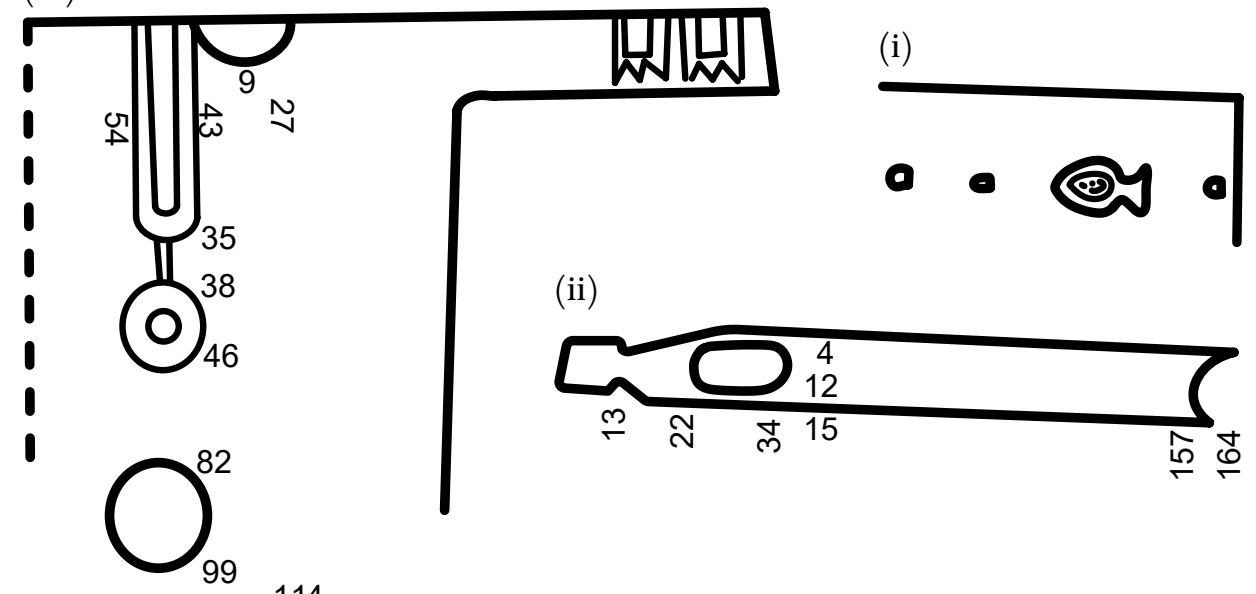


rosette remaining of red cloth (inwoven) with lines of white thread and insertion of colored wools. Under, a cloth wrapping of coarse sackcloth was thrown back over feet. Between this wrapping and the shirts, a quantity of dried leaves and a quantity of salt. Under body, between sackcloth and shirts, 2 palm sticks tied together at ends. Outer shirt of usual kind with 2 seams down each side, corded. Running up middle of front and back, 2 bands of blue and red cloth inwoven with tree and other designs in colored wools. Round bottom and down each, a wide band of blue cloth with white cord decoration was sewn on. Colored cloth in wool only. 1 sleeve remaining with broad band of drawn work, all wool gone, and narrow band of blue sewn on. From under shirt, under shirt had 2 bands of colored cloth down front and back, on woof merely. Outer shirt: width approx. 10o. Same width all the way down (i). Border of blue with white decoration was sewn on. At corner, a turn of the strip was made to continue up side. This border apparently did not go up sides at back. Bands of color were continued to bottom, underneath the blue border. Panels: borders of dark blue with red (ii). Ground of main part red with floral designs in green, yellow, blue, and 2 shades of red. Of these, red ground at any rate was put in on loom. Others may have been also. Warp was crosswise to shirt. Under shirt: In very bad condition. Bottom of shirt plain. Down front and back, 2 panels 11.5 wide. Borders red with pattern in original thread. Ground of main part of panel original thread. Designs in red, green, yellow, and blue, apparently put in in the weaving. At 57 from bottom of shirt, a tuck 11 wide sewn up with yellow thread. Sides of shirt not corded, the ends of the cloth being simply folded in together and sewn with a running stitch. There were no circles at bottom of shirt. Upper part destroyed, so neck and shoulders? Sleeves also?

\section{$\mathrm{N} 2134$ (TC) Map D4}

9o down. Copt. Head west. Wrapped first in a covering of fairly fine yellow cloth. Then in sackcloth. Adult male. On outside, covered with a wrapping of cloth with patterns in red thread. This was tied round feet by the corners. This was a shawl with corded ends. Patterned ridges were left in weaving. A line of ornamentation down end in red thread inwoven (i). Underneath, remains of binding of 2-strand fiber cord, but almost all gone. Below, 2 or possibly 3 wrappings of sackcloth in very bad condition. Quantity of salt and several plant seeds on body. By head, presumably a circlet, a twist of red wool. On head, a quantity of long, dark brown, almost straight hair. On shirt, quantity of 2 shades of red cloth ornamentation (inwoven) with yellow thread decoration. Under body, outside shirt, under wrapping, roughly shaped board approx. 5 thick (ii). Left patella was broken in half. This was bound up and a piece of palm wood $18 \times 4$ was bound in over joint on under side. Outside this wood, an extra pad of red-brown striped cloth was placed. The bandage was bound 
N 2137
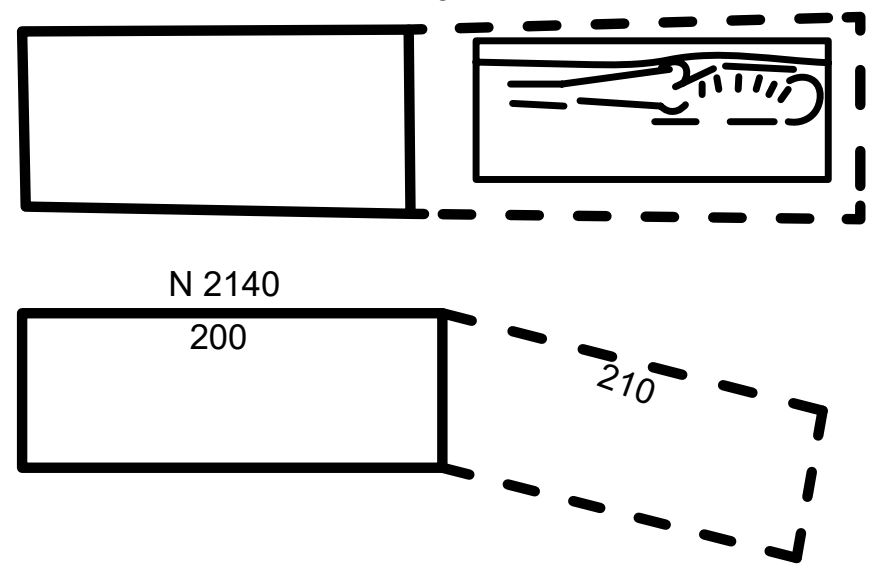

N 2142

N 2143

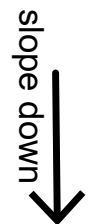

remains of brick blocking 20 high, 33 wide

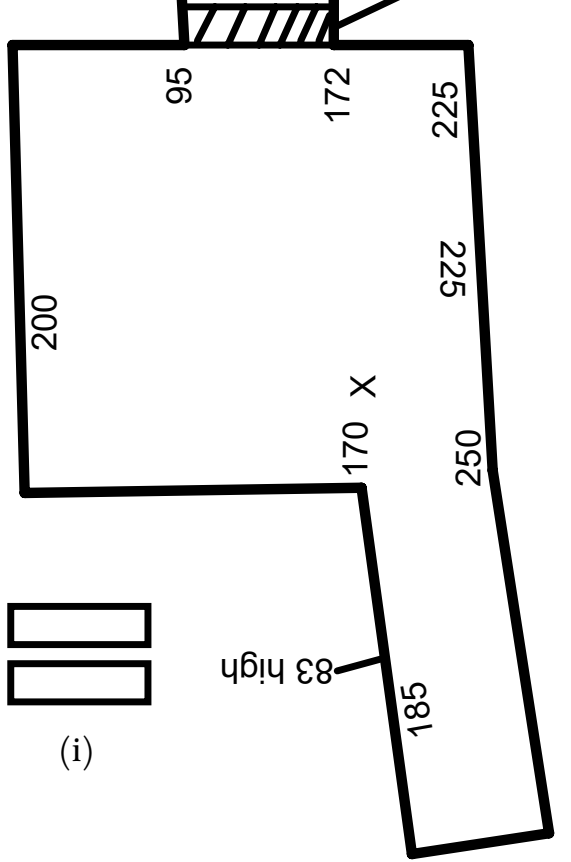

N 2138
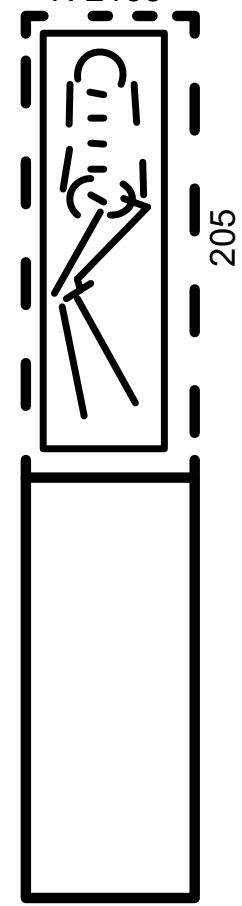

N 2139

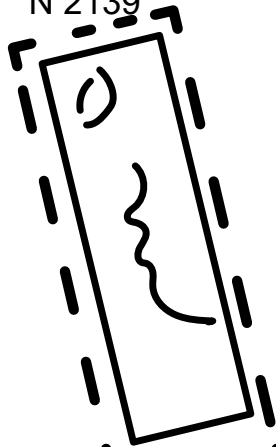


round with red wool cord. The bandage was torn from an old shirt? as there was remains of embroidery on it. Shirt in very bad condition (iii). Pattern outlined in lines of original white thread. Dumbbell outside bands in dark red and inner in light red with white thread ornamentation. Sleeves ditto. All inwoven. Shirt made from one piece. Edges corded.

\section{N 2137 (TC) Map E3}

200 down from gebel level. 75 high. Chamber under chamber of 2630. Adult male. Burial half over on left side, resting against side of coffin. Inside measurement of coffin $160 \times 40 \times 40$. Thickness of wood 2 . Corners as usual.

\section{$\mathrm{N}_{2138}$ (TC) Map E3}

NE of 2232. 180 from present level. Approx. 9o high. Adult. Female? Aged approx. 3 o. Burial on back, but legs bent. Inside measurement $125 \times 45 \times 5$ o. Thickness of wood 3.2. Corner as usual: round pegs.

\section{N 2139 (TC) Map E4}

Northeast of 2233. 185 deep from gebel level. 85 high? Adult male. Small dent on top of skull? from a blow. Burial plundered: position? Head had been north. Inside measurement of coffin $176.5 \times 44 \times 5$ o. Thickness of wood 3.2. Corners as usual: round pegs.

N 2140 (тC) Map B3

370 deep. Contained nothing.

N 2141 (тс) Map B3 (red)

430 deep. Contained nothing.

N 2142 (TC) Map B4

Contained nothing. ? Coptic.

\section{N 2143 (TC) Map B4}

236 deep from present level. $150 \mathrm{~W}$ of N. Height of chamber about 10o. Nearly all broken away. In small chamber, few broken bones. Blocking of door built (i) with radim between the bricks. X. 140 up from floor, there had been a burial in an oval pottery coffin, most of which had fallen through into chamber. 
N 2170

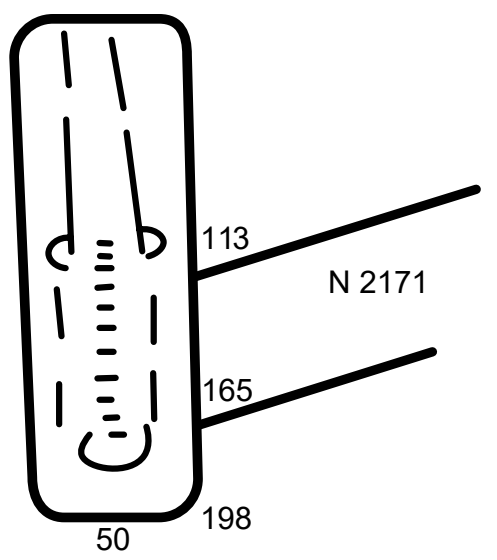

N 2172
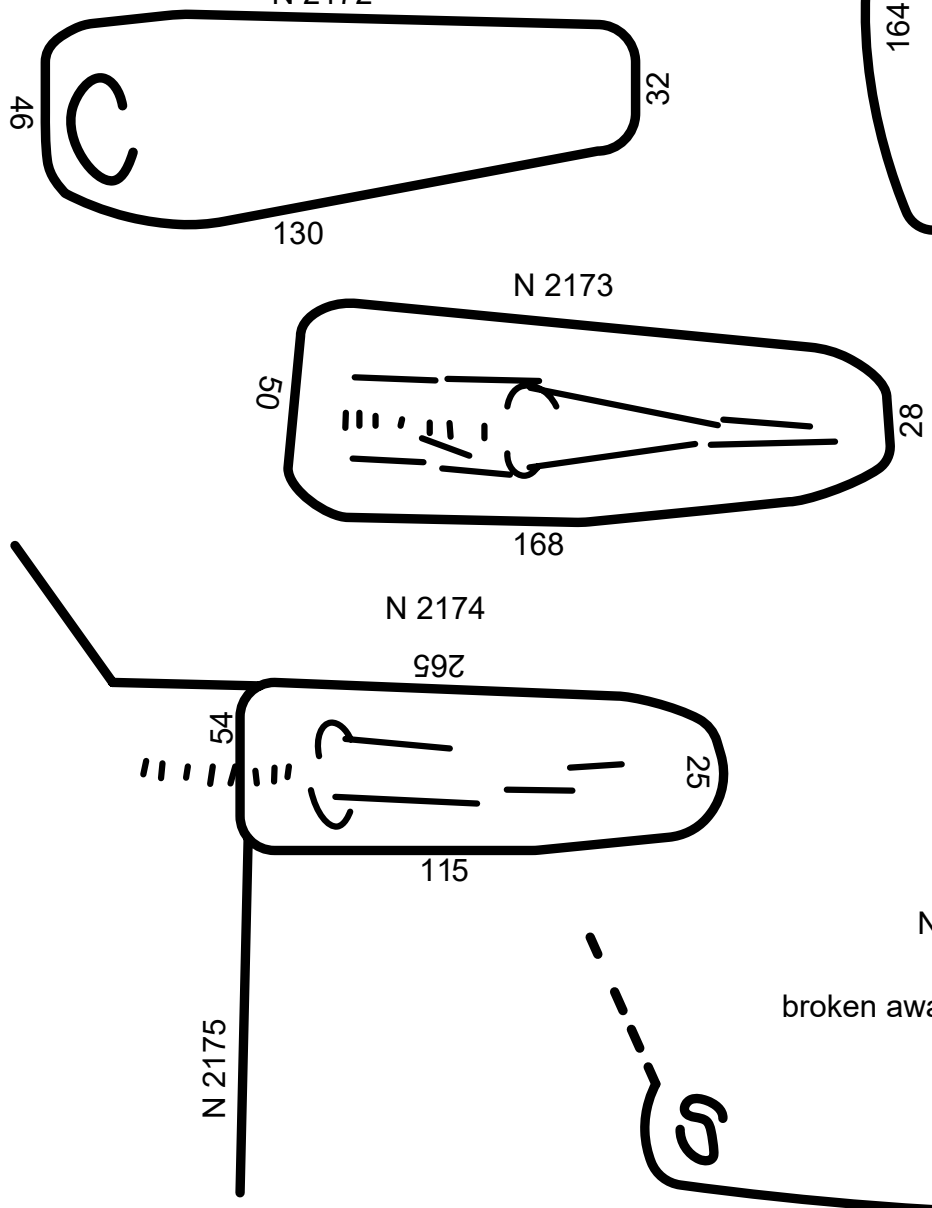

N 2171

N 2170

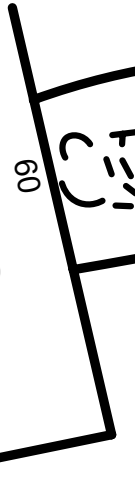

N 2175

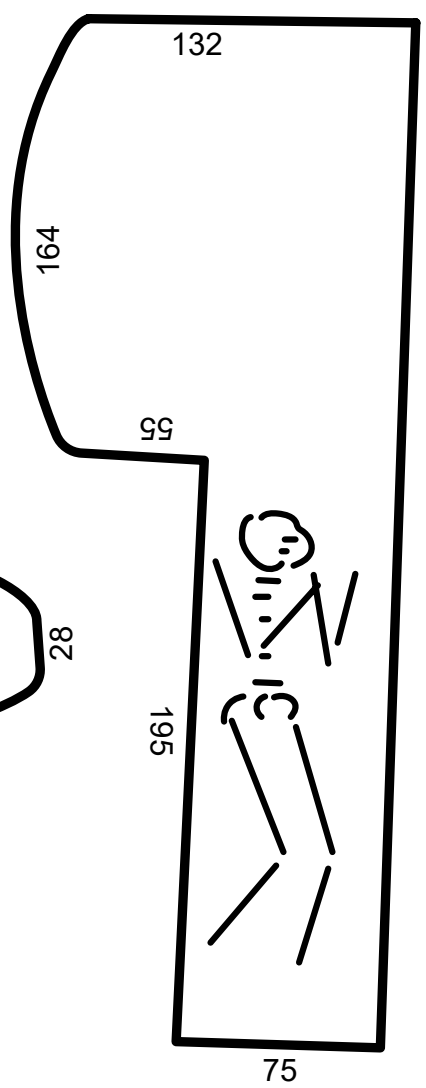

N 2176

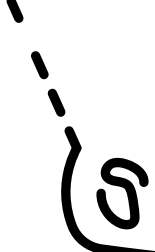

broken away

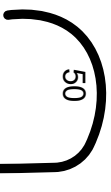




\section{N 2170 (TC) Map B4}

72 down. Coptic burial. Adult: sex? Usual position. Head south. All trace of cloth gone.

N 2171 (TC; MM) Map B4

9o down. Coptic burial. Male? On back, head west, arms by side. No cloth preserved.

N 2172 (тC; MM) Map B4

Coptic burial. Shallow grave running east-west. 85 down from gebel. On back, head west, arms by side. Child about 9-10. No cloth preserved. Bronze bracelets on both arms.

N 2173 (TC; MM) Map B4

Copt. Shallow grave running east-west. Approx. 8o down. Female? adult. On back, head west, arms by side. Skull gone. No cloth preserved.

\section{N 2174 (тC; MM) Map B4}

Copt. Shallow grave running east-west. West end projecting over early pit. 8 o down from gebel. Adult female. On back, head west. Upper part of body gone. No cloth preserved.

\section{$\mathrm{N} 2175$ (TC) Map B4}

Approx. 125 from gebel. 145 from present level. Adult female. Slightly over on left side. From way bones were spread, there could hardly have been a coffin. No discoloration of soil from one under body.

\section{N 2176 (TC; MM) Map B4}

Copt. Shallow grave running east-west. Approx. 100 down from gebel. Adult female. On back, head west, arms by side. No cloth preserved.

\section{N 2200 (TC; M M) Map E3}

Coptic. Shallow grave running east-west. 80 down. Head west. Adult male. On back, head west, arms by side. Skull gone. Under the body, there were 2 palm sticks, which had been fastened together. The cloth was in very bad condition, but apparently there had been one shirt and a single wrapping of sackcloth. 


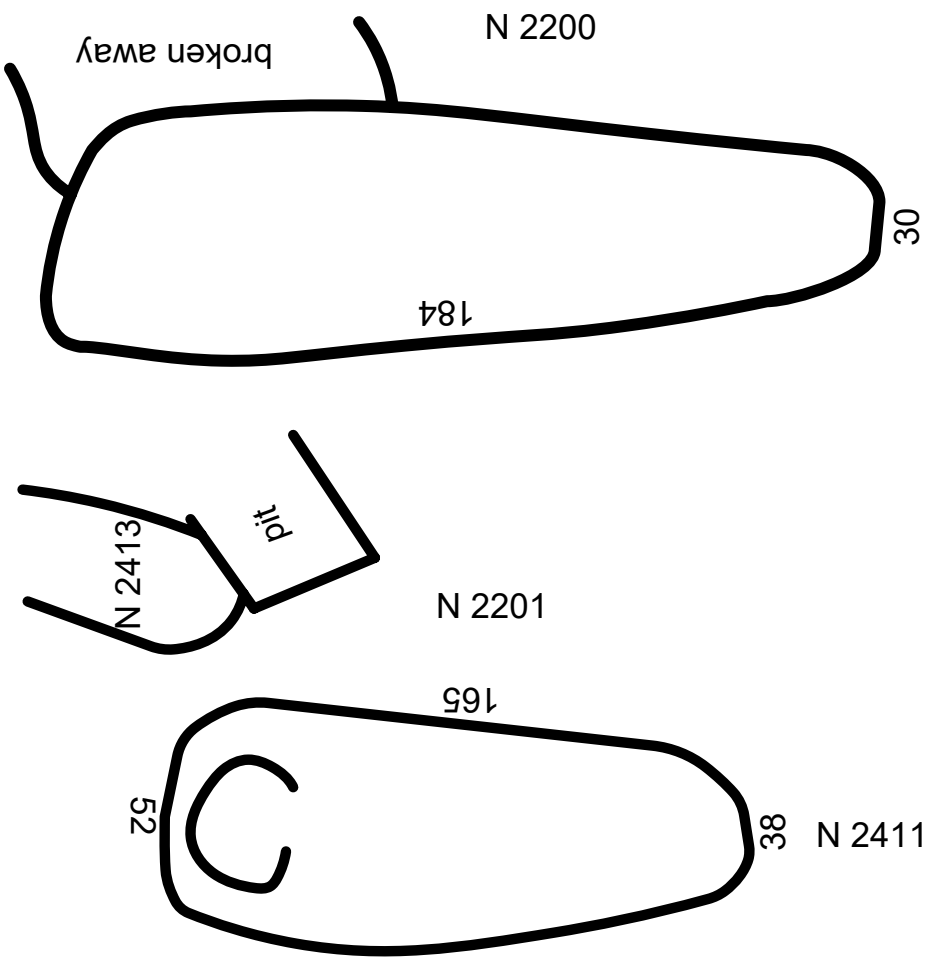

N 2412

(i)
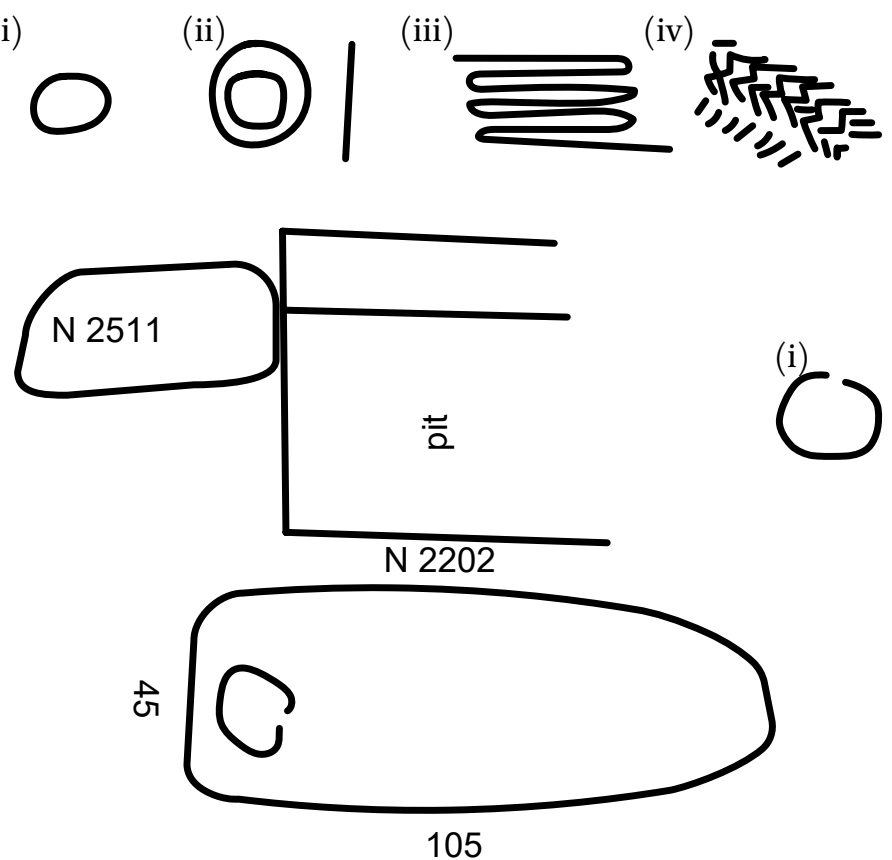


\section{N 2201 (TC; MM) Map D4; photo C 8470}

Copt. Shallow grave running east-west. 55 down. Adult female aged 22-23. On back, head west, Arms by side. Remains of dark brown curly hair. On the left forearm, an iron bracelet, and on the left wrist, iron and bronze bracelets, all (i). On one of the fingers of the left hand, a copper ring. On the right wrist, a bronze bracelet. By the left arm, but apparently not on it, a quantity of glass, shell, and carnelian beads. By head, a tiny copper ring (ii), possibly part of an earring. The body was clothed in a shirt of yellow cloth. There were no colored wool decorations, but round the bottom of the skirt and of the sleeves, the usual bands of blue with designs in yellow thread were sewn on, 4 wide on skirt, 1.8 on sleeves. At one place, near right shoulders, apparently edge of cloth was tasselled. Yellow and blue on bottom of skirt and sleeves put on as usual, i.e., yellow thread sewn on (iii), and blue thread worked into it so as to leave geometrical patterns of the yellow. On the head, there were traces of a net cap or hood. By the head, there were remains of a bag(?) of red cloth sewn (iv), containing scraps of yellow cloth and a few seeds, possibly part of a neck pad. Under the body, there were 2 palm sticks, fastened together at the feet, but widening out so that at the other end, 1 stick came under each shoulder. On the body, there was a quantity of salt, some plant seeds, and a few twigs. The body was wrapped in a single shawl of sackcloth with fringed edges, and a band of decoration [was] near the ends. The right side of this was first thrown over, and then the left and the edges were sewn together. The binding cords were in such bad condition that the type could not be determined.

\section{N 2202 (TC; MM) Map D4}

Shallow grave running east-west. Approx. 50 down. Coptic child. Aged approx. 2. On back, head west, arms by sides. Remains of a plain shirt, reaching apparently to the knees. On each ankle, a copper anklet (i). The innermost wrapping consisted of a shawl of thick yellow cloth. Outside this, there was a white shawl, with tapestry-woven designs in colored wool. All traces of cord bindings had disappeared.

\section{N 2203 (TC; M M) Map D4; photo C 8572}

Copt. 9o down. Reuse of an early grave, a Dynasty 6-9 wooden coffin being destroyed to make room for the new burial. Adult female. On back, head west, arms by side. Quantity of dark, curly hair. Lashes of left eyes also preserved. The shirt had almost entirely disappeared. On the head, there were traces of a net cap or hood. Under the body, there were 3 palm sticks. The innermost wrapping consisted of a shawl of mixed red and black cloth, decorated with elaborate tapestry-woven plant and figure designs (i). This shawl had been darned in several places, chiefly with thick black thread. Sides were corded 

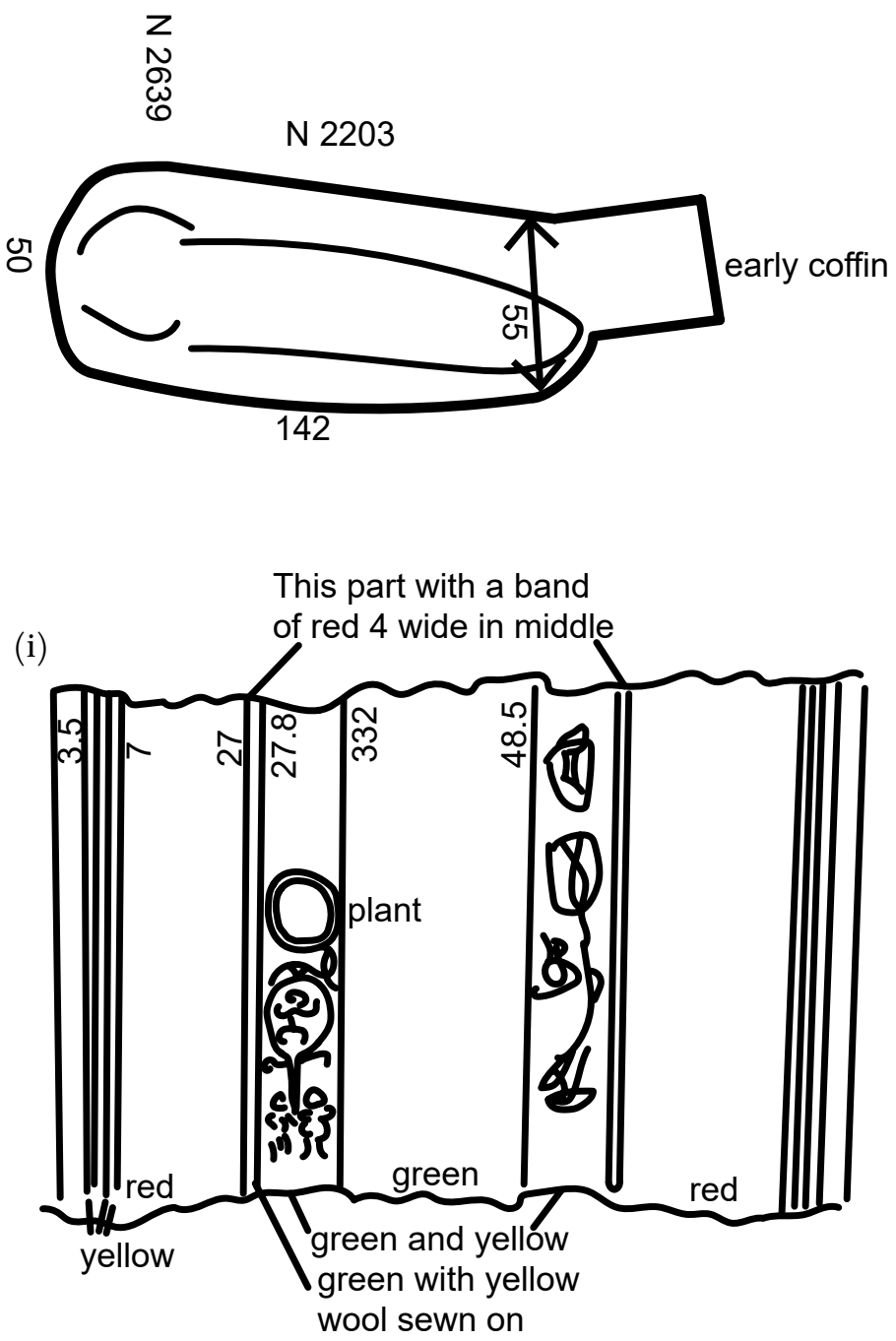

(ii)

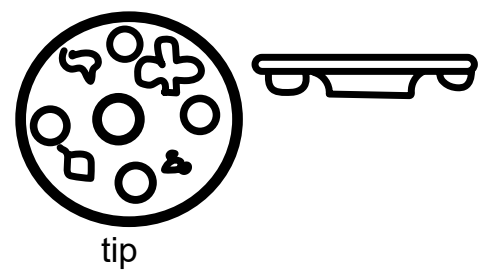




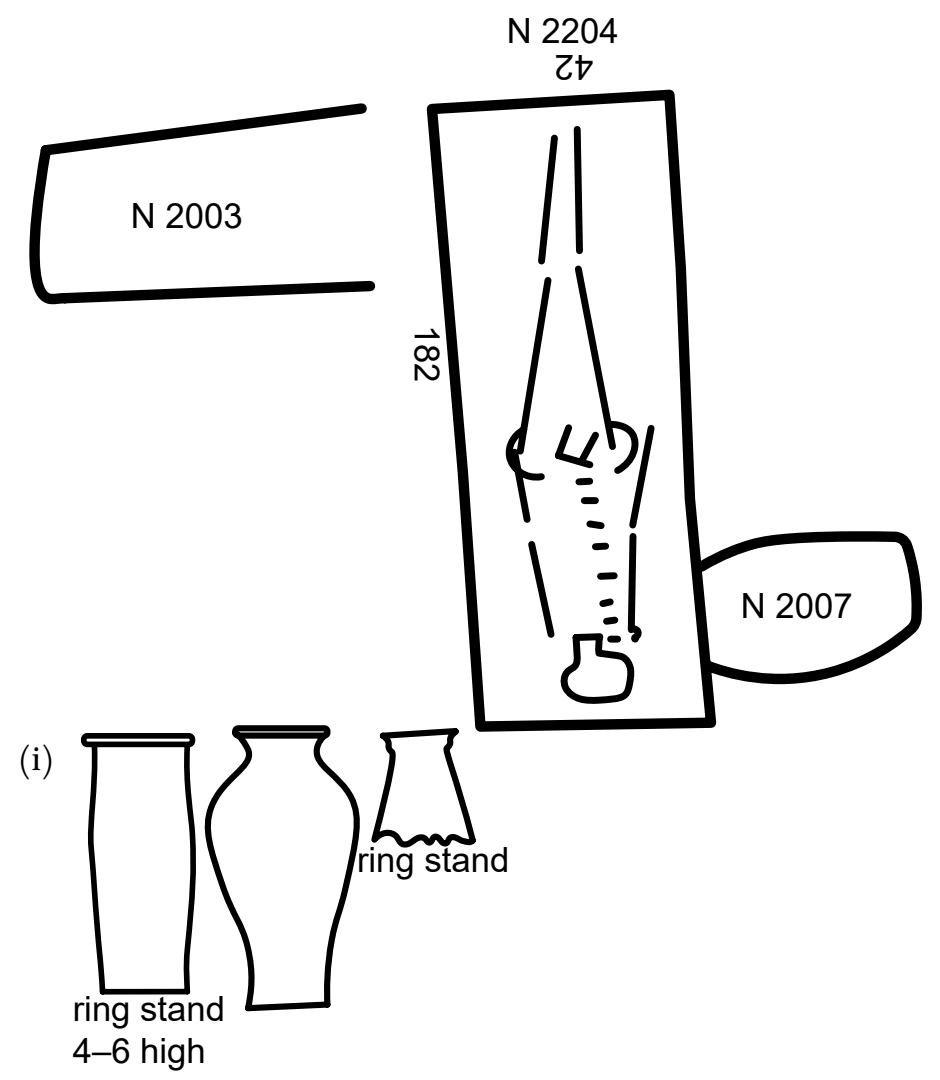

N 2205

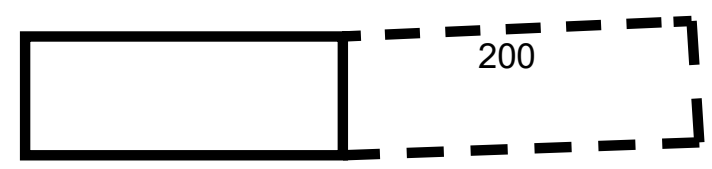

N 2206

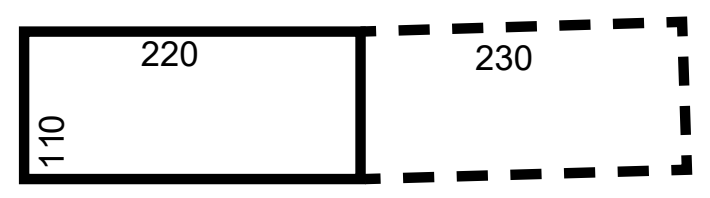

N $2207=$ N 2431

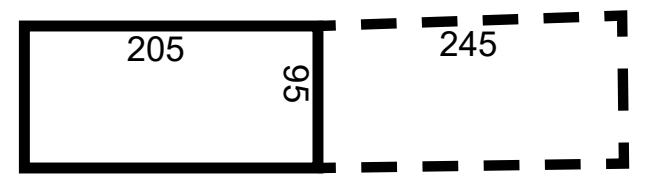



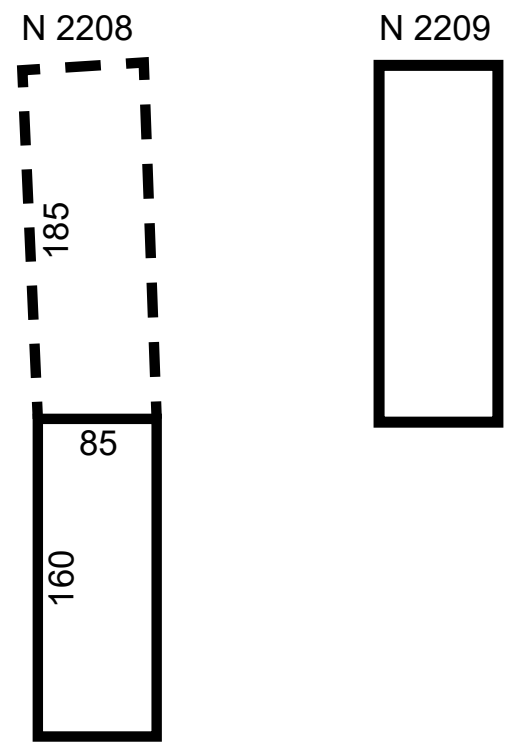

N 2211
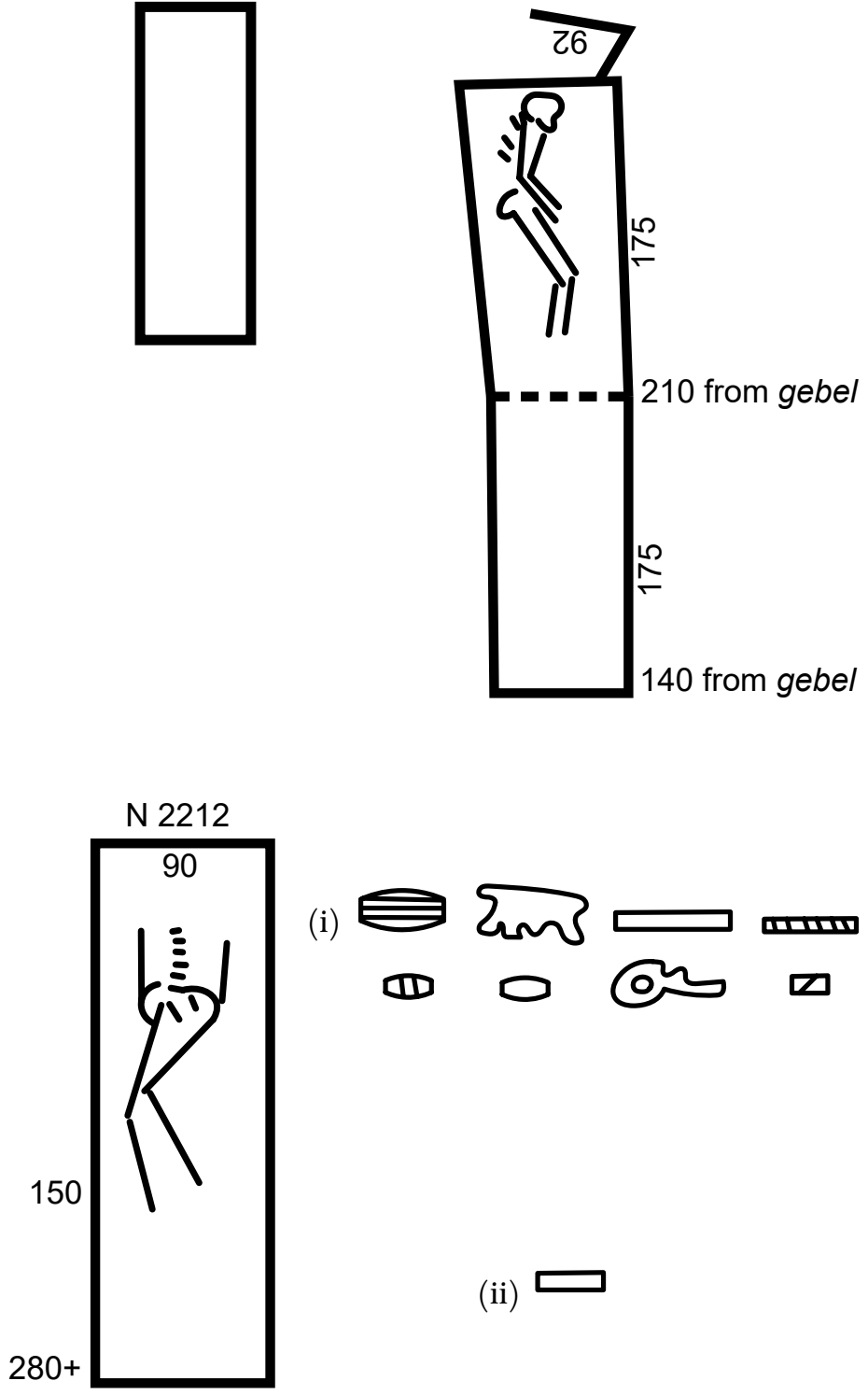

(i)

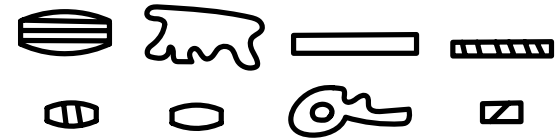

(ii) 
with small cords. First, inside, a thick cord was sewn in, on one side green, the other yellow. Colors were all inwoven except yellow wool in decorated panels. Near each side, 1 wide and 2 narrow lines of yellow thread, the wide in the middle. The decorated panels consisted of alternate flower and figural designs. The outer shawl was of sackcloth. The cord bindings had almost entirely disappeared. In the filling of the grave, there were pieces of a large pottery dish (ii).

$\mathrm{N}_{2204}$ (TC) Map D3

Approx. 180 down from hard gebel. Regularly cut up for about 50 above irregular. Actual grave actually cut in gebel. Above gebel, contracts at both ends. Facing straight on north side, but on south, cut away irregularly. No traces of cloth. Skull may have fallen out of position. Traces of wood from coffin under body. In filling above, 3 broken pots (i).

$\mathrm{N}_{2205}$ (TC) Map D4

Contained nothing.

N 2206 (TC) Map E3

400 deep. 130 high. Contained nothing.

N 2207 = N 2431 (TC) Map N/A [ed.: Map location not listed in excavation records; there is another tomb labeled $\mathrm{N} 2431$ whose map location is also not listed in excavation records.]

335 deep from present level. $42 \mathrm{E}$ of N. 115 high. Contained nothing.

N 2208 (TC) Map E4

100 down from gebel level. $107 \mathrm{~W}$ of N. Contained nothing.

N 2209 (TC) Map E3

180 deep from present level. Probably pit and chamber, but most of latter broken away. Contained nothing.

N 2210 Map D4 (red) [ed.: For drawing, see N 2019.]

N 2211 (TC) Map D4 (red)

Height? Male? 2 or 3 fragments of wood from coffin. Body on left side.

N 2212 (TC) Map D5 (red)

Remains of decayed coffin. Upper part of body gone. Head faced west. Had been probably pit and chamber. Trace of roof on west side about 75 high. By 
N 2213

GL

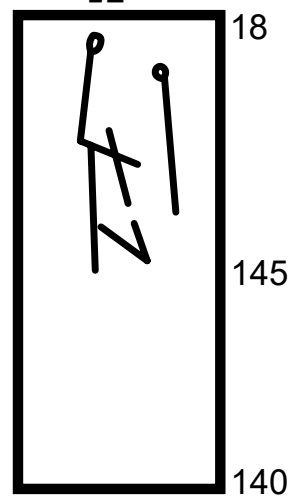

N 2214

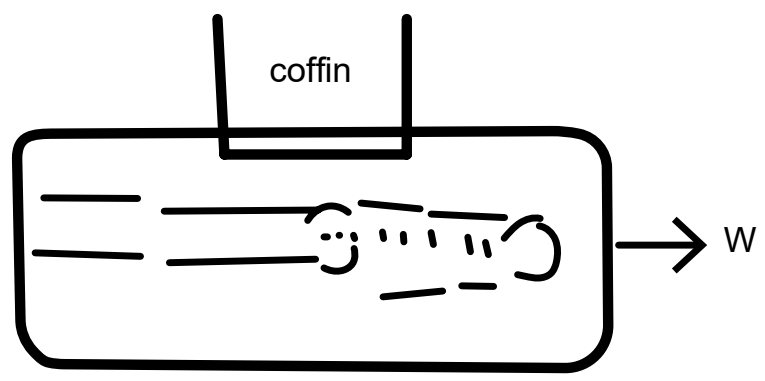

N 2215

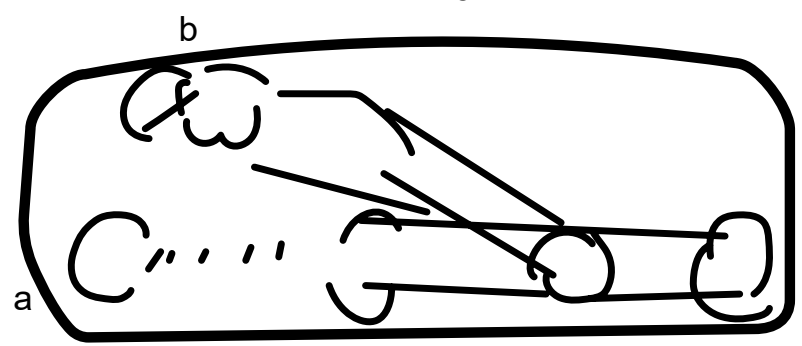


upper part, remains of necklace of, in faience, 1. "was" head amulet, 2. Bes eating snakes, 3. sphinx amulets, (i), frog, stone (ii), carnelian (ii) and disc, 3 shells (6-14440). [ed.: Note that Hearst Museum records erroneously attributed those objects to $\mathrm{N}$ 2112.] In filling, pieces of or saucers of M type.

\section{$\mathrm{N} 2213$ (TC) Map D4}

Burial about 6o down from gebel. Pit going down beneath. Remains of burial in coffin. Burial had been on left side, almost over on stomach. 120 down from gebel. Remains of coffin and burial of small child. Also disturbed. No chamber.

\section{N 2214 (тC; MM) Map D4}

Coptic. Shallow grave running east-west, cut across an earlier grave at right angles. Adult female. On back, head west, arms by side. Only traces of sackcloth left.

\section{N 2215 (1) (TC; M M) Map D4}

[ed.: There are two tomb cards numbered 2215. This record was also included in Mace's manuscript.]

Coptic burial. Shallow grave running east-west, cut across an earlier grave at right angles. Contained 2 burials. a. Adult. Sex? On back, head west, arms by side. Wrapped in rough cloth. Wrappings had almost entirely disappeared. Pads over head and feet. Palm sticks under body. Had been bound round with cord. b. Child aged approx. 12. On back, head west, arms by side. Skull gone. Shirt gone. Palm sticks under body. Wrapped first in sackcloth, and then in an outer shawl of fine cloth, with 3 tapestry-woven bands of colored wool at each end. (1) red, reddish brown, red, (2) yellow, blue, yellow, (3) brown, red, brown. Cord bindings too far gone for the type to be determined.

\section{N 2215 (2) (TC) Map D4}

[ed.: There are two tomb cards numbered 2215.]

(Female. Long, wavy, brown hair. Copper earring.) S. Body covered with remains of several wrappings with a variety of patterns of wool work, etc. Shawl: with fringed ends and ridged ornamentation. One panel showed (i) red ground with decoration of blue, green, and yellow wools. Red may have been unwoven. Other colors were certainly put in with the needle? Shirts: blue border with yellow thread decoration, 9 wide, sewn on, row bottom of skirt and running some distance up sides. Remains of 2 large circles near bottom of shirt with decoration in green, blue, yellow, and red. 
N 2216

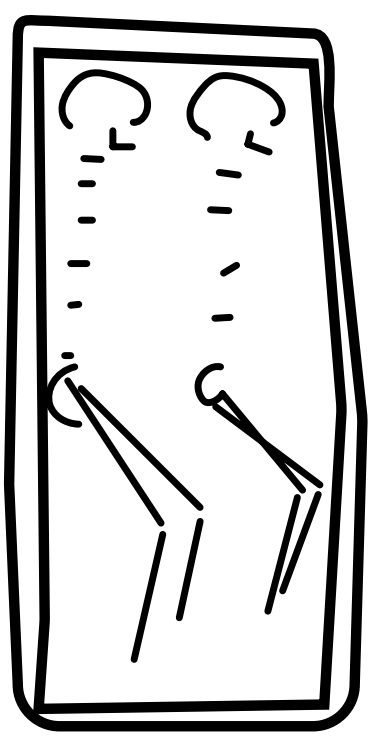

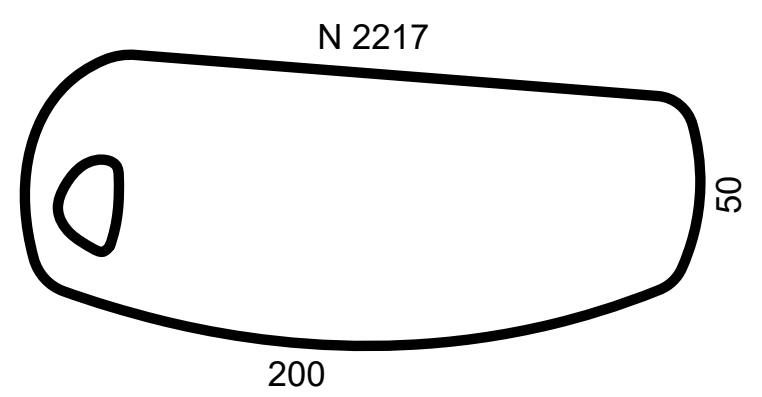

N 2218

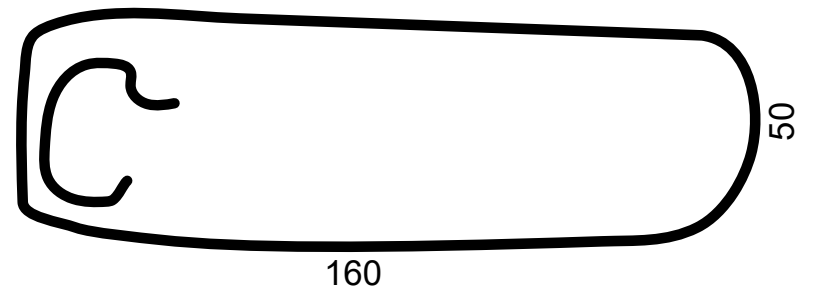

N 2219

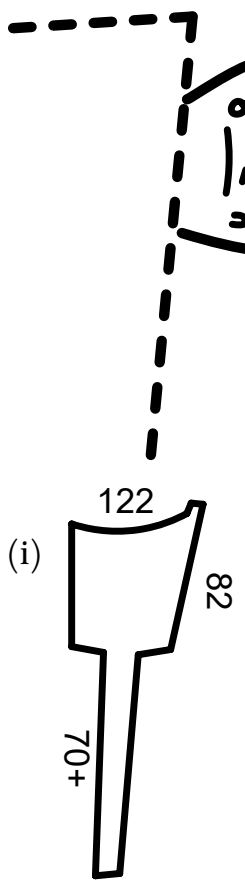

(i)

N 2230 (see N 2401)

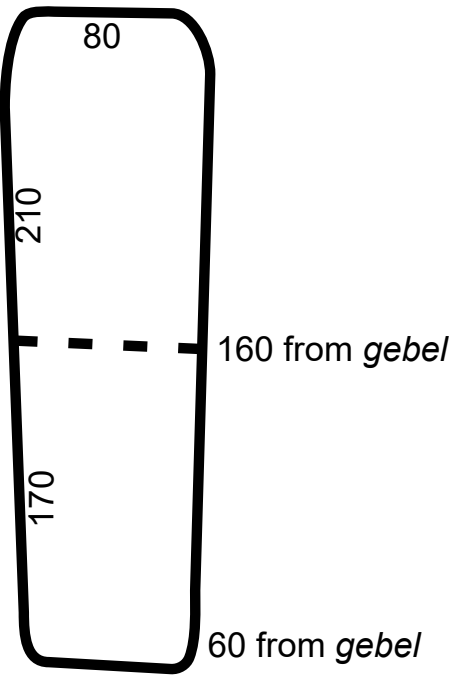


N 2216 (тC) Map D4; photo C 7064

Coffin in very bad condition. Bodies of 2 children in 1 coffin. Both on left side. Position of arms? Traces of cloth under bodies. Inside measurement of coffin $145 \times 42 \times$ ? Thickness of wood 3 . Corners as usual. White stucco inside and out.

\section{N 2217 (тC; MM) Map D4}

8 o down. Coptic. Shallow grave running east-west. Adult female. On back, head west, arms by side. Remains of straight, dark brown hair. By head, remains of an earring of decomposed silver (?) with bronze pendant and 2 glass beads. The cloth had for the most part disappeared, but fragments that were left showed traces of woven designs in colored lines.

\section{N 2218 (тC; MM) Map D4}

8 o from gebel. Coptic burial. Shallow grave running east-west. Adult female. On back, head west, arms by side. Remains of dark brown hair on skull. On lower jaw, only 3 teeth remaining. Cloth almost entirely gone. Over head, large pad consisting of a sackcloth fringed shawl rolled up.

N 2219 (тс; мм) Map D4; photo C 7709

90 down. $33 \mathrm{E}$ of N. Coptic burial. Shallow grave running east-west. At west end, projecting over early pit. Adult. Sex ? On back, head west. Skull and lower part of body gone. Under the body, there was 1 palm stick and a broken wooden spade with rough curved handle, head towards feet (i).

$\mathrm{N} 2230$ = N 2401 (TC) Map E4

90 high. Contained 1 piece of pottery stand (i).

\section{N 2231 (TC) Map E4}

90 from gebel. Entrance at gebel level. Upper part of burial in small chamber. Perfect, but leg bone from the thigh missing. All trace of coffin gone. In one place, 4 vertebrae joined. In another, 3 . In large chamber, 8 A pots.

\section{N 2232 (TC) Map E4; photos C 7468, C 8589, C 8590}

90 from gebel. Male. Body was wrapped in cloth, not strips, but 1 or more large pieces folded over. Headrest (i) corners pierced with double holes and tied with cord (6-14445, 6-14446). a. Extra piece pegged on middle of inside. Rounded. 1 wide at ends, 2 at corner. Wood of main pieces 2 thick, 7 wide. 23 square. Body almost over on stomach. Right arm bent under body. Head had certainly not been placed on rest. Inside measurement of coffin $130 \times 42 \times 28$. Thickness 
N 2231

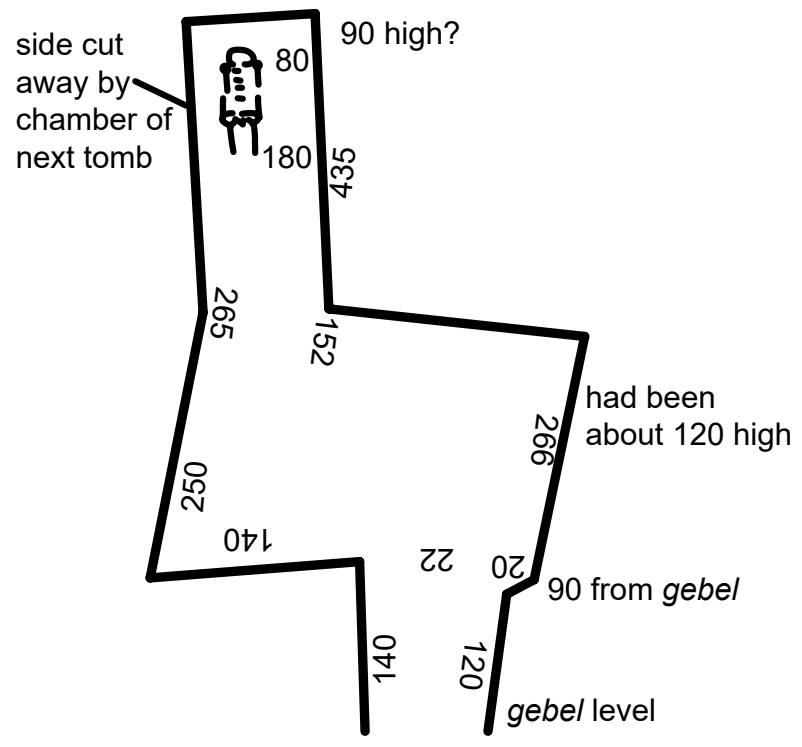

(i)

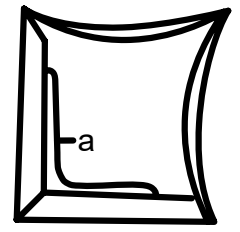

N 2232

cord work

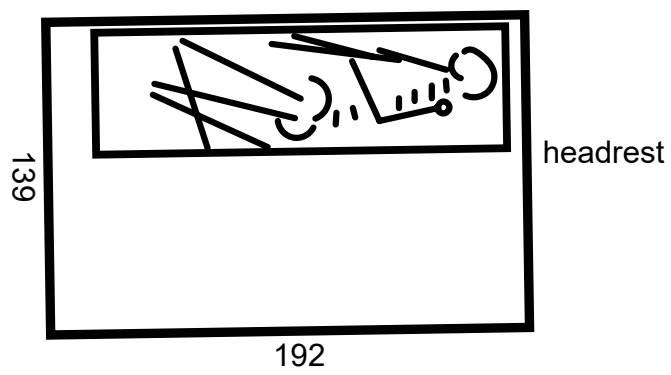

N 2233, N 2234

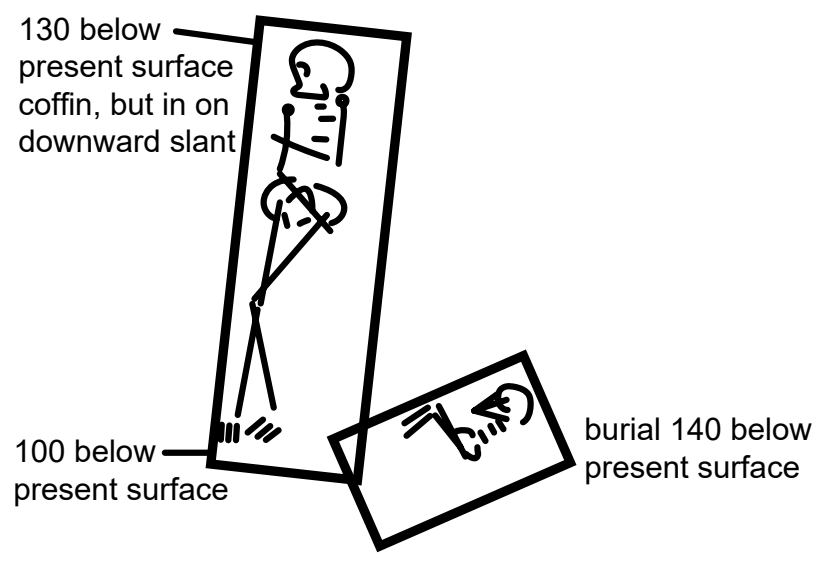




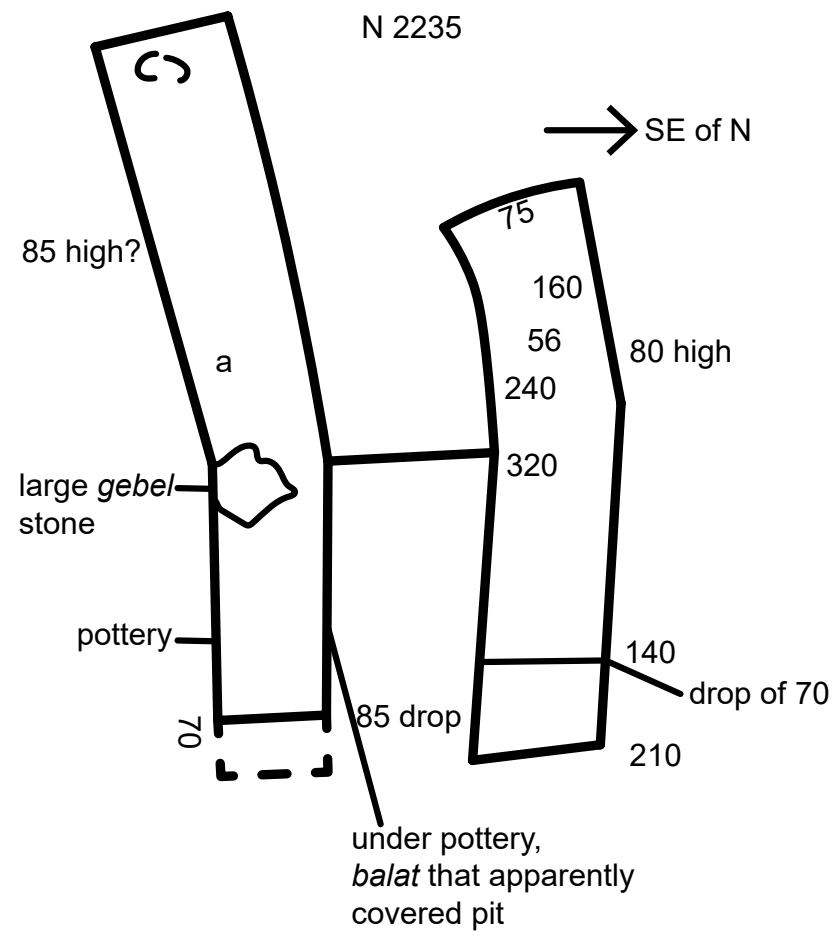

(i)

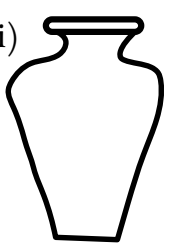

N 2236

(ii)
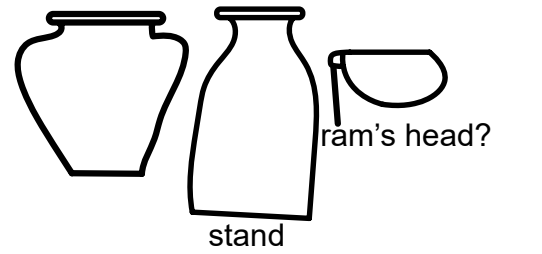

N 2237, N 2238

85

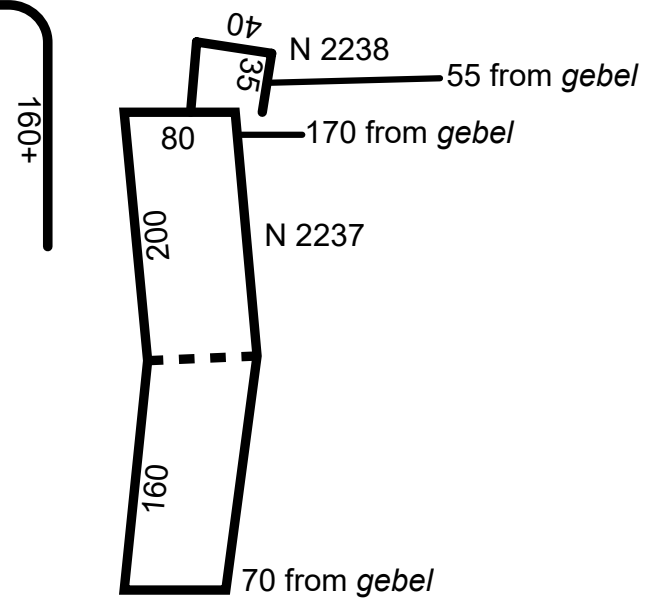

N 2239

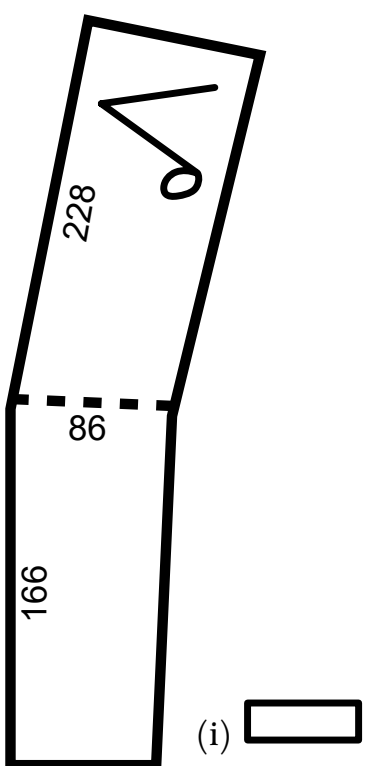




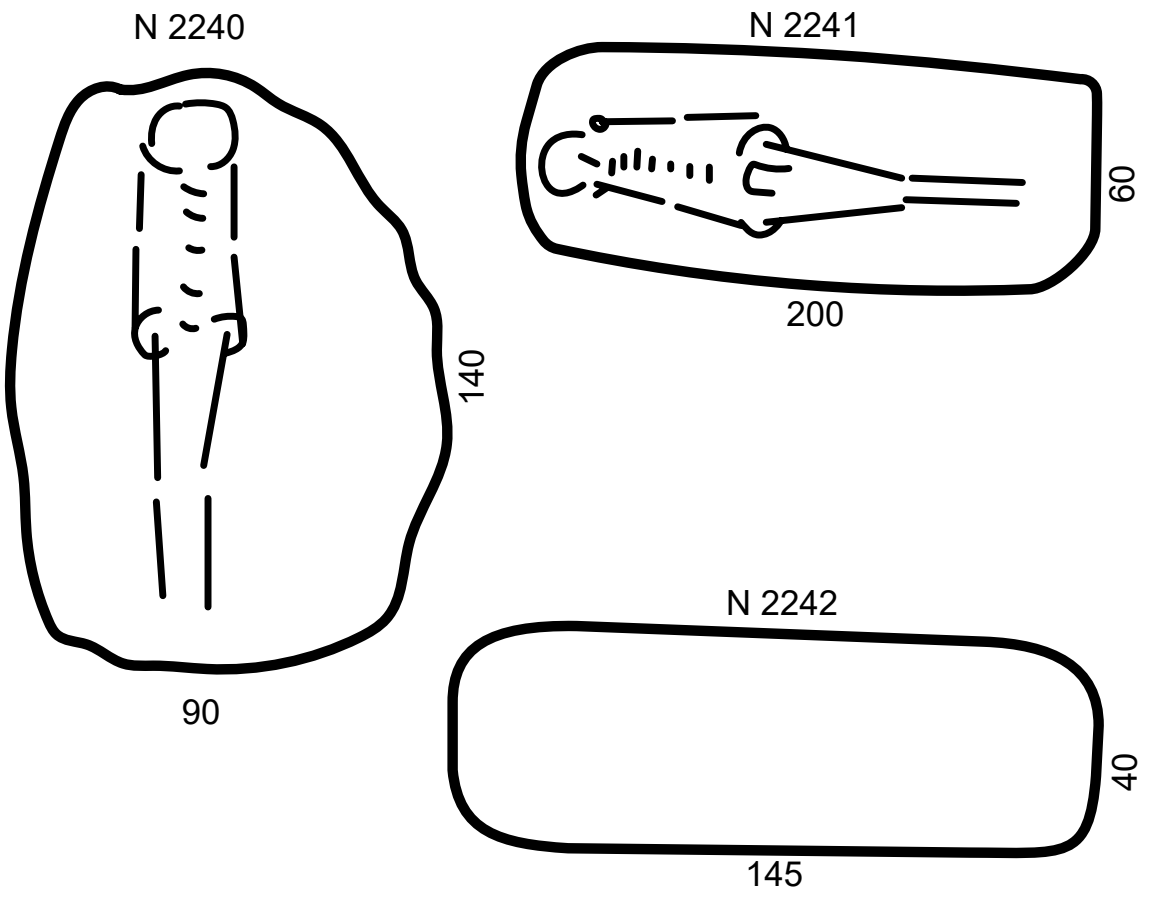

N 2243
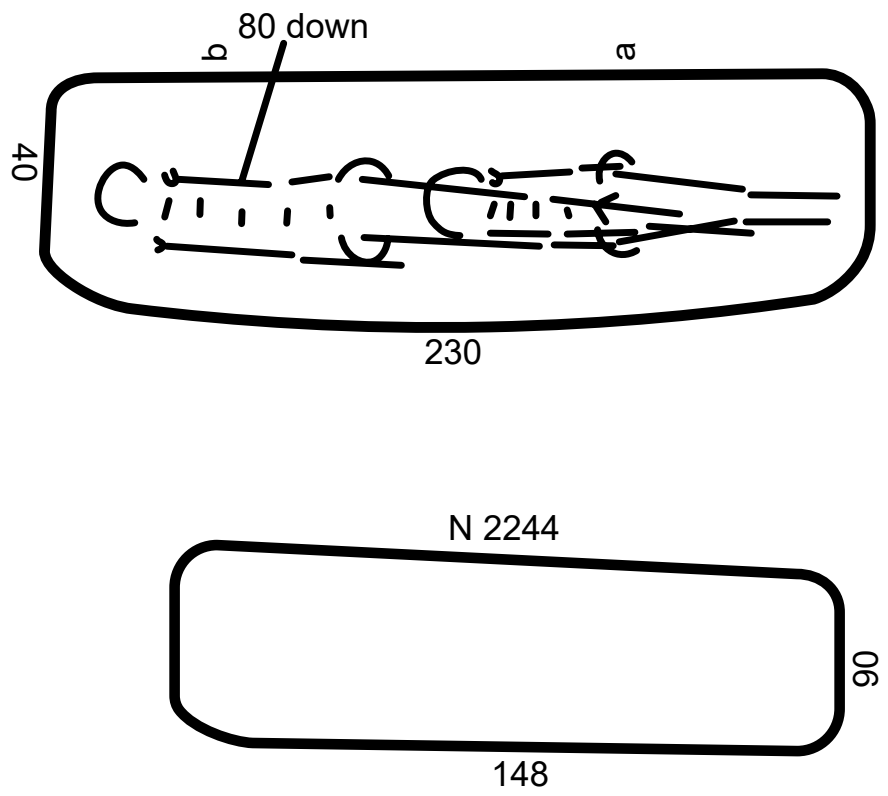
of wood 1.5. Corners as usual. White paint outside and in. Originally probably chamber and pit, but roof had entirely gone. At side of coffin, remains of basket work with clay sealings attached (6-14447, 6-14448, 6-14449, 6-1445o). May have originally enclosed coffin. Body was apparently untouched, but coffin had no lid remaining. Sealings were only at top of coffin on north side: no trace underneath. Each was marked with 2 round seals. At west end of tomb, outside coffin, traces on bronze on a stone.

$\mathrm{N}_{2233}$ (TC) Map E4 (red)

2 pits apparently broken into 1 . Burial on right side. Traces of cloth by pelvis and by head. Inside measurement $175 \times 45 \times 48$. Thickness of wood 4 . Corners as usual, round pegs throughout. White stucco inside and out.

$\mathrm{N} 2234$ (TC) Map E4 (red)

2 pits apparently broken into 1 . Burial of a baby. Body covered with decayed cloth. Inside measurement of coffin $57 \times 34.5 \times 18$. Thickness of wood 1.5. Corners as usual. Round fragments everywhere. White stucco inside and out. Rim of coffin painted red and band of red of 4 on outside top and of 2 on inside top.

N 2235 (TC) Map E4; photos B 7114, B 8251, C o996, C 8193

In large chamber, quantity of pottery, about 4 As (i) (6-14451 a-b, 6-14452, 6-14453, 6-14454, 6-14455, 6-14458), M with white rings (ii). Number of small clay discs (6-14456). Quantity of glaze disc beads (6-14457). Entrance to chamber a, blocked by large stones and smaller stones underneath. Pit filled with stones, covered over with balat [i.e., stone slabs]. In chamber a, remains of burial. On back? Adult. Sex? [ed.: According to Hearst Museum records, 6-14462 (assorted amulets and beads) are from this burial.]

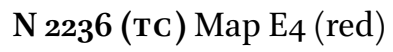

105 from gebel. 80 high? 180 above floor level of 2231 . Tomb broken away by falling in of roof of 2231. Contained nothing.

N 2237 (тC) Map D4

Contained bottom of a wooden coffin and a fragment of an A pot. Roof of chamber entirely gone.

$\mathrm{N}_{223} 8$ (TC) Map D4 (red)

End of a narrow chamber cut away by falling in of roof of 2237.135 above level of 2237 . 

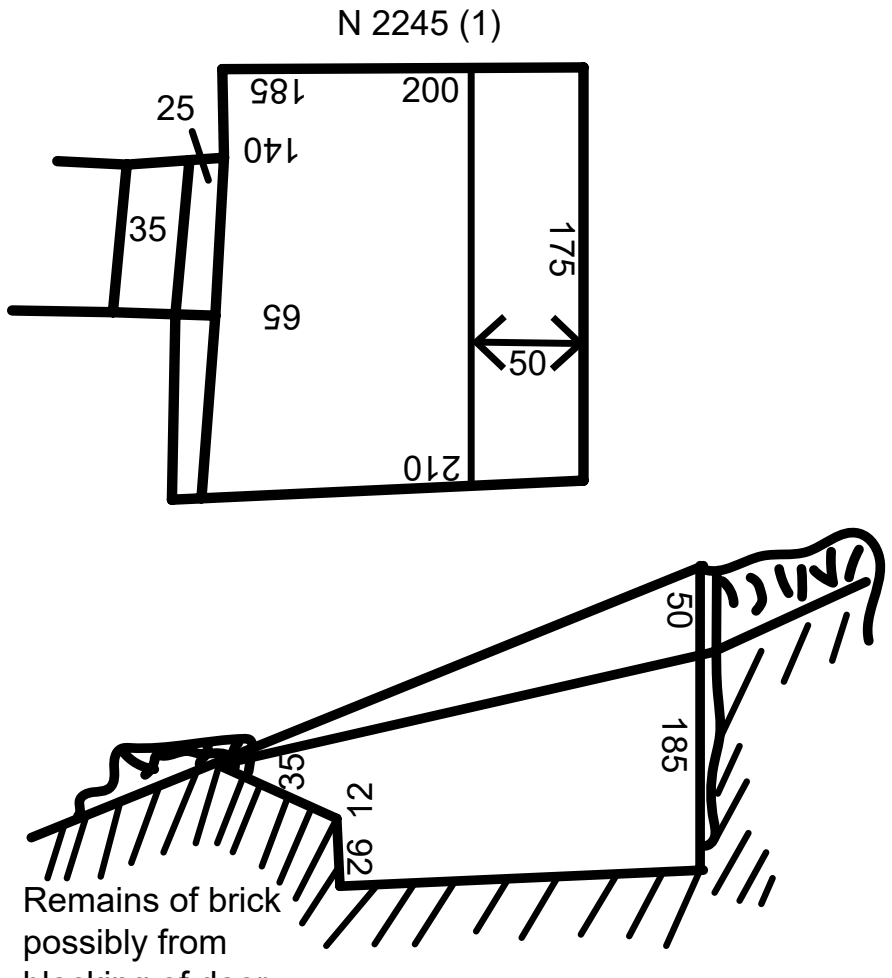

blocking of door

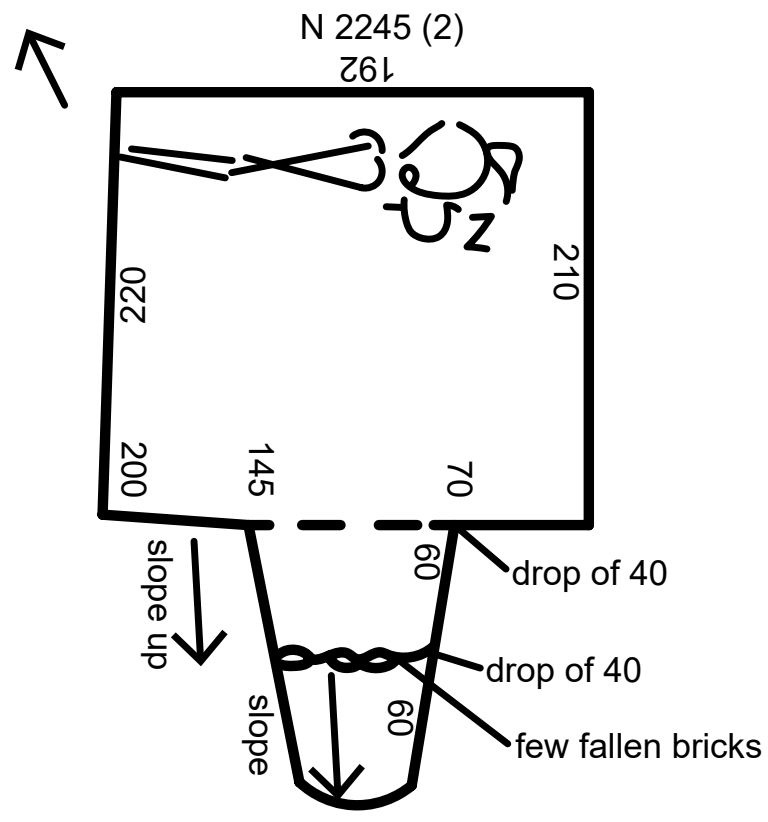




\section{$\mathrm{N} 2239$ (TC) Map D4 (red)}

180 from gebel. 80 high. Contained broken skull and few bones. 1 femur and tibia apparently in position. Part of a decayed coffin (angled corners), which had been inscribed with black ink. Parts of wooden sandals, painted white, with remains of rush bindings. Round and square (i). Green stone beads (6-14459).

\section{N 2240 (TC) Map B4 (red)}

8 o down. Irregular hole. Remains on cloth. Body of a child about 10. Under body, remains of palm sticks. On right ear, gold earring, ends twisted together.

\section{N 2241 (TC; MM) Map B4}

8 o down. Coptic burial. Shallow grave, running east-west. Adult female. On back, head west, arms by side. All cloth gone. In the filling of the grave, two bronze bracelets.

\section{N 2242 (TC; MM) Map B4}

9o down. Coptic burial. Shallow grave, running east-west. Adult female. On back, head west, arms by side. On each ear, a plain bronze earring, ends twisted round each other. No traces of cloth left.

\section{$\mathrm{N} 2243$ (TC; MM) Map B4}

Shallow grave, running east-west, containing two burials, one above another. a. Coptic child aged approx. 12. On back, head west, arms by side. b. Underneath, 30 down. Adult male. On back, head west, arms by side. The second burial was $30 \mathrm{~cm}$ below the other. The cloth wrappings in both cases had entirely disappeared.

\section{N 2244 (TC; MM) Map B4}

8 o down. Copt. Shallow grave, running east-west. Adult. Sex? On back, head west, arms by side. No traces of cloth left.

\section{$\mathrm{N}_{2245}$ (1) Map C4}

[ed.: There are two tomb cards labeled 2245.]

Traces of stucco from coffin on all 4 sides. Burial plundered. Contained nothing.

\section{$\mathrm{N}_{2245}$ (2) Map $\mathrm{C}_{4}$}

[ed.: There are two tomb cards labeled 2245.]

180 from gebel. Plundered, and upper bones disturbed. Had been right over on stomach. Traces of stucco on side of tomb showed that there had been a coffin, but all wood gone. 


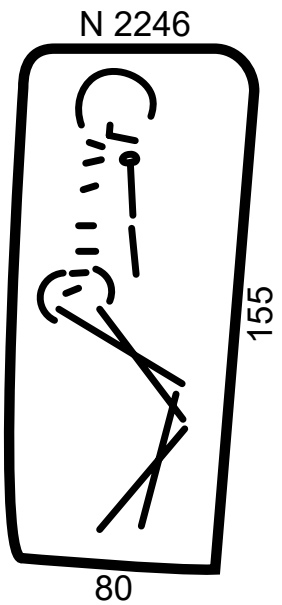

N 2247

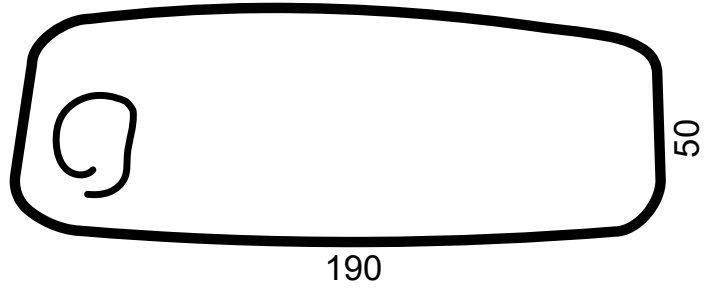

N 2248

15 wide $+08 \mathrm{l}$ wall 20 high

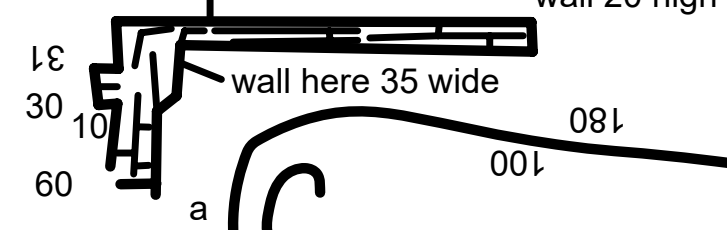

N 2249
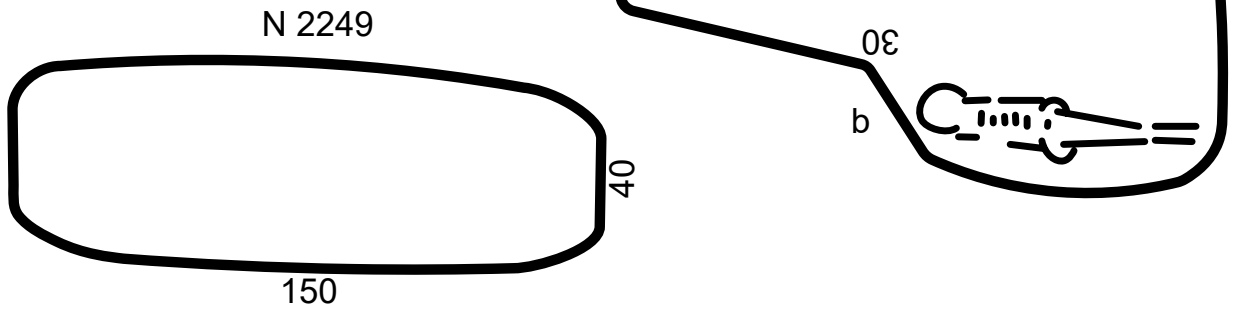

150

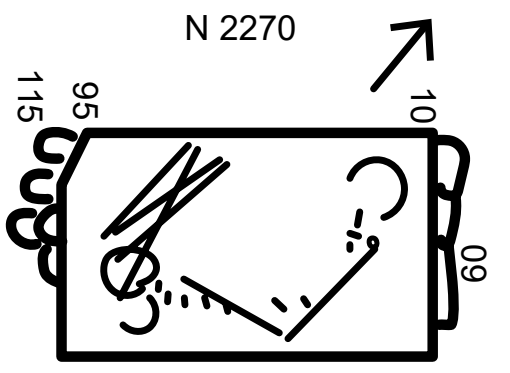

N 2271

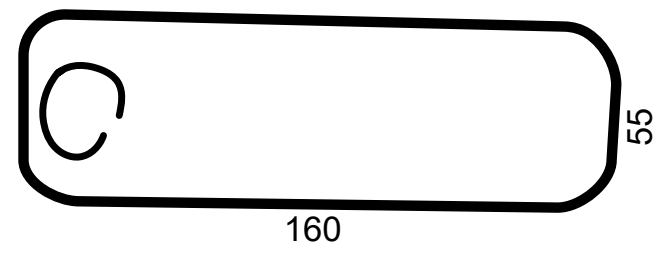

N 2272

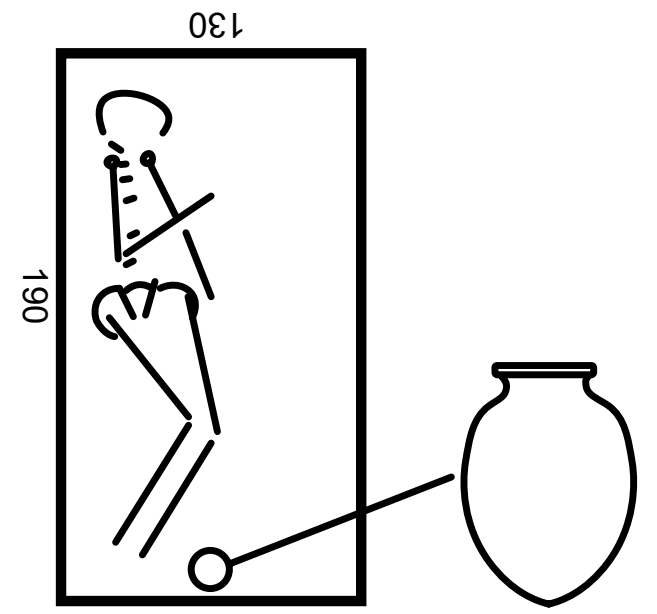


N 2246 (тC) Map B4

100 deep. On left side. Shugf [i.e., sherd] from a ? pot in filling. Bones in bad condition.

$\mathrm{N} 2247$ (TC; MM) Map B4

120 down. Coptic burial. Shallow grave, running east-west. Adult. Sex? On back, head west, arms by side. No traces of cloth left. Bones very rotten.

\section{N 2248 (тC; Mм) Map B4}

13 o below level of wall. Shallow grave, running east-west, containing 2 Coptic burials. a. Adult. Sex? On back, head west, arms by side. b. Small child. On back, head west, arms by side. With neither of the bodies was there any trace of cloth. In the filling of the grave, fragments of bronze and a piece of yellow glass. Remains of brick superstructure with buttress on west end.

N 2249 (TC; MM) Map B4 (red)

100 deep. Coptic burial. Shallow grave, running east-west. Adult. Sex? On back, head west, arms by side. By elbow of each arm, fragments of broad ivory bracelets. No traces of cloth left.

N 2270 (TC) Map A4

40 below black ash level. On right side. Left arm gone, right arm under body. South side broken away. On east and west sides, remains of brick and stone enclosing walls.

N 2271 (TC; MM) Map A4

4o below black ash level. Coptic burial. Shallow grave, running east-west. Adult. Sex? On back, head west, arms by side. No traces of cloth left.

$\mathrm{N}_{2272}$ (TC) Map A4

105 below black ash level. 170 below present level. On left side. (i) in smooth red (6-14461).

\section{N 2273 (TC; MM) Map A4}

70 below black ash level. Intrusive burial in a Dynasty 6-9 grave. a. Coptic burial. Child aged approx. 6. On back, head west, arms by side. No trace of cloth left. b. Remains of an ancient burial. c. Remains of a burial, ancient? In radim above, bottom of a Coptic dish with incised Maltese cross on inside bottom and a Coptic amulet. By head of b, few glaze amulets, 1 ivory amulet, and 1 rough shell bead. 
N 2273

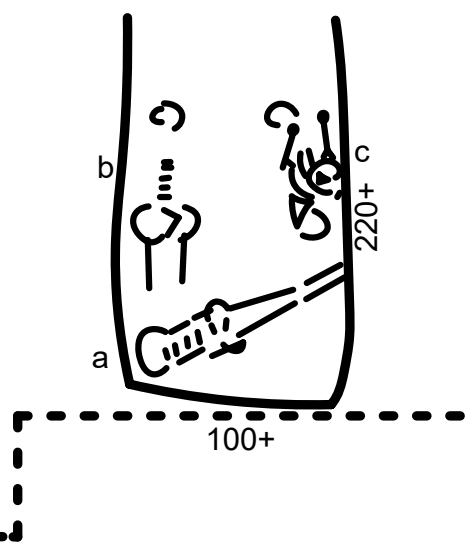

N 2274

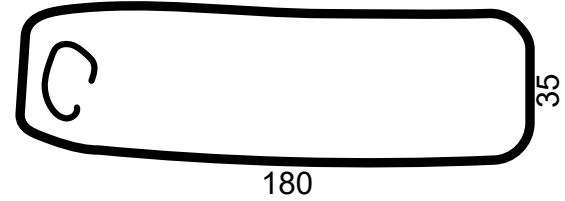

N 2275

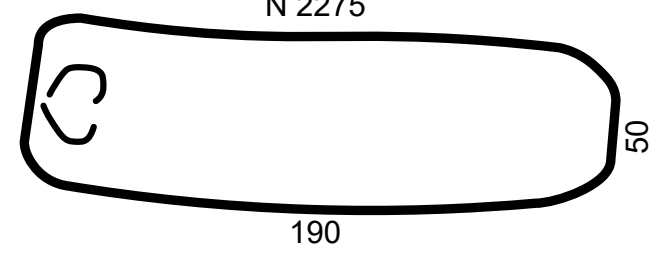

N 2276

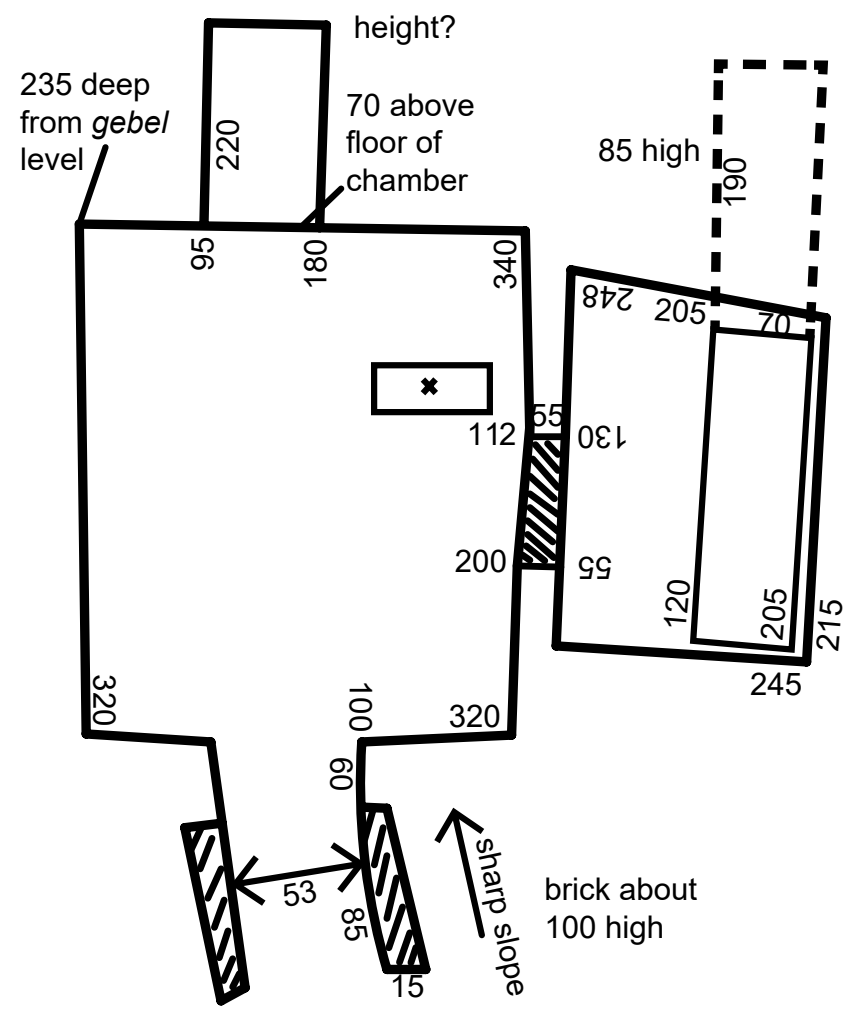

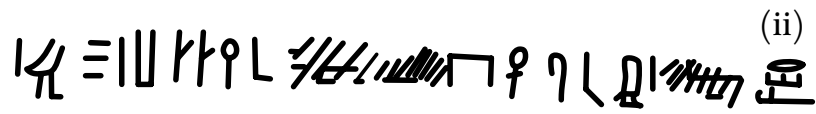




\section{N 2274 (тC; мM) Map A4}

8 o below black ash level. Coptic burial. Shallow grave, running east-west. Adult. Sex? On back, head west, arms by side. No trace of cloth left.

N 2275 (TC; MM) Map A4 [ed.: Mistakenly inked on map as 2276, but labeled 2275 in pencil.]

70 from black ash level. Coptic burial. Shallow grave, running east-west. Adult. Sex? On back, head west, arms by side. No trace of cloth left.

\section{N 2276 (TC) Map A4; photos B 8428, C 708o, C 8524, C 8525, C 8526}

Chamber had been 165 high, but roof nearly all broken away. Pit 185 deep. In filling, several broken pots. A (i) round shoulder, incised inscription (ii). Ring stands, etc. $\times$ had been a wooden coffin ? Only red stucco left in position. $100 \times 40 \times$ ? Contained nothing.

N 2277 (TC) Map A3

120 down. Body on back. Bones in very bad condition. No trace of coffin.

N 2278 (тс; мм) Map A5

3 o below black ash level. Coptic burial. Shallow grave, running east-west. Adult. Sex? On back, head west, arms by side. No trace of cloth left.

\section{N 2279 (TC) Map A3}

18 o down. Height? Bones in very bad condition. No trace of coffin. At door, remains of stone blocking, 40 high, 45 wide.

\section{N 229o (TC) Map C4}

Bricks built on sides. Built inside tomb to bottom. Burial on back. Traces of coffin under body. Bones in bad condition. Had been pit and chamber, but pit gone.

\section{N 2291 (TC; MM) Map C4}

70 below gebel. Copt. Shallow grave, running east-west. Adult. Male. On back, head west, arms by side. By head, one green glass bead (6-14550). No trace of cloth left. Under body, remains of palm sticks.

N 2292 (TC) Map C4; photo B 8251

100 below gebel level. Remains of burial. No skull. On north end, traces of white from coffin. Scattered several glass beads (i), and disc (6-14463, 6-14464), 1 carnelian (ii) (6-14465). Fragment of bronze from ? (6-14465). 


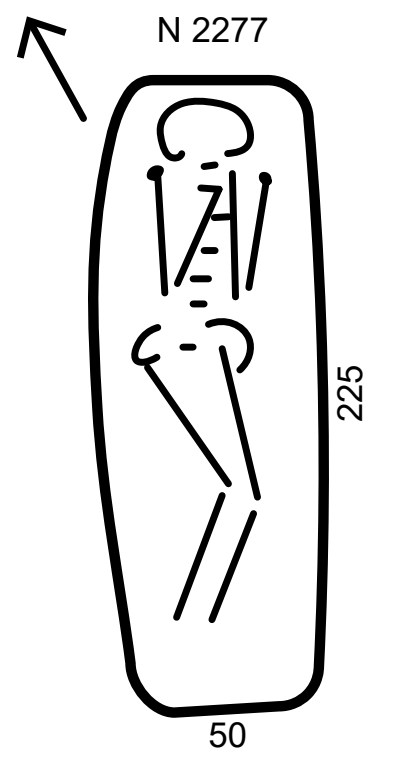

N 2278
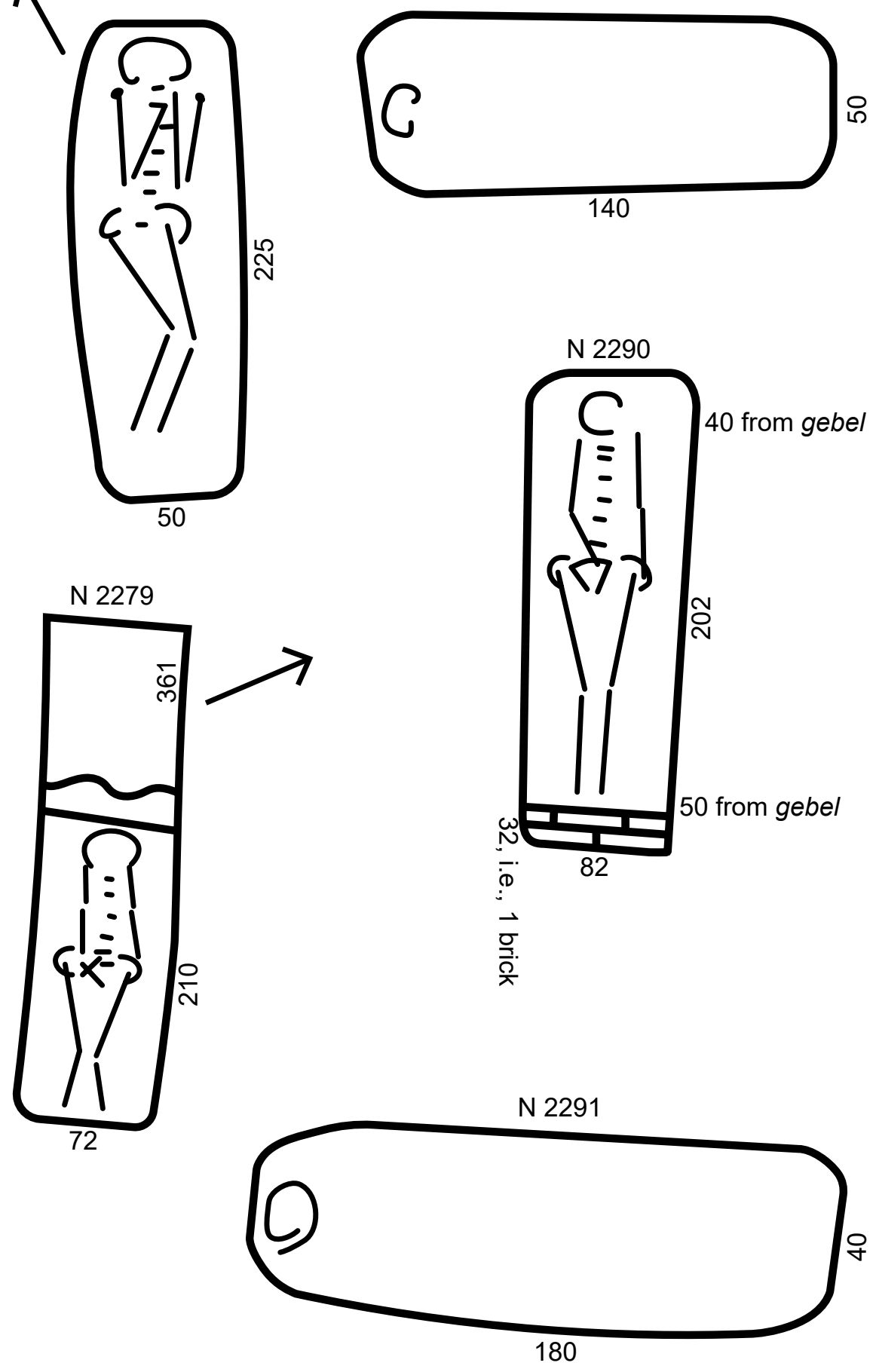


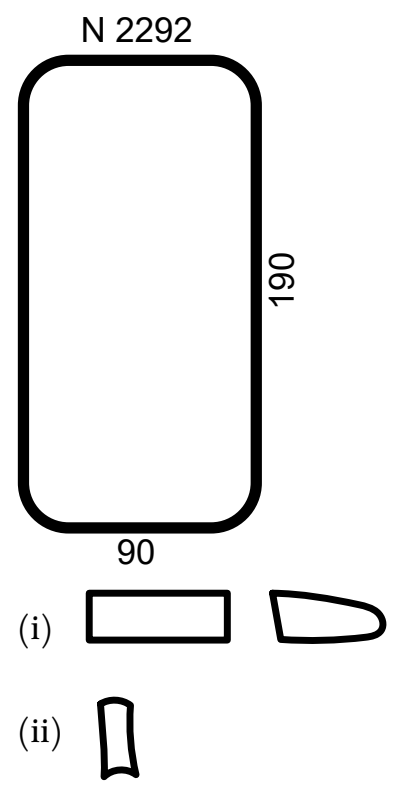

N 2293

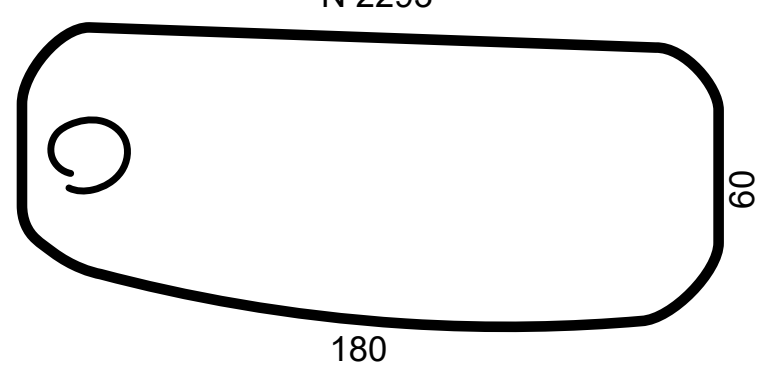

N 2294

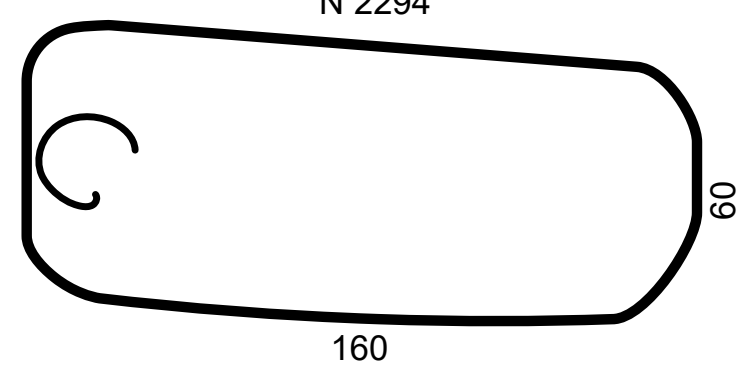

N 2295
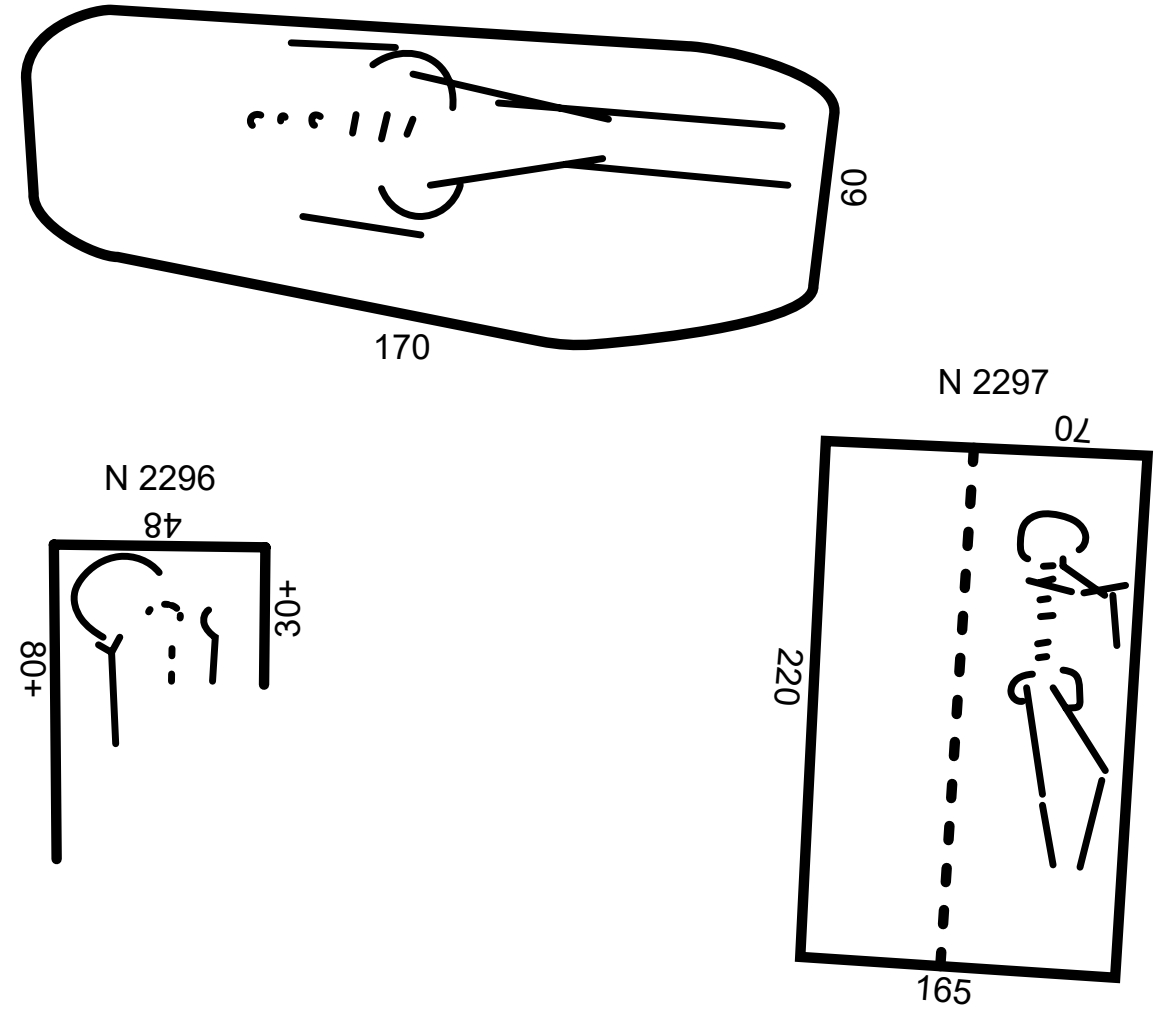

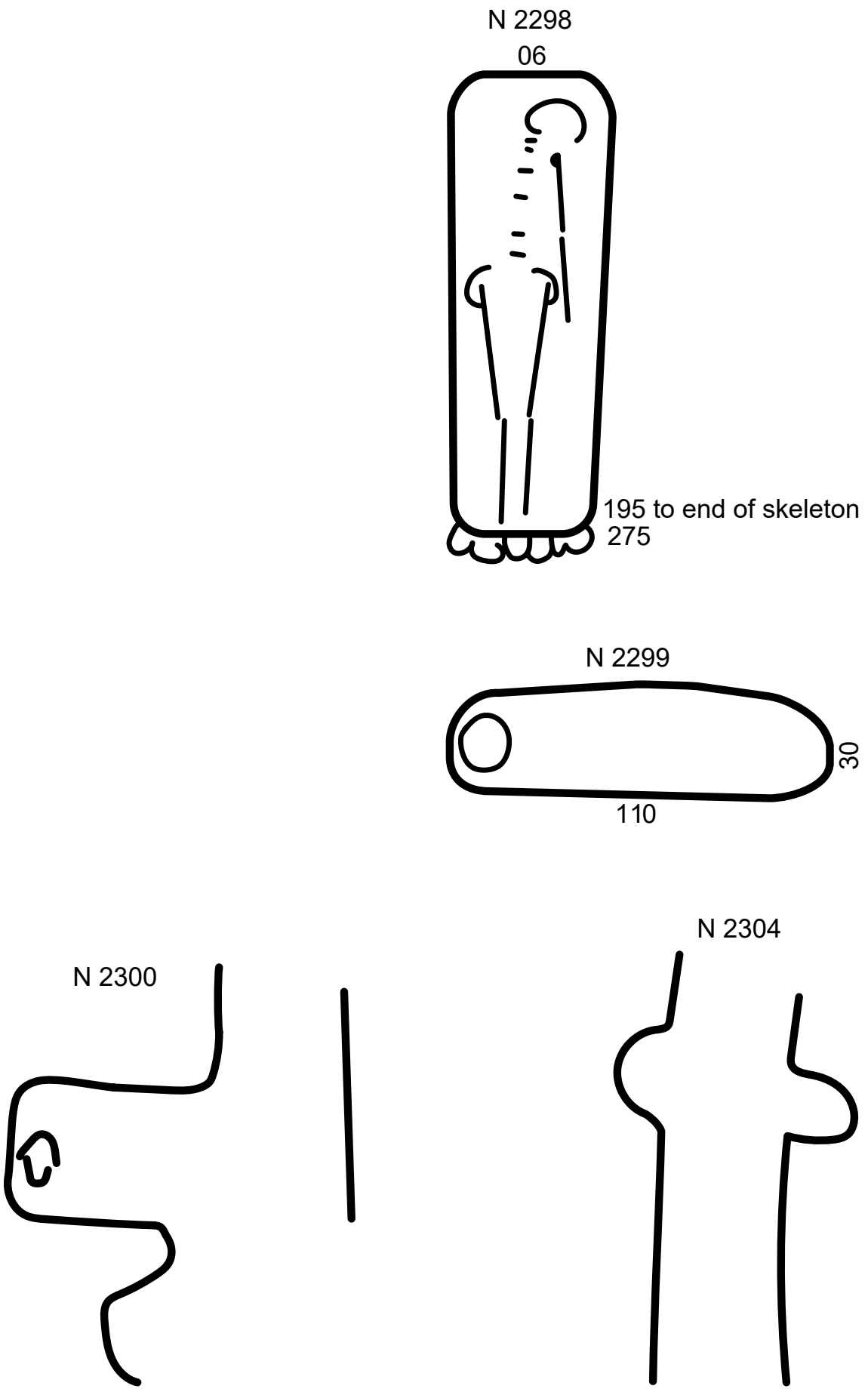
$\mathrm{N} 2293$ (тC; MM) Map C4 (red)

100 below gebel level. Copt. Shallow grave, running east-west. Adult. Sex? On back, head west, arms by side. Traces of decayed cloth.

\section{$\mathrm{N} 2294$ (тC; м M) Map C4 (red)}

100 from gebel level. Copt. Shallow grave, running east-west. Young adult. Joints not quite ossified. Sex? On back, head west, arms by side. No trace of cloth left.

$\mathrm{N}_{2295}$ (тC; м м) Map $\mathrm{C}_{4}$

120 from gebel. Coptic burial. Shallow grave, running east-west. Adult. Sex? On back, head west, arms by side. Upper part of body gone. No trace of cloth left.

\section{$\mathrm{N} 2296$ (тс) Map $\mathrm{C}_{4}$}

40 from gebel. Upper part of Egyptian burial. Rest of tomb broken away. Traces of wood from coffin on sides of tomb.

$\mathrm{N}_{2297}$ (тC) Map C4

205 deep. 92 high. Burial of a small child. All traces of coffin gone.

\section{$\mathrm{N} 2298$ (TC) Map $\mathrm{C}_{4}$}

115 from gebel. Had been buried on back. Upper part of body disturbed. Portion of right arm doubtful. Bones in bad condition. All wood of coffin gone, but traces of the plaster on north end of grave. South end of tomb blocked by stones. Type had been pit and chamber.

N 2299 (TC; MM) Map N/A [ed.: Map location not listed in excavation records; tomb seemingly not on the map.]

5 o down from gebel. Burial at end of Dynasty 6-9 pit. Small Coptic child. On back, head west, arms by side. Remains of light brown hair. 2 palm sticks under body. The wrappings were in very bad condition, but enough remained to show that there had been at least 2 shawls, the outer being of coarse cloth, which had originally been tied round with cord, and the inner of fine, with traces of tapestry-woven designs in colored wool.

N 23 оо (тс; мм) Map C4

Coptic. See Smith. Shallow grave, running east-west, east end projecting over early grave. Adult. Sex? Head west. Under body, 2 (?) sticks of acacia. Over head, a quantity of palm fiber. Remains of roll of cloth from head with worked edge and broad black? stripes (inwoven). The wrappings had almost entirely disappeared. 
N 2305

(i)
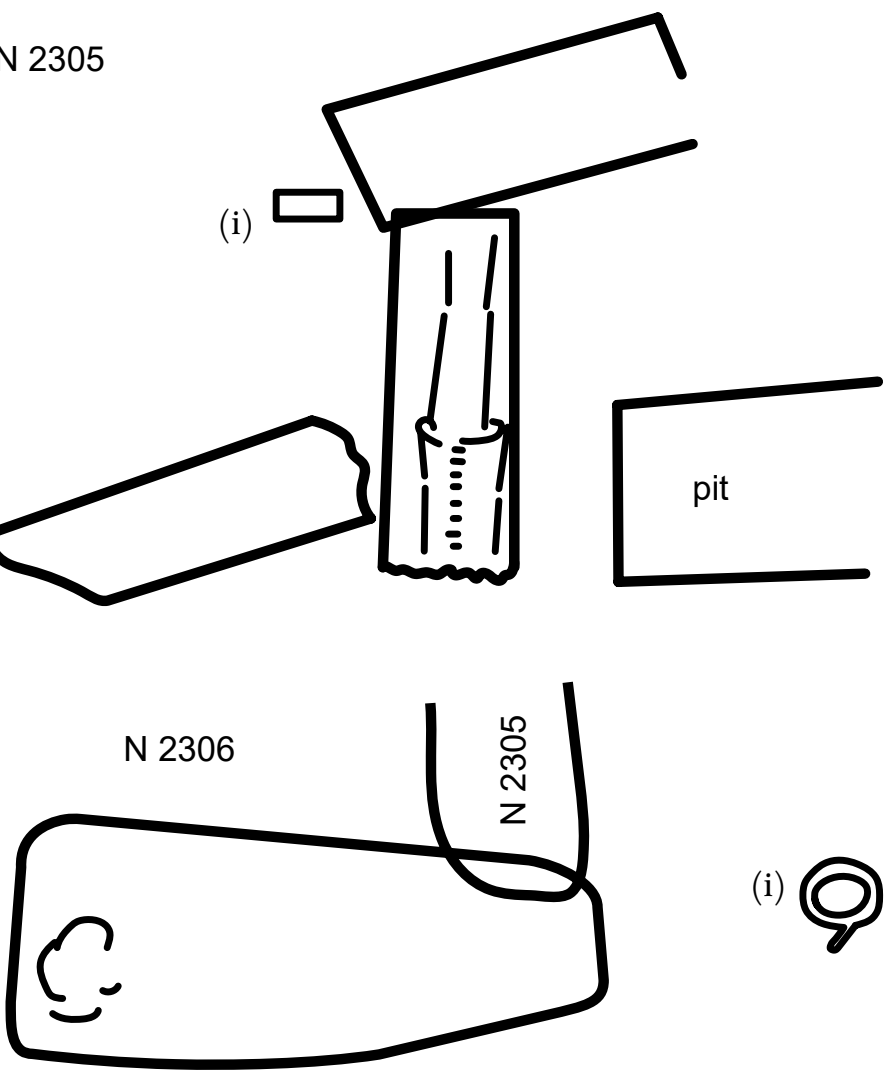

(i)

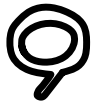

N 2309

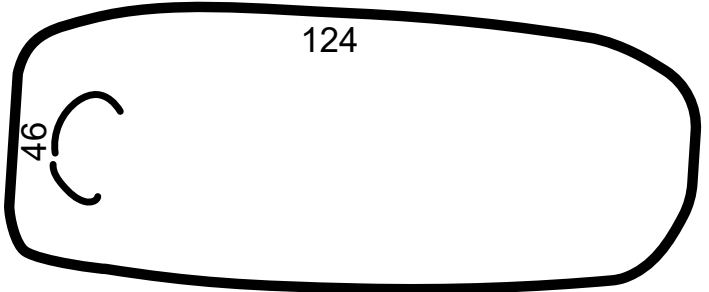

N 2310

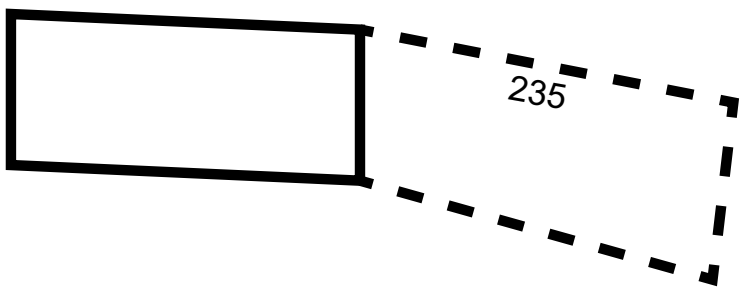


$\mathrm{N}_{23}$ о1 (TC; MM) Map $\mathrm{C}_{4}$

Coptic. See Smith. [ed.: No image.]

$\mathrm{N}_{23} \mathbf{0 2}$ (тC; MM) Map C4 (red)

Coptic. See Smith. (Packed.) [ed.: No image.]

$\mathrm{N}_{23} 3$ (TC; MM) Map C4

30 below black ash level. Copt. Shallow grave. (2 bodies, both female. Northerly one had a completely ossified hyoid, showing that she had reached at least to middle age.) S. [ed.: No image.]

$\mathrm{N}_{23} 3$ (тс; MM) Map C4 (red)

Coptic burial at end of early pit. Shallow grave, running east-west, cutting across Dynasty 6-9 pit at right angles. Child about aged $15^{-16}$. Sex? Traces of sticks under body. Cloth had almost entirely disappeared.

$\mathrm{N}_{23} \mathrm{O}$ (TC) Map D4

Female? adult. Burial just below gebel level. Sides of grave broken away. Remains of wooden coffin, so probably Dynasty 6-9. Corners of coffin angled. Measurements of coffin? By head, 2 (i) stone beads, 2 carnelian disc, and 1 black glaze disc.

N 23 o6 (тс; MM) Map C4 (red)

Copt. S. Shallow grave, running east-west. Girl aged approx. 17. On back, head west, arms by side. With body, a plain bronze ring (i). Under body, remains of palm sticks. The wrappings had almost entirely disappeared.

N 2307 (тс; MM) Map D4

Copt. See Smith. [ed.: No image.]

N 2308 (TC; MM) Map D4

Copt. (Probably girl aged approx. 13. Extreme hydrocephalus. Head $171 \mathrm{~mm}$ broad.) S. [ed.: No image.]

N 2309 (TC; MM) Map D4

8 o deep. Copt. Shallow grave, running east-west. Child aged approx. 8. On back, head west, arms by side. Bronze bracelet on right arm, above wrist, made of one piece bent round to meet. Also, on body, a bronze cross. The wrappings had almost entirely gone.

N 2310 (TC) Map D3

Contained nothing. 
N 2311

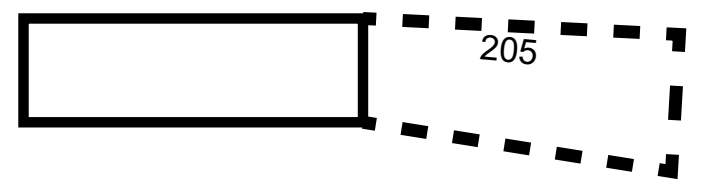

N 2312

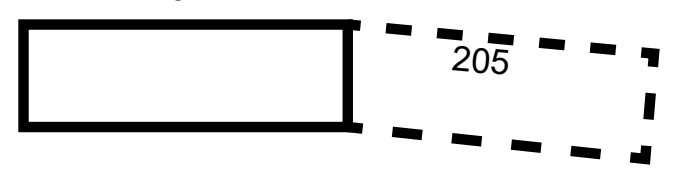

N 2313

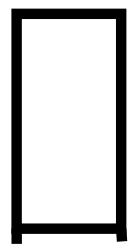

1 I

$1 \quad \vec{\Delta} \mathbf{0}$

1

- -1
N 2314

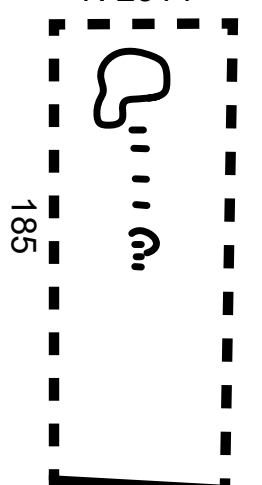

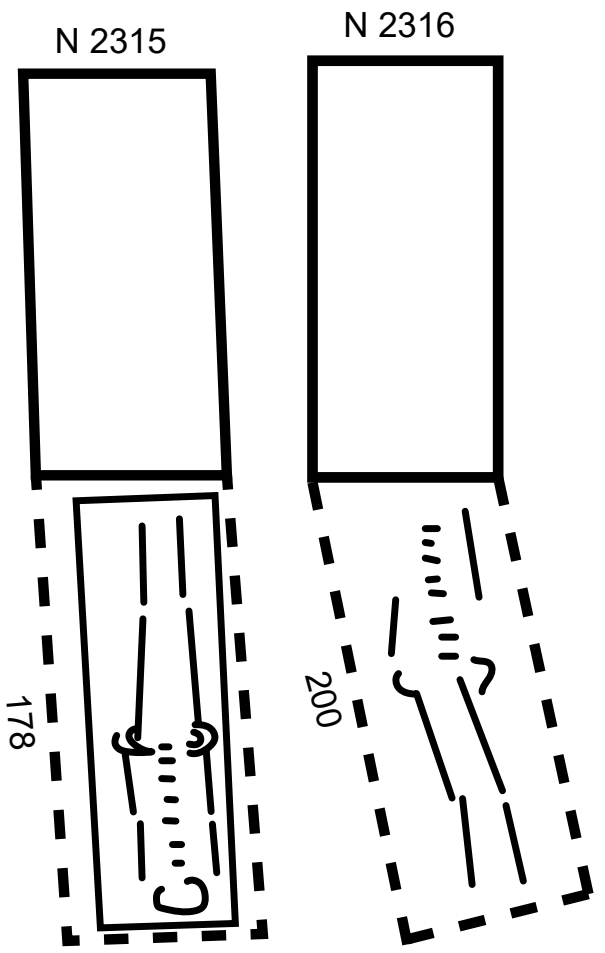

N 2318

N 2319

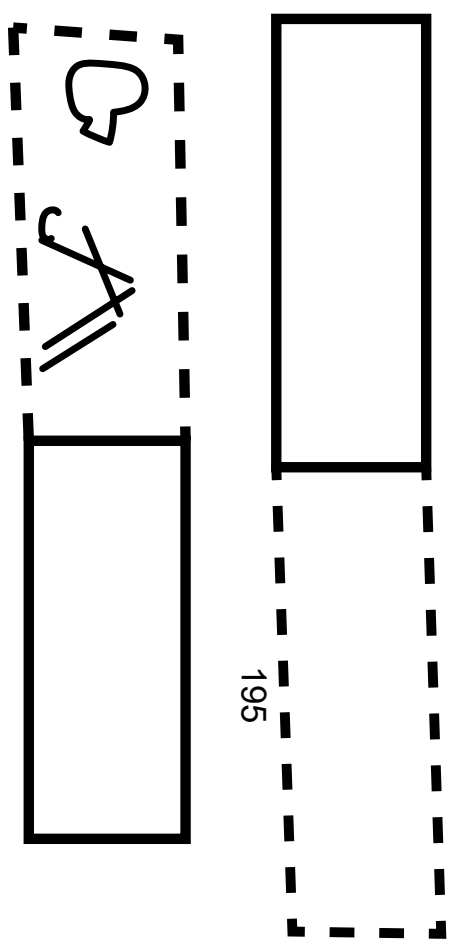

N 2317

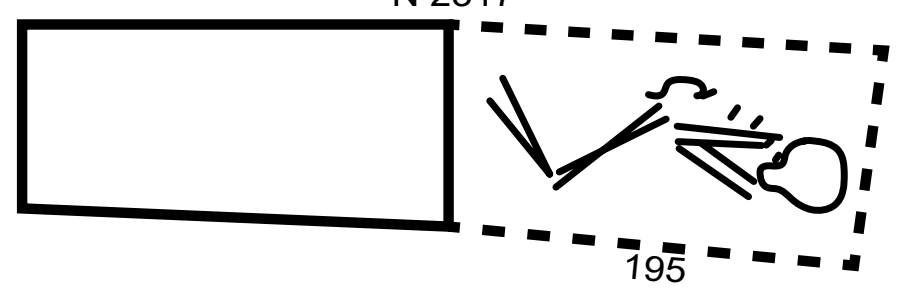


N 2311 (TC) Map D4

205 down from present level. Contained nothing.

N 2312 (TC) Map D4

Approx. 210 deep from present level. Contained nothing.

N 2313 (TC) Map D4

210 deep from present level. Approx. 90 high. Contained nothing.

$\mathrm{N} 2314$ (TC) Map D4

210 deep from present level. 85 high. Adult female. Upper part of burial.

N 2315 (between 2414 and 2416) (TC) Map D3

200 deep from present level. Adult male. Burial on back. Completely covered with a loose linen wrapping, apparently a wide shawl with fringed edges. Inside measurement of coffin $168 \times 40 \times 41$. Thickness of wood 4 . Angled corners, round pegs.

$\mathrm{N} 2316$ (between 2411 and 2838) (TC) Map $\mathrm{D}_{4}$

19o down from present level. Approx. 9o high. Adult. Sex? Upper part of burial disturbed. On back. Traces of wood from coffin.

N 2317 (between 2412 and 2410) (TC) Map D4

Approx. 200 deep from present level. 80 high. Adult. Sex? Leg bones somewhat scattered, but approximating position as given. Burial on left side, head south. Traces of wood from coffin.

N 2318 (by valley) (TC) Map D5

Adult. Sex? Position of arms? Remains of wooden coffin. Bones much broken.

N 2319 (TC) Map D4

240 deep. Contained nothing.

N 233 (TC) Map E3

Contained nothing.

N 2331, N 2332, N 2333, N 2334 (TC; MM) Map E3 (2331, 2332, 2333), D4 (2334: red) Coptic graves. Burials gone. [ed.: No image. According to Hearst Museum records, 6-14466 (jar) is from $\mathrm{N} 2332$. 
N 2330

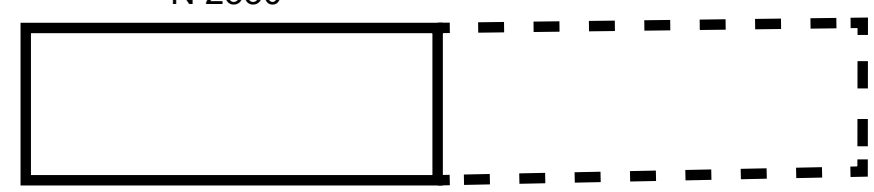

$N 2401=N 2230$

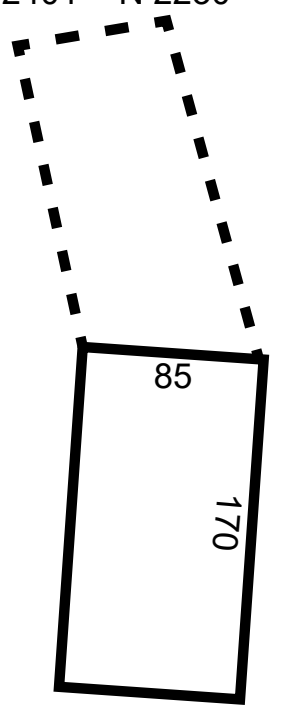

N 2407

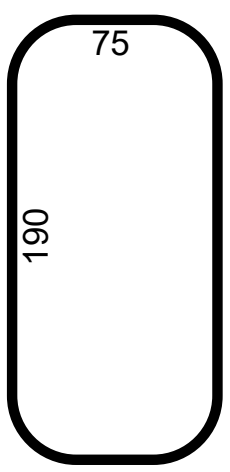

N 2402

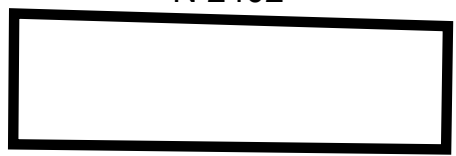

N 2400

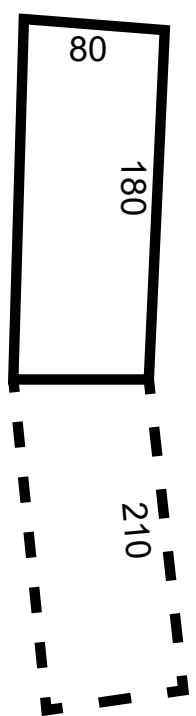

N 2405

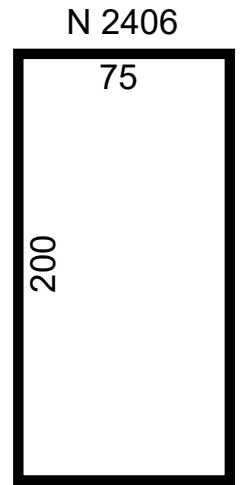

$\Gamma 7$

$I_{0} 1$

$1^{\infty}$

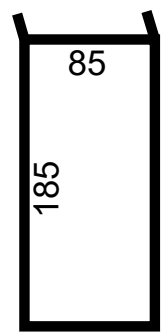

N 2408

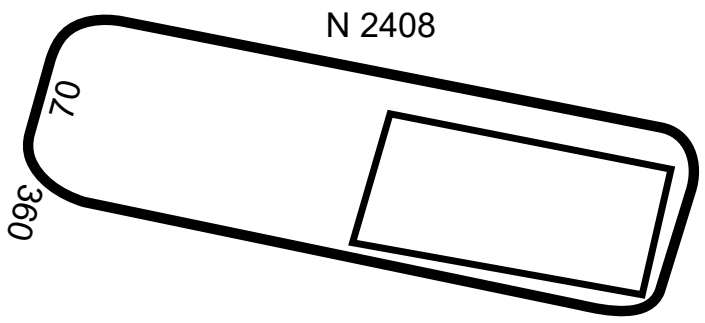


$\mathrm{N}_{2400}$ (TC) Map E3

8 o E. 200 deep from present level. 80 high. Contained only the bottom of a wooden coffin.

N 2401 = N 223 o (TC) Map E4

Plundered out.

N 2402 (TC) Map E3

May have been pit and chamber, but all trace of chamber gone. Contained nothing.

$\mathrm{N}_{2403}$ (TC) Map E3 (red)

Had been standing open.

N 2404 (TC) Map E3 [ed.: 2405 in ink, but 2404 in pencil.]

Broken away. Contained nothing. [ed.: No image. According to Hearst Museum records, 6-14468 (broken jar) is from this burial.]

$\mathrm{N} 2405$ (TC) Map E3 [ed.: 2 tombs are labeled 2405 in E3. The one more to the south and east is actually 2404. The pencilled label 2404 is visible on the map.] $97 \mathrm{~W}$ of N. 6o deep from gebel. Contained nothing.

N 2406 (TC) Map E3

85 W. 8 o down from gebel. Contained nothing.

N 2407 (TC) Map E3

$112 \mathrm{~W}$ of N. 100 from gebel. Contained nothing. Arab kusha [i.e., temporary structure?] built above.

N 2408 (TC) Map E3 (red)

Originally probably pit and chamber, but all trace of roof gone. At north end, remains of a wooden coffin. Inside measurements $160 \times 35 \times$. Width of wood 3. Corners angled.

N 2410 (тс; мм) Map D4

Coptic burial. Shallow grave, running east-west. (Adult male. 1.527 high. Bad fracture of femur. Wavy black (or dark brown) hair $12 \mathrm{~cm}$ long.) S. On back, head west, arms by side. The body was clothed in a shirt of yellow cloth. Some of the cloth was apparently from a linen garment with corded edges or some 
N 2410

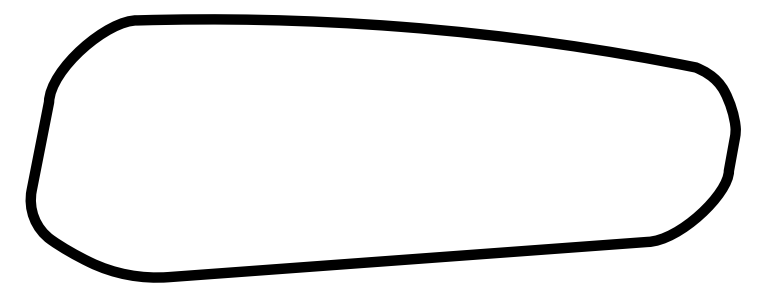

(i)
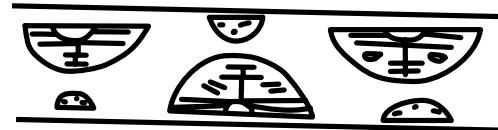

응

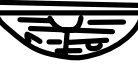

$\approx$

(ii) $\operatorname{cccc}$

N 2411

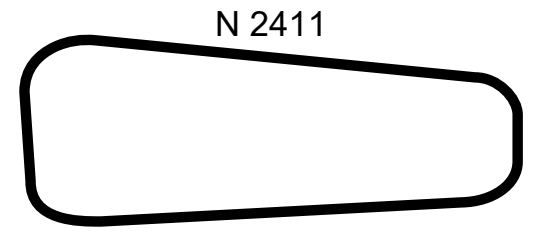

N 2412

N 2413

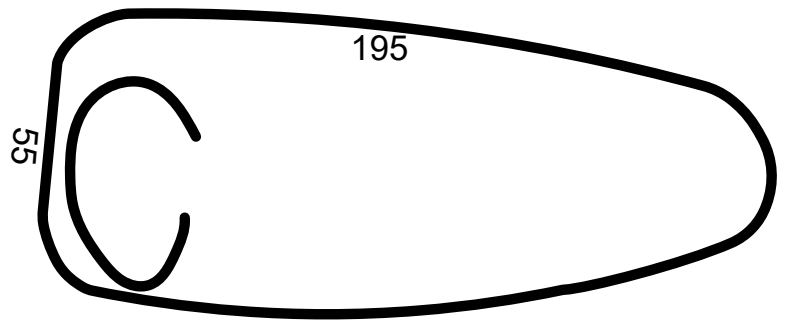


kind of cord work? This was decorated on the sleeves at any rate with bands of green, inwoven possibly from sleeves, on which animal (hares?) and other designs were left in the original yellow thread with border by each side of (i). The innermost wrapping consisted of a shawl of fine cloth with fringed ends and 11.5 from end, a band of inwoven red threads 3.2 wide (ii). Pattern was irregular, but main feature was alternation of 2 semicircles, first 2 being green ground with yellow lines and side details of yellow between 2 lines of red, second 2 being yellow ground with red lines and side details of yellow between blue. Small semicircles were always yellow and blue. The extra colors were apparently all added to the original yellow warp at the time of weaving. In every case, a thin line of original thread was left round patterns. Width of shawl was $72+$. Outside this, there was a shawl of rough sackcloth.

\section{N 2411 (тс; мM) Map D4}

Coptic burial. Shallow grave, running east-west. Adult. (Sex? Height $145 \mathrm{~cm}$.) S. Under body, 2 palm sticks. Remains of several wrappings, some of which showed traces of tapestry-woven designs in colored wool.

\section{N 2412 (TC; MM) Map D4}

Coptic burial. Shallow grave, running east-west. Young adult, male. Head west. The cloth was in very bad condition, but there had been 2 shawls at any rate, the outer being of sackcloth and the inner of fine cloth with tapestry-woven designs.

\section{N 2413 (тC; мM) Map D3}

100 down. Copt. Shallow grave, running east-west. Adult male. On back, head west, arms by side. Quantity of long, dark brown, curly hair. Bottom of right ulna broken, and bone worn down to a point. Growth of bone round top of right radius. Left ulna broken near middle and roughly set. The body was clothed in a plain shirt with a band of ridges made in weaving down either breast. Sides corded. Round neck turned over and hemmed. Bottom ditto. Sleeves open all the way down. The arms were not in the sleeves. On the body, there were a number of plant seeds. On the left side of the body, not underneath, there was a stick of sesban and on the right side, one of palm. Over the head, there was a pad of cloth, consisting of an old shirt. The innermost wrapping shawl was of coarse cloth. Outside this, there was a shawl of sackcloth with fringed ends and a band of open work near the ends. Next came the binding cords, but these were in too bad a condition for the type to be determined (perhaps 2-strand fiber). The final wrapping was a shawl of yellow cloth, which had apparently completely enveloped the body and was tied over the chest by the corners. 
N 2414

N 2415

(i) O-Lo

(ii)

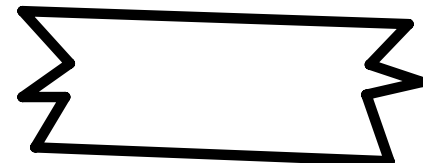


Sides were corded. Ends worked off in weaving. In each corner, a rosette of heliotrope (inwoven) and designs in white thread (original weave), and blue, green, yellow, and red (worked on).

\section{N 2414 (TC; MM) Map D3; photo C 8463}

Approx. 100 from true gebel. Coptic. Shallow grave, running east-west, containing three burials. a. (Adult. Sex? $150 \mathrm{~cm}$ high.) S. On back, head west. The feet were in leather sandals. The cloth was in very bad condition, but enough remains to show that there had been 2 wrapping shawls, the inner being of finer cloth and the outer of sackcloth. Over the feet, there was a quantity of frayed ends of cloth, and over the head, there was a pad, rolled up, made of an old shirt (?) much patched and darned. Remains of embroidered cloth from small burial. b. and c. (2 children of the same size, aged about 5 or 6 . Full set of milk teeth. No permanent teeth.) S. These were placed one on each side of the legs of the adult burial. Both were in the usual position. The cloth was in very bad condition, but there were remains of inwoven designs. There were palm sticks under both bodies.

\section{N 2415 (тC; мM) Map D3 (red)}

S. Shallow grave, running east-west. Adult. Male? On back, head west, arms by side. Body was in good condition, most of the skin being left. Quantity of reddish-brown hair. Quantity of pubic hair. The body was clothed in 2 shirts. The outer one badly damaged with a quantity of pattern in dark blue cloth, and yellow medallions, and (i) pattern. Ornamentation in dark brown? panels, pattern in original cloth. Sleeves near end double in same ornamentation (ii). On sleeves, designs were floral. On main part of shirt, animal? Underneath, a white shirt, also much damaged. Back part was rucked up to small of the back. Shirt made of 2 pieces of cloth sewn together laterally to body, joint coming just below arm holes. Right sleeve left, sewn to about 22 above wrist, above open. Arm was not in sleeve. 4 carnelian beads scattered ? from neck. Sprinkled over the body, outside the shirts, there was a layer of salt. Under the body, there were 5 palm sticks bound together at each end with palm cord. The innermost wrapping consisted of a shawl of fairly fine cloth. Between this and the outer wrapping, which was of sackcloth and was tied round with cords, there was a lot of extra padding on the head. This consisted of a sheep-hide (?), worked, but with wool still remaining, and of a number of bundles of straw tied round with cord. [ed.: No image of burial/tomb.] 
N 2416

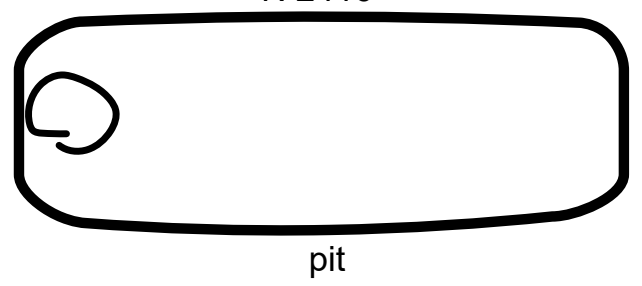

N 2417

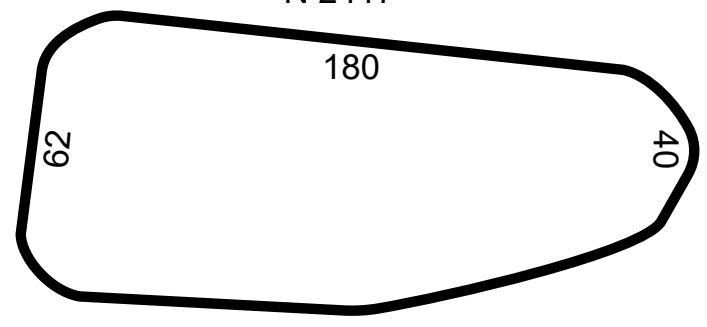

(i)

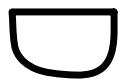

(ii)

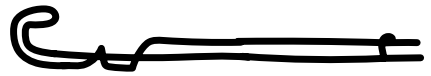

N 2418

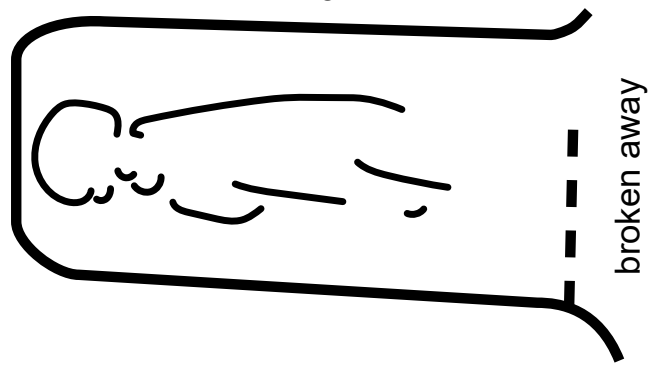




\section{N 2416 (тс; мM) Map D3 (red)}

Coptic burial. Shallow grave, running east-west. Young adult, about 18-20. Ends of bones almost ossified. Sex? On back, head west, arms by side. Body in very good condition, a good deal of the skin being still preserved. Fingernails preserved. The body was clothed in 2 plain shirts of coarse cloth. The right arm was in the outer sleeve, but not in the inner, while the left arm was in the inner sleeve, but not in the outer. In each case, the sleeve seams were sewn together at the shoulder and the wrist, but were open between. The inner of these was a plain shirt that reached almost to the knees. The body thus attired was laid on a flat board to which it was bound by a wide strip of cloth that went round the hips. Board and body were then placed on a wide strip of cloth, spread open on the ground. A number of dried leaves were placed on the breast, and a quantity of salt was poured/sprinkled over the whole body. Over the face, a layer of very fine soft fiber was added. The left side of the shawl was turned over the body, and then the right side, the whole being bound together with fiber cords. At feet end, this cloth ended in a fringe. Above this shawl, there was a very elaborate combination of headpads. First, over the face, there was a roll of fine cloth. Next came a quantity of loose straw, embedded in which there were 5 bundles of straw, each tied up separately with cord and then all bound together. These were roughly kept in place by cords fastening round the head and were finally secured by a cloth that completely enveloped the head, with its various paddings, and that was itself fastened on with cords. Next came a shawl of rough sackcloth that completely enveloped the body. The outer binding cords were of type 1 .

\section{N 2417 (TC; MM) Map D4; photo C 8472}

95 deep. Coptic burial. S. Shallow grave running east-west. Adult male. On back, head west. All trace of cloth gone. Behind the head, a copper dipper (i) with handle made in 2 pieces, which were attached to one another in such a way that handle could be lengthened at will (ii). The handle was soldered to dipper. In the filling of the grave, 4 copper signet rings. [ed.: The drawings of 2 TCs numbered 2417 have been combined into 1.]

\section{N 2418 (тс; MM) Map D4}

Shallow grave running east-west. Coptic burial. Child. On back, head west, arms by side. Quantity of straight, dark brown hair. On left arm, remains of an iron bracelet, almost all decayed away. Under body, 2 palm sticks. Round head, several wrappings of finer cloth innermost one of which had patterns in colored wool. The cloth wrappings were in very bad condition. Outside this was a shawl of sackcloth. 

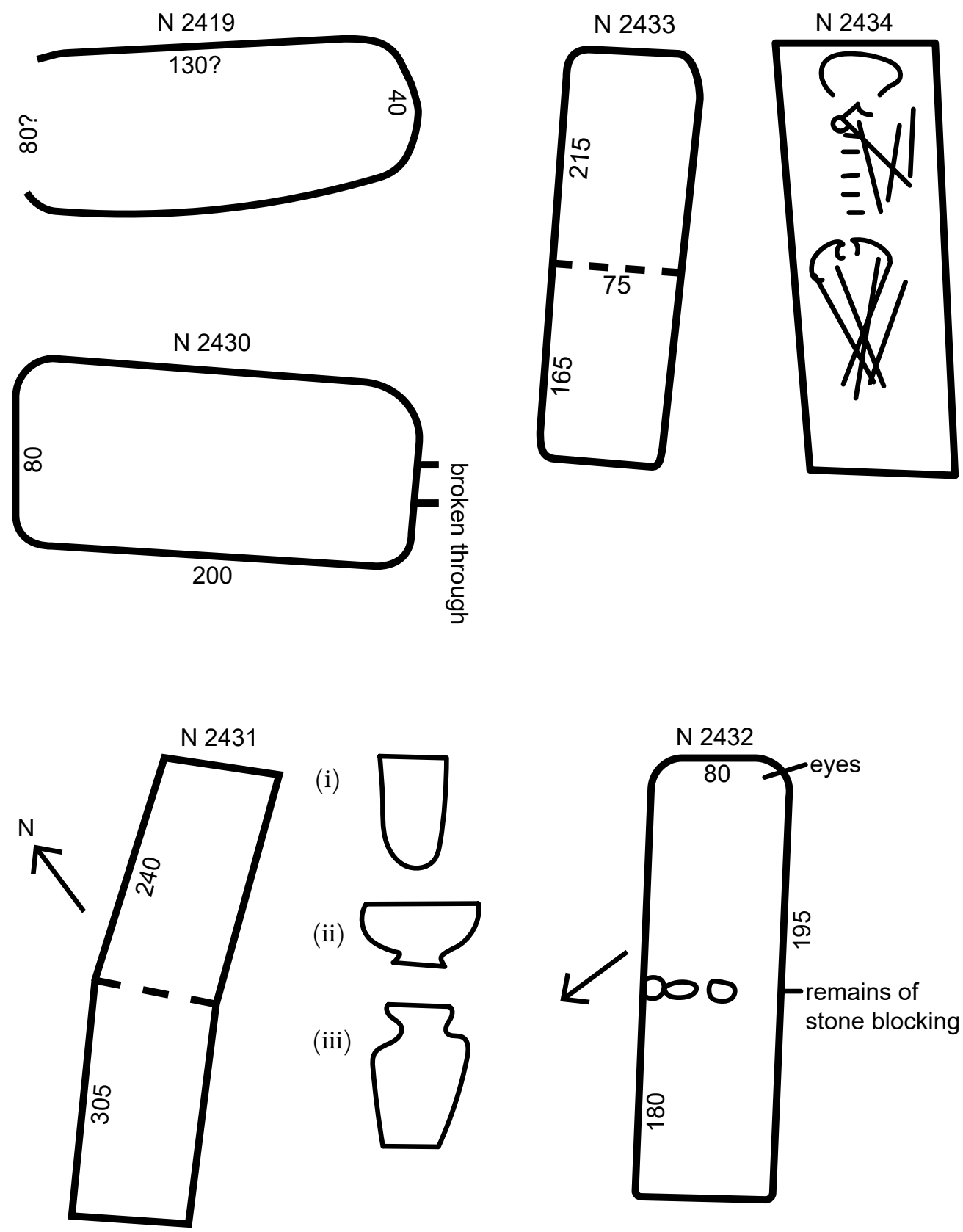

(i)

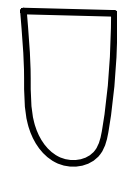

(ii)

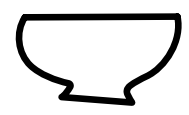

(iii)

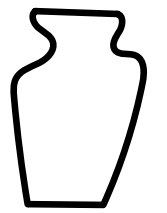

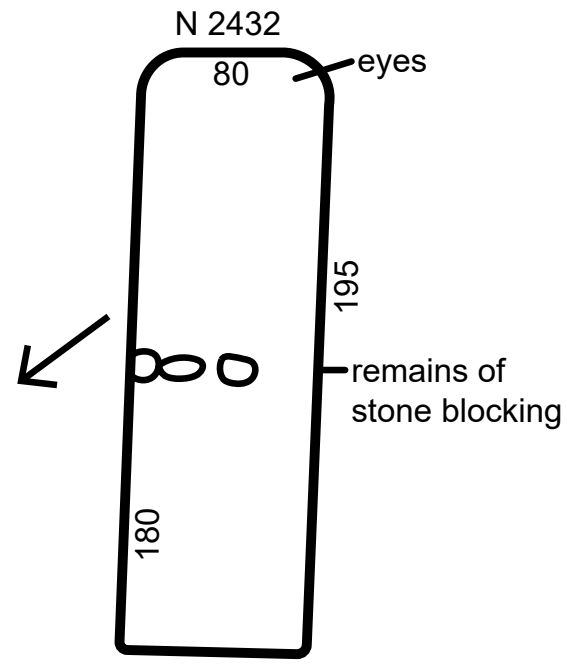




\section{N 2419 (тC; MM) Map D4}

72 down from gebel. Coptic burial. Shallow grave running east-west. Adult male. On back, head west, arms by side. Quantity of dark brown remaining with thin moustache of a rather lighter color. The shirt and inner wrappings had entirely disappeared. under the body, there were 3 or 4 thin sticks of sesban. On the head, there was a pad consisting of a much patched and darned shirt with corded edges. 1 wrapping shawl of sackcloth remained, and outside this, there were traces of a very thin wrapping of red cloth.

\section{N 243 o (TC) Map D4}

100 below gebel? Apparently, a pit was begun, and when it broke through at bottom to next tomb, it was abandoned.

N 2431 (TC) Map $\mathrm{D}_{3} / \mathrm{D}_{4}$ [ed.: Map location not listed in excavation records; possibly between $\mathrm{N} 2637, \mathrm{~N} 2636$, and $\mathrm{N}_{26} 63$ in tear on map. Note that there is another tomb labeled $\mathrm{N} 2431$ that is associated with $\mathrm{N} 2207$.]; photos $\mathrm{C} 8466$, C 8467

270 down from gebel. 38 high? Contained 1 skull. Few fragments of coffin (angled corners). 2 rough sticks, both of which had fragments of cloth adhering to them. Piece of a pottery soul home? Several broken pots (i) A, (ii) rough outside, red polish inside (6-14470), piece of a (iii)? Fragment of rim of a slate bowl. Fragments of Coptic pottery in filling of pit with scratched inscriptions. [ed.: According to Hearst Museum records, 6-14469 (jar fragment) is from this burial.]

\section{N 2432 (TC) Map D3; photo B 8251}

200 down from gebel level. 94 high. In chamber, remains of coffin 174 long. Wood 3 thick. Eyes in black, white irises, red corners. Coffin yellow outside, white inside. Angled corners, round pegs throughout. Remains of inscription in dark blue paint. Piece of a nabut and several rough sticks. Few black and blue glaze disc beads, large size (6-14471). 1 skull.

N 2433 (TC) Map D3

200 from gebel. 9o high. Contained only a few fragments of coffin (angled corners).

\section{$\mathrm{N} 2434$ (TC) Map E3}

Burial on gebel level. Lid [ed.: and(?)] tibia had been moved. On left side. Both legs had been bent sharp from knees, feet by pelvis. Coffin had been broken 


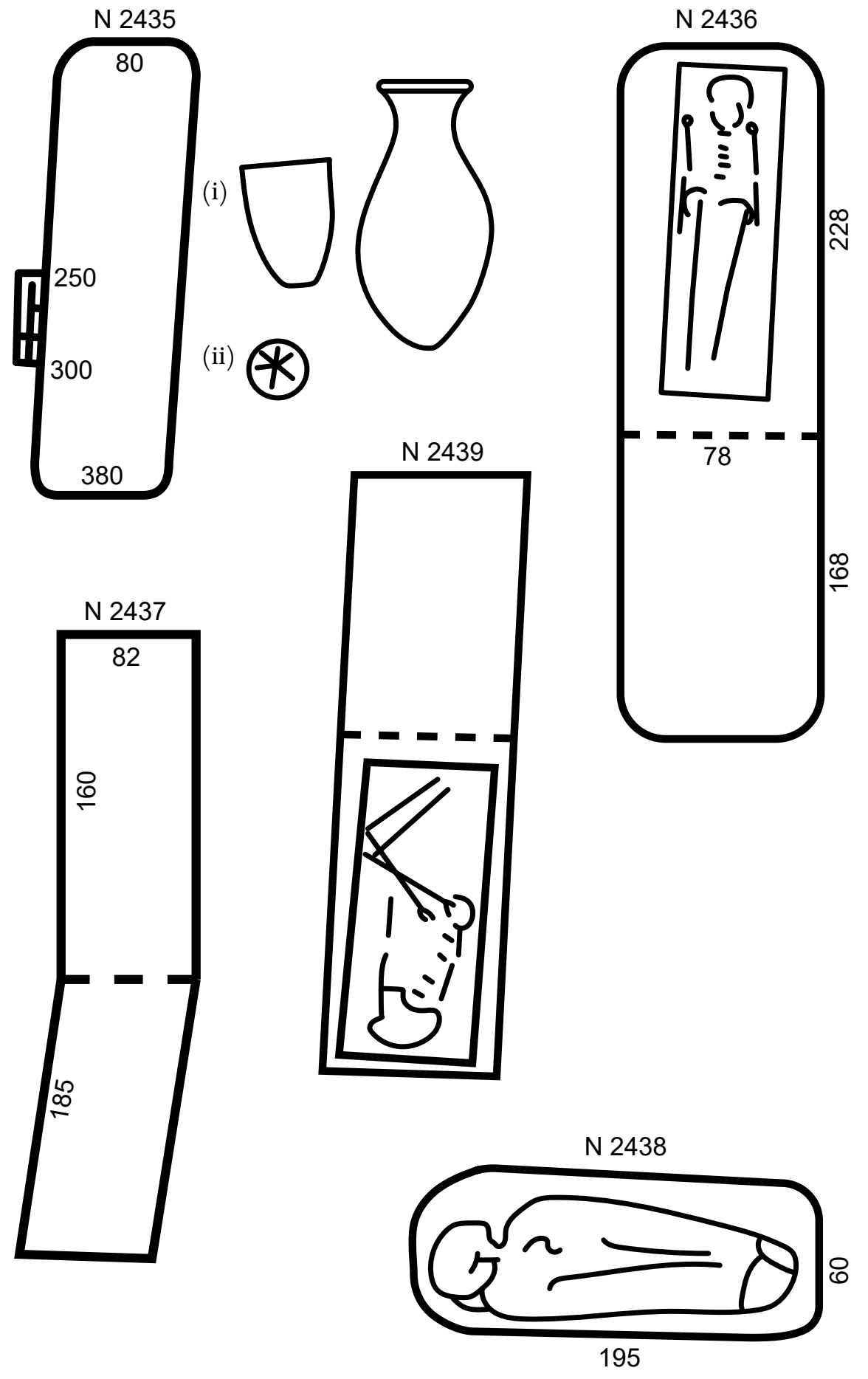


by plunderers and was scattered above. Coffin about 125 long. Few traces of cloth on body. In radim above, few black and blue glaze beads, 1 crumb bead (6-14472). Protuberances on left side of skull.

\section{N 2435 (TC) Map E3}

150 from gebel. Remains of brick building with 2 stones built above brick, $3^{2}$ high. It was 20 above, 1 brick wide. Roof of chamber fallen in. Contained pieces of 2 or 3 pots (i), small fossil (ii). Part of foot, all bottom joints of toes ossified to main part of foot.

\section{$\mathrm{N} 2436$ (Tс) Map E3}

16o to gebel. 82 high. Male. Burial on back. Few traces of cloth on body, including skull. Coffin white, inside and out. Inside measurements $188 \times 41 \times 47$. Thickness of wood 5. Corners as usual, round pegs. In filling of pit, 2 rough nabuts about 140 long, possibly both from one in which each pole would have been 270 long and still broken at each end. Possibly from a Coptic burial.

\section{N 2437 (TC) Map E3}

160 from gebel. Roof of chamber entirely gone. Contained remains of a wooden coffin. 1 skull. Contained fragments of 2 or 3 As and of a Coptic dish.

\section{N 2438 (тC; MM) Map E4 (red)}

100 down. Coptic burial. Shallow grave running east-west. Adult. Sex? Head west. The shirt had disappeared, and the inner wrappings were in a very fragmentary state. The innermost shawl seems to have been coarse cloth with a border decoration in red and yellow wool. Over feet, pad of cloth with openwork decoration. These were probably from a wrapping shawl. Above this, over the face, there was a layer of thin reeds bound to the head by a strip of cloth. Above the reeds, there were 2 pads of cloths, 1 consisting of an old shirt decorated with lines of rosettes in colored wools, blue, yellow, green, red, and black. Also, near neck, a band of openwork. Second roll consisted of a strip of ordinary coarse cloth, about 100 by 40 , rolled up. The outer wrapping was of sackcloth tied round at neck and feet with cord. The binding cords had almost entirely disappeared.

N 2439 (тC; Mм) Map E4; photo C 7068, C 8559

Coptic burial of a child in the chamber of a Dynasty 6-9 pit, the early coffin and burial being still in position underneath. By the head, a few twists of black, plaited hair. On right arm, by elbow, an iron bracelet. The body was clothed in a plain shirt that reached to just below the knees, sleeves down to hands. Under 

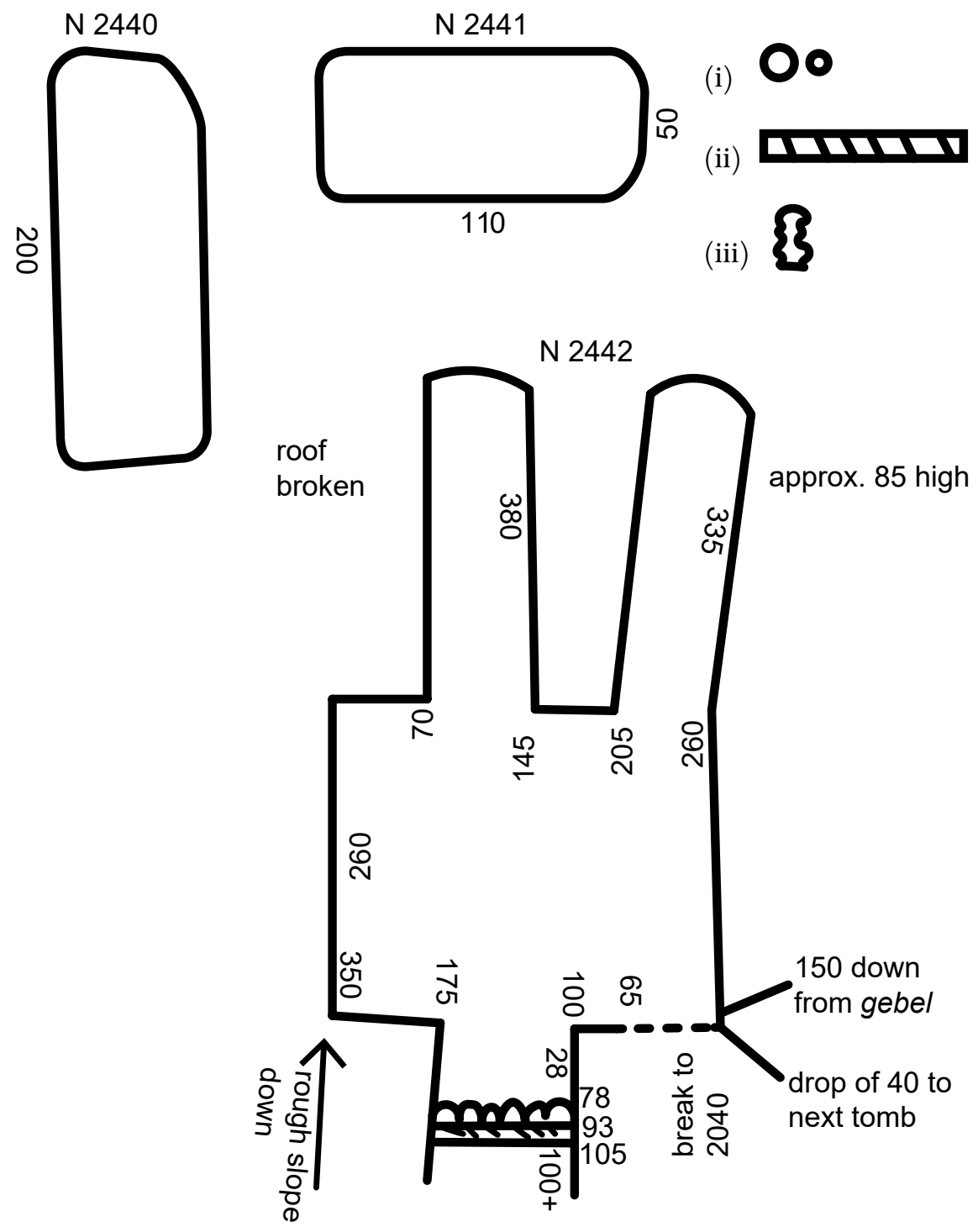

(i)

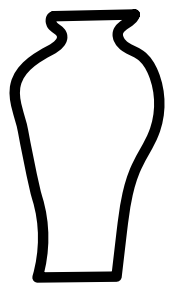

(ii)

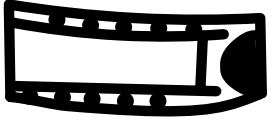


the body, there were 2 palm sticks and on the body, reaching down from the stomach to the ankles, there were a few dried branches of some aromatic herb. Thick pads over head and feet. There was apparently but 1 wrapping shawl and that of sackcloth bound round with cords that crossed in all directions.

\section{N 244 O (тC; M M) Map B4}

110 deep. Coptic burial. Shallow grave running north-south. Adult. Sex? On back, hands by side. No cloth preserved.

\section{N 2441 (тC; MM) Map B3; photo C 8469}

100 down. Coptic burial. Shallow grave running east-west. Small child. On back, head west, arms by side. By the head, there were a number of beads, blue and green glass, shell, and carnelian (i), ivory (ii), several ivory (iii) pendants threaded on bronze wire, and a small bronze cross. In the filling of the grave, there were pieces of 2 dishes and the upper part of a pottery doll. No cloth preserved.

\section{N 2442 (тC) Map B4; photos B 8429, C 7473}

Height of chamber had been approx. 130. Outside bricking of doorway, few A pots (i). In filling of chamber, few more As, M, broken pottery cone, and broken pottery?(ii).

\section{N 2446 = N 2522 (TC) Map E3; photos B 7142, B 7144, C 7474}

Height of chamber? Chamber a: blocked with rough stones and mud. Broken away at top by plunderers. Remains of wooden coffin, rotted entirely to pieces. Adult. Sex? Head north. Bones had rotted away so completely that position of burial was indeterminable. Probably on back. Chamber b: contained nothing. In main chamber, a quantity of pottery (see photo) and a few glaze beads, disc and (i). [ed.: According to Hearst Museum records, the ceramics from this burial are 6-14473-6-14536.]

\section{N 2447 (TC) Map B4; photo C 8542}

135 down from black deposit. 175 from gebel. 75 high. Adult. Female? Half over on left side. Position of right arm ?, but apparently under body, both hands being together. Traces of wood from a coffin. Bronze mirror (6-14537), resting on 2 rough stones. Cloth on under side. Greater part of roof of chamber had broken away. Above tomb, (i), (ii) drab, M, (iii). 
$\mathrm{N} 2446=\mathrm{N} 2522$
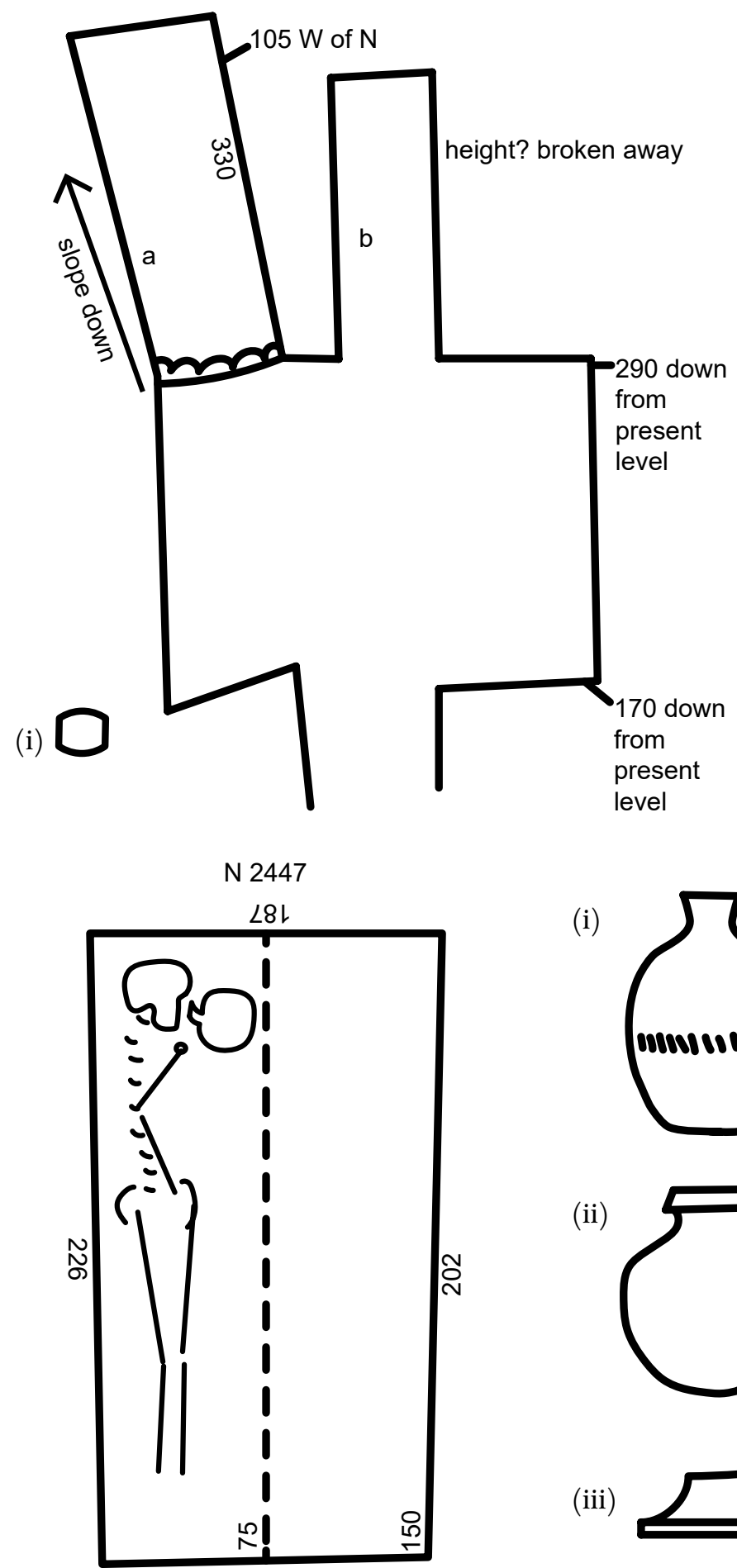

(i)

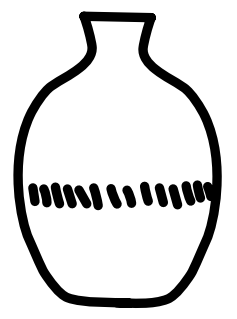

(ii)

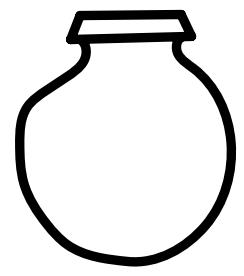

(iii)

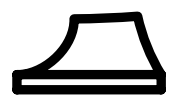




\section{N 2448 (TC) Map B4}

Approx. 50 down from gebel. 45 high. Wall 12 wide, i.e., half brick. Adult. Male? Traces of wood from coffin? Roof of chamber, if any, entirely gone.

\section{N 2449 (TC) Map B4}

Approx. 210 deep. 80 high. Female? From skull, pelvis too broken to determine. Burial on left side. Head north. On breast, at X, a bronze button (i) with loop back, covered with cloth on both sides (6-14539). Brick wall 16 high. Chamber was apparently originally blocked above wall by stones. 2 or 3 large stones still remaining at north end. Built in with brick wall at south end, a large pot (ii), approx. $42 \times 35$, in dull brown ware. In filling of pit near top (iii) with decoration in white spots. Bottom roughed and had been on a stand or dish. [ed.: According to Hearst Museum records, 6-14538 (mirror) is from this burial.]

N 2470 (TC) Map B4

Not a burial. $30 \mathrm{~W}$ of N. 140 deep from present level.

\section{N 2471 (TC) Map B4}

9o down. Color of soil under bodies showed that there had been a coffin. 2 bodies must have been in the same coffin. a. On left side. Adult. Female? b. Almost over on stomach. Adult. Female?

\section{N 2472 (TC) Map B5}

Brick 13 wide, about 6 o high. Apparently in construction of tomb, hole was cut into next and bricked up. Just outside doorway, few A pots (i).

N 2473 (TC) Map B5; photos B 8427, C 8495

In main chamber and in door of east chamber, a quantity of pottery: table of offerings (i); A (ii) (6-14540, 6-14541); M (iii); smooth pottery, 3 black paint lines, large bowl (iv).

N 2474 (TC) Map B5

$40 \mathrm{~W}$ of N. 185 to gebel level. Contained 1 broken skull.

$\mathrm{N} 2475$ (TC) Map A4 (red)

$68 \mathrm{E}$ of N. Depth from present level 15o. All roof of chamber gone.

N 2476 (тC) Map B4

$5^{2}$ W. 225 deep from surface. Contained nothing. 
N 2449

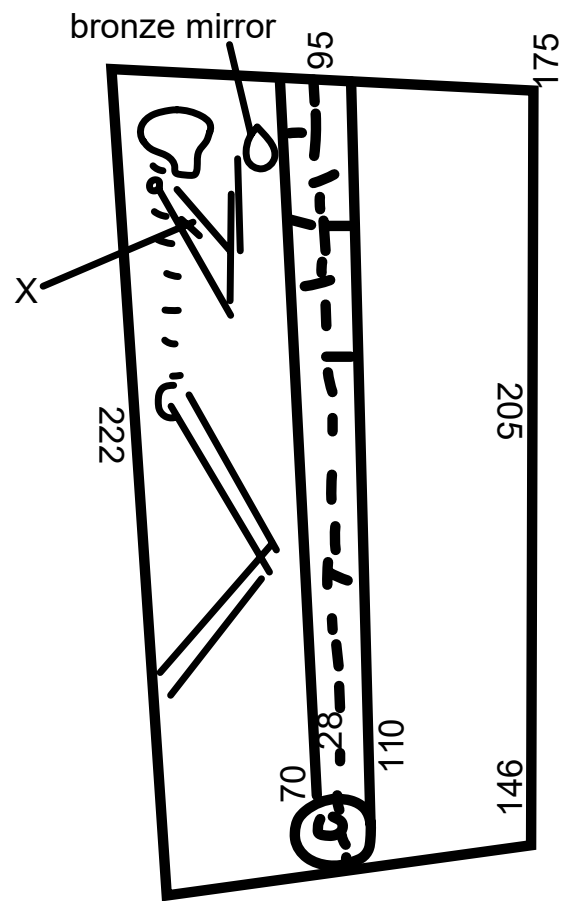

(i)

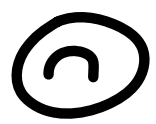

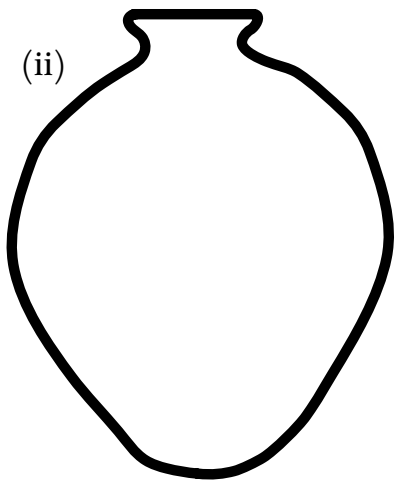

N 2448

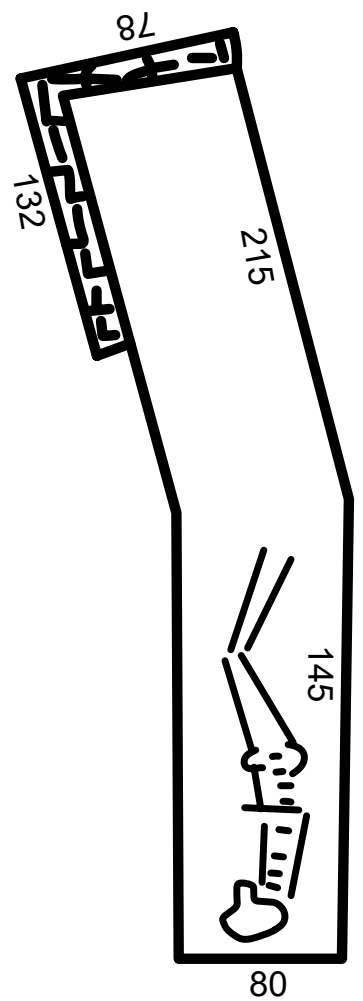

(iii)

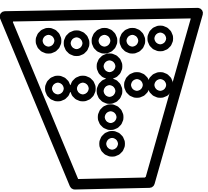




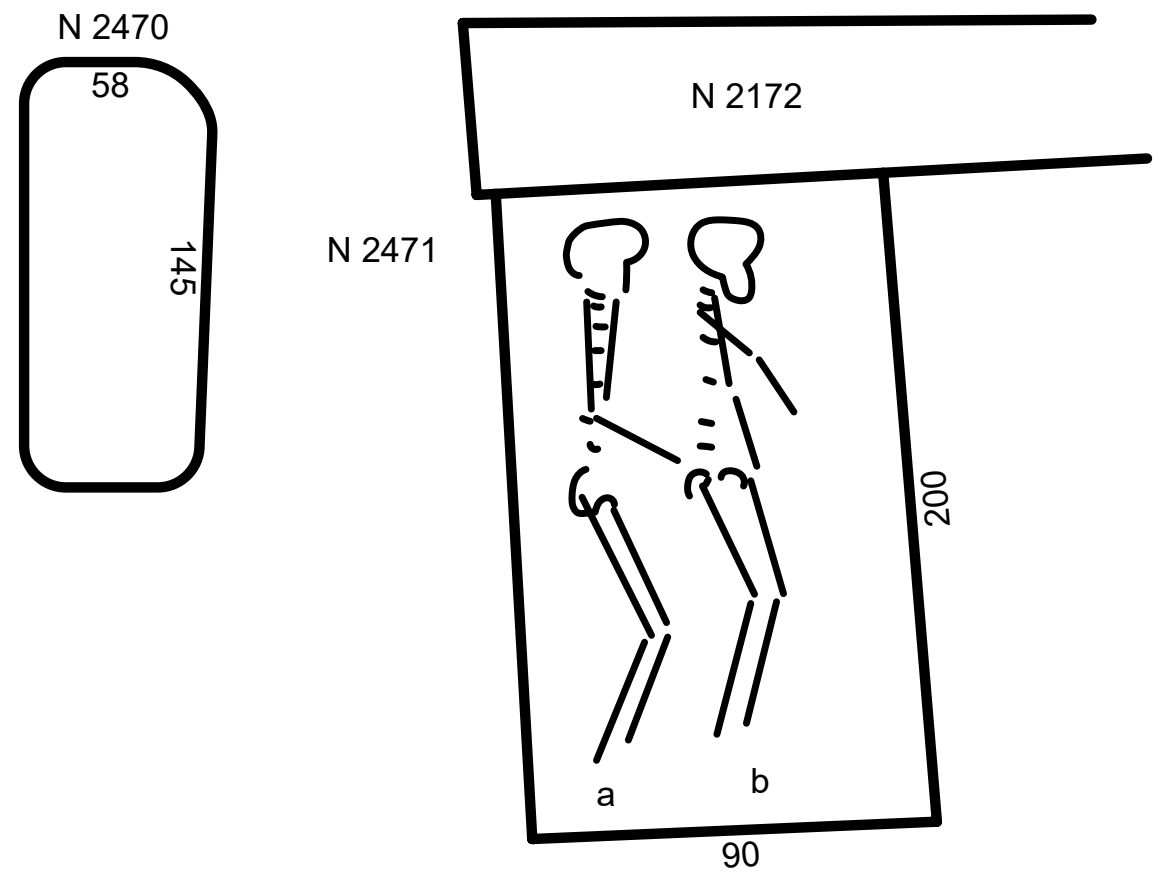

N 2472

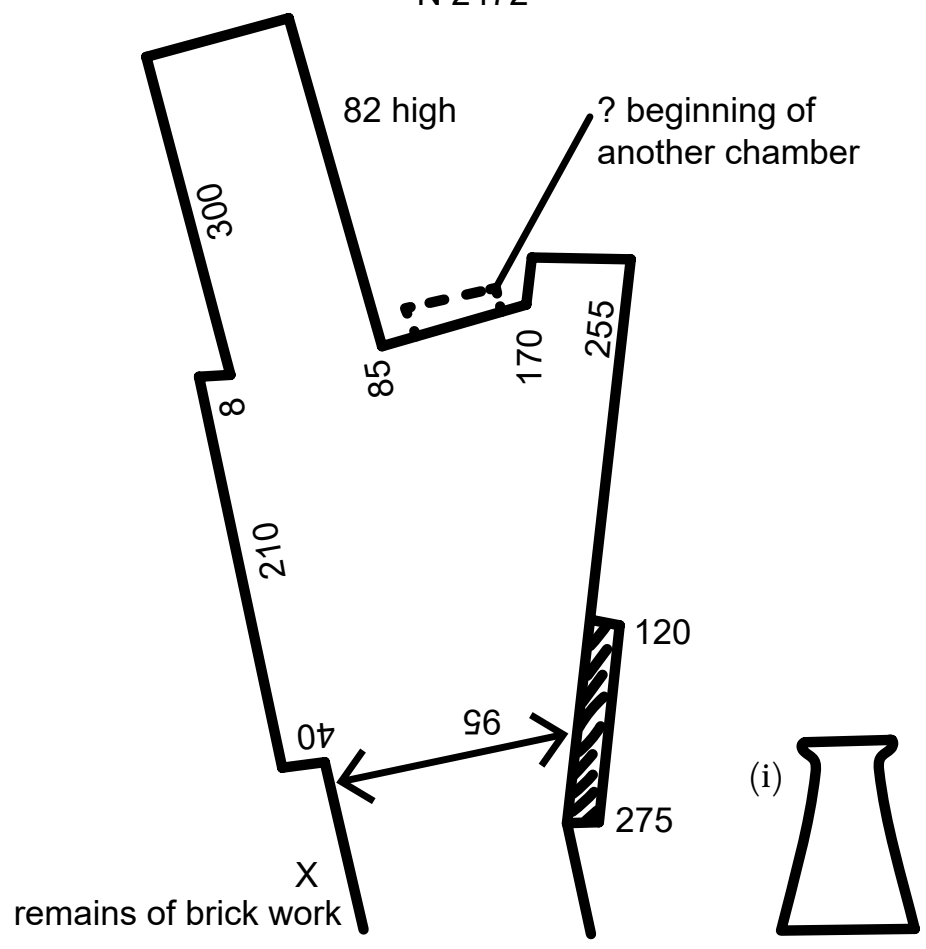




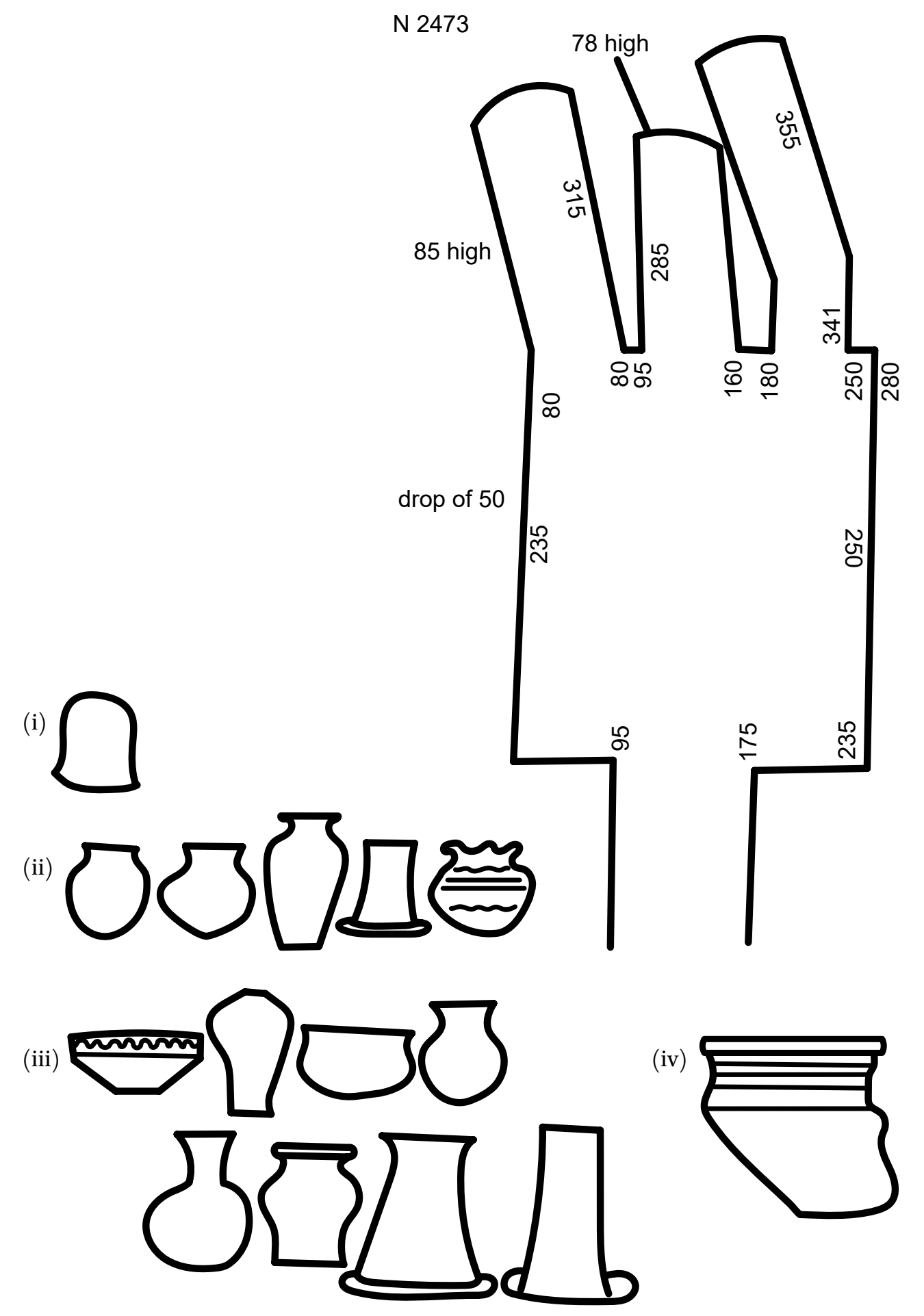


N 2474

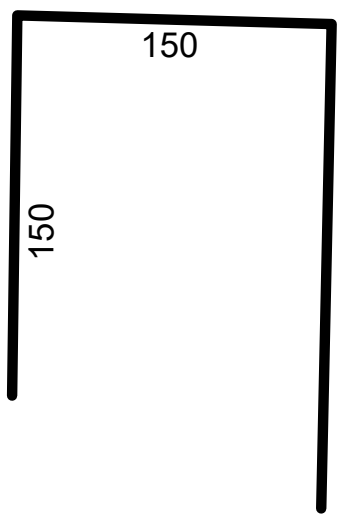

N 2476

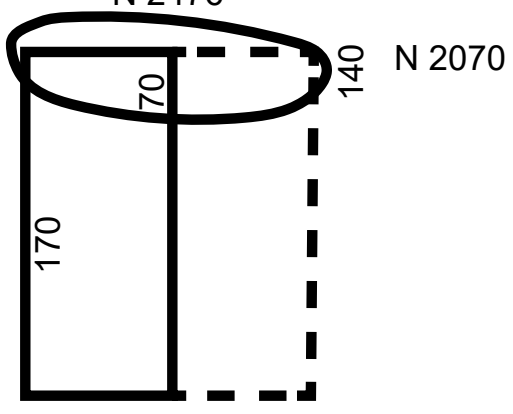

N 2475

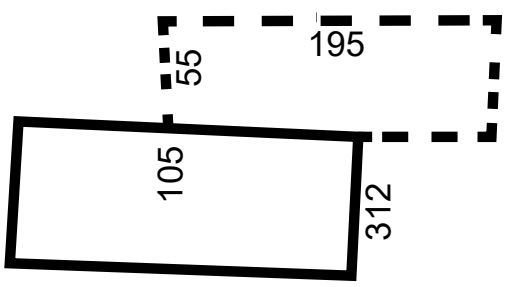

N 2477

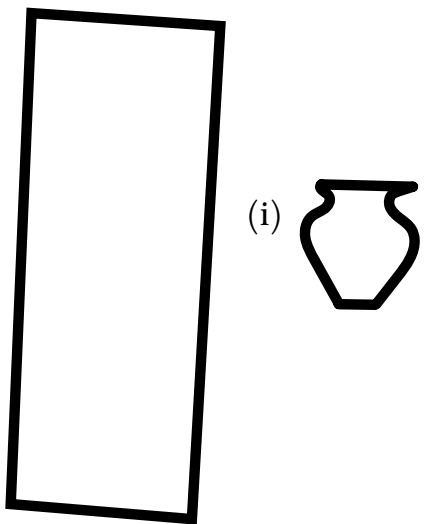

N 2479

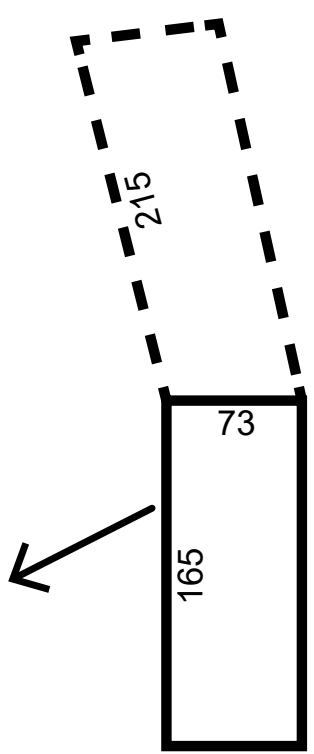




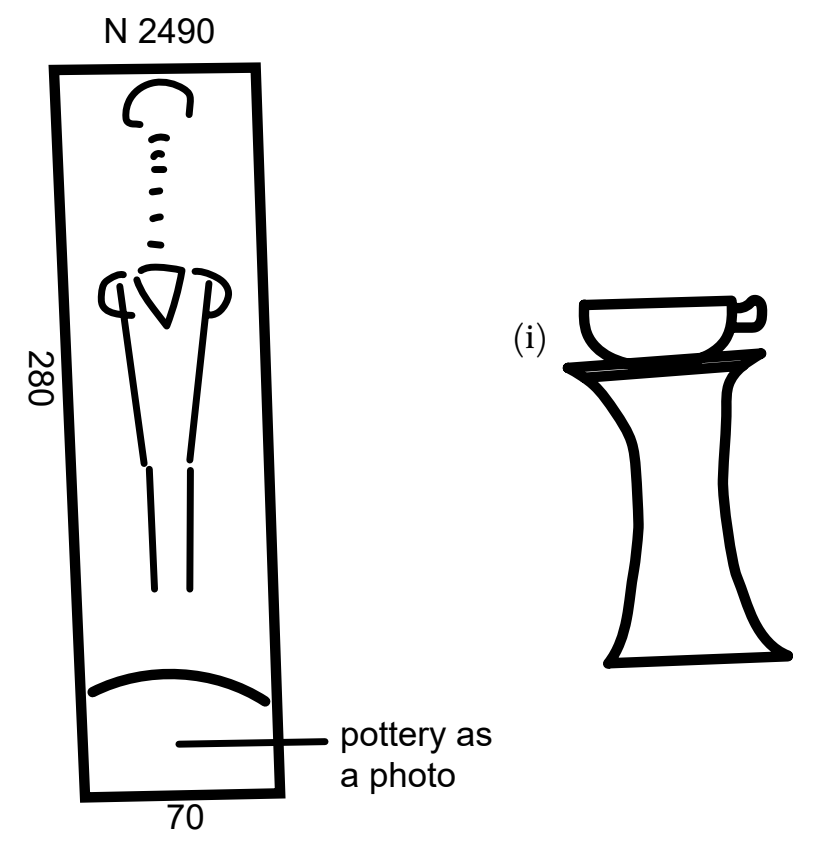

(i)

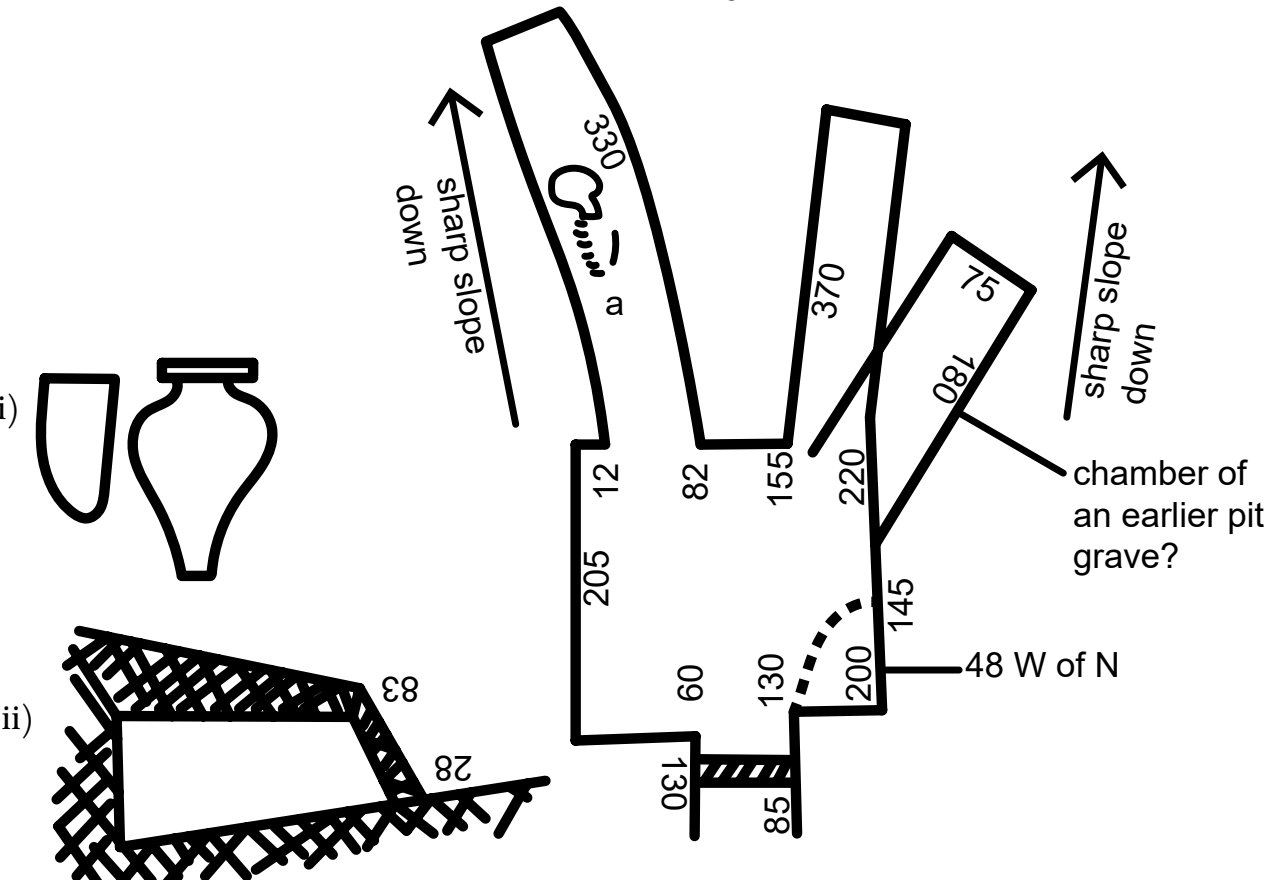

N 2491 
N 2477 = N 2531 of Green's (TC) Map B4

140 E. Contained a few pots only, (i) [with] spout, A.

$\mathrm{N} 2478$ (TC) Map A4

Approx. 5oo deep from present level. Down almost to water. Abandoned as unsafe.

$\mathrm{N} 2479$ (TC) Map A4

19o deep. Contained nothing.

N 249o (тC) Map C4 (red); photos B 7146, C 7158, C 7467

Originally probably chamber and pit, but all roof broken away. At entrance to pit, quantity of pottery (see photo), dish on stand (i) (6-14542.1, 6-14542.2).

$\mathrm{N} 2491$ (TC) Map C4

75 to present level. Roof of main chamber entirely broken away. In (a), remains of burial. On left side. Adult. In dotted space, a quantity of pottery, A, M, (i). Brick blocking (ii) built on [ed.: not filled in] of radim. Batter 21 [i.e., receding slope of wall?]. Wall 12 thick.

$\mathrm{N}_{2492}$ (тC) Map C4

$30 \mathrm{~W}$ of N. 245 deep. 75 high. Lower part of burial in chamber. Head been on left side, head northwest. No trace of coffin. Pit must have been constructed before chamber of moghar, as roof of moghar chamber came above level of floor of pit chamber. [ed.: According to Hearst Museum records, 6-14549 (bone chisel) is from this burial.]

\section{$\mathrm{N} 2493$ (тC) Map C4}

110 high. 360 deep from present level. Contained nothing. [ed.: According to Hearst Museum records, 6-14543 (jar), 6-14544 (broken jar), 6-14545 (broken jar) and 6-14546 (cup) are labeled as potentially from this burial.]

$\mathrm{N} 2494$ (тC; MM) Map C4

Coptic. Shallow grave running east-west. Contained only a few bones.

$\mathrm{N}_{2495}$ (тC;

Coptic. Shallow grave running east-west. Contained nothing. 

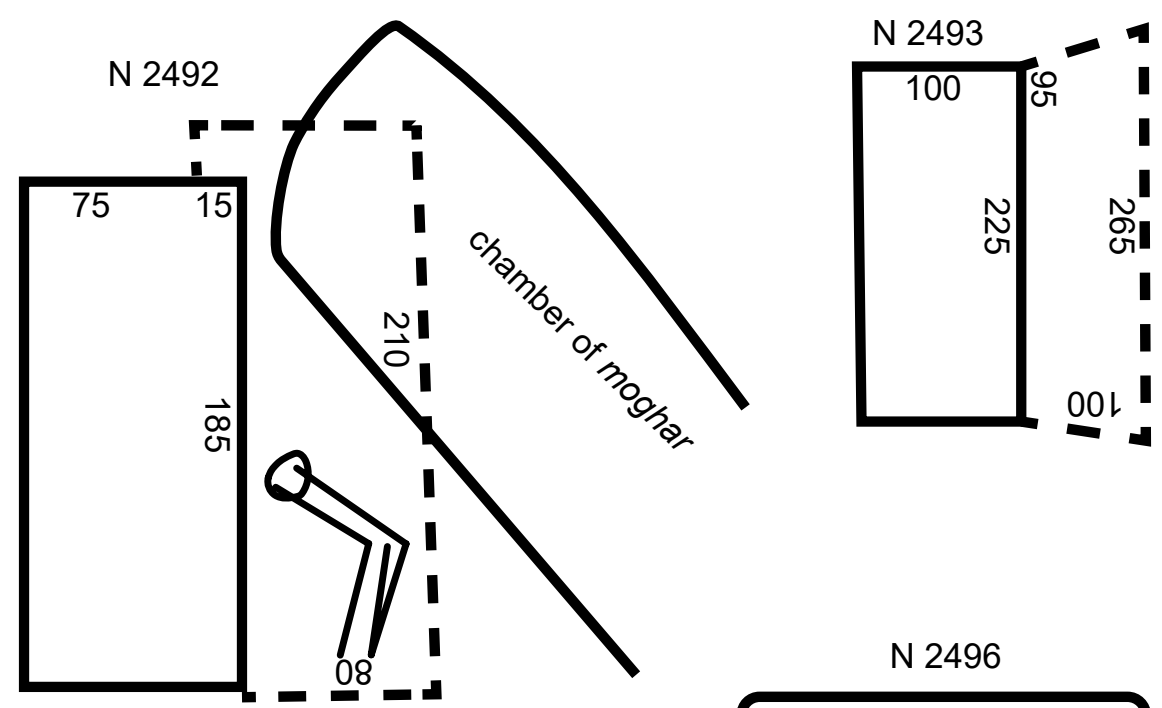

N 2494

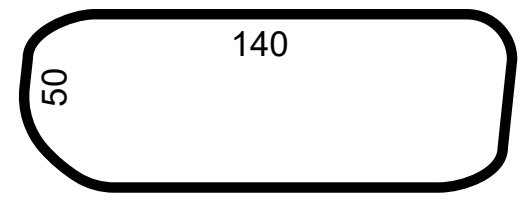

N 2495
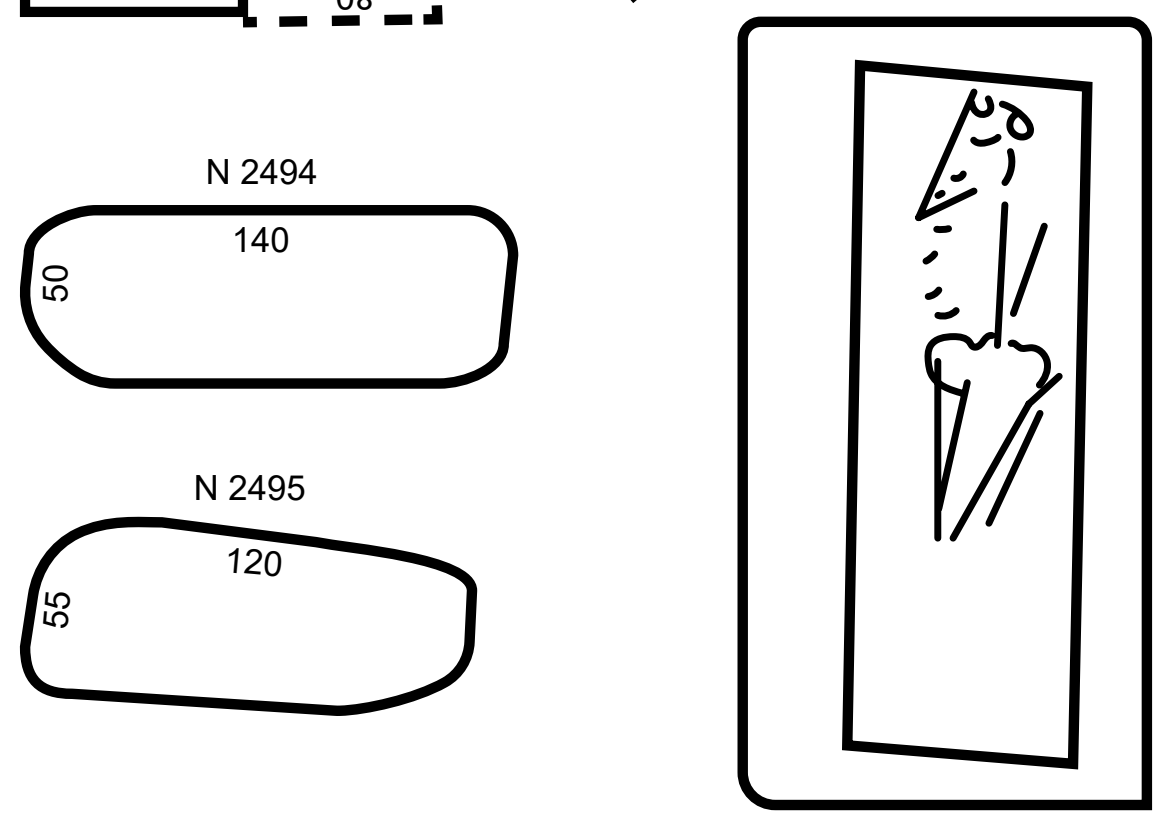

N 2497

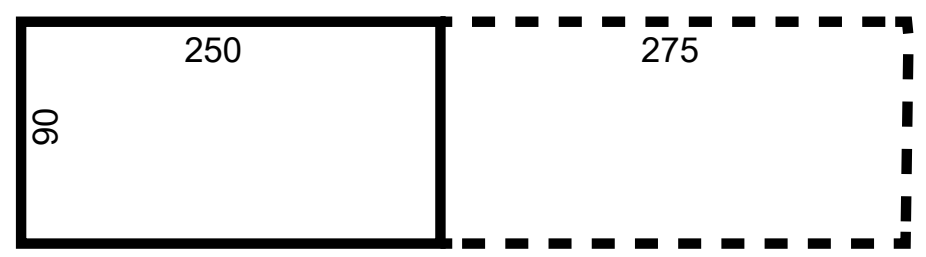




\section{$\mathrm{N}_{2496}$ (TC) Map C4 (red)}

120 down from present level. Male adult. Knees $5^{2}$ from end of coffin. Body completely wrapped up in cloth (not bandages). Bones in relative position to one another, but whole body twisted and distorted into a position impossible without dislocating joints. Right shoulder over face, humerus straight down, and lower arm bones up at right angles. Left shoulder below chin, humerus straight, ulna and radius bent straight back. Pelvis bones twisted apart. Balls of femurs still in sockets of ilia. Lower leg bones bent straight back to pelvis, but left tibia out of place. Two of the middle vertebrae forced right out of the spinal column. Lower jaw bone resting against side of face, standing upright. This was not a cut up burial, as all evidence pointed to twisting the complete body, rather than to recomposing a cut-up body. Either body was deliberately distorted before burial, or else was reburied here while bones were still more or less holding together. Inside measurement of coffin $135 \times 35 \times$ ? Thickness of wood 3. Corners as usual.

\section{N 2497 (TC) Map C4}

50 E. 45 o deep. 13 o high. Contained nothing. Remains of bricks above pit, probably from a superstructure, but all fallen out of position.

\section{N 2498 (тC) Map C4; photo C 7705}

General direction $55 \mathrm{~W}$. All small chambers were plundered out. In main chamber and outside door, quantity of pottery A (i).

$\mathrm{N} 2499$ (TC) Map C4

Coptic. Contained nothing.

N 2500 (TC; MM) Map C4

Copt. Adult. (Male. $166 \mathrm{~cm}$ high.) S. On back, arms by side. [ed.: No image.]

N 2501 (1) Map N/A [ed.: This record is Reisner's note of preliminary work that was done in 1901.]

Hole in hillside south, walled-up door in wall. Scarab (i), alabaster (ii) (6-125o1), rubbing stone kohl bits (iii).

N 2501 (2) (TC) Map C4; photo C 8546

Burial in a plundered [state]: position of bones approximate. Adult male. All roof of main chamber gone. Door of $d$ had been blocked with large stones. In doorway, quantity of pottery, Coptic (i). Brick at door 115 high to stone. Lintel 


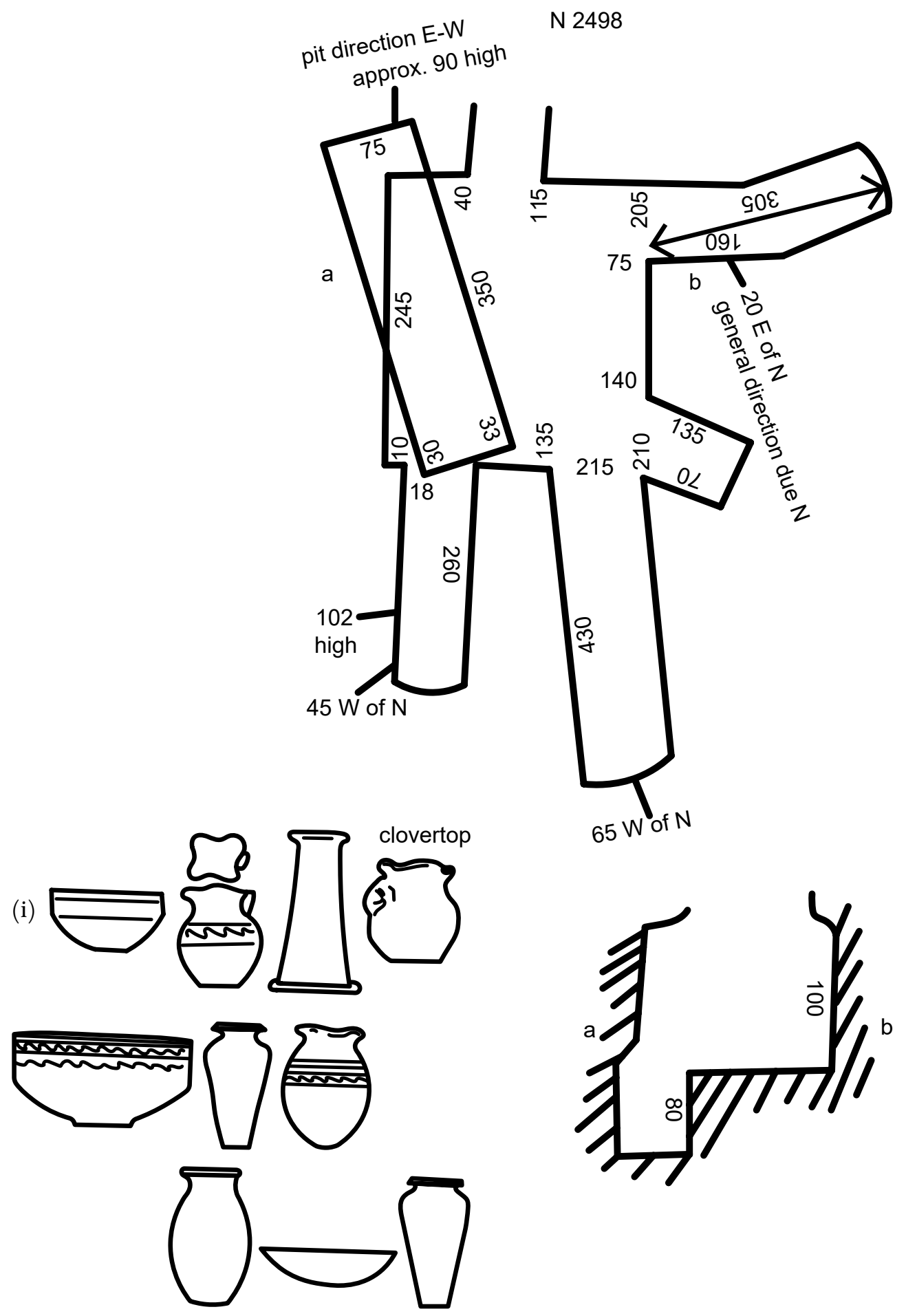



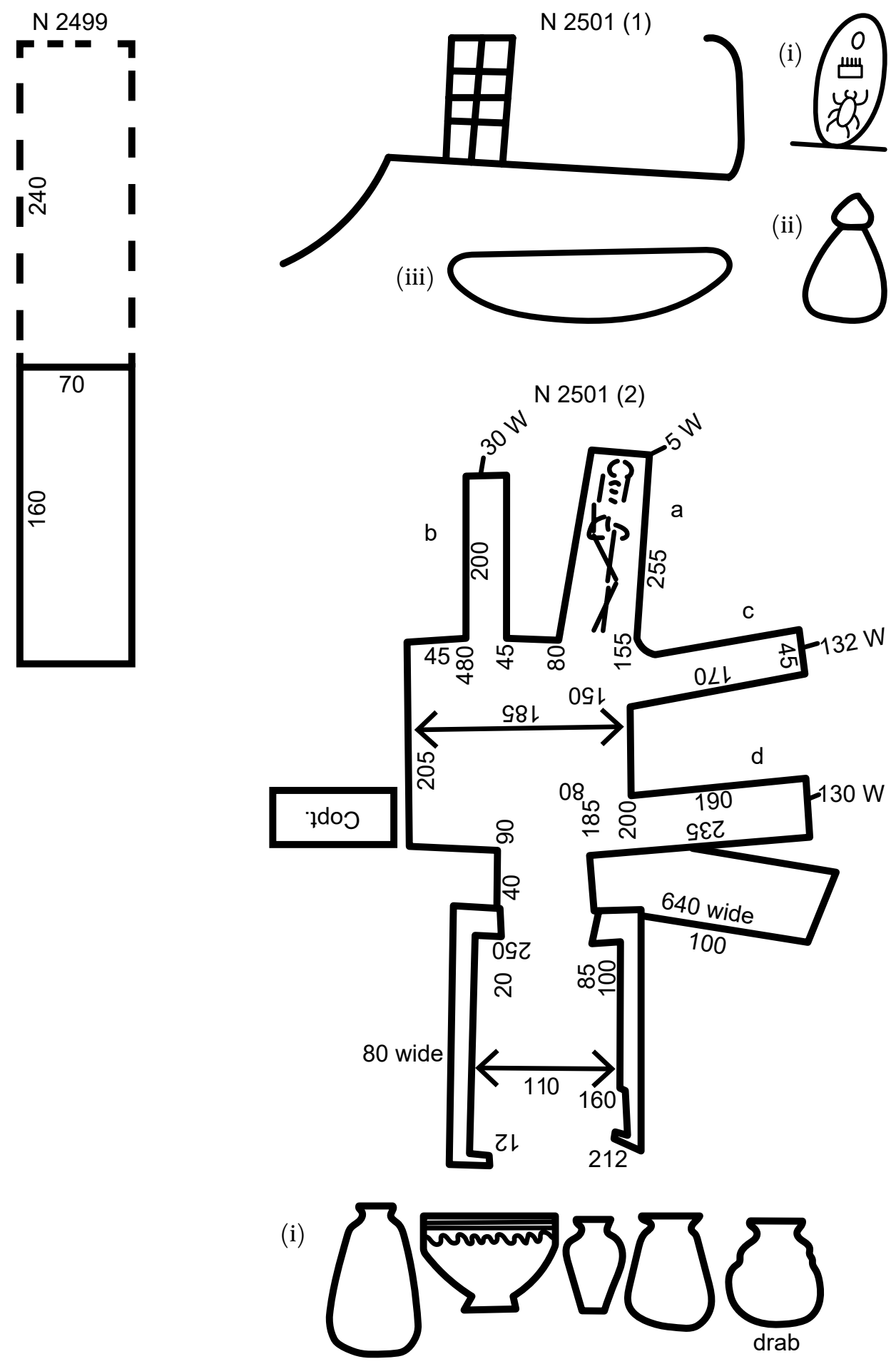

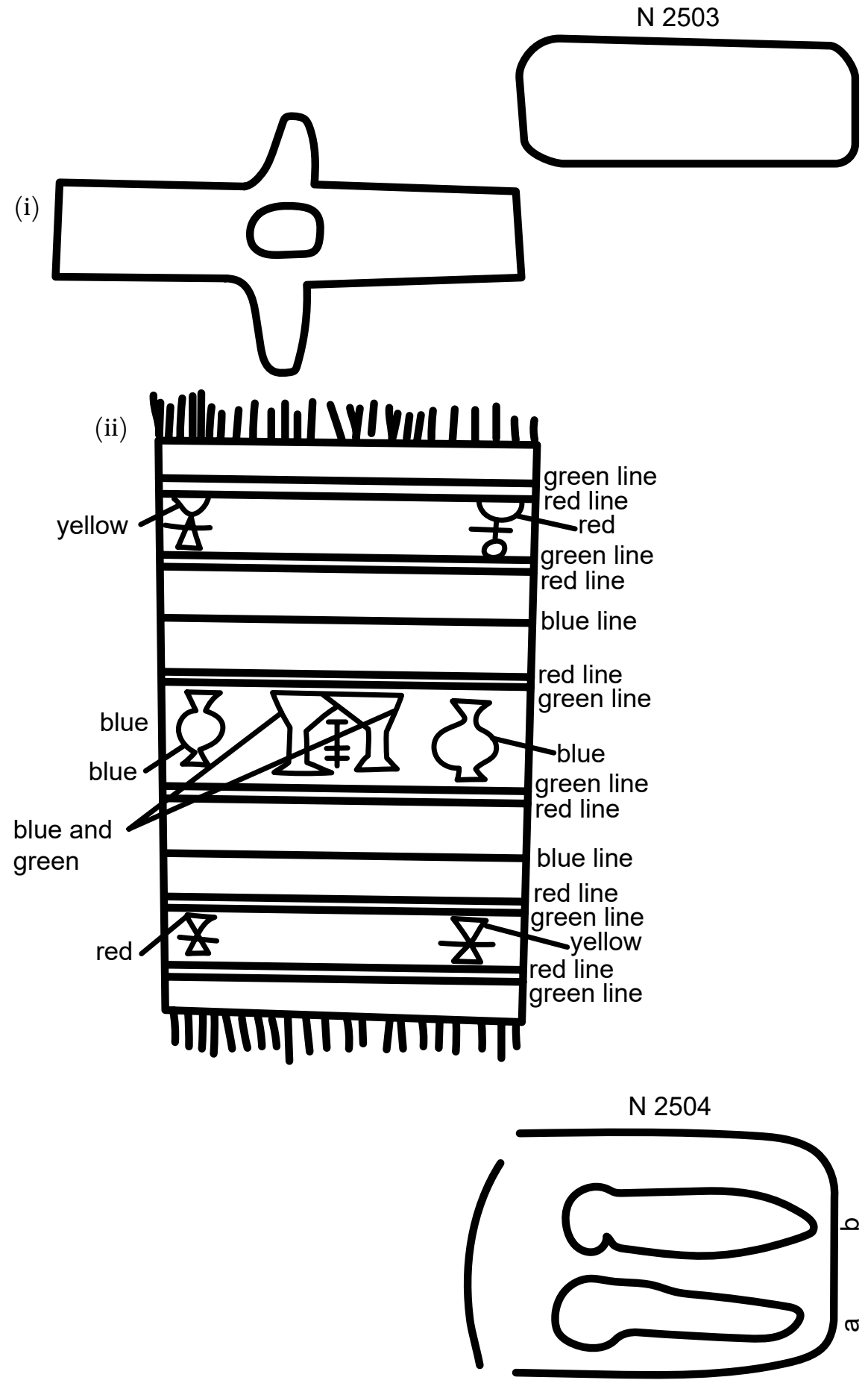
$3^{2}$ wide, 16 thick. This lintel was cut flat on underside in upper left rough. Side walls to top of lintel at south, 50 high from gebel level at north. This made the top of the wall level right along.

\section{N 25 O2 (тC; мM) Map C3 (red)}

Coptic burial. Double burial in the doorway of a Dynasty 6-9 tomb, At entrance to 2501. a. (Adult male. Height of man $154.5 \mathrm{~cm}$.) S. On back, head west. b. (Child aged about 2. Bronze bracelet on right wrist.) S. [ed.: No image.]

\section{N 2503 (TC; MM) Map C4}

Copt. Shallow grave running east-west. Adult male. On back, head west. Quantity of long, dark brown, curly hair. (164 cm high. Hair $14 \mathrm{~cm}$.) S. The body was clothed in a plain shirt of rather finer cloth [ed.: than the wrappings]. This shirt was apparently made of 2 pieces as there was a double corded border at each side that ran down sleeves (i). None of the borders were sewn together, but may have been originally and threads rotted. Under the body, there were 2 sticks, 1 of acacia, and the other of tamarisk [ed.: in TC: atl]. The innermost wrapping was a shawl of coarse cloth. Next above, there was a small shawl, $60 \mathrm{~cm}$ by 40 , folded up and placed on the face as a protecting pad. End fringed, with ornamentation in green, red, blue, and yellow wool (ii). This ornamentation only showed on one side and was worked under and over alternate threads either of wrap or woof. Outside, there was a wrapping shawl of sackcloth.

\section{N 2504 (TC; MM) Map D4 (red); photo C 8475}

Shallow grave running east-west containing the burials of 2 Coptic children, both aged approx. 3. a. On back, head west, arms by side. Skull gone. Round neck, a string of glass beads of different various colors on linen cord. On left arm (?), a small iron bracelet. The cloth was in bad condition. There had apparently been 2 shirts, both with tapestry-woven designs in colored wool. The outer wrapping was of coarse cloth. b. On back, head west, arms by side. The body was clothed in 2 (?) shirts, decorated with tapestry-woven designs. Over the head, there was a net hood or cap covered with a piece of fine decorated cloth. This latter may have been part of an inner wrapping shawl. On the body, there was a quantity of salt, and underneath it, there were 2 palm sticks outside all wrappings. There was apparently only a single wrapping shawl of green (?) cloth with occasional inwoven bands of black and run round with cords. 
(i)

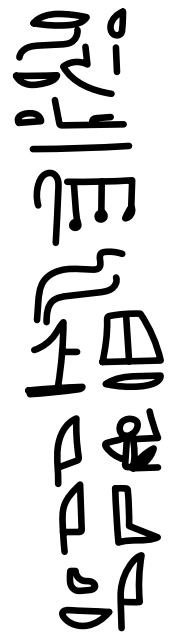

N 2507

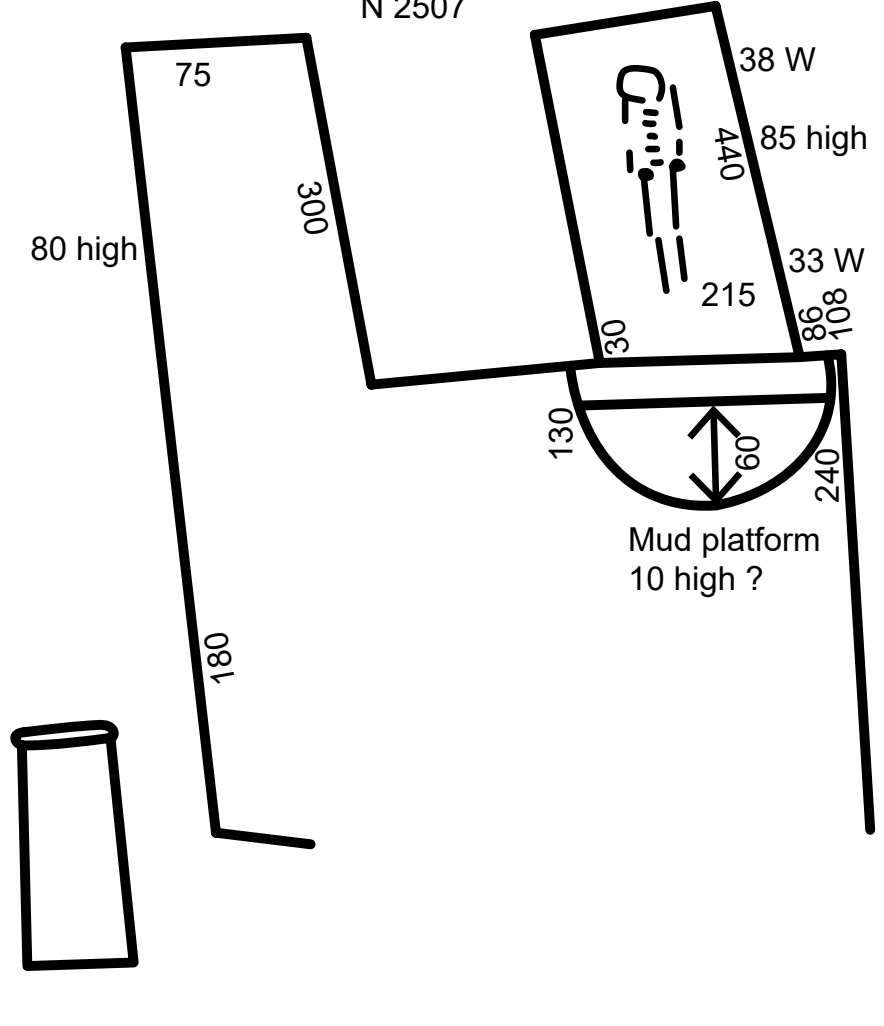

N 2508

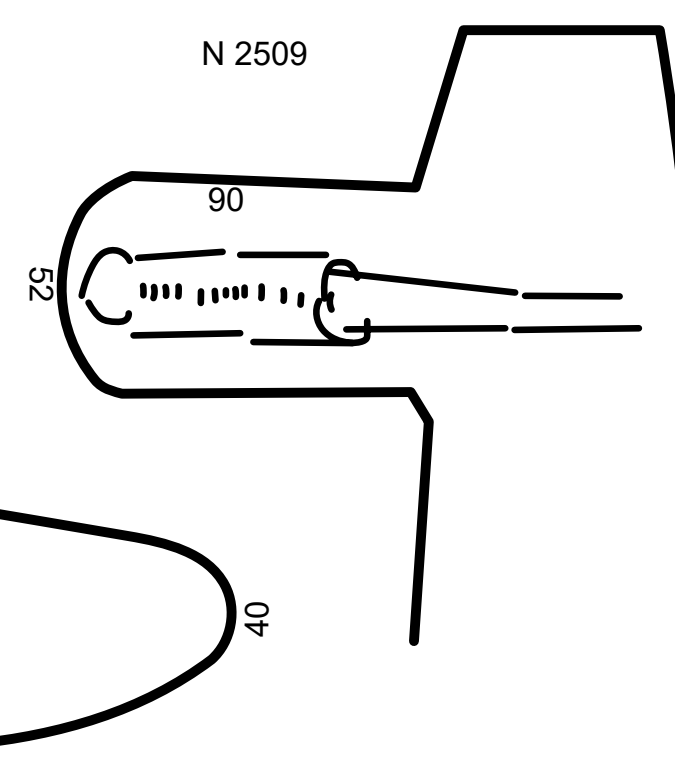




\section{N 2505 (тс; MM) Map D4}

Copt. Shallow grave running east-west. (Female aged 19-20. $153 \mathrm{~cm}$ in height. Iron bracelets on both arms, and by the head, much corroded bronze earrings.) S. No cloth preserved. [ed.: No image.]

\section{N 2506 (TC; MM) Map D4; photo C 8478}

( $?=2509$ of Smith's) Copt. Shallow grave running east-west. Girl aged approx. 9. On back, arms by side. 2 bronze bracelets on left arm and 1 on right, each came above the elbows. Bronze rings on the right hand. Round neck, glass, shell, and amber (?) beads. Remains of bronze earrings with glass bead pendants. [ed.: No image.]

\section{N 2507 (тC) Map C5; photos B 8076, B 8428, C 7466, C 7770, C 8522}

Roof broken away. East chamber blocking a painted stela (6-14553), which projected slightly into main chamber and built in with mud and rough stones. Man red, [animal] skin yellow, inscription red (i), wife yellow, offerings red and yellow, borders alternate red, yellow, and black (?). Upper register of stela worn off. On wood at each side of stela, scratched marks: possible meant for hieroglyphs. Behind stela, blocking of rough stones and mud with a second mud facing. Behind this, blocking went in 20o. Male? Burial on back. Traces of wood from coffin. Bones in very bad condition. In main chamber, quantity of pottery (ii) (6-12502).

\section{N 2508 (тс; MM) Map D4 (red)}

100 down. Copt. Shallow grave running east-west. Adult male. On back, head west, arms by side. Cloth in very bad condition, but traces of 2 shawls left, the outer being of sackcloth and the inner of finer cloth. 2 or more palm sticks under body.

\section{$\mathrm{N}_{25} \mathrm{O9}$ (тC; M M) Map $\mathrm{C}_{4}$}

9o down. Copt. Shallow grave running east-west, east end projecting over Dynasty 6-9 grave. Adult male. On back, head west, arms by side. Lowest vertebra joined to sacrum. At either side of body, not underneath, a stick of sesban. Very little cloth remaining.

N 2510 (TC; MM) Map D4

Coptic grave. Burial gone. [ed.: No image.] 
N 2542

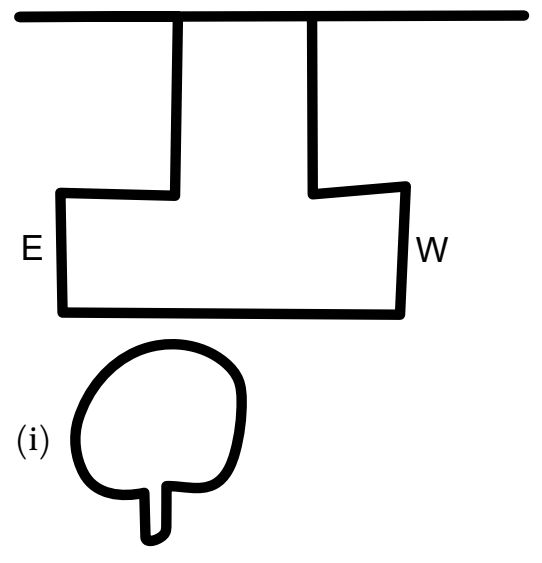

N 2511
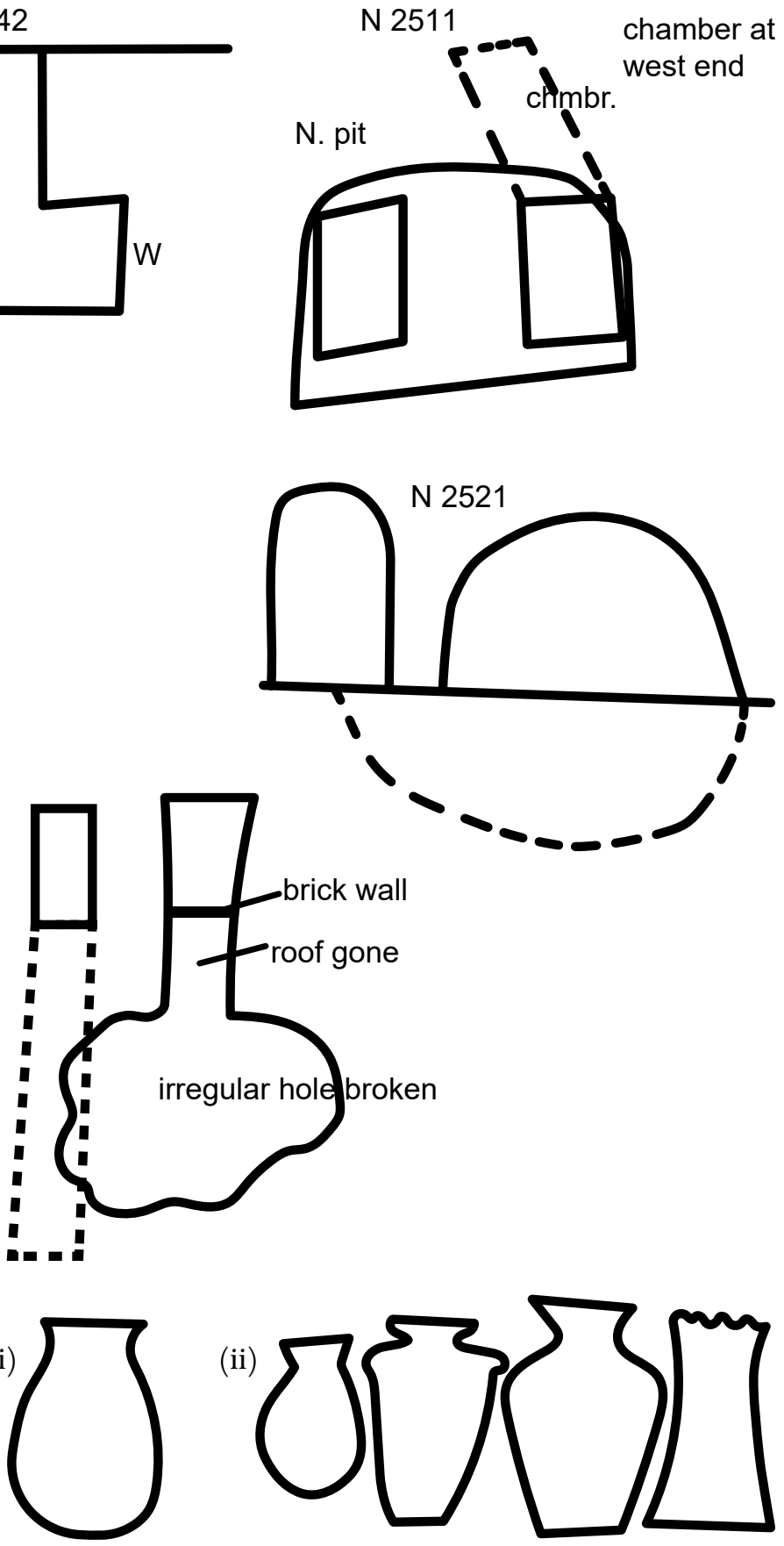

brick wall
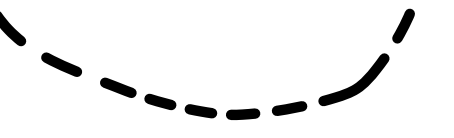
$\mathrm{N} 2511$ Map N/A [ed.: This record is Reisner's note of preliminary work that was done in 19o1. For this tomb on a map, see Reisner (1932, Fig. 1)]; photos C 2112, C 2113

Wednesday. Ahmed [el-]Mizlif Ismain [illegible]. Open hillside cave-two pits. Cont[ained] acct. coffin. ME [i.e., Middle Kingdom] joins. Wooden sandals on top. Photo. Flash.

N 2511 (TC; MM) Map D4

Coptic grave. No burial. [ed.: No image.]

$\mathrm{N} 2512$ and $\mathrm{N} 2513$ (TC; MM) Map D4

do. do. [i.e., ditto. ditto.] [ed.: No image.]

$\mathrm{N} 2514$ (тC) Map D4

Shallow grave. Copt or possibly Egyptian. [ed.: No image.]

N 2521 Map N/A [ed.: This record is Reisner's note of preliminary work that was done in 1901.]

Tuesday. Hasan Hasib-en-nebi. Pots in ghadim of irregular hole, alabaster beads, and turtle bones. (i) thrown ware, smoothed, painted red (i), ditto (ii). Glazed stone (iii). Carnelian (iv). [ed.: According to Hearst Museum records, 6-12503 (beads) is from this burial.]

$\mathrm{N} 2522=\mathrm{N} 2446(\mathrm{TC})$

$\mathrm{N} 2531$ of Green's = N 2477 (TC)

N 2542 Map N/A [ed.: This record is Reisner's note of preliminary work that was done in 1901.]

Abu'l Hasa[n] [ed.: Osman]. 2 burials. Head to north. Near head of east burial, bronze mirror (i). Also staff, red pot[tery] bowl, and rough brown ware.

N 2610 (тC; MM) Map D3

Coptic burial. Shallow grave running east-west. Adult female. (139.5 m high. Preserved with salty substance. Prognathous. Flat nose. All soft parts preserved. Eyebrows, etc. in position.) S. The body was clothed in a plain linen shirt. Outside this, there was a quantity of salt. The first wrapping shawl was of fine cloth, square with 2 sides fringed, 2 sides corded, covered with narrow inwoven lines of color, not wool. The second was of sackcloth and bound with cords. 


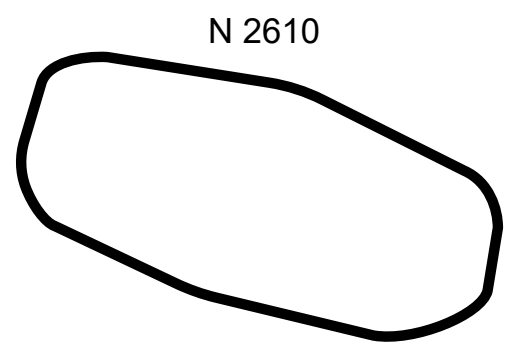

N 2611

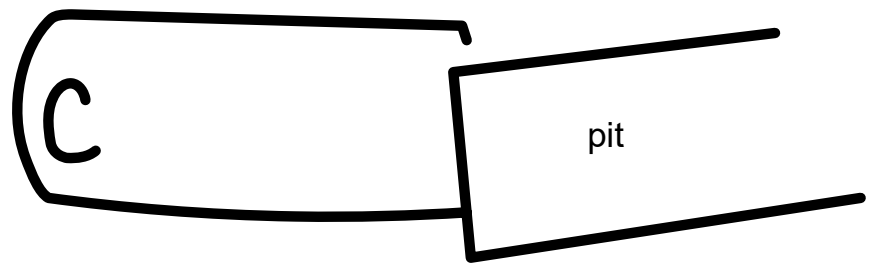

(i) $\begin{array}{ll}0 & 0 \\ 0 & 0\end{array}$

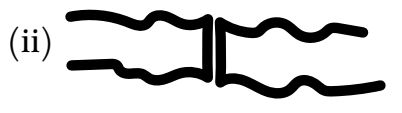

(iii)

(iv)
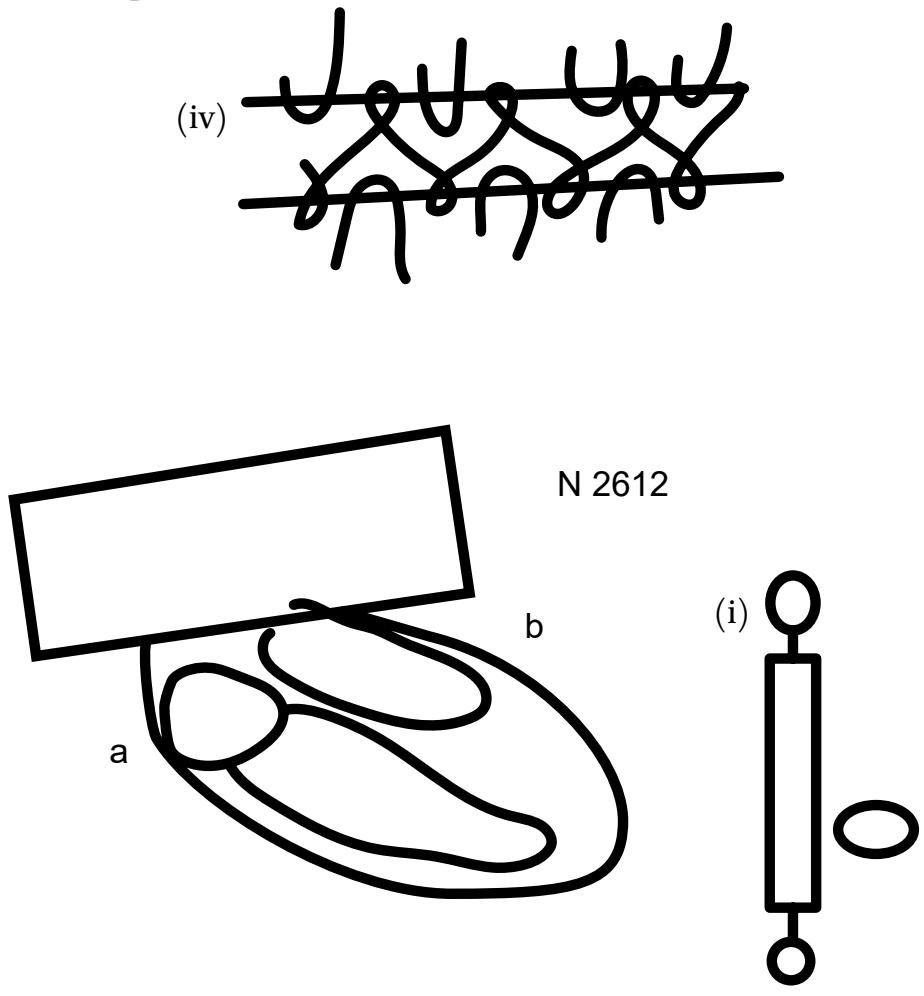


\section{N 2611 (тс; мм) Map D3 (red); photo C 8476}

Shallow grave running east-west. Coptic child aged approx. 8. On back, head west. Round neck, string of colored glass beads, dark blue, green, yellow, and resin colored. These were strung on cloth irregularly with a few plain shells being mixed with them. By left ear, bronze disc with 4 holes (i) apparently not strung with beads. On right arm, iron bracelet. On left arm above elbow, 2 bone bracelets. On left wrist, a bronze bracelet (ii). On left hand, bronze ring (iii). Over the body, there was a single shirt decorated with tapestry-woven designs in colored wool. At the bottom, there was an applied band of blue. This shirt was made up of two pieces of cloth, a straight join coming at the waist. Over the head, there was a pad of extra cloth consisting of a shawl of very fine mesh, $38 \mathrm{~cm}$ wide. On the left side of the body, not underneath, next to shirt, there were 3 palm sticks tied together. The first wrapping shawl was of fine cloth with occasional inwoven double lines of green thread. This entirely covered body? Went over head at any rate. Outside this, there was a shawl of sackcloth with fringed edges and bands of tapestry-woven designs of wools at either end. The binding cords were of type 4 (iv). Tied first with horizontal bindings of 2-strand cord. Then with 2 vertical bindings of 2 cords each fastened together in middle and round back.

\section{N 2612 (тC; MM) Map D3}

Coptic burials. Shallow grave running east-west, west end projecting over early pit. Contained 2 burials. a. Adult. Sex? On back, head west. Quantity of dark, curly hair. The body was clothed in a single shirt decorated with tapestrywoven designs in colored wool. The arms were not in the sleeves. Over the face, there was a quantity of extra padding. First came a square of cloth with colored wool decoration (i). Above this, there was an old decorated shirt with patterns in colored wools rolled up inside a piece of coarse cloth. By feet, cap or ? with fringed edge. Under the body, there were 2 palm sticks. The number of wrapping shawls could not be ascertained. b. Adult Sex? On back. Upper part of body had broken away and fallen into the early pit. There were 2 shirts on the body. Of the under one, remains of the bottom of the shirt reaching to knees. Round bottom, blue band similar to that on other shirt, but with a different pattern. Remains of elaborate wool ornamentation inside. The upper one was worn inside out. Width at bottom was about go. Round bottom, an extra applied band of blue cloth with yellow patterning was sewn 4.2 wide. On each side of front and back of shirt, there was a medallion of colored wools 11 from bottom, 16 from sides. Edges of shirt were cord-bordered. On medallion, 2 dancing figures and cherubs above. All upper part of shirt was gone with exception of end of one sleeve with sewn edges. This had a narrow band 


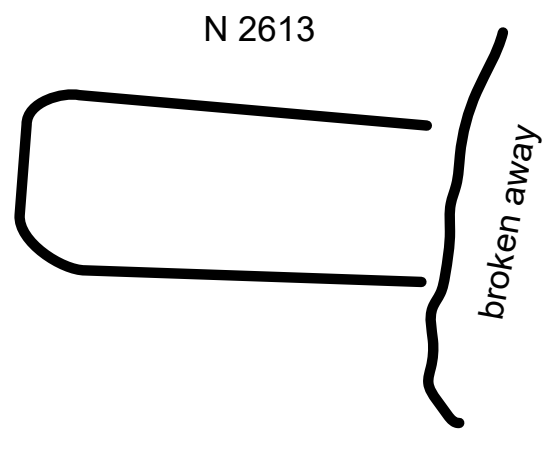

(i)

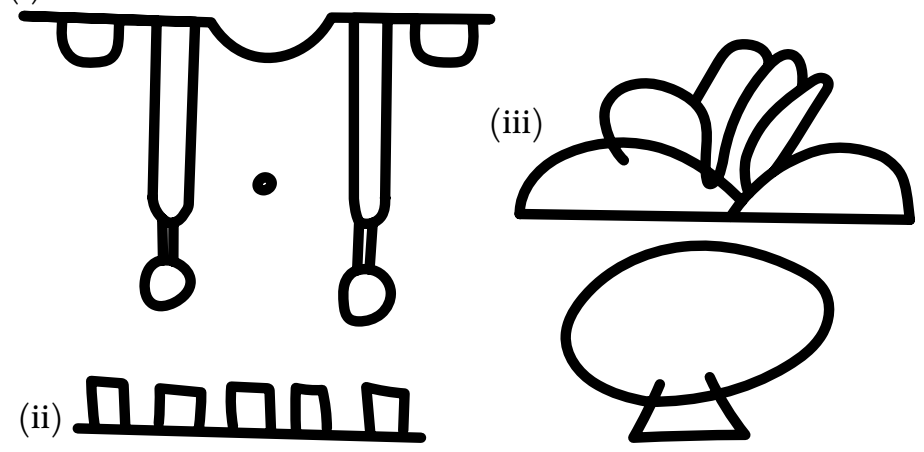

N 2615

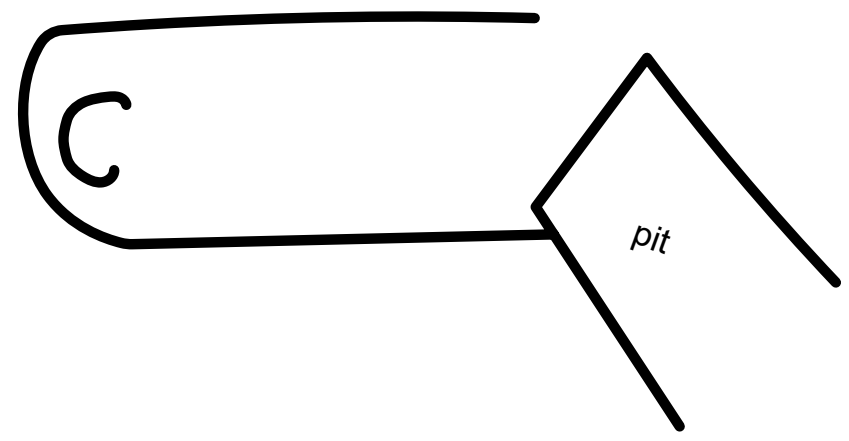


of colored cloth near bottom and a wider band higher up. This shirt reached to halfway down tibia. Beneath the body, between inner wrapping and shirt, there were 2 sticks of sesban. Outside the shirts, a cord was tied round the body at the level of the knees and knotted in front, possibly to keep the shirts from rucking up during the wrapping. The inner wrapping consisted of an old shirt of finer material with a medallion of red cloth by feet with interior medallion of colored wools. Above, there was a shawl of rough cloth, wrapped once round, ends overlapping, and tied round with cords.

\section{N 2613 (тс; Mм) Map D3; photo C 7o6o}

Coptic burial. Shallow grave running east-west. Head west. Adult. Sex? [ed.: Tomb card reads "female."] There was 1 shirt on the body of usual pattern made from a single piece of cloth. Apparently, cut from a shawl with fringed edge, as on both sides, edges were fringed and corded as well. Round neck, there was a narrow band of applied cloth, dark blue or mauve with patterning in yellow. Similar band round skirt. Over shoulders, usual pattern of embroidery (i). Floral designs in red, yellow, green, and blue between borders of (ii). Round sleeves, double bands of similar work. Remains of outer shawl with (iii) designs at intervals in red, yellow, and shades of blue, and green, and pink wools. Occasionally, several strands of the woof were not cut away, but were left at the back. The body was wrapped in 2 or more shawls, the outer one of fine cloth, being decorated with tapestry-woven floral designs in colored wools.

N 2614 (TC) Map D4; photo C 7075

Copt. (Female. No head. Feet and hands exceptionally well preserved.) S. [ed.: No image.]

\section{N 2615 (тс; мм) Map D3}

Coptic burial. Shallow grave running east-west, east end projecting over early pit. Adult female. On back, head west. Remains of a single shirt, apparently plain. On the body, there was a quantity of salt and a few dried fruits [ed.: on TC: "a few plant seeds"], and under it, 4 palm sticks. There were 2 or possibly 3 wrapping shawls of sackcloth. Traces only of the 2-strand fiber binding cords remained and of an outer covering of fine yellow cloth. In the bottom of the grave, underneath the body, there were a number of dried palm leaves, 2 tied together at head. 
N 2616

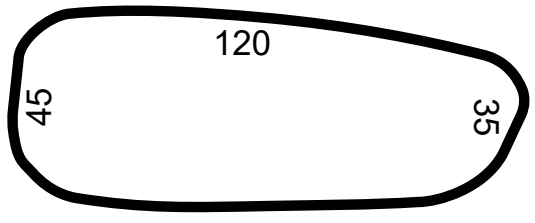

N 2630

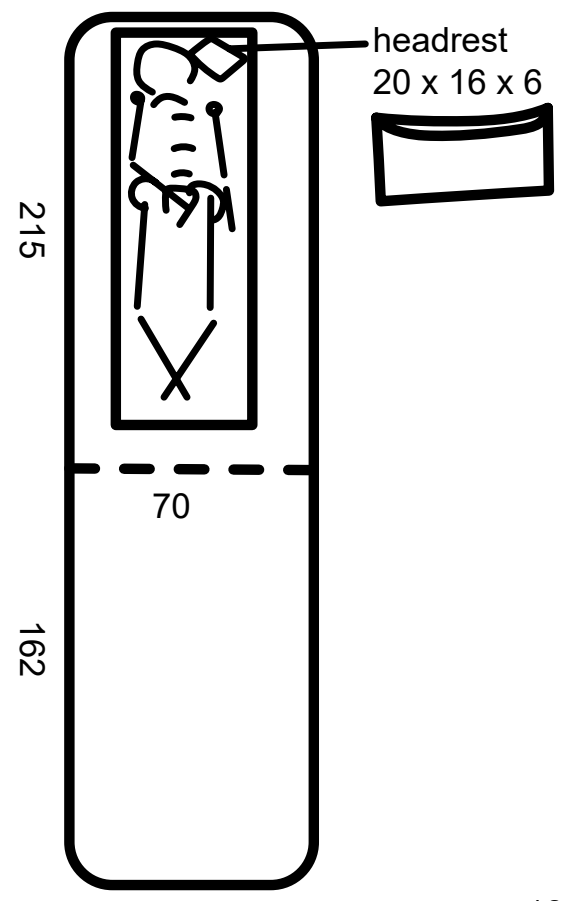

N 2617

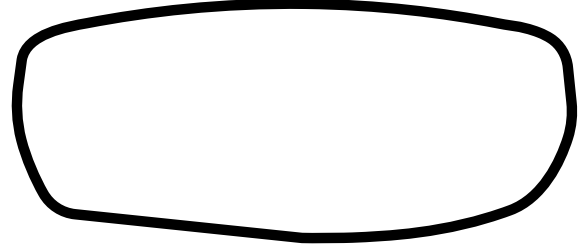

N 2619

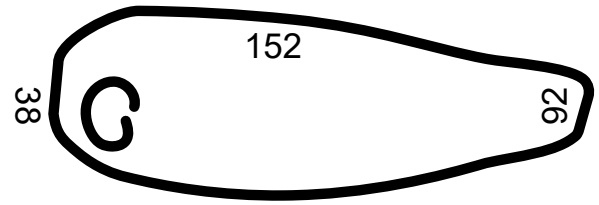

N 2618

(i)
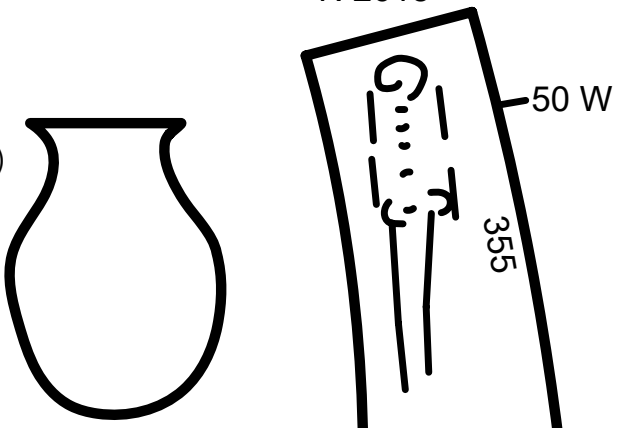

180 from

gebel level

approx. 70

from gebel level

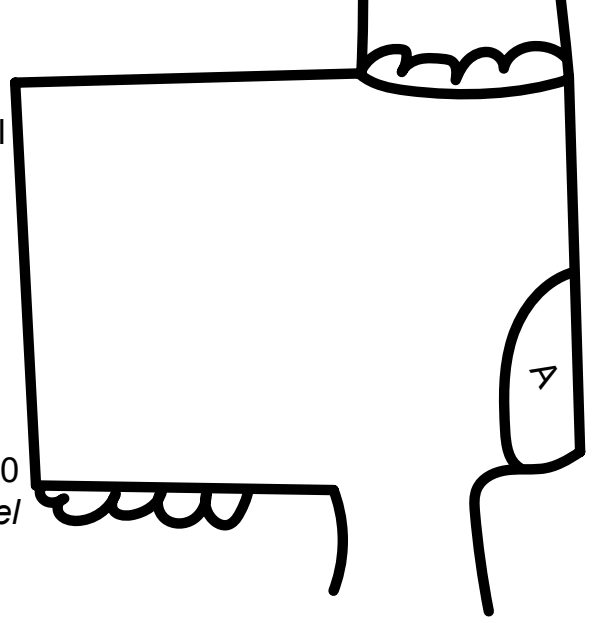




\section{N 2616 (тC; MM) Map D3; photo C 7071}

95 down. Copt. Shallow grave running east-west. (Girl aged approx. 5.) S. (Skull 12-4893 [ed.: According to Hearst Museum records, the skull belongs to a male.]) (Bronze bracelets on both wrists. Earrings [material?] still attached to ears. Lower opening of the intestine was patent, and the intestine had been stuffed with preservative material.) $\mathrm{S}$. The body was clothed in a single shirt. Edge turned over at neck. On the left ulder of it, a knot of cloth was sewn as a button. Down each breast and running over shoulder and an equal distance down back (?), a band of openwork wool ornamentation almost all gone. Sleeves with bands of openwork round wrist. There were 2 wrapping shawls, 1 of ordinary cloth with fringed edges and bands of colored wool at either end, the other of sackcloth.

\section{N 2617 (тс; MM) Map D3}

Coptic grave. Shallow grave running east-west. (Female aged approx. $18.1 .47 \mathrm{~m}$ high. Bronze bracelet on left arm at elbow.) S.

\section{N 2618 (тC) Map D5; photos C 8193, C 8520, C 8545, C 8594}

85 high. Chamber had been approx. 120 high. Roof almost all gone. In large chamber, small gold bird amulet (6-14547). Within space A, 12 pots all of one type (i). In front of chamber, another. On south side, built up with rough stones to 70 above gebel level, starting on gebel level. Chamber blocked with rough stones, faced with mud. On facing, rough scratchings, apparently only "fantasia." This blocking went in a distance of 180 . Adult. Male? Burial on back. Traces of wood from coffin. Bones in very bad condition.

\section{N 2619 (TC; MM) Map D4}

8 o deep. Copt. Shallow grave running east-west. Adult. Sex? Head west. Only 2 teeth preserved in upper jaw, more in lower. Remains of short, brown hair. Cloth in very bad condition. Had been wrapped first in sackcloth with cloth underneath. Under body, 2 or more palm sticks.

N 2630 (тс) Map N/A [ed.: Tomb not on map, and map location not listed in excavation records.]

125 below gebel. 80 high. Female. Chamber cutting through chamber of adjoining tomb. Coffin placed on top of earlier coffin. Bones somewhat fallen apart. Left leg fallen over right. 1 rib broken and joined anciently. Inside measurement of coffin $170 \times 3 \times 36$. Thickness of wood 3.5. Corners as usual. White paint outside and in. Red rim. Lid 5.5 thick. 2 battens under lid. 3 under coffin. Headrest $20 \times 16 \times 6$. 
N 2631
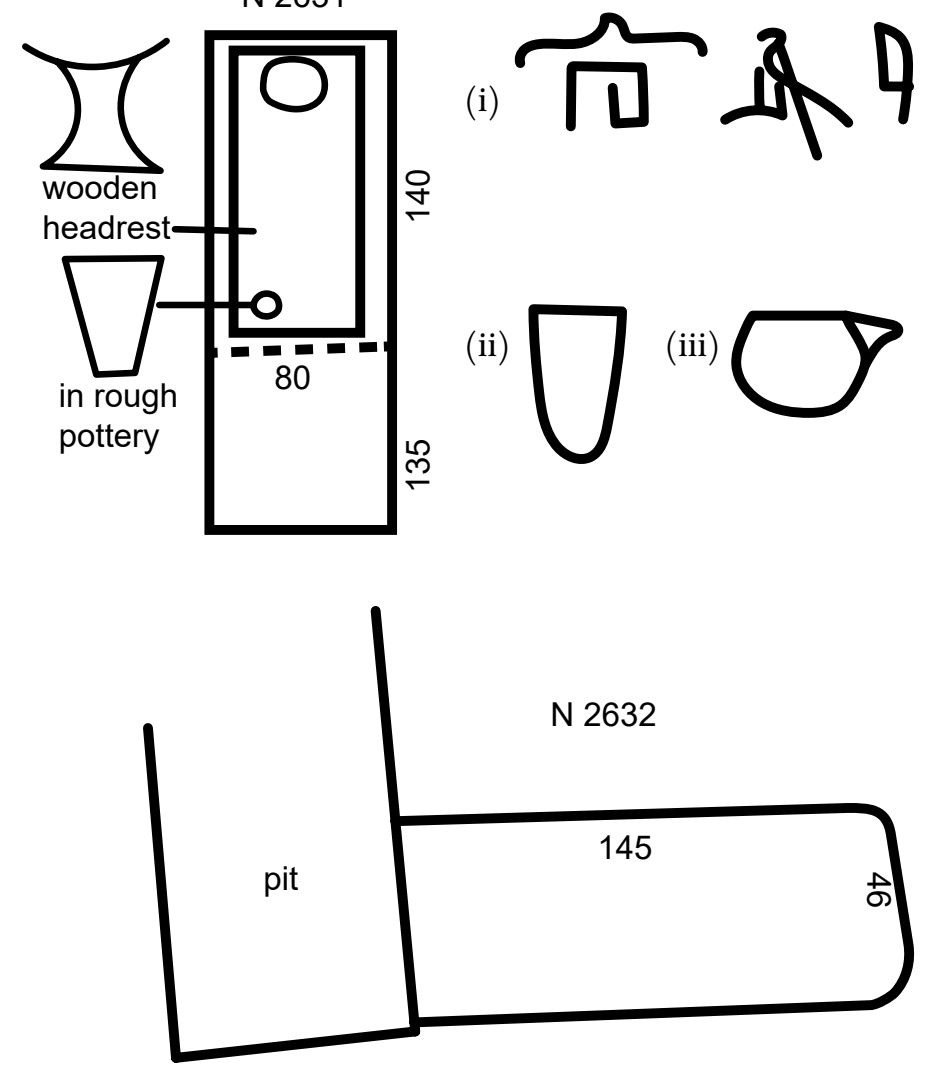

N 2633

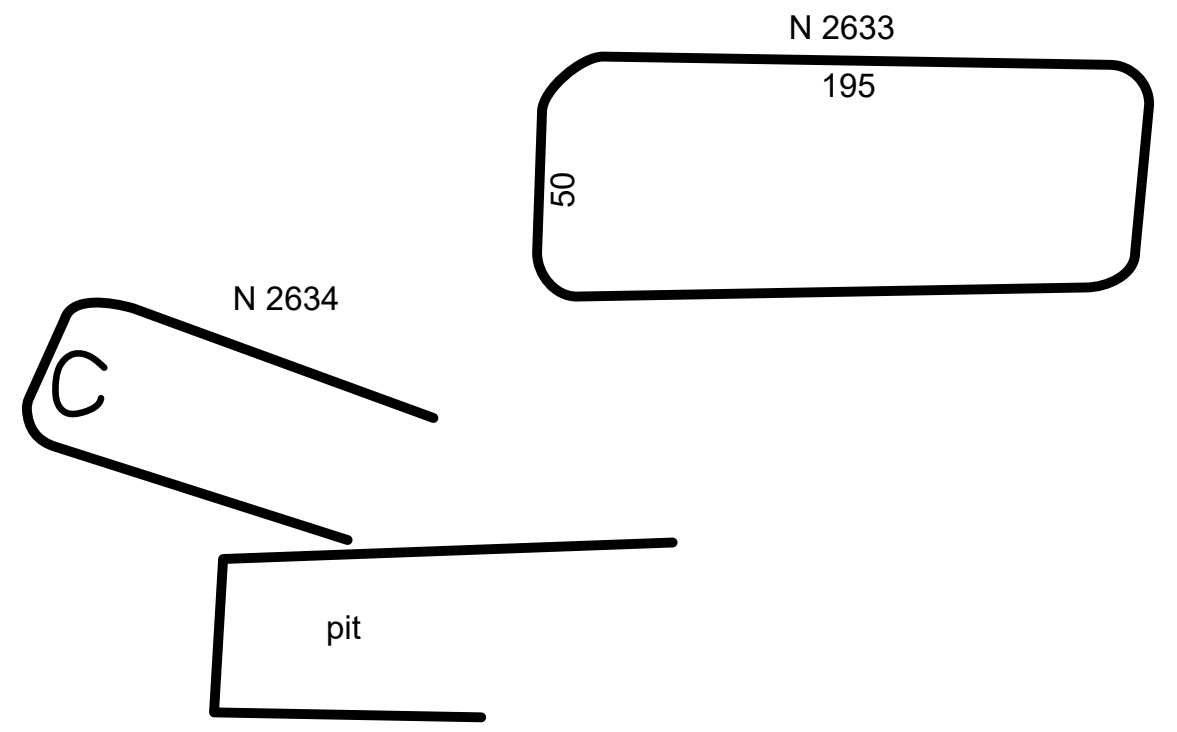




\section{N 2631 (тC; MM) Map E4; photo C 7156}

120 from gebel. 80 high. Reuse of an inscribed coffin. Corners as usual. White paint inside, yellow outside. Inscribed coffin of (i). $185 \times 54 \times 52.4$ thick. Lid broken, and Coptic burial placed inside, pieces of lid being afterwards placed carelessly on top. Original burial scattered in bottom of coffin. Adult. Sex? On back, head north. All back teeth in lower jaw gone. (Skull 12-4894 [ed.: According to Hearst Museum records, the skull belongs to a male.]) Details of the clothing could not be determined. Remains of a wrapping shawl of sackcloth pad over the face. This latter consisted of a linen cloth about $210 \times 150 \mathrm{~cm}$. At each corner of this cloth, there was a pattern of 5 large rosettes and 4 small ones in colored wools (green, red, blue, and yellow). Thread was first drawn in desired pattern, and then wool was worked in? Over feet, extra pad of odd pieces of cloth. Copt had been bound in sackcloth and tied round with many cross cords, but cloth had mostly decayed. Cord occasionally threaded through outer cloth. Under the body, there were 4 sticks of gotn? [ed.: i.e., cotton?]. In pit, 3 (ii) and 1 (iii). [ed.: According to Hearst Museum records, 6-12506 (headrest) is from this burial.]

\section{N 2632 (тC; Mм) Map D3}

8 o down. Copt. (Male.) S. Shallow grave running east-west. Adult male. On back, head west. The shirt had almost entirely disappeared. A finer cloth, over feet at any rate, apparently not a shirt. On the body, there was a quantity of salt, and underneath it, there were 4 palm sticks, originally tied together, 2 on each side, apparently inside sackcloth, but outside inner wrapping or shirt. The first wrapping shawl, or it may have been the second, was of sackcloth. Outside this, there was a second shawl of finer cloth with a tasseled edge and bands of woolwork at either end.

\section{N 2633 (тC; мм) Map D3}

About 8 o down. Copt. Adult male. ( $161 \mathrm{~cm}$ high.) S. Shallow grave running eastwest. Adult male. On back, head west. Remains of a plain shirt. On the body, a quantity of salt and 2 palm sticks underneath it, outside shirt and inside sackcloth. The innermost wrapping shawl was of fine cloth with corded end and a pattern of 6 stars of purple wool, apparently needleworked, at each corner. Outside this, there was a shawl of sackcloth.

\section{N 2634 (тс; M M) Map D4}

Copt. Shallow grave running east-west. (Female.) S. On back, head west. Remains of soft, dark brown hair. Remains of a shirt that was apparently unornamented. This was probably made in 1 piece. At each side, there were 2 corded edges sewn together in such a way that 1 cord was outside and the other in. 

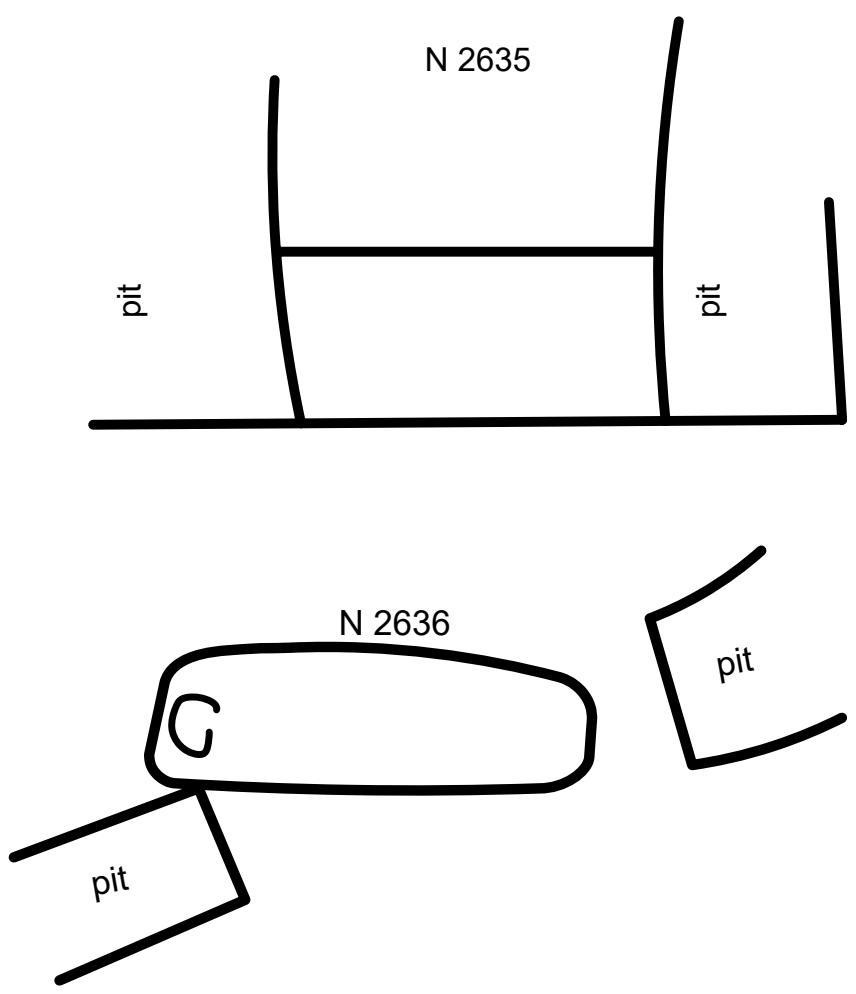

(i)

yellow with 2 black lines middle

yellow with 2 black lines in

middle

red

yellow with 4 black lines, 2 at either end

yellow with 4 black lines, 2

at either end

red

yellow with 2 black lines

yellow with 2 black lines

yellow with 2 black lines

yellow with 2 black linew

yreen

yellow with 2 black lines

yellow with 2 black lines

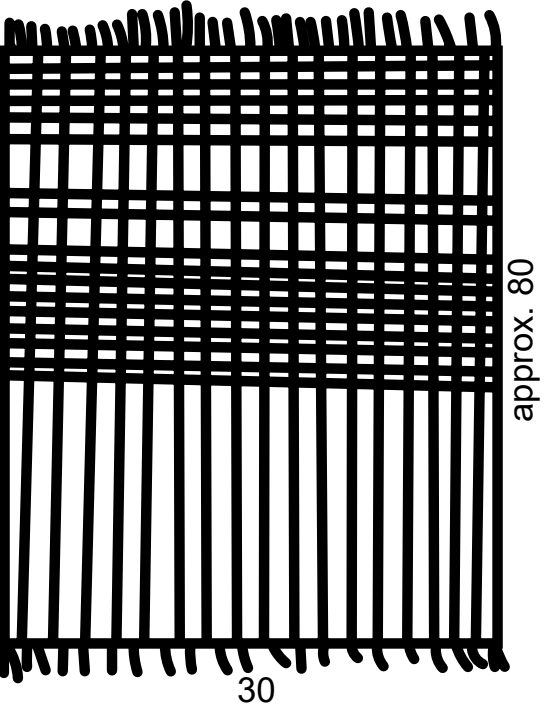


Sleeves and neck ? Over head, a mass of cloth rolled up. A quantity of salt on the body and underneath it, 2 palm sticks bound together on 1 side and 2 ? on the other. There were apparently 2 wrapping shawls of coarse cloth.

N 2635 (TC; MM) Map D3 [ed.: In tear on map, per pencil on map and excavation records.]; photo $\mathrm{B} 7 \mathrm{O} 27$

Coptic burial. Shallow grave running east-west. Adult. (Male.) S. On back, head west. Remains of a shirt with corded edges. 1 sleeve remained with a pattern of black woolwork round wrist. 1 wrapping shawl of sackcloth.

\section{N 2636 (тс; м м) Map D3; photos C 7028, C 8456, C 8457}

Copt. Shallow grave running east-west. Female aged approx. 25. On back, head west, arms by side. Quantity of long, straight, dark brown hair. Round neck, a string of glass beads of different colors and shapes together with a few of green stone and a small Dyn. 18 scarab [ed.: on TC: "a small scarab of glazed pottery with a figure of Re? (Dyn. 18-19)"]. On left arm, above elbow, an iron bracelet. By right hand, a small glass bottle (MFA 47.1686). Folded into a bandage and tied tightly round the waist, next to the skin, there was a plaid shawl (i) of dark brown, yellow, red, and green, about $80 \times 70 \mathrm{~cm}$ in size, with triple selvage, all in red. Narrow, vertical lines of black were all double, all in the warp. 1/3 from either end, a line of alternate red and yellow stitched to prevent unraveling. All the colors except the vertical black lines were in the woof. Ends left with fringe. The body was clothed in a single shirt (ii) made up of 2 pieces of cloth with a straight join at the waist. All upper part cut from 1 piece. Neck turned over and sewn. Sides and ends of sleeves corded. Bottom plain. The tapestrywoven decoration was of finer work than usual, the motifs of the designs being animal and human figures. Lines in black, background red (iii). Animals and figures in blue, green, and yellow wool. ? all inwoven. Or woof cut out, and wool sewn in. Rosettes on skirt (iv). Border of blue with plant decoration in yellow thread and green and red wool. Interior background red with yellow thread and blue and green wool decoration. Center circle blue with yellow thread decoration. Yellow thread was woof of original cloth. Other colors were worked in. Background in red thread (v). Patterns in green, blue, and yellow wool. All apparently worked on to warp. Sleeve sewn for 25 from bottom at any rate. At bottom of skirt, a strip of blue cloth with yellow thread decoration was sewn on. This was blue warp and woof. Yellow thread was added. The left arm was not in the sleeve, which was thrown back over the head. Over the face and head, there was a net veil or head shawl of mixed yellow linen and red and green wool. Covering this, there was a shawl of coarse cloth rolled up into a pad. On the body, there was a quantity of salt and mixed with the salt, there were a few 

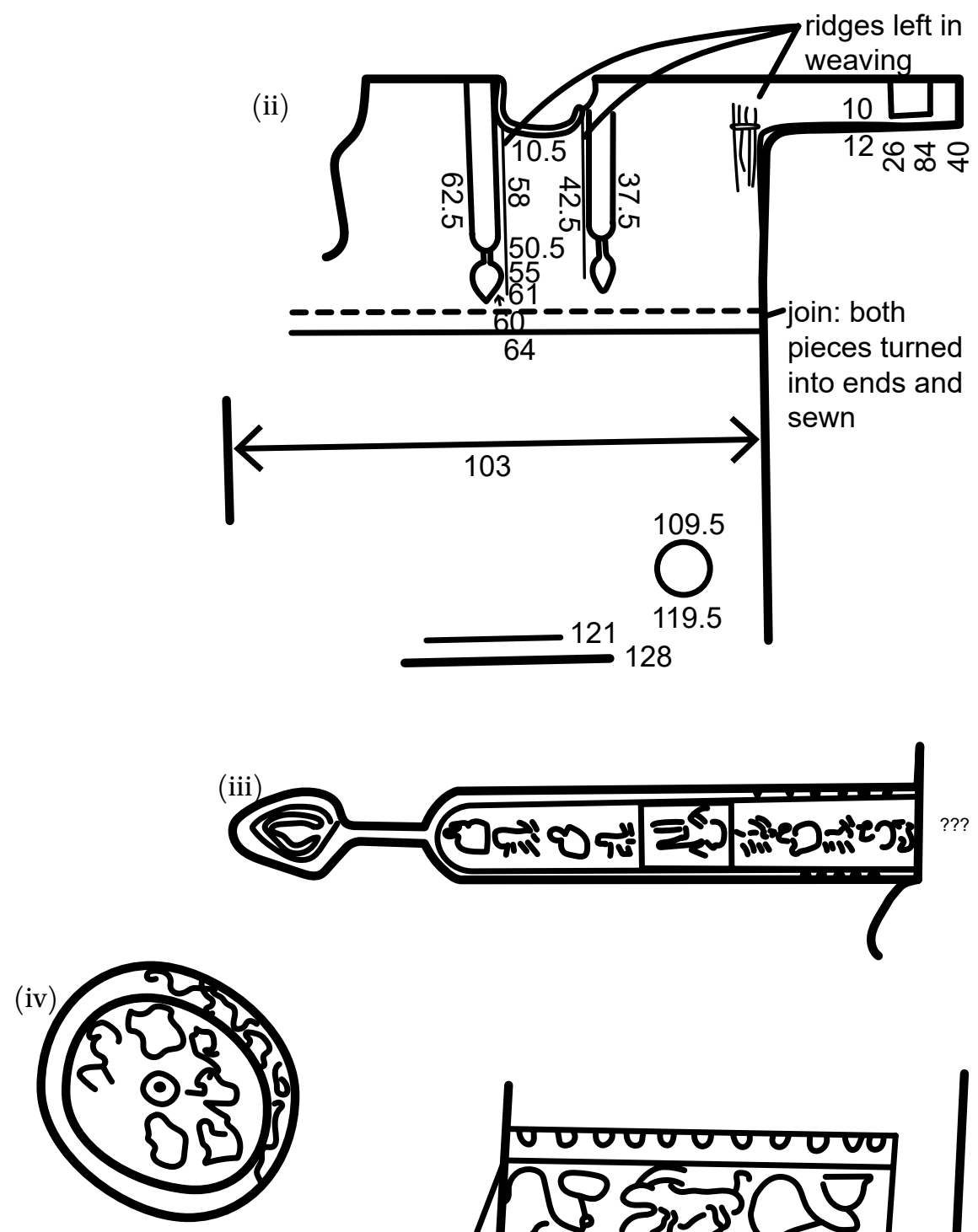

(v)

lines of original yellow cloth left and 2 [illegible] lines, half yellow, half green

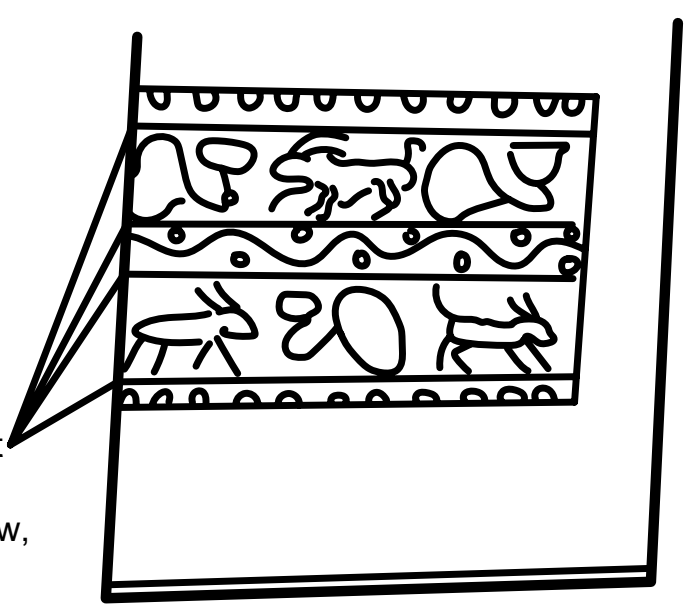


plant seeds and a date pit. Under the body, there were 2 sticks of palm and 1 of sesban. The first wrapping shawl was of yellow cloth with a narrow fringe and 6 lines of white thread insertion at head end, probably also at feet end. This was merely laid on top of the body. It completely covered body, excess at head being rolled up over face, 75 wide. Outside it, there was a shawl of very coarse cloth with fringed ends and bands of tapestry-woven woolwork at either end that was wrapped right round the body in the usual way, i.e., sides thrown over first and then ends. The type of cording could not be ascertained, but apparently tied with the usual horizontal and vertical cords. [ed.: According to Hearst Museum records, 6-12507 (headrest) is from this burial.]

N 2637 (тс; Mм) Map D4 [ed.: Map location given in excavation records and in drawing; in tear on map.]

Coptic burial. Shallow grave running east-west. Adult male. On back, head west. Back teeth all gone. The body was clothed in a single shirt with corded edges and a small amount of ornamentation near neck in green cloth (inwoven) with yellow thread decoration. Over the face, there was a pad consisting of an old shirt rolled up into a ball. This had originally been very elaborately decorated with a rosette (i) with tapestry-woven designs (human figure motifs) in a mixture of red $(\mathrm{R})$ and dark brown $(\mathrm{B})$ thread and green $(\mathrm{G})$ and yellow $(\mathrm{Y})$ wool. Hands of figure and parts of beasts were outlined in dark blue. Background always red. Red and dark brown were inwoven. Other colors worked in in wool. Round head, remains of 2-strand fiber cord. Quantity of salt and a few plant seeds on body. Under the body, there was 1 palm stick and 1 of shaum that were tied together at the ends and had notches cut in them to hold the cords. The first wrapping shawl was of coarse cloth, possibly a shirt. Outside this, there were 2 of sackcloth. These were all folded over the body in the usual way. The cord bindings had almost entirely disappeared.

\section{$\mathrm{N}_{2638}$ (тс; мм) Map $\mathrm{D}_{4}$}

Coptic burial. S. Shallow grave running east-west. On back, head west. Remains of a single shirt undecorated. There were 2 wrapping shawls, the inner being of coarse linen cloth with corded edge and the outer of sackcloth. Under the body, put between sackcloth and inner wrappings, 3 sticks (not palm). The method of binding was indistinguishable.

\section{N 2639 (тс; мм) Map D3; photo C 7033}

Coptic burial. Shallow grave running east-west. Adult. (Male. Long, brown, wavy hair. Abundant long, reddish, curly pubic hair. Short reddish beard.) S. On back, head west. Remains of 2 shirts with corded edges and elaborate 

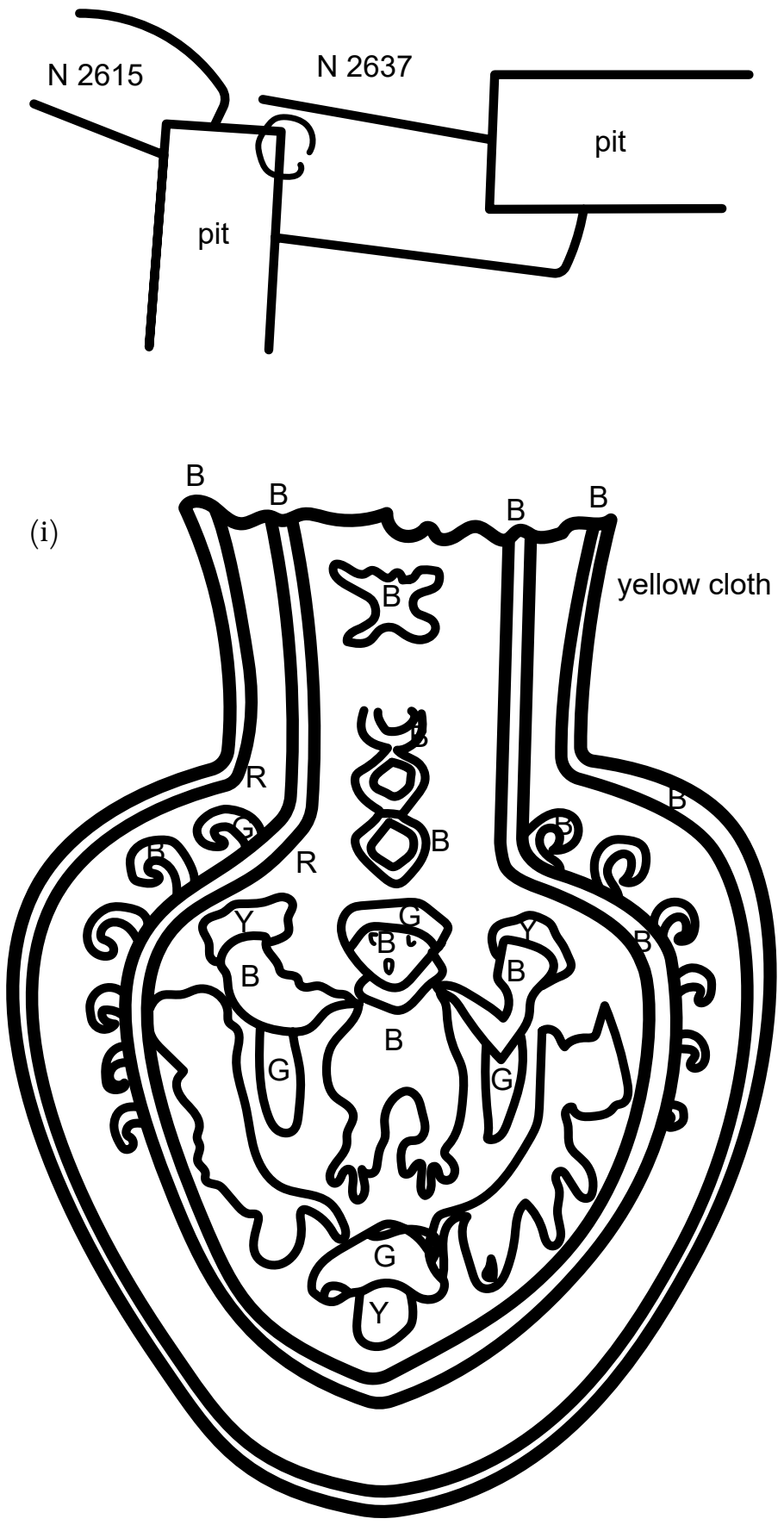

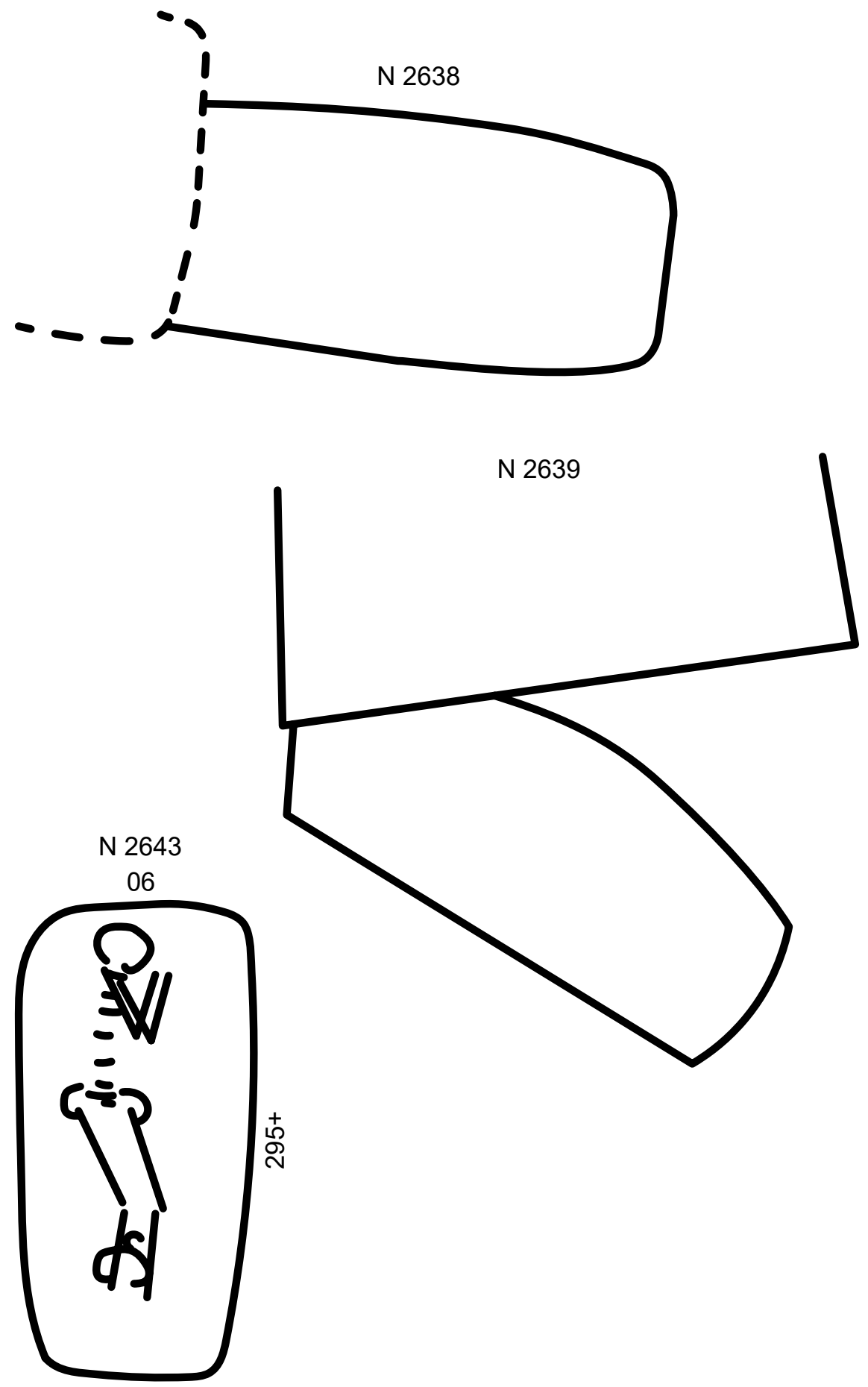


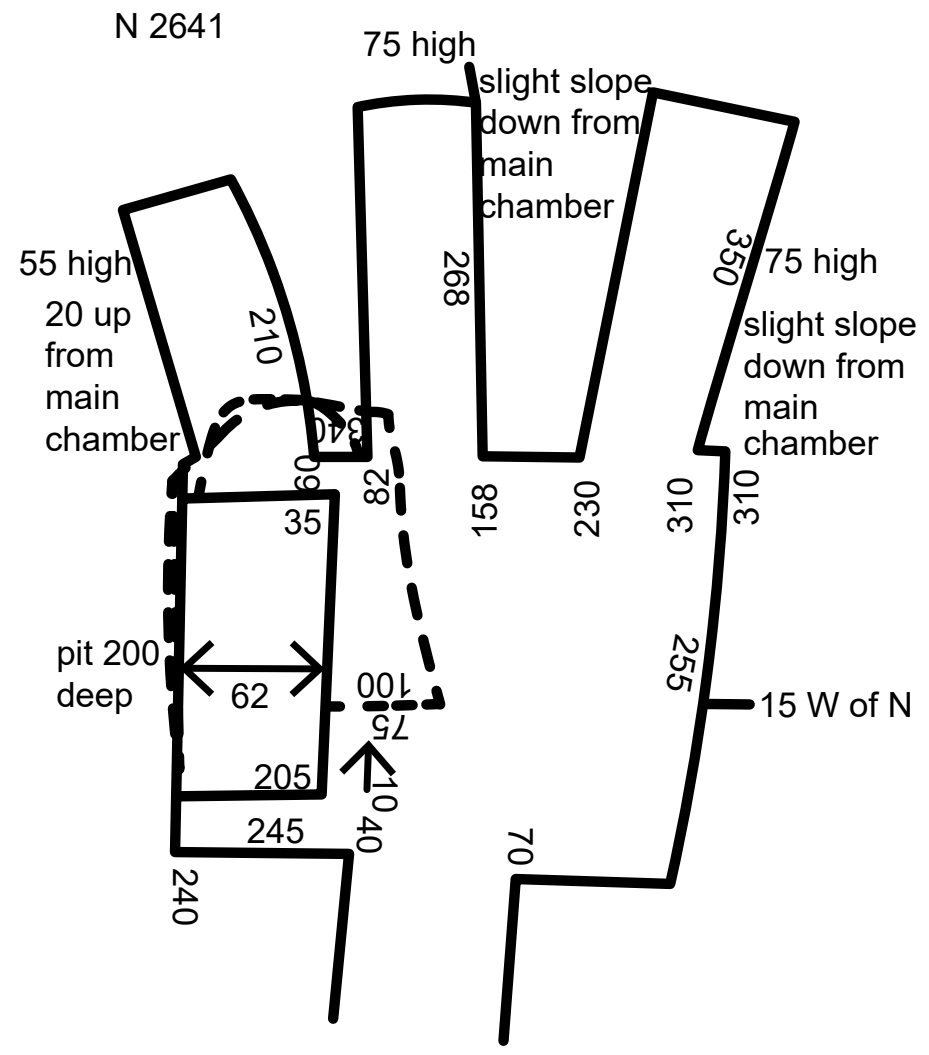

(i)

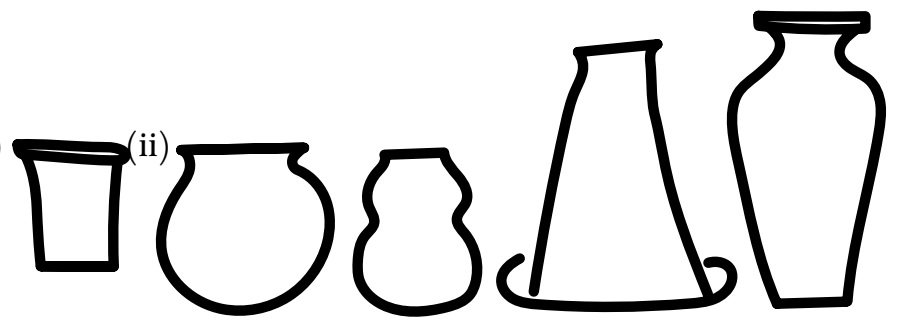

(iii)

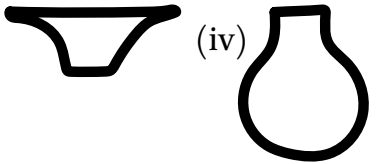

(v)
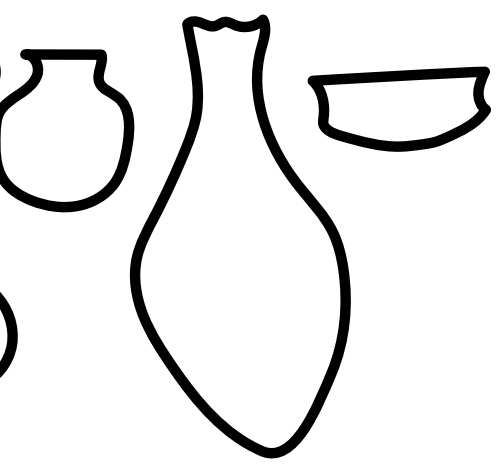
tapestry-woven decoration in colored wools. Only 1 wrapping shawl could be distinguished, a white one of fine linen with elaborate fringe. End extended considerably beyond feet and was turned back and wrapped round them. By feet, a twist of cord.

$\mathrm{N}_{2640}=\mathbf{N} 3747$ in notebook (TC) Map C3 [ed.: $\mathrm{N}_{3747}$ is in $\mathrm{D}_{3}$.]; photo C 8503 [ed.: No image.]

N 2641 (TC) Map C5 (red); photo B 8425

Pit 200 deep. Pit chamber exceedingly irregular. Had been filled with large desert boulders. In main chamber, a quantity of pottery: alabaster (i) (MFA 47.1652), different varieties of A (ii) (6-12508), M (iii). In smaller chamber, only a few broken bones. Outside doorway, several pots: drab (iv), (v).

$\mathrm{N}_{2643}$ (TC) Map B4 (red)

100 to gebel level. Skull and remains of another burial over feet. On left side.

$\mathrm{N}_{2644}$ (TC) Map B4 (red)

$6 \circ \mathrm{W}$ of N. 140 deep to gebel level. Contained nothing.

$\mathrm{N} 2645$ (TC) Map B4

Usual position. Head fallen into pit.

$\mathrm{N} 2646$ (тс) Map B4

Shallow hole. Contained nothing.

$\mathrm{N}_{2647}$ (тс) Map B4

Contained nothing.

$\mathrm{N} 2648$ (тс) Map B4

$47 \mathrm{E}$ of N. 85 deep from present level. Coptic. Burial gone.

N 2649, N 2840 (TC) Map B4

110 E. 240 deep. 8o high. Upper part of burial in position. Head south.

N 267o (тC) Map A3

Coptic. Contained nothing.

N 2671 (TC) Map B3

185 deep from present level. Originally pit and chamber. Contained nothing. 


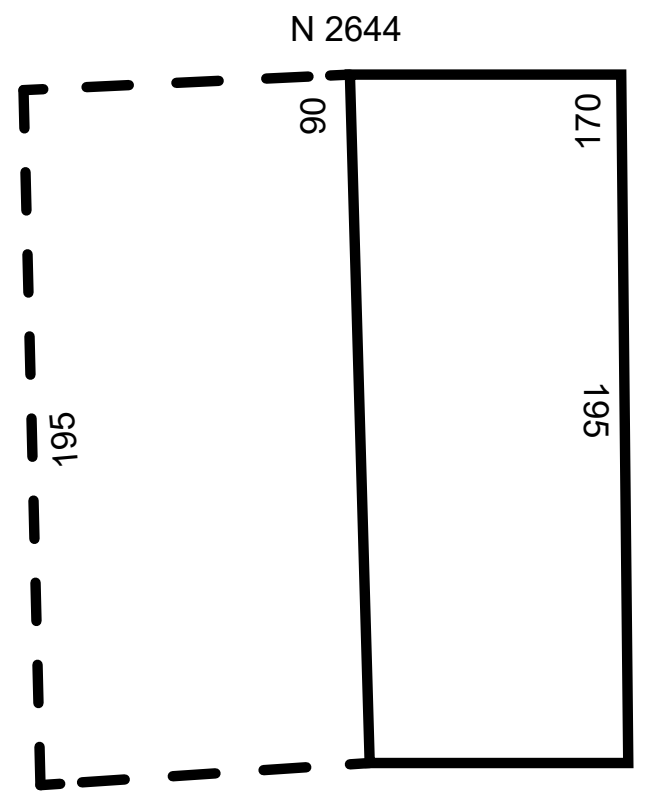

N 2645
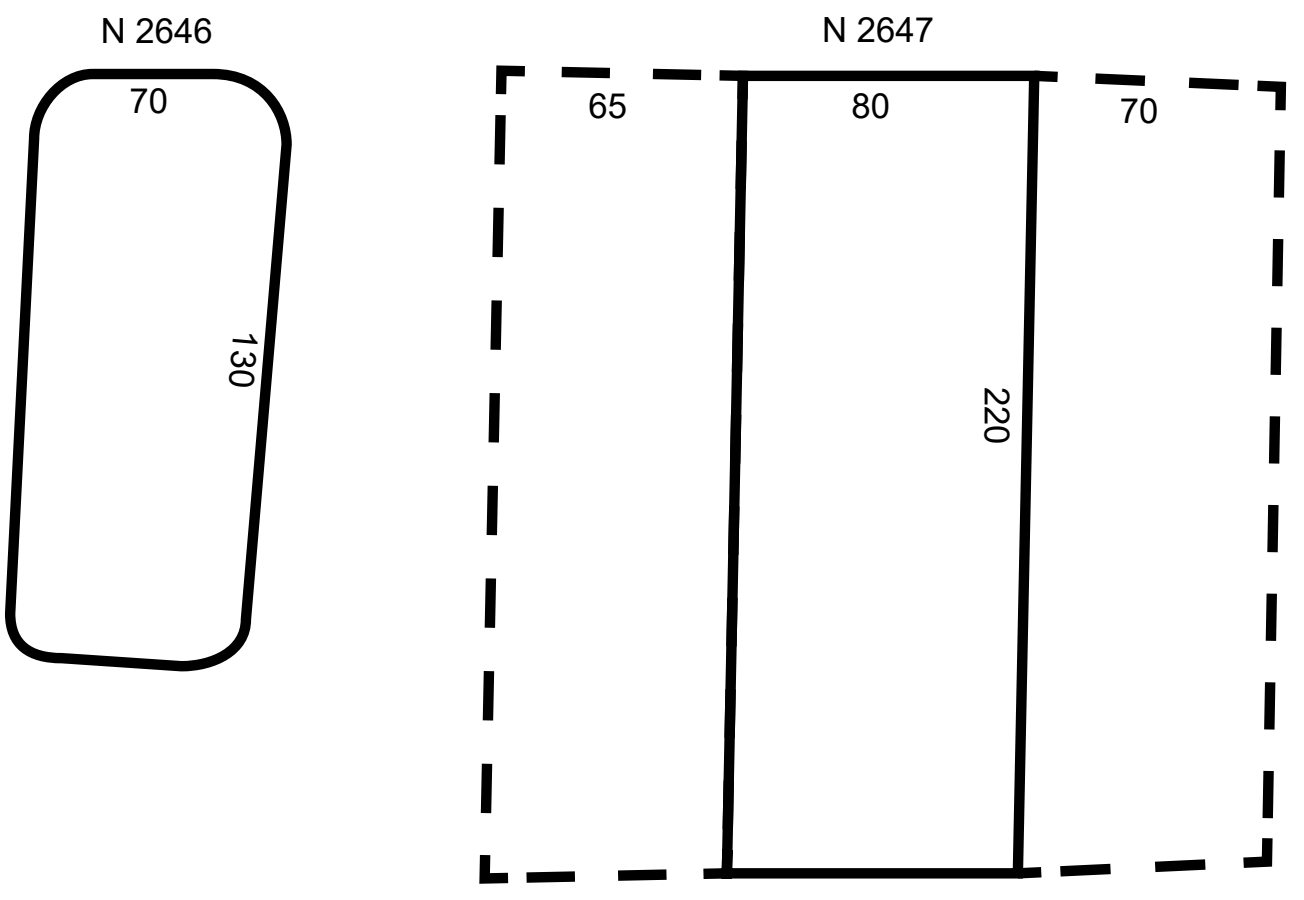

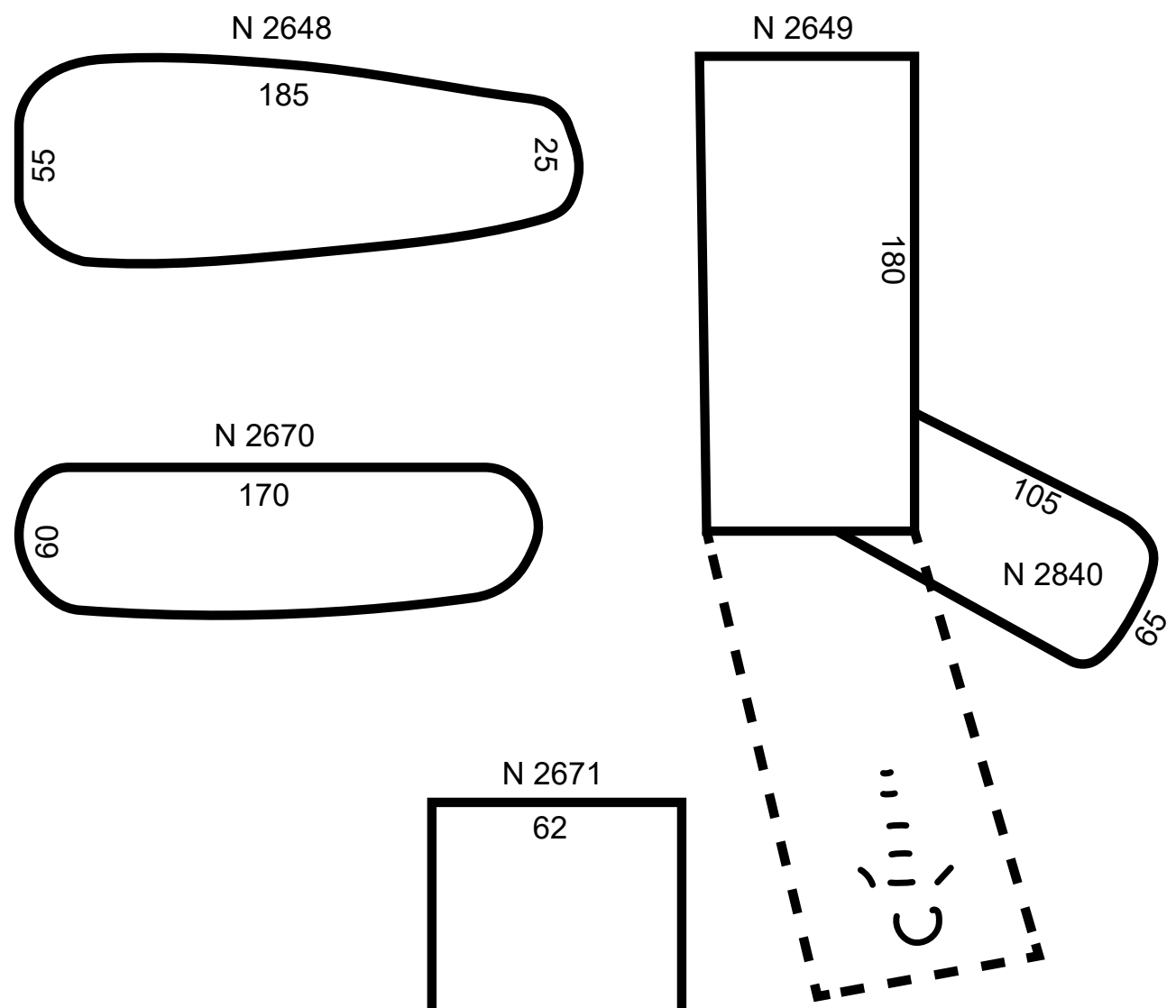

N 2672 


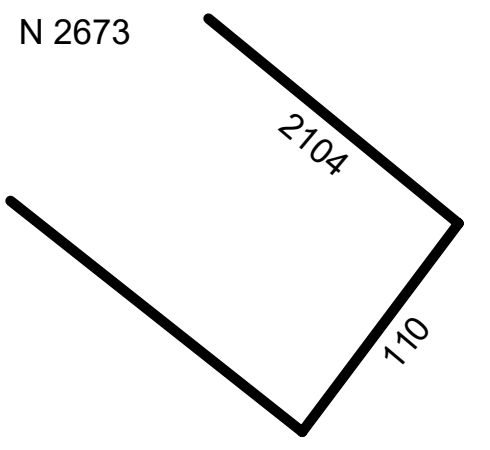

N 2678

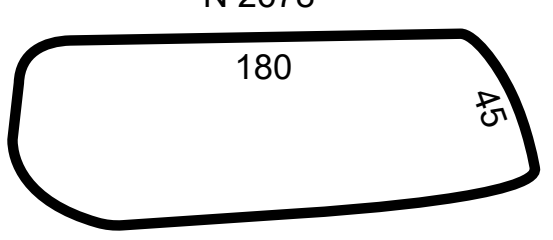

N 2674

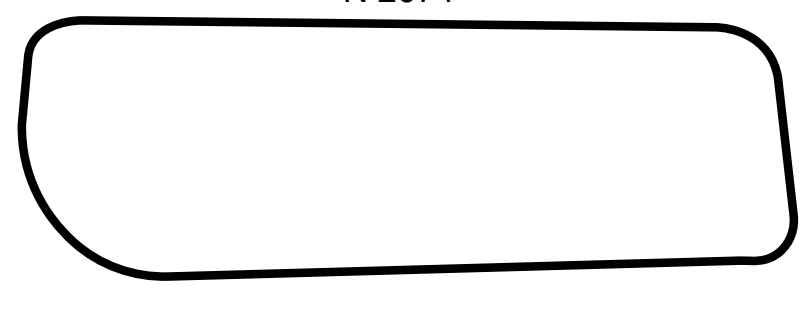

N 2675
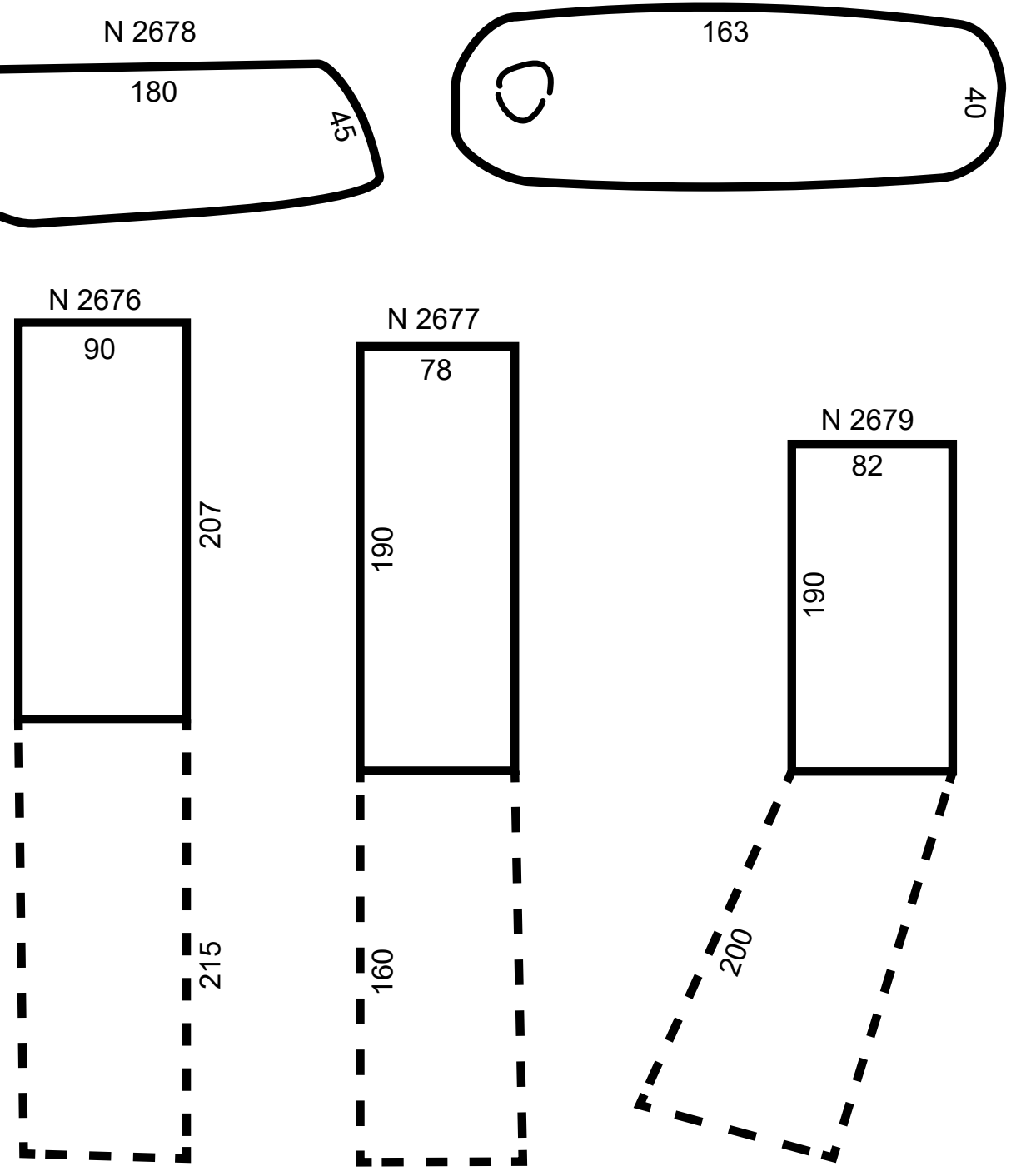
N 2672 (TC) Map B4

Copt?

$\mathrm{N}_{2673}$ (тC) Map B3

Pit?

$\mathrm{N}_{2674}$ (тC) Map B3

Copt? Contained nothing.

N 2675 (тс; мм ) Map A3

110 W. Copt. Shallow grave running east-west. Child. Sex? On back, head west.

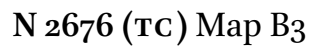

Phot. burial.

N 2677 (TC) Map B3

23 W. 340 deep. Contained nothing.

$\mathrm{N}_{2678}$ (тс) Map B3

120 W. Copt. Contained nothing. Above, remains of an Arab "kush."

N 2679 (TC) Map B3

$300+$ deep. Contained nothing.

N 269o (TC) Map N/A

Not a tomb. Numbered by mistake.

N 2691 (тс) Map C4

180 deep from present level. Roof almost all broken away. Contained nothing.

$\mathrm{N}_{2692}$ (тс) Map C3

Burial of a very young child in a large coffin. On right side. Position of left arm doubtful. Remains of cloth by legs. Coffin put into grave on slant, north end being considerably lower than south. Inside measurement of coffin $175.5 \times 32 \times$ 42. Thickness of wood 5. Corners as usual. At a height of 60 in middle from top of coffin, there seems to have been a kind of arched covering of mud. The top of this in middle was 6o deep from present level. Outside bottom would have come about 80 from coffin on each side. May have no connection with coffin. 


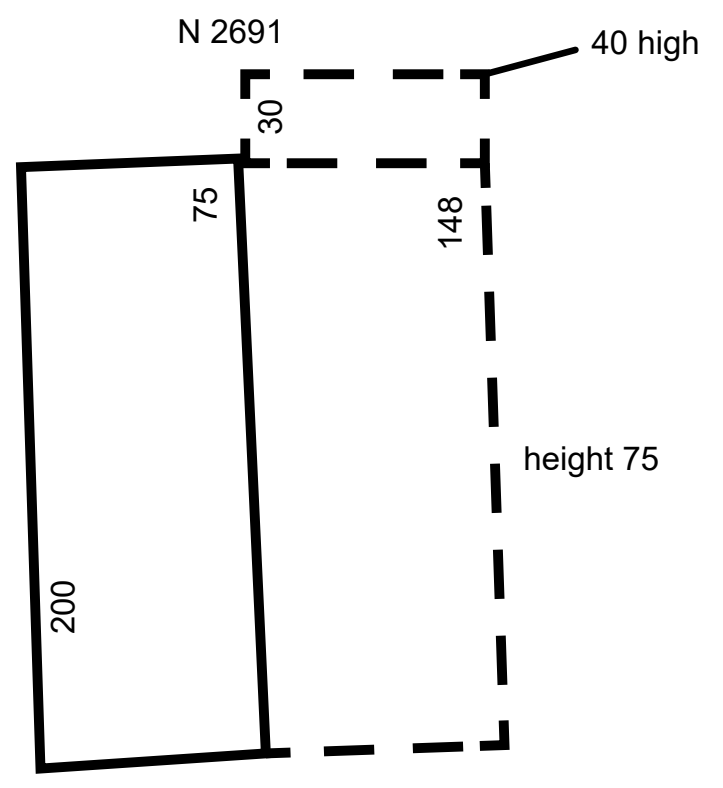

N 2692
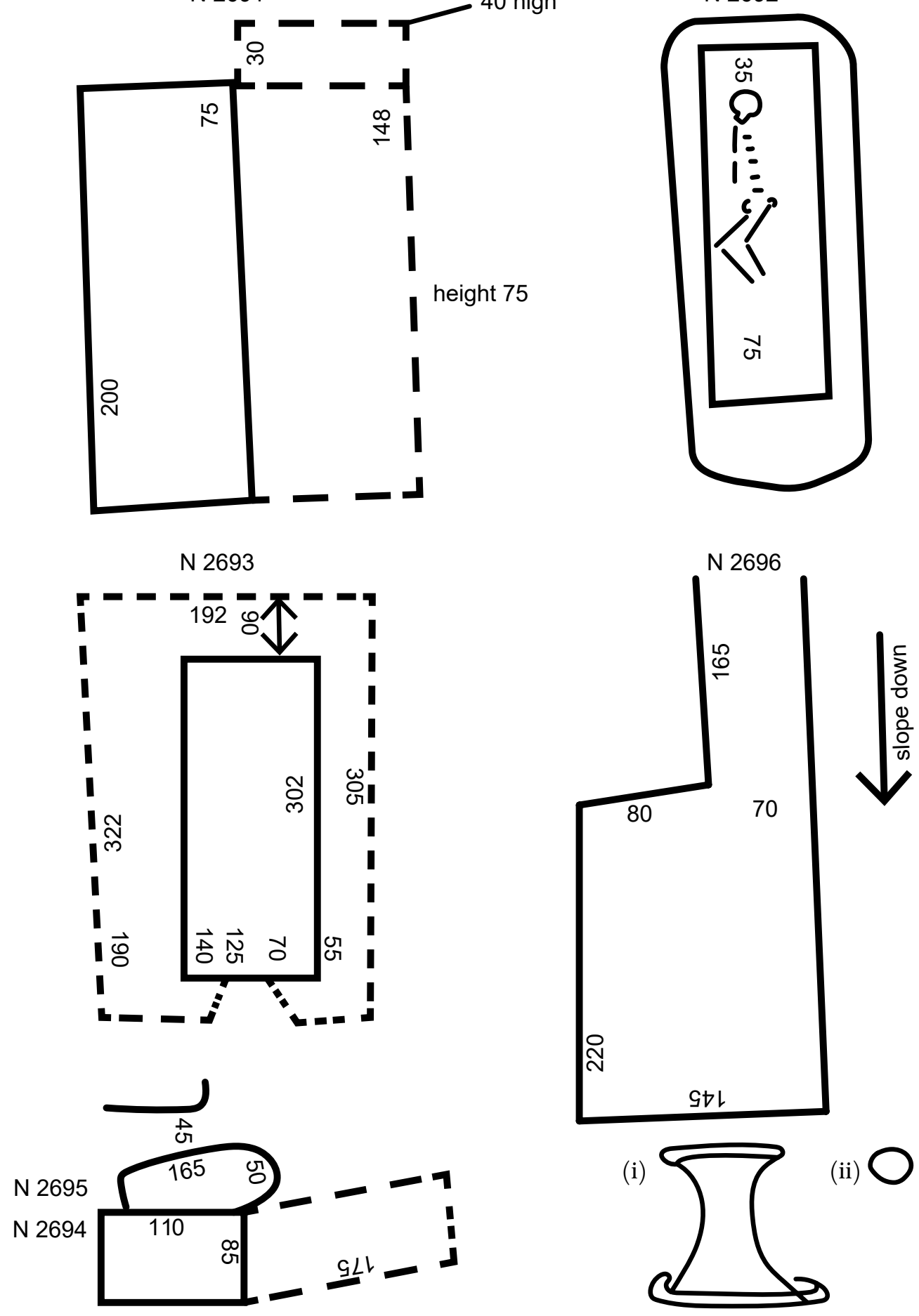
$\mathrm{N}_{2693}$ (TC) Map $\mathrm{C}_{4}$

295 deep. Height of chamber 75 ? Broken away. Contained nothing.

$\mathrm{N}_{2694}, \mathrm{~N}_{2695}$ (TC) Map C4, $\mathrm{C}_{3}$

$72 \mathrm{E}$ of N. Contained nothing. 2695 Coptic. No burial left.

$\mathrm{N}_{2696}$ (TC) Map C4

115 high. Approx. 230 to gebel level. Contained fragments of pottery M, and (i), and 1 carnelian (ii) bead.

$\mathrm{N} 2697$ (тс) Map B4

$60 \mathrm{~W}$ of N. 250 deep from present level. Contained nothing.

$\mathrm{N} 2698$ (TC) Map B4

Coptic. Burial gone.

N 2699 (TC) Map B4

60 deep. Remains of a wooden coffin. On east side, space between coffin and side of grave filled with thin stone slabs (not worked). Plundered out.

N 2700 (тс; Mм) Map D4 (red)

8 o down. Copt. Shallow grave running east-west. Adult female. On back, head west. Long, wavy hair. The body was clothed in a single shirt with tapestrywoven designs in colored wools. Round neck and sleeves, a band of blue sewn on, 4 wide, with yellow decoration (i). Round bottom of skirt, band of blue with yellow decoration, 14 wide (floral patterns). Down front and back, 2 panels. Border blue with green patterns. Main part red with figure designs in blue, green, and yellow. In one place, panel mended with red wool. Similar band round sleeves. Outside the shirt, round the waist, there was a cloth bandage folded to a width of $4.5 \mathrm{~cm}$. Under the body, inside wrappings, outside shirt, there were 4 palm sticks. The body was enveloped in no fewer than 6 wrapping shawls. The innermost one was of fine, wide-meshed black cloth. Next above that came a similar shawl of yellow cloth. Next, there were 3 shawls of ordinary coarse, white cloth, and on the outside of all came a fine, wide-meshed shawl of a reddish color. Reddish cloth had a border of 10 lines of white near ends. Black cloth had similar yellow lines and a strengthening cord of threads down sides. Yellow cloth had tasselled ends and similar lines. Black cloth was 54 wide. 1 of the 2 ordinary shawls had 3 lines of inwoven red near ends with a line of green in the middle of each. All these coverings completely covered the body. The method of binding could not be distinguished. 
N 2697

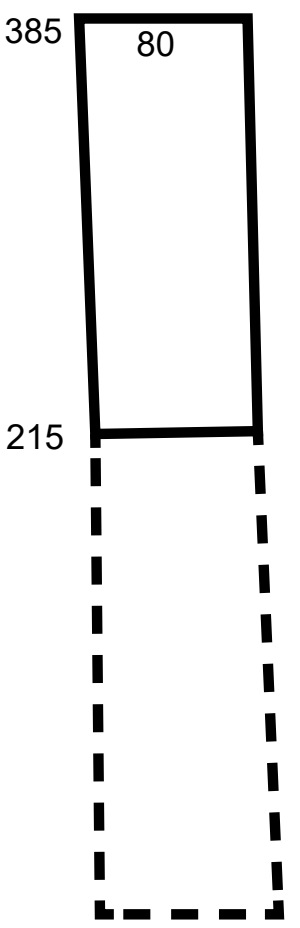

N 2700

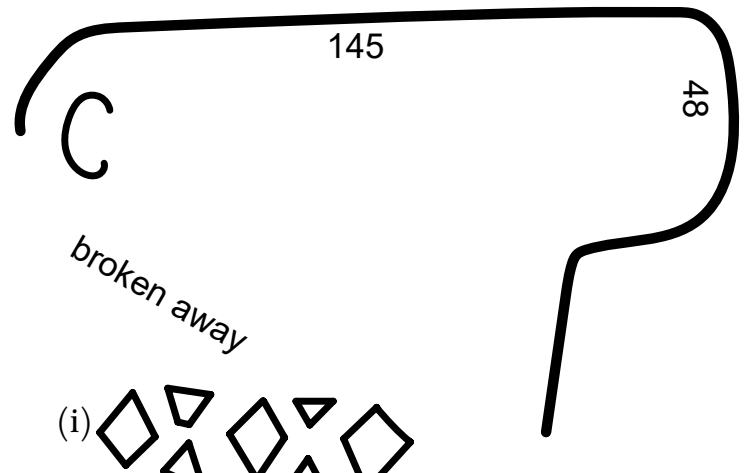

N 2699

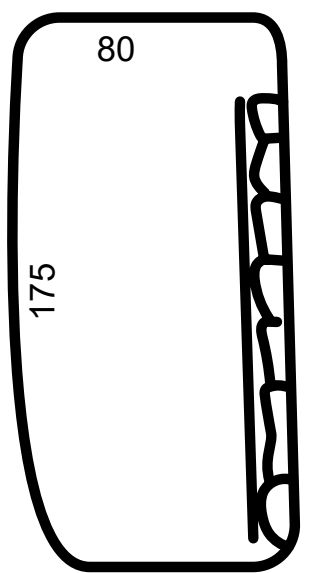

N 2701

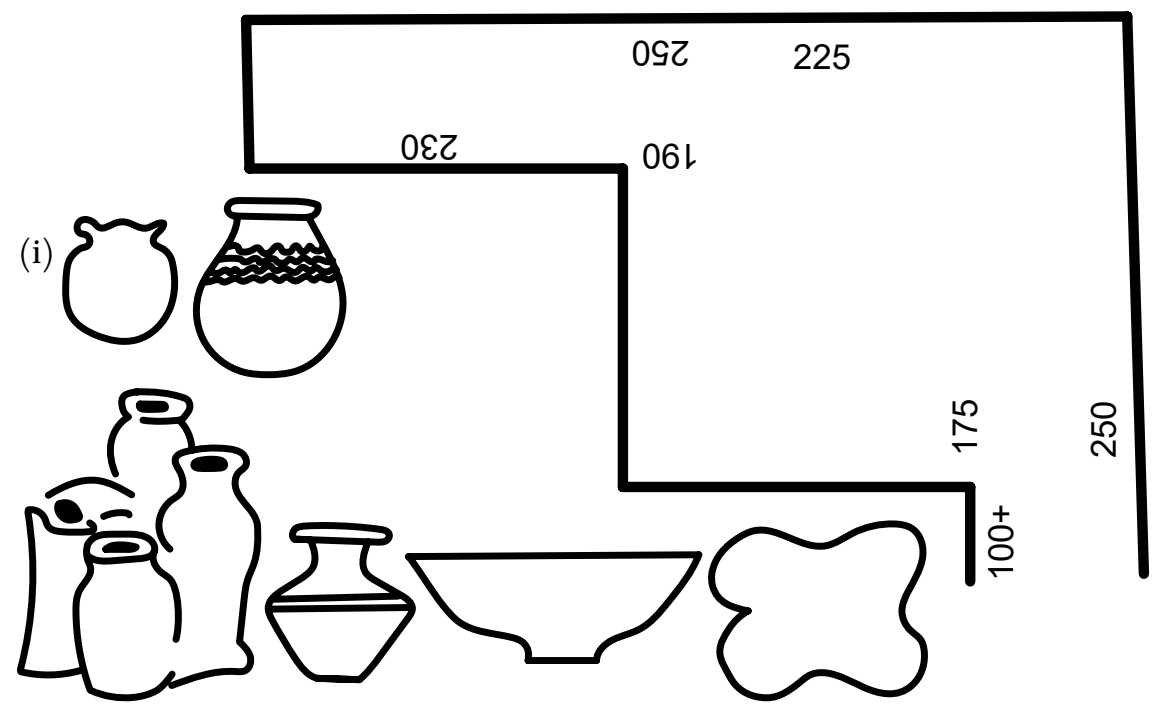




\section{N 2701 (Green) (TC) Map C4}

Height 9o. Depth from gebel 19o. Original height of chamber go. Contained several As (i) (6-12509, 6-12510), small saucer, piece of ring stand. [ed.: According to Hearst Museum records, 6-12511 (broken flint knife), 6-12513 (flint knife) are from this burial.]

$\mathrm{N} 2702$ (TC) Map C4

170 down from gebel. 50 of radim above. Contained nothing.

$\mathrm{N} 2703$ (Green) (TC) Map D 3

$105 \mathrm{~W}$ of N. 220 deep. No chamber. Contained nothing.

N 2704 (Green) (TC) Map D4

Apparently an early grave, as it contained fragments of an early coffin. No burial left.

$\mathrm{N}_{2705}$ (TC) Map D4 (red)

68 W of N. 8 o down from gebel. Contained nothing. Not Coptic.

N 2706 (TC) Map D4

Height 7o. Depth 255 from present level. Contained nothing.

N 2707 (TC) Map D5

55 W of N. 82 high. 125 down from gebel level. Contained only a few broken bones.

N 2708 (TC) Map D5

$33 \mathrm{~W}$ of N. Contained nothing. Sides broken away.

N 2709 (TC) Map D5

$21 \mathrm{~W}$ of N. 95 high. Roof fell in before measured, so measurements only approximate.

N 28oo, N 28o1 (TC (with 29o7-29o9) Map D4 (N 28oo; red), C4 (N 28o1)

Coptic graves. Burials gone. [ed.: No image.]

N 2802 (TC) Map D4

140 deep from present level. Contained nothing. 
N 2702

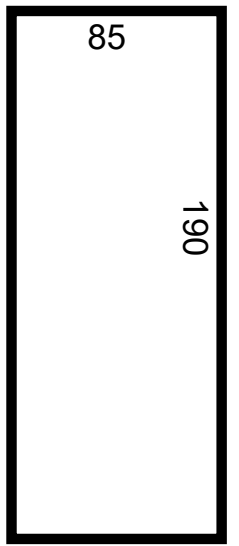

broken through to $\mathrm{N} 2702$

[ed.: error for N 2701?]

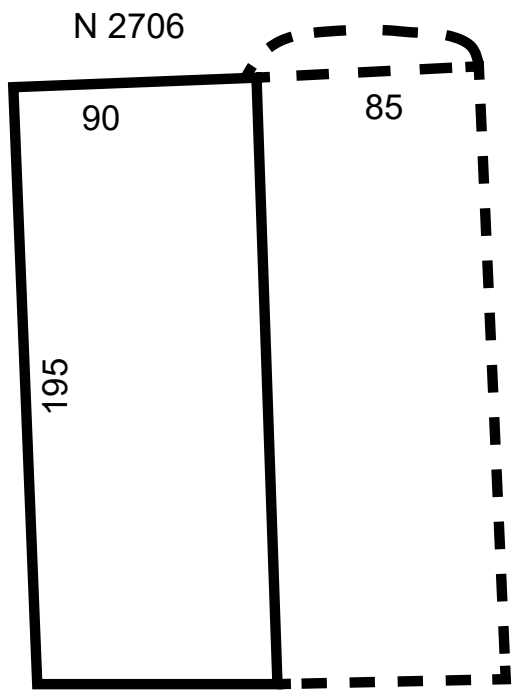

N 2703

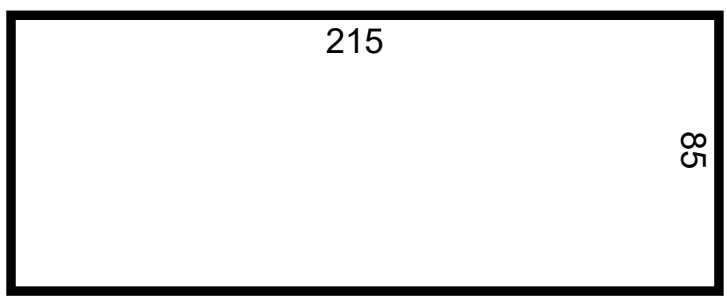

N 2704

185

N 2705

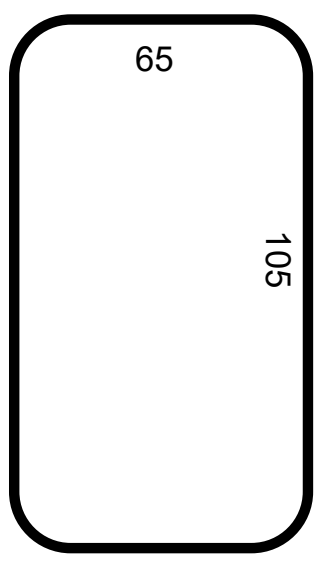



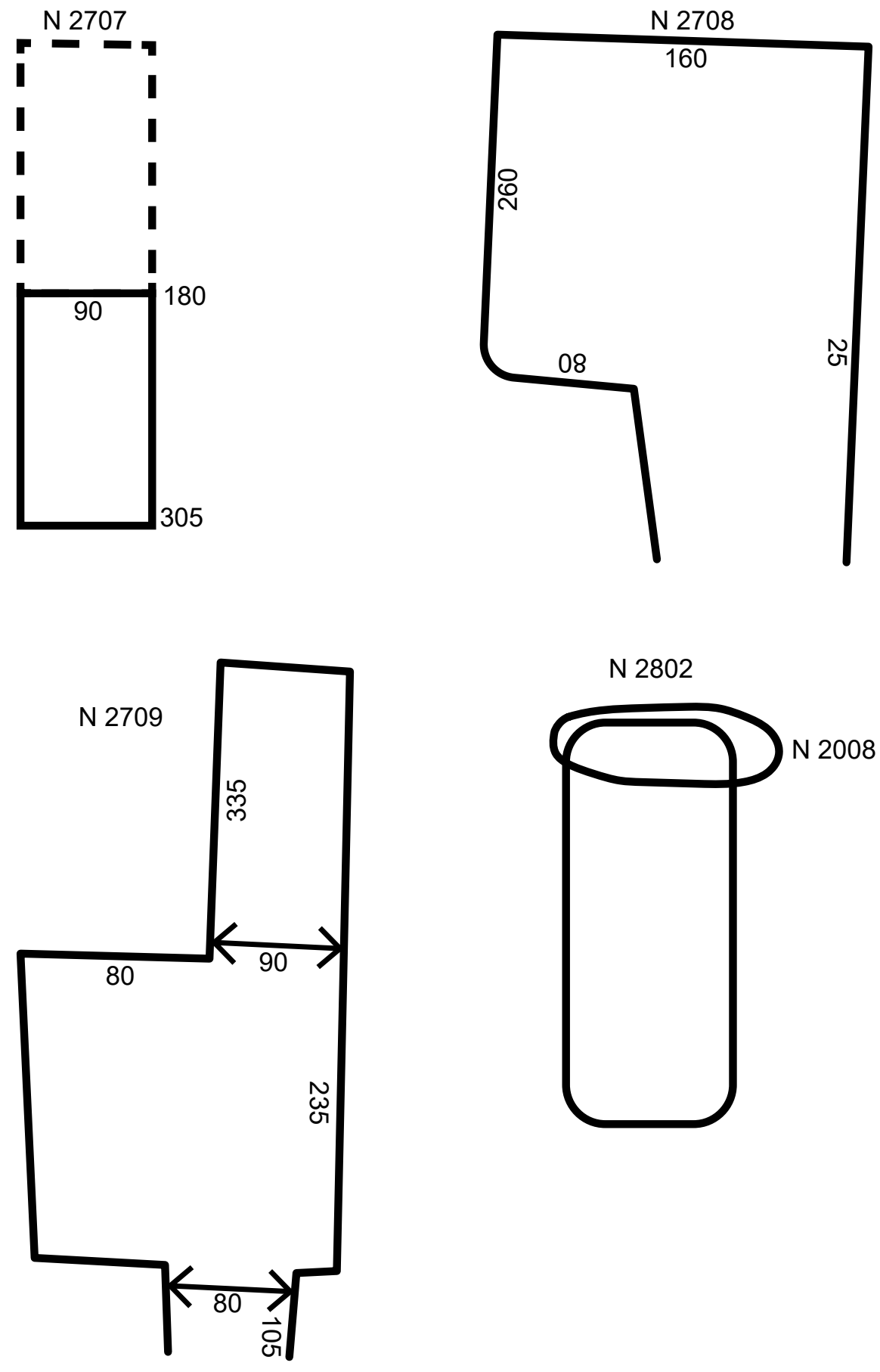

N 2802

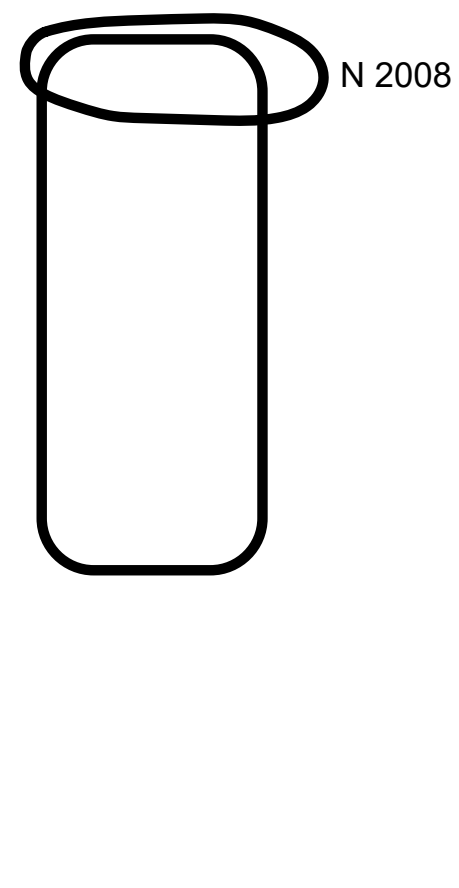


(i)

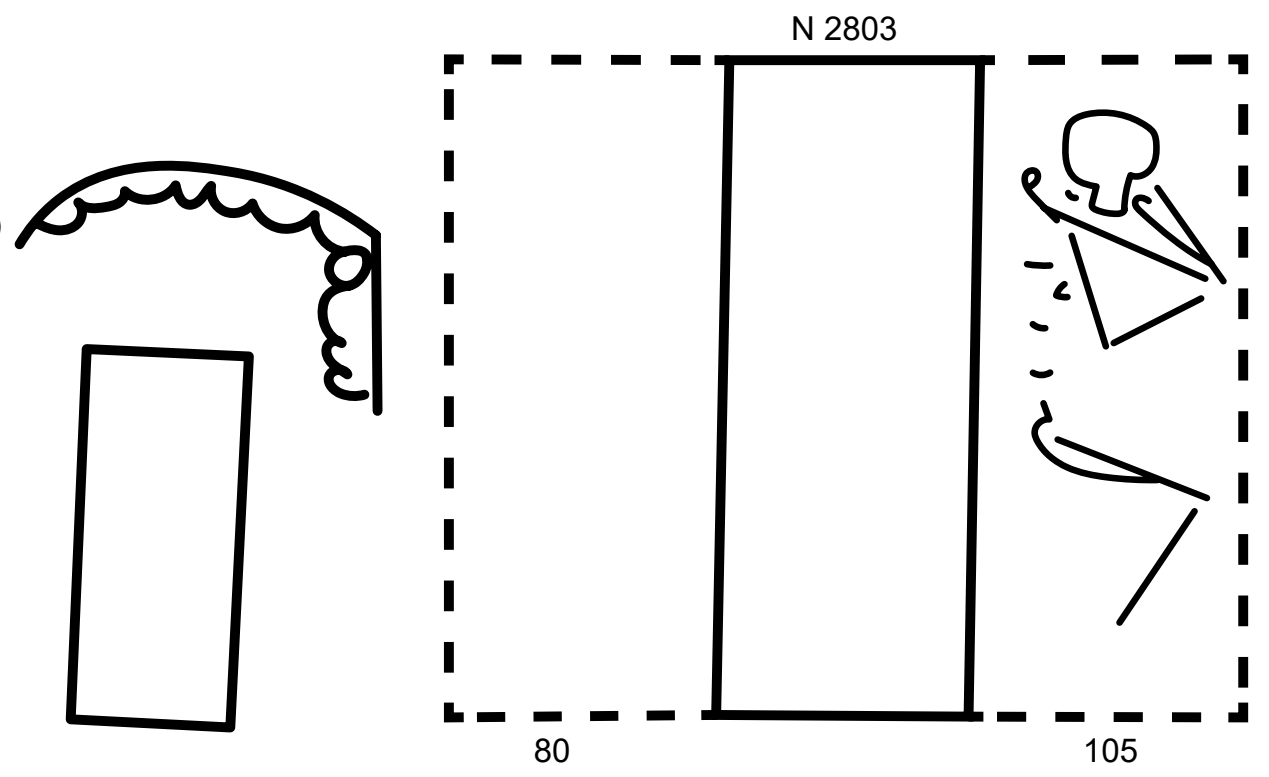

N 2810

N 2805

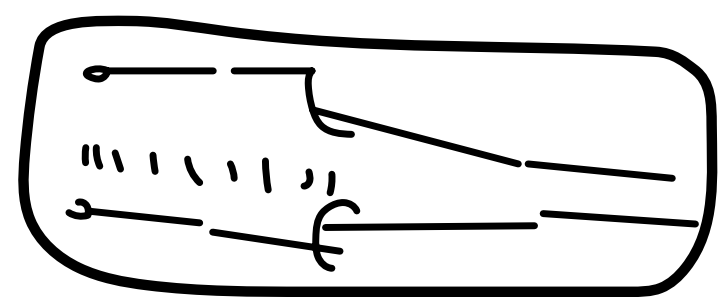

(i)
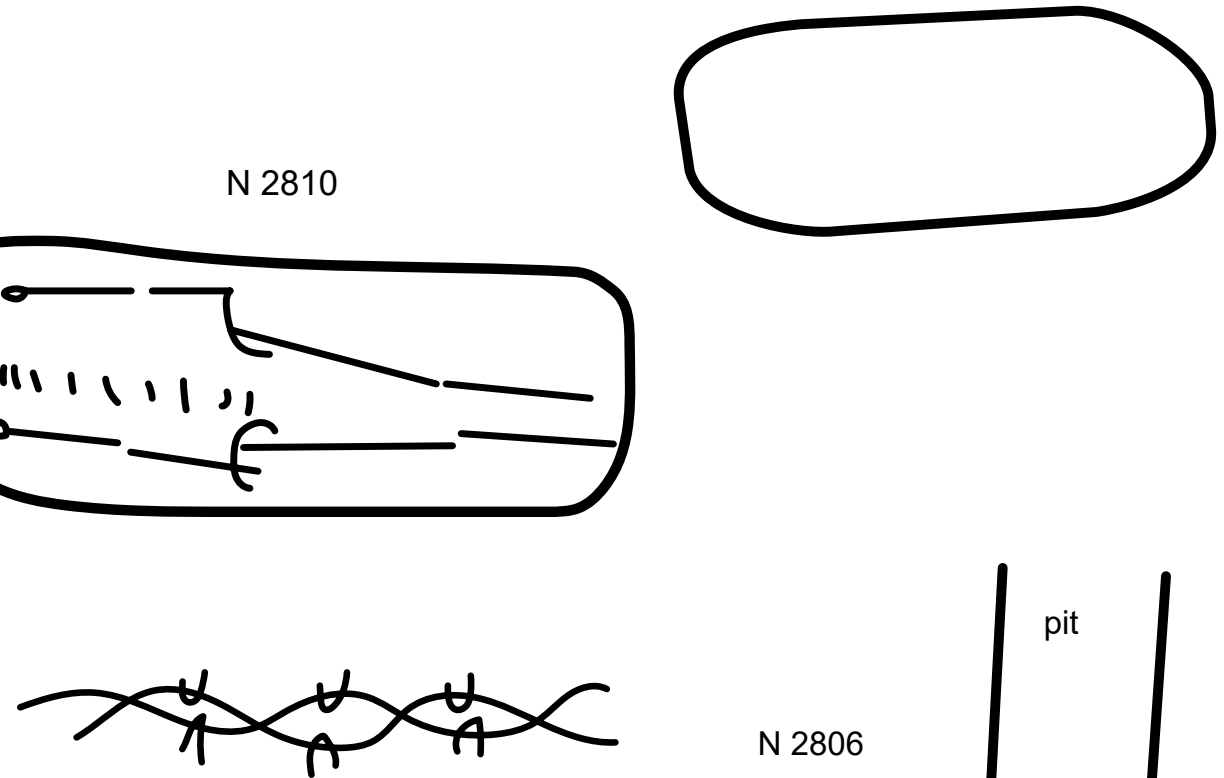

(ii)

N 2806

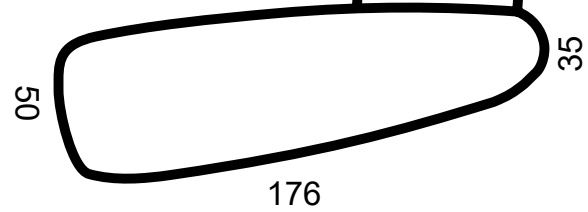


$\mathrm{N} 28$ o3 (TC) Map D4

85 high? 175 deep from present level. Adult. Female? Burial on left side, portion of right leg doubtful. No trace of coffin. Remains of mud superstructure approximately $0.5 \mathrm{~cm}$ high (i).

$\mathrm{N}_{28}$ o4 Map D4 [ed.: This burial is on the map, but there was no tomb card for it.]

$\mathrm{N}_{28} 85$ (тс) Map C4 (red)

Coptic grave. Burial gone.

$\mathrm{N} 2806$ (тс; мм) Map D4

Shallow grave running east-west. Adult male. On back, head west. Remains of dark, curly hair. There was a single shirt that had narrow inwoven lines of blue thread across the shoulders, and at bottom of sleeves, 2 similar lines with a small, needleworked pattern of 4 rosettes in colored wool. Over face, an extra pad. Between this and shirt, there was a quantity of salt. Under body, next to shirt, there were 2 stout poles (not palm). The first wrapping shawl was of coarse cloth, not sackcloth, with inwoven bands of blue, 2 wide, at either end. Next came a wrapping of sackcloth outside which the mummy was corded in style 3 (i). Outside the cording, there was an upper covering of fine yellow cloth, the corners of which were tied round the neck. This had small tapestrywoven designs in one corner at any rate (ii) in dark brown wool with a border at end of alternate (iii) and (iv).

N 2810 (тC) Map D4

Coptic burial. Head gone. Position with head west. Traces of sackcloth and of finer cloth. 2 palm sticks under body.

\section{N 2811 (TC) Map D4}

45 down. Coptic burial. (Female. Height $146 \mathrm{~cm}$.) S. Head west. Outside wrapping of sackcloth. Inside, 2 palm sticks. Quantity of salt with body. Next to sackcloth and outside sticks, there was a covering of elaborately worked cloth with red bands of cloth in the middle of which were wide bands of colored wools. On border, a band of blue sewn in. This was probably a shirt. Over head, extra wrappings. Outside, a wrapping of cloth with lines of drawn work and inside, a net of colored threads. By head, a ring of bronze beads of a single thread, ends being wound round after joining. Shirt had been very elaborate, designs being mixture of plant, animal, and human. 
N 2811

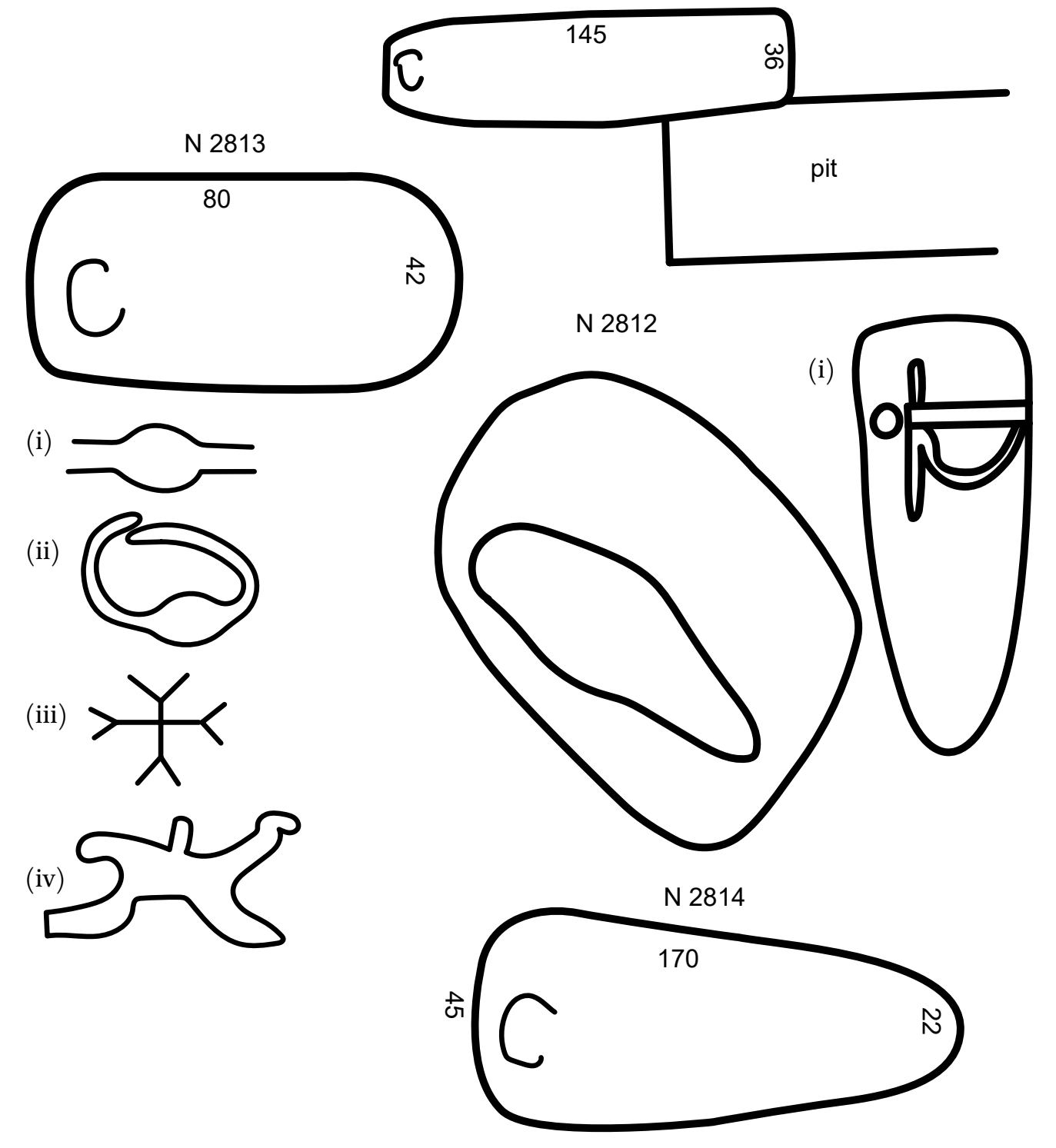

N 2815

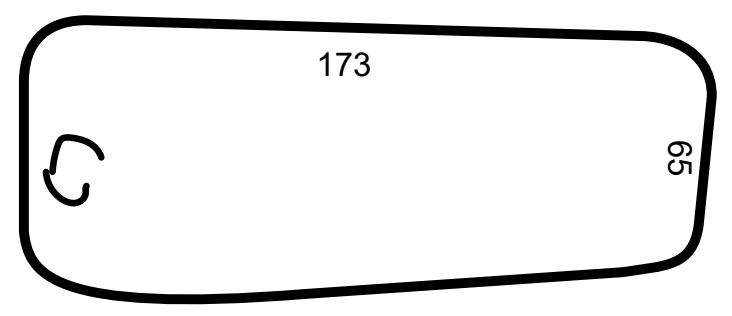


N 2812 (тс) Map D3; photo C 8451, C 8559

Coptic child. Wrapped in rough cloth, not sackcloth, and tied round with cords. Outside, a wrapping of yellow cloth with colored wool pattern round neck (i). Rosette and vertical banded black cloth with yellow and purple wool decoration (not sewn on). Horseshoe piece was a band sewn on to yellow cloth; of purple cloth with black wool decoration and a border each side of red cloth with white spots. On another part of yellow cloth, a wider band similar to horseshoe pattern (sewn on). First cloth wrapping was a shawl with fringed edge. Body was laid on it, sides were turned over. End by feet turned over. Border torn up and wound round just above feet. Under this, a quantity of dried twigs and leaves of ? 1 leather sandal by right hand. Below, a wrapping of cloth, not a shirt. Over face, 2 or 3 thicknesses with soft fiber wool between. Skull broken. By skull, 2 gold earrings (ii). Also, bronze cross and 1 green star bead. Also, remains of 2 bone bracelets. Below, 2 shirts. Under one (iii): cloth brown with blue stripes, vertical on skirt, horizontal on sleeves, irregular in number from $1-5,2-8$ between rows of stripes. Border at bottom on front turned up at right angles so shirt was probably divided for a certain distance at sides. Under part of shirt was rucked up to small of back, so exact shape could not be determined. Upper shirt (iv): worn inside out. Strip sewn on of dark blue or black cloth with yellow wool decoration (v). 2 wide. Sleeves entirely gone.

\section{N 2813 (TC) Map D4; photo C 8459, C 8477}

70 down. Coptic baby. Head west. Traces of cloth left on body with traces of wool ornamentation. On left wrist, bronze bracelet (i). On right wrist, similar bracelet (ii), but with a larger plaque and a cross ? (iii) on it. By right ear, a bronze earring? (iv).

\section{$\mathrm{N} 2814$ (TC) Map D4}

95 deep. Copt. Adult. Female? Head west. Cloth almost entirely gone. Position of body as usual. Had been a large pad of cloth over head, part of which was embroidered cloth. Under body, 2 palm sticks at least. Quantity of dark brown hair left. Round neck, a string of small shells with a few green stone beads. ( 5 shells were together.)

\section{$\mathrm{N} 2815$ (TC) Map D4}

90 down. Copt. Head west. Usual position. Cloth almost all gone. Length of body 157, but none of joints ossified. All the parts of the sacrum unjoined. Had been wrapped first in sackcloth and then in finer cloth, part of which was dyed red. Large pad over head. Under body, 2 palm sticks. 
N 2816

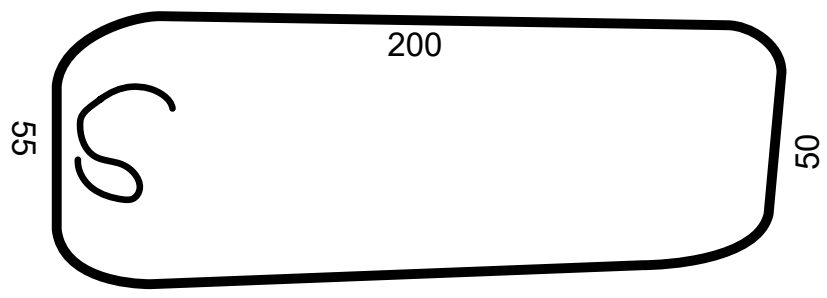

N 2817
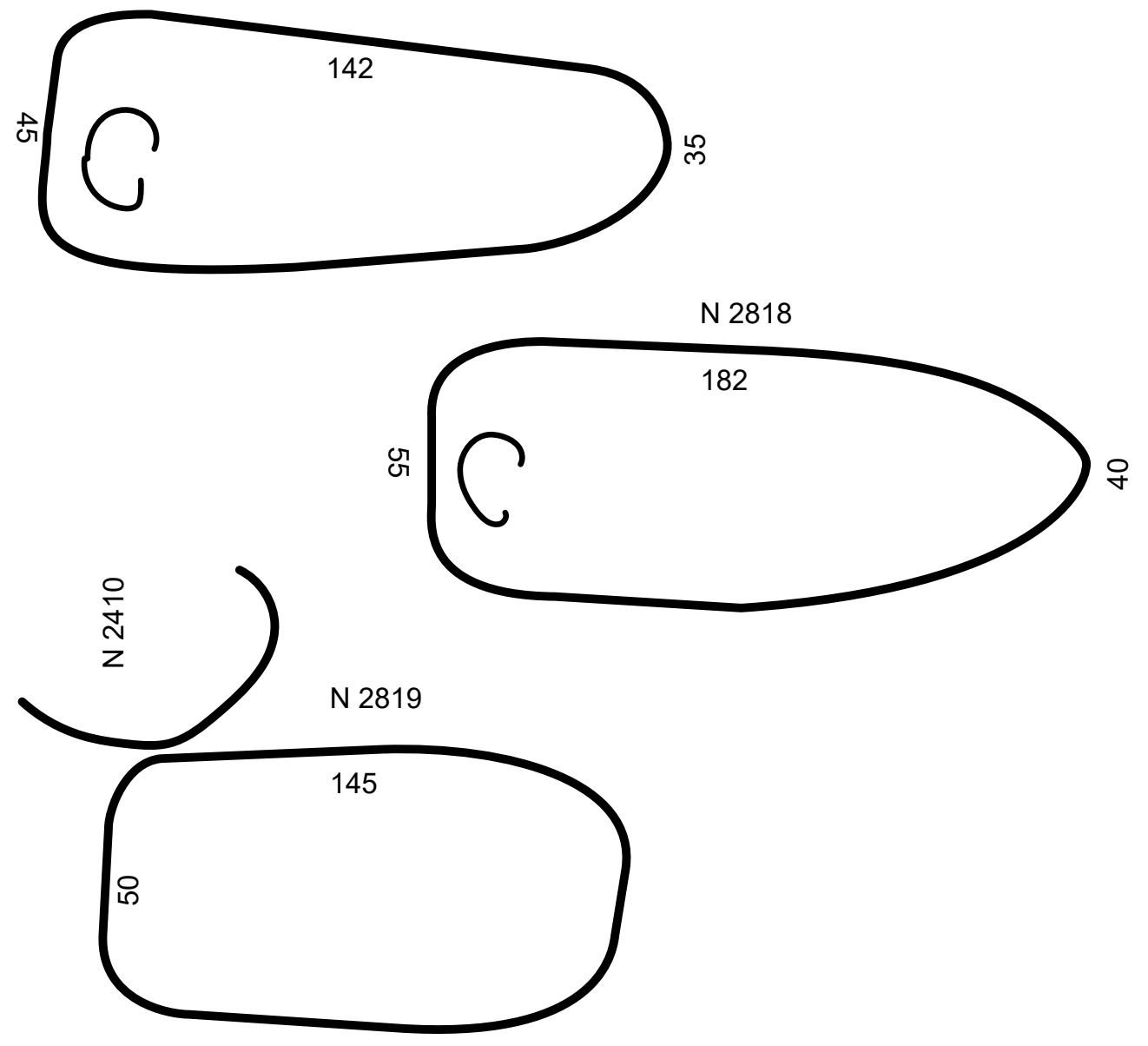

N 2830 (1)

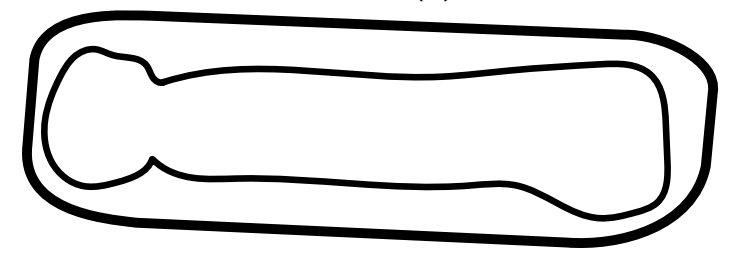




\section{$\mathrm{N} 2816$ (тC) Map D4}

8 o down. Copt. Adult male. Head west. Cloth nearly all gone. 6 palm sticks under body, 2 on each side and 2 in middle. Also, 6 above body inside wrappings. Over feet, there had been a quantity of fibrous material. Fibrous material over whole body inside wrappings, especially over head. Back teeth almost all gone, and bone worn away.

\section{$\mathrm{N}_{2817}$ (TC) Map D4}

90 down. Copt. Adult female. Head west. Only 2 teeth left in upper jaw. All back ones gone in lower. Almost all traces of cloth gone. Had been wrapped in sackcloth and also in finer cloth. 2 or more palm sticks under body. Over head, remains of a cap ? of green and red cloth cord work. (Possibly they were just odd ends put in to fill up.) Head propped up, so head looked towards feet.

\section{N 2818 (TC) Map D4}

105 down. Copt. Adult male. Head west. Very few teeth left. On left side of lower jaw, a large hole drilled right through. Cloth practically all gone from body, but a large pad still remaining on head consisting of sackcloth and a finer cloth inside. Under body, on right side, 2 palm sticks. On left, 1.

\section{N 2819 (TC) Map D4}

100 down. Remains of a Coptic burial. Head southwest. Head gone, and bones considerably disturbed. Under body, 1 palm stick and 1 sesban.

\section{N 283 o (1) (TC) Map E3; photo C 7026}

Coptic burial. Body wrapped in rough sackcloth. Over this on top of body, apparently orig[inally] on top a strip of fine cloth, which went over head and was tied round the neck.

\section{$\mathrm{N}_{283}$ (2) (TC) Map E3}

Coptic burial. Adult male. Head west. Almost all back teeth gone. Under body, dried palm leaves. On outside, wrapped in a shawl of yellow cloth (almost all gone). Under this had been tied with fiber cords, but these had almost entirely disappeared. Wrapped outside in a shawl of sackcloth, folded over in usual way, and sewn up down front with cord. Over this, on top of body, apparently only on top, a strip of fine cloth that went over head and was tied round neck. Under excess over head, a quantity of palm fiber. Under this, a large pad of cloth. Skull had fallen out of position. The extra pad consisted of an old shirt, very much darned, rolled up into a ball. Below, completely enveloping body, a shawl of coarse cloth with a border of wool embroidery. Patterns in green, blue, and in shades of red (sewn in). Between this and shirt, a small amount of salt and 
N 2830 (2)
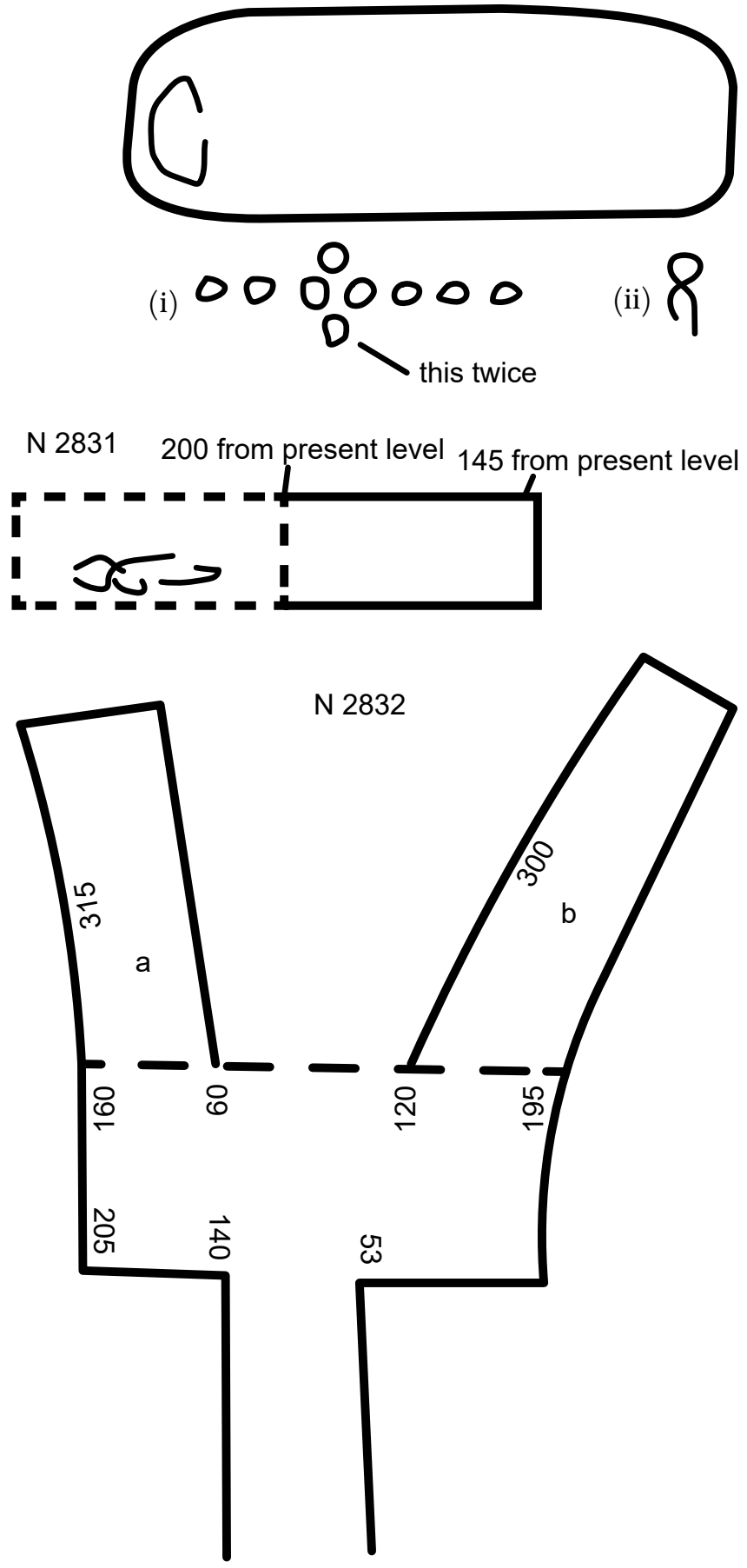
remains of a few dried plants on breast. Remains of short, straight hair, discolored. Below, 2 shirts. Outer: reached to very bottom of feet. Bottom selvage end of cloth. Neck, simple opening. Edges finished off similarly to bottom. Under body inside wrappings, 4 palm sticks and 1 acacia. These had been fastened together. Sleeves very long, coming below bottom of hand. Ends corded. Near cord, line of ridge work left in weaving. Inside this, line of tiny rosettes in dark blue and heliotrope wool (i). 2 similar rosettes on front of shirt over stomach. Both arms in sleeves. Sleeves sewn to above elbows. Under shirt: Similar, but only reaching to halfway below knees. Neither arm in sleeve. Bottom of shirt very much darned. This shirt was made of 2 pieces, join being across chest. Inside wrappings, a lock (ii) [of] artificially curled woman's hair: dark brown.

N 2831 (тC) Map E3; photo C 7043

(Female.) S. Coptic burial in chamber of early pit on 6o of radim. Usual position. Head west. Remains of cloth wrappings. Palm sticks under body, also a few palm leaves.

\section{$\mathrm{N}_{2832}$ (TC) Map E3}

$125 \mathrm{~W}$ of N. Remains of burial in b. Roof of main chamber and also of b completely fallen away. Contained nothing.

\section{N 2833 (TC) Map D3; photo C 7046}

Upper part of Coptic burial. Male? Middle aged. Wrapped round with sackcloth. Outside bound round with strips of coarse white cloth with red and black ornamentation: red and black on separate strips (i). Also, bound with fiber cords. Ends of sackcloth crossed over body and fastened together on breast with a fiber knot. Body was laid on cloth, a good deal being left projecting beyond head. This projecting part was thrown back over face, sides also thrown over and then bound. Under this, a second covering of sackcloth similar to first. Between first and second wrappings, by right side of face, a ball of fine, soft cloth. Under second, a third similar sackcloth. Underneath, remains of 2 or more shirts of fine linen. Quantity of salt on body inside wrappings. The fine cloth between first and second wrappings consisted of an irregular piece of cloth with cord border. Near this border, 3 cent [ed.: imeters?] in, a pattern in purple ? 1.5 wide (ii). Further in, at intervals, (iii) in same color, $6.8 \times 3$. Under body, 1 stick for carrying, inside sackcloth wrappings. 
N 2834

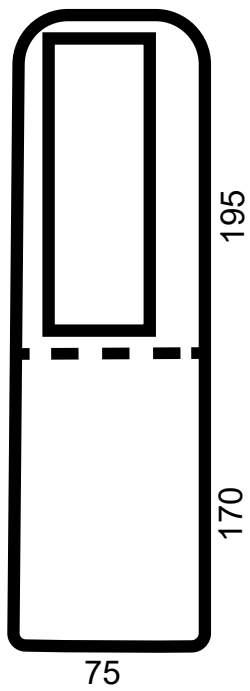

(i)
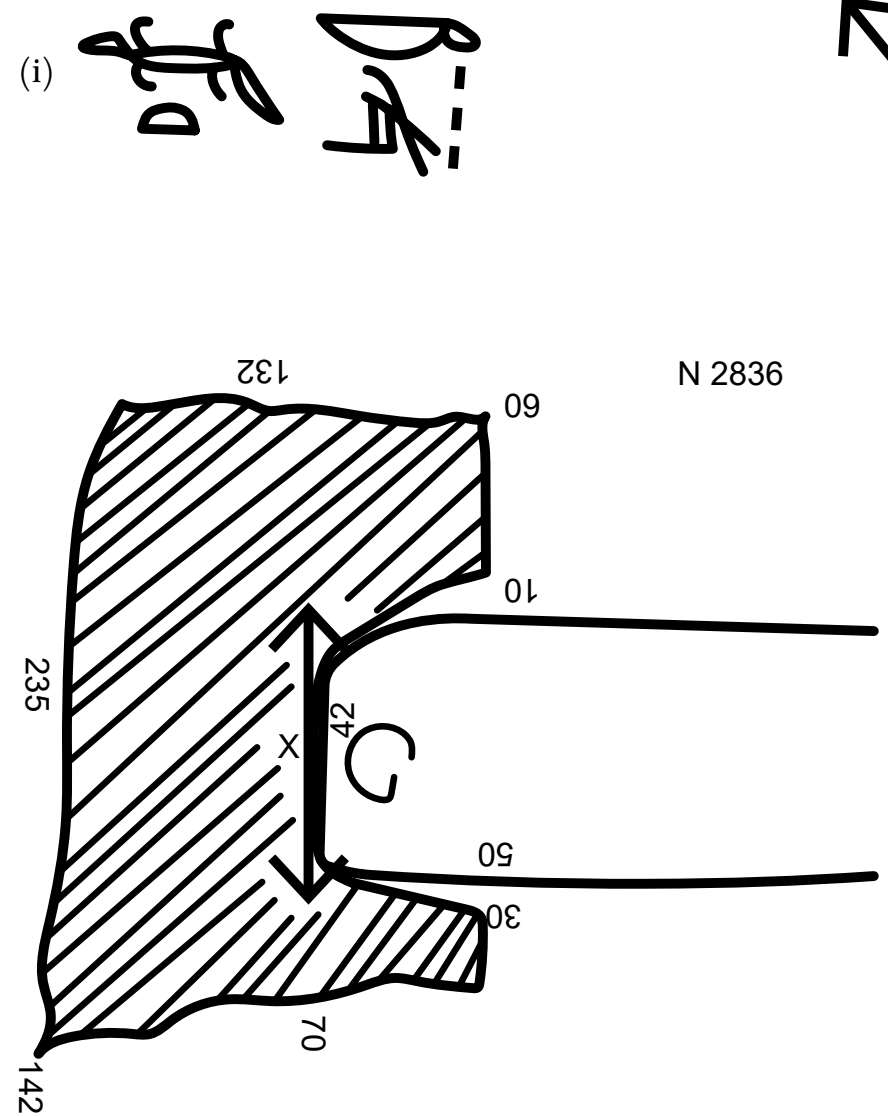

N 2833

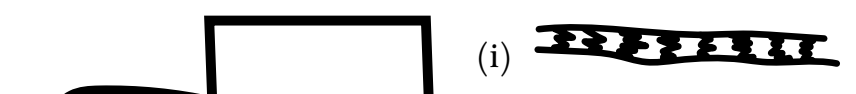

(iii)

(ii) B PbB

N 2835

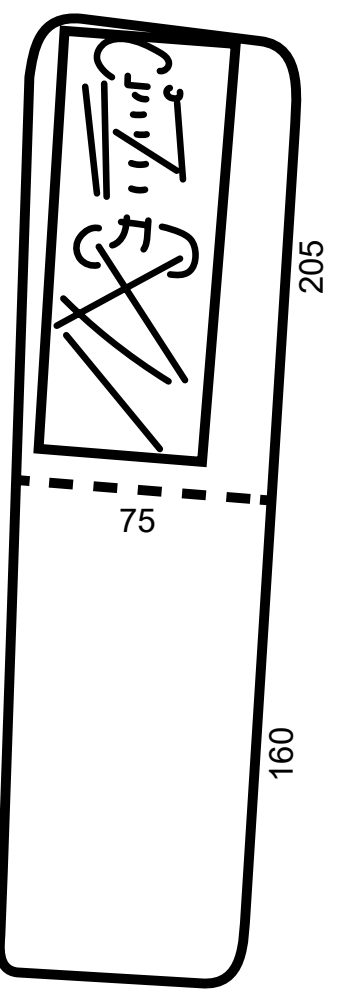




\section{N 2834 (TC) Map D3; photo C 8193}

About $8 \mathrm{o}$ high. Badly broken up inscribed coffin in black paint to (i). Corners as usual. Measurements doubtful. In radim, 2 tiny glaze amulets (6-12515).

\section{$\mathrm{N} 2835$ (TC) Map D4}

180 from gebel. 85 high? Female. Body on back, legs crossed. Remains of several wrappings of cloth over body. Inside measurement of coffin 148, 34.5, 41.5. Thickness of wood 4.5. Corners as usual. White paint outside and in. Lid was broken and out of position.

\section{N 2836 (тC) Map E3; photo C 7732}

95 deep. Coptic. Head west. (Short, brown, wavy hair. 1.597 m high. Sex?) S. Remains of an early coffin at W end of grave, just below surface X. At W end of tomb, brick construction 10-20 thick. Over head, 2 large bunches of dried grass tied round. Under body, 3 palm sticks and 1 atl. These were all together and had been tied together. Inside sackcloth, outside shirt. Quantity of salt on body. Wrapped first in very fine cloth with corded edge and ornamentation of black cloth with yellow thread decoration. Below, 2 thicknesses of sackcloth. Below, a wrapping of yellow cloth with broad green line decoration (inwoven). Below, 2 sheets? with varied thread patterning and elaborate decoration in green cloth with yellow thread patterns? Also, a piece (? from shirt) with corded edge and decoration in green wool. On head, a mass of cloth, some of which at any rate was of same stuff as cloth and with similar decoration.

\section{N 2837 (N 2634 opening from it) (TC) Map E3; photo $\mathrm{C}_{7058}$}

260 deep from present level. 80 high. Adult. Female? Suture right down forehead. Burial on back. Inside measurement of coffin $180 \times 45 \times 5$. Thickness of wood 4.5. Corners as usual.

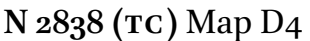

About 200 deep from gebel. 95 high? Adult. On left side. Position of arms doubtful. Skull badly broken: sex? Traces of decayed wood from coffin.

\section{N 2839 (TC) Map E3 (red)}

Lower part of Coptic burial. (Male.) S. Remains of several wrappings of linen, 1 or 2 pieces with elaborate decoration in colored wools. Outside these linen wrappings, there were 3 palm sticks under the body tied together at the end. Outside these 2 wrappings of cloth with twigs and dried leaves between. Fragment of a shawl (i) showed doubly corded edge into one of which cords a 
N 2837

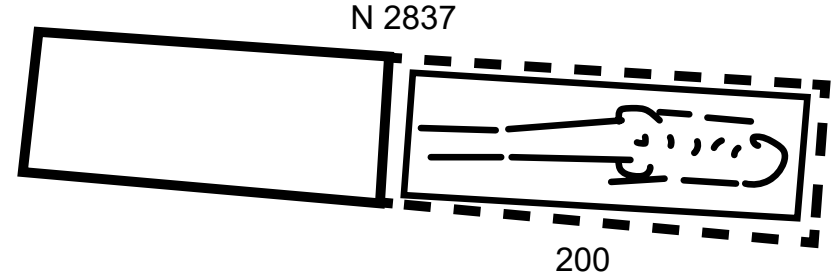

(i)

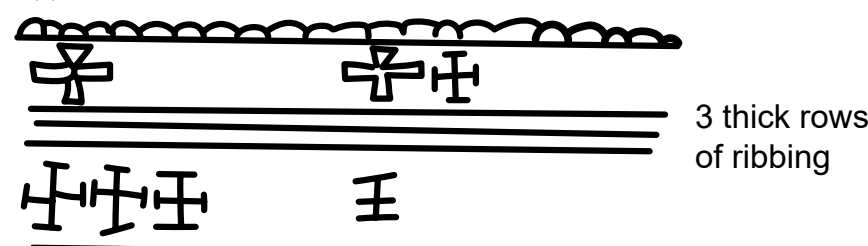

3 thick rows of ribbing

王王
N 2838

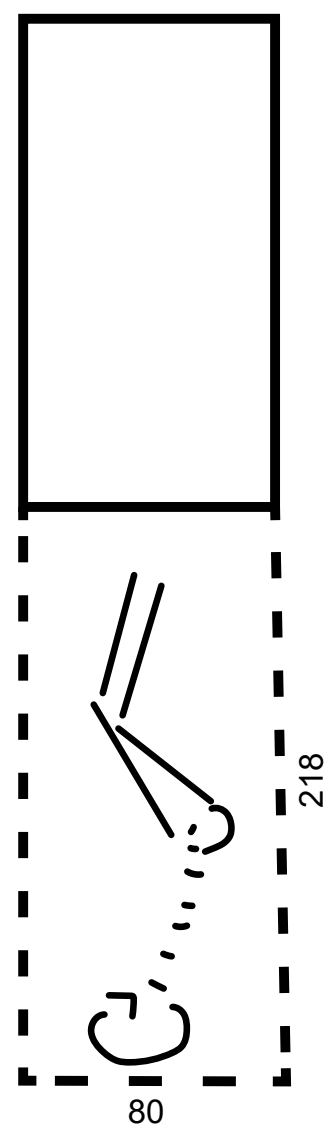

3 thick rows of ribbing

\section{王王王}


quantity of reddish brown wool was mixed. Crosses between lines of ribbing in the same reddish brown wool: sewn on. Also, part of shirt with lower part of usual breast ornamentation. Colors and pattern?

N 2840 Map B4 [ed.: For drawing, see N 2649.]

N 2841 (тс) Map B4

255 deep. 75 high. 115 E.

N 2842 (TC) Map B4

Depth from present level 75. $110 \mathrm{E}$ of N. Contained nothing. Doubtful whether Copt or Egypt Old.

$\mathrm{N} 2843$ (TC) Map B4

233 deep from present level. 88 high. Contained nothing.

$\mathrm{N} 2844, \mathrm{~N} 2845$ (TC) Map B4

Both 150 deep from present level. $35 \mathrm{~W}$ of N. 2844 had possibly been pit and chamber. 2845 was probably a Copt. Neither contained anything.

$\mathrm{N} 2846$ (TC) Map B4 [ed.: Number is in pencil only on map, not ink.] 270 deep from present level. Height? Contained nothing.

N 2847 (TC) Map B3

85 deep. Probably Coptic. Contained nothing.

$\mathrm{N} 2848$ (TC) Map B3

465 deep. 95 high. Contained nothing.

N 2849 Map B3 [ed.: No tomb card for N 2849.]

N 2870 (тC) Map B3

110 W. Copt. Usual position. Head west.

N 2871 (тс) Map A3

Copt. Contained nothing.

$\mathrm{N} 2872$ (TC) Map A3

Copt. Contained nothing. Burial gone. 
N 2841

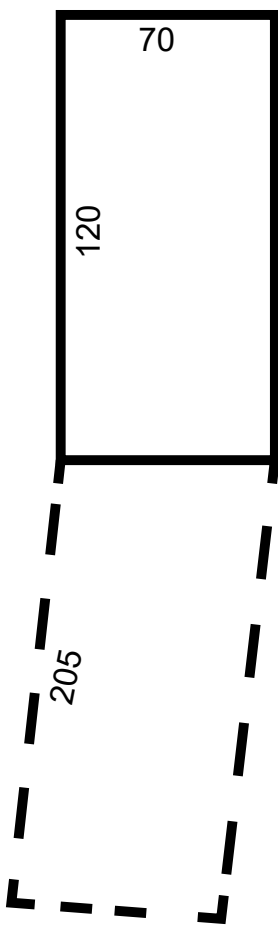

N 2844

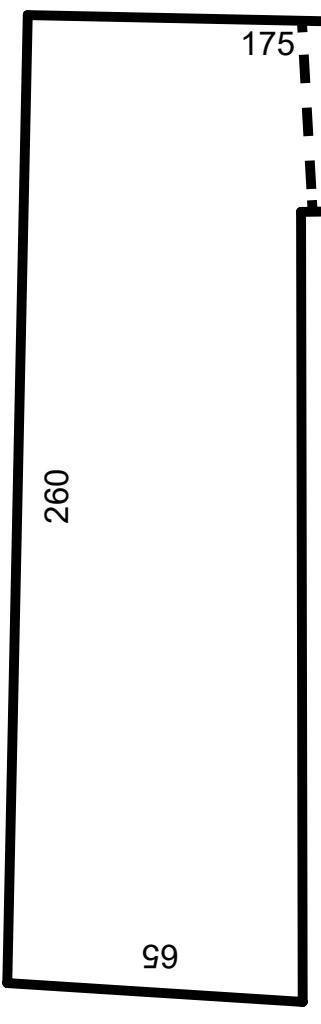

N 2843

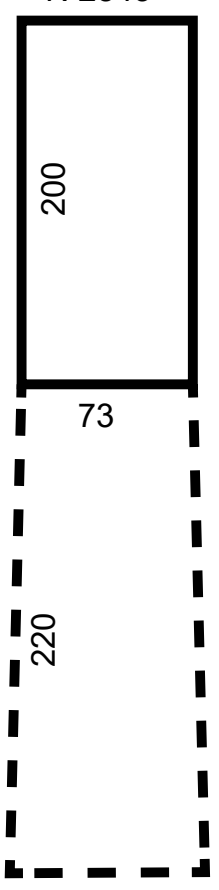

N 2846

80

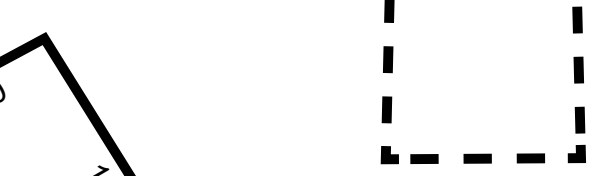

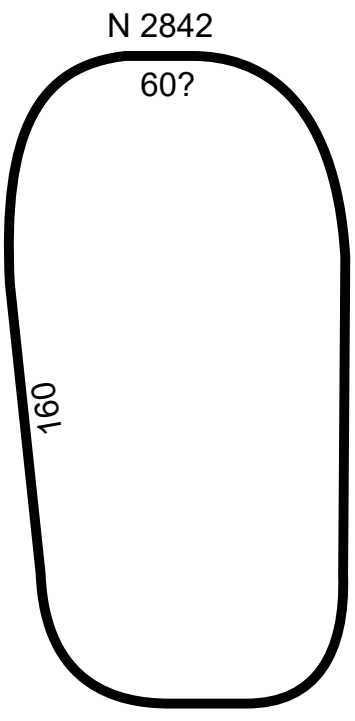


N 2847

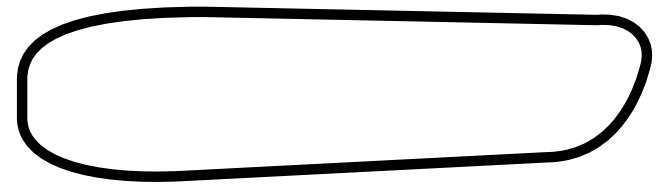

N 2848

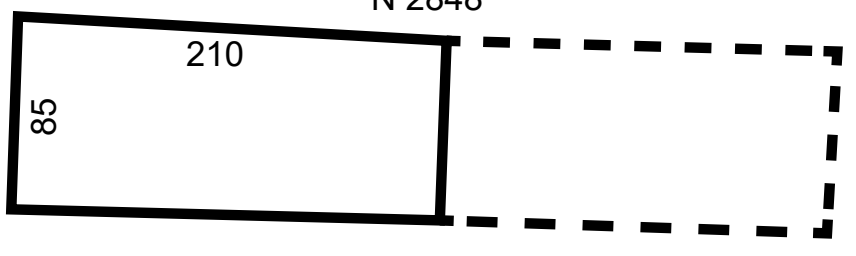

N 2870

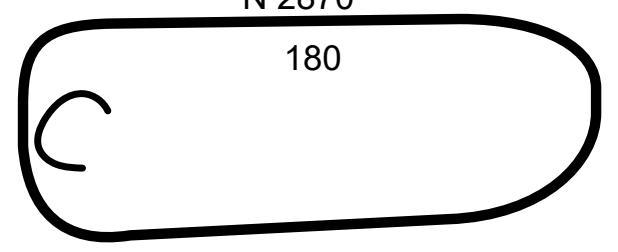

N 2871
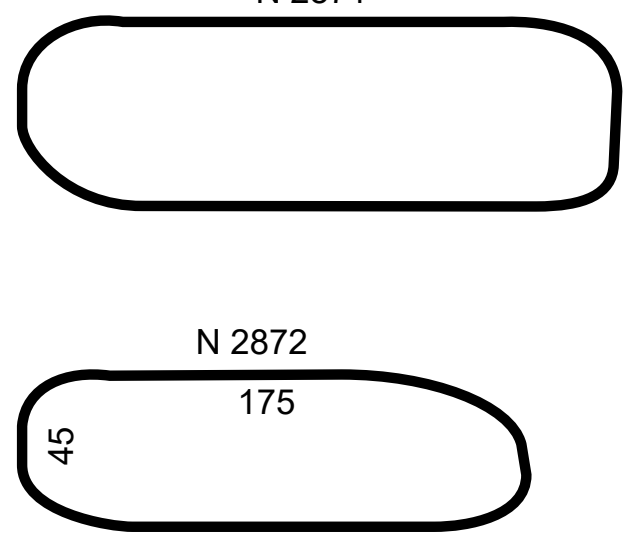
N 2890

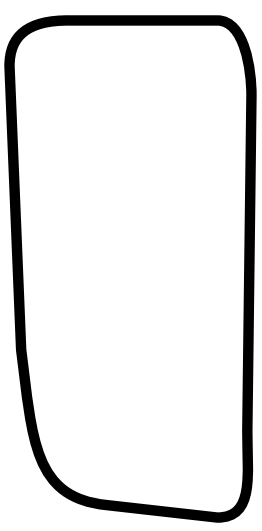

N 2876
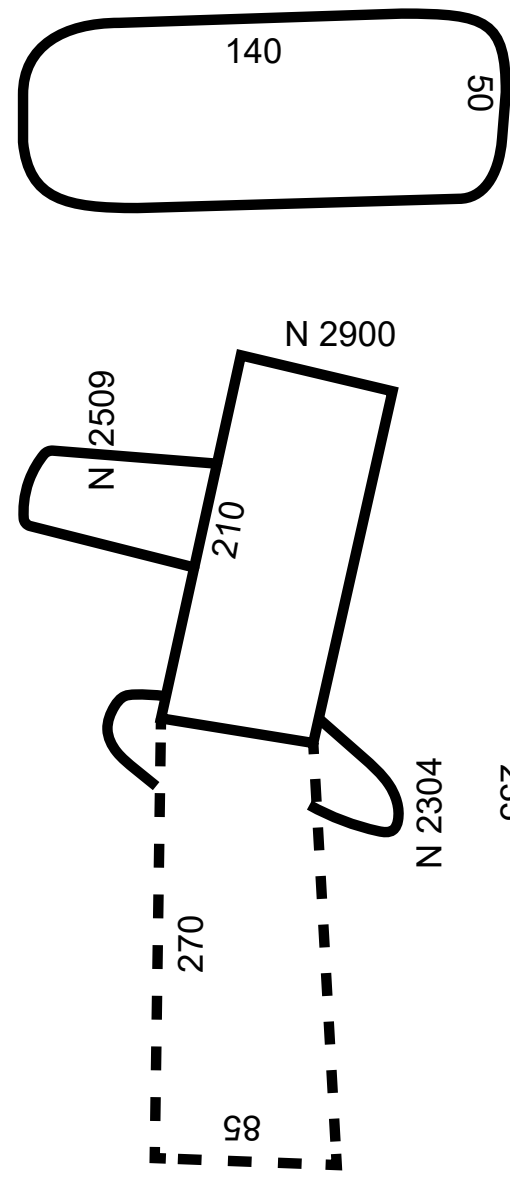

N 2875

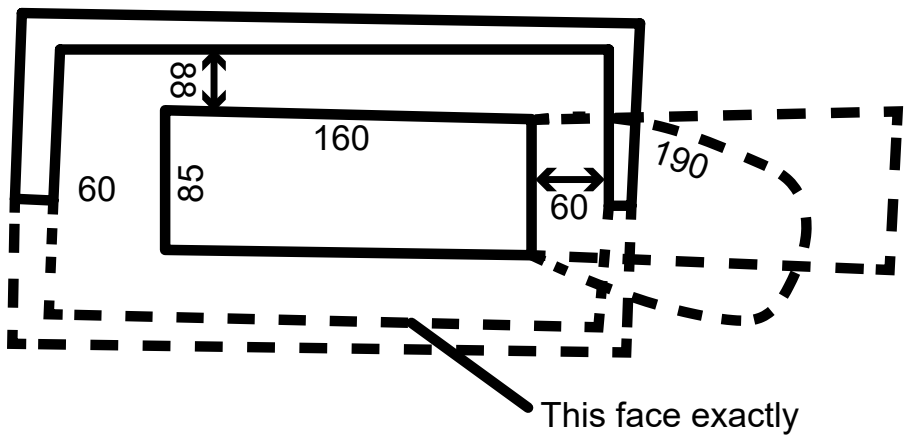
over pit.
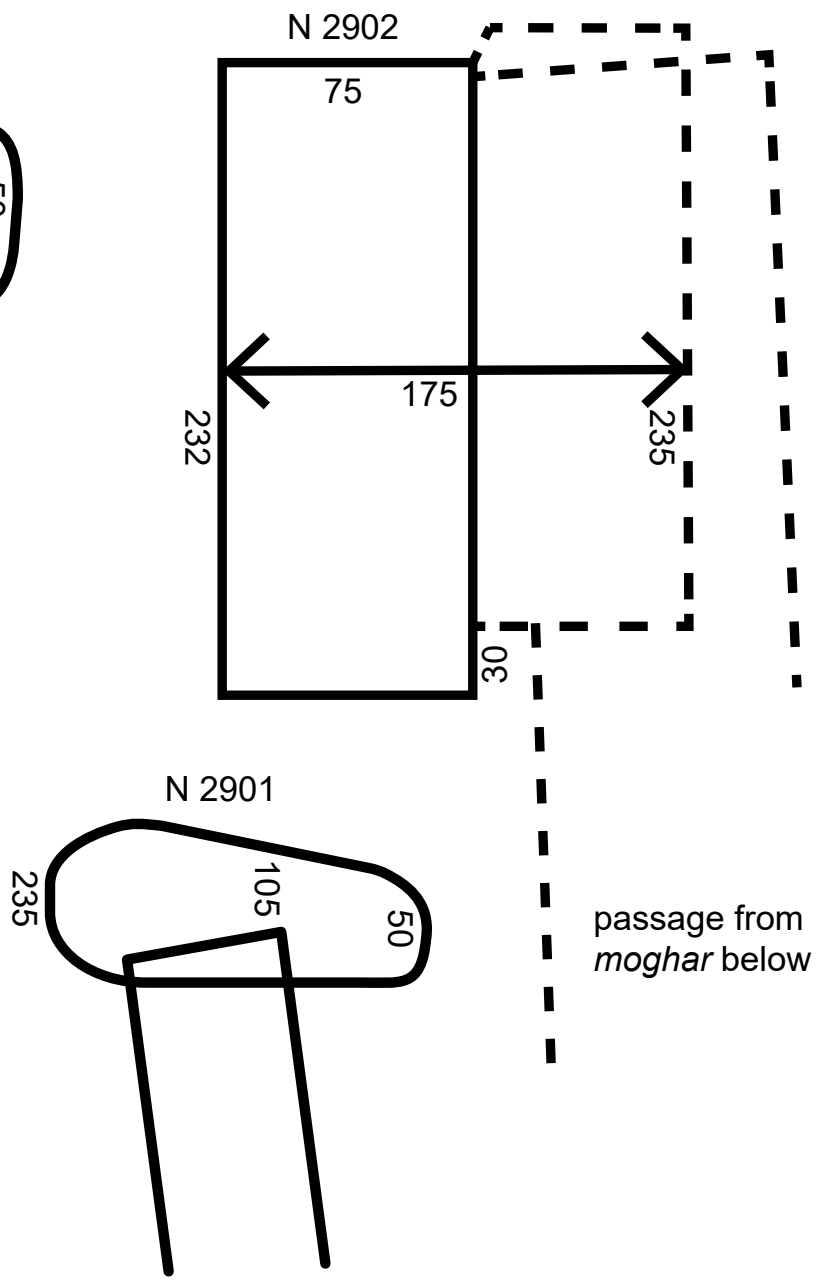
$\mathrm{N} 2873$ (TC) Map A3

Copt. Burial gone. [ed.: No image.]

N 2874 (TC) Map A3

Copt. Burial gone. [ed.: No image.]

$\mathrm{N} 2875$ (TC) Map A3

120 W. Contained nothing. Remains of walls to keep back radim. 70 high at east end, starting at 120 below present level. On north and west sides, started at same level, but only a course or two preserved. On south side, started 55 below present level. Only traces left. $1 \mathrm{~b}$. wide.

$\mathrm{N} 2876$ (тC) Map A3

95 W. Copt. Burial gone.

$\mathrm{N} 2877$ (тC) Map B4

Copt. Burial gone. [ed.: No image.]

$\mathrm{N}_{289}$ (TC) Map C4

Shallow grave. Not Coptic.

$\mathrm{N}_{2891}$ (TC) Map $\mathrm{C}_{4}$

Shallow grave: broken away by falling in of roof of 2491. [ed.: No image.]

$\mathrm{N}_{29} 90$ (TC) Map $\mathrm{C}_{4}$

Originally pit and chamber, but roof of chamber almost all gone. Contained nothing.

$\mathrm{N}_{2901}$ (TC) Map $\mathrm{C}_{4}$

Coptic grave. Burial gone.

$\mathrm{N}_{2902}$ (TC) Map C4 (red)

$60 \mathrm{~W}$ of N. 28o deep from present level. Height of chamber 7o. Pit must have been made before moghar below as floor was completely broken away by making of chamber below. Contained nothing. Pit had been filled apparently with mud and boulders. 

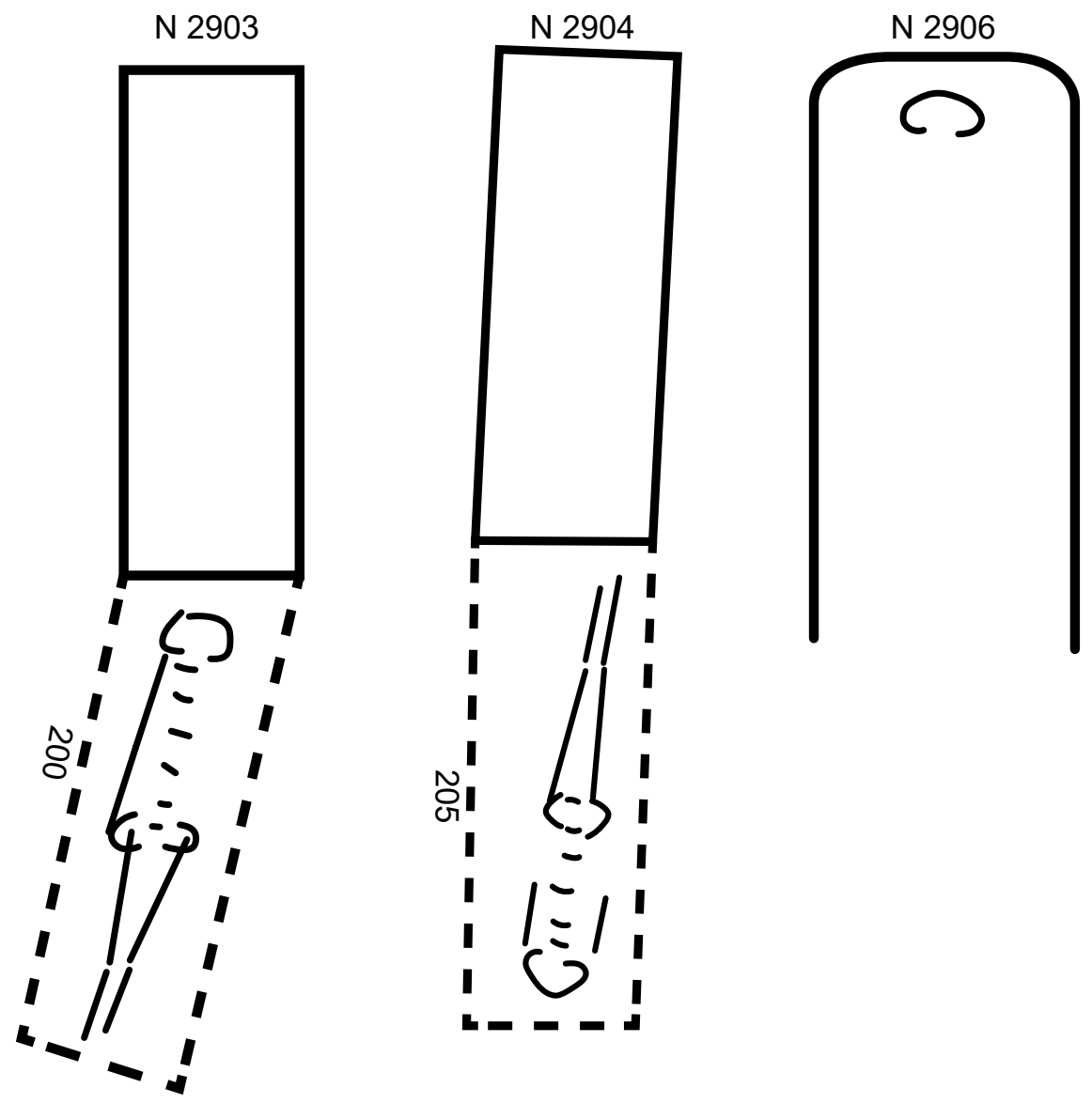

N 2905

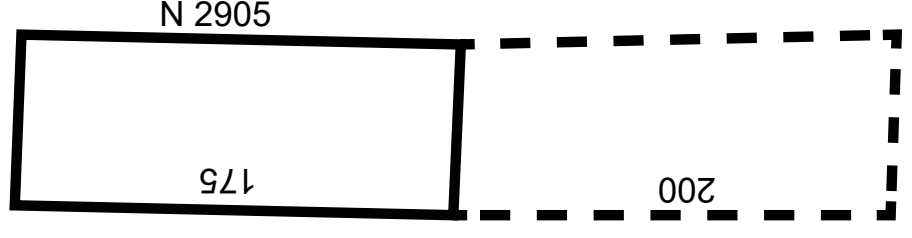

(i) 


\section{$\mathrm{N}_{2903}$ (TC) Map C4}

265 deep from present level. Height? S of Coptic. Adult. Sex? Position of left arm doubtful. Burial on back. No trace of coffin. Scraps of decayed cloth on body.

\section{$\mathrm{N} 2904$ (TC) Map C4} 240 deep from present level. 8 o high. S of brick tomb. Adult. Sex? Position of lower arm bones doubtful. No trace of coffin. Remains of cloth on body.

$\mathrm{N} 29 \circ 5$ (TC) Map D3

225 deep from present level. Height? Contained a broken (i) and M.

\section{N 2906 (TC) Map C5}

Adult. Sex? Burial head north. Position? Bones disturbed. Originally probably pit and chamber.

N 2907, N 2908, N 2909 (TC) Map C4 (N 2907, N 2908 black; N $29 \circ 9$ red) 3 Copts. Usual position. Head west. All adults. [ed.: No image.]

N 3747 (TC) [ed.: See also N 2640.] Map D3; photos C o212, C o213, C o781, C o814, C 775o, C 7751, C 7752, C 7753, C 7754, C 7755, C 7756, C 8503, C 8504, C 8574

Layer of stones and radim on floor. Above number of Copts, lying one upon another in all directions.

1. On top layer. Direction 7 . Head south.

2. Child in corner $\times \uparrow$. Head south.

3. Child in corner. Behind and partly under 2. Head south. Lying on stomach. 4. Top layer in middle $\uparrow$. Head south.

5. Across(?) tomb $\longrightarrow$. Head southwest. Under head of 1 and 4. Head broken/ between of upper bones fallen through(?) on both ----. There had been 2 earrings of bronze and carnelian.

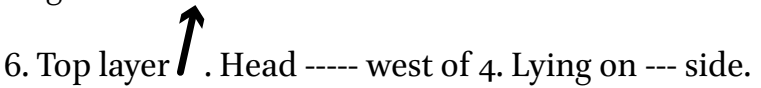

7. Middle layer, in middle of tomb $\sim$. Head west.

8. Middle layer, near north end $\longleftarrow$. Head west. Laid on large stones to keep it from touching under bodies.

9. Under 7 and $8>$. Head southwest.

10. Partly under 9 near door $\rightarrow$. Head southwest. 

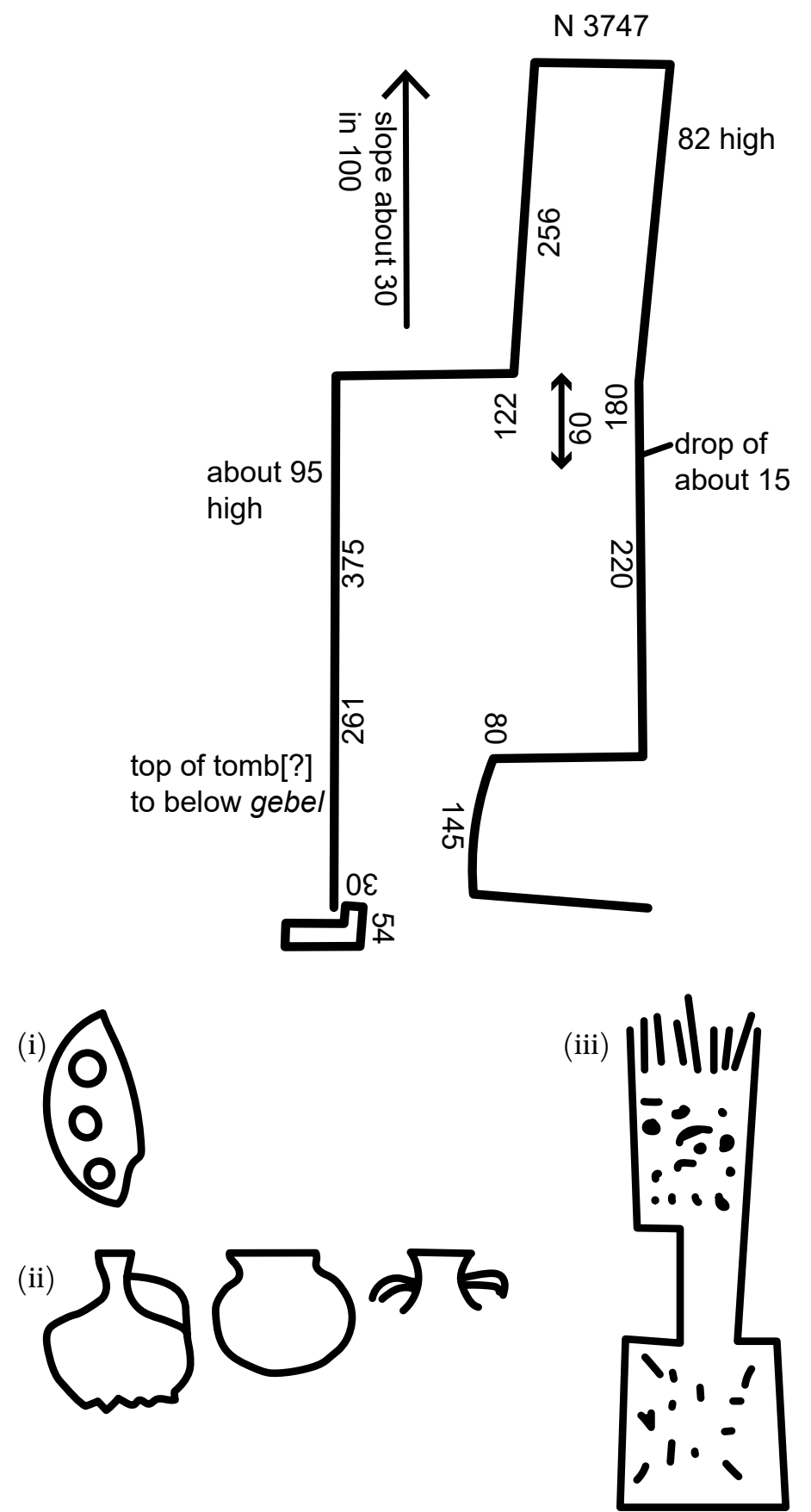
11. Partly under 10 near door 7 . Head southwest. Under bottom layer, about 20 of radim to floor of tomb. In northeast corner, a number of rough limestone boulders.

12. Under 7 and 8, nearer end of tomb $\rightarrow$ Head southwest.

13. Partly under 13, near door $\rightarrow$. Head southwest.

14. Small child near northeast corner, under 8 . Head southwest

15. Small child against north wall, top $\longrightarrow$. Head west. Feet projecting beyond door of small chamber.

16. Young child. Top layer at door of small chamber.

17. ---- 16 Sloping down into small chamber. Head just outside door. Head south.

18. By north wall, legs across door of small chamber. Under 14 and 15 . Head west.

19. Immediately under 18 . Head west.

20. Partly under 19, nearer door $\longrightarrow$. Head west.

21. Partly under 17. Head at door.

22. Child, under 21. Head just outside door $\rightarrow$. Head south.

23. Under 21, sloping into small chamber. Head south. Head fallen away from body.

24. By side of 23 , skull and scattered bones of a very young child.

In filling outside chamber, pieces of several Coptic vases. Large dish (i) with (ii) and several dishes with black paint and incised line decoration. Also pieces of ornamented wooden wool corders (?) (iii).

7 children.

1. Adult male. Tied round with the usual vertical and horizontal bindings of 2-fiber cord. A few additional horizontal bindings of cloth cord. Wrapped in a single covering of rough cloth (not sackcloth). This was brown in color, had fringed ends, and 3 bands of inwoven white threads near ends. This was folded over in usual way, and ends rolled up over head and feet. Underneath, remains of a second wrapping of yellow cloth with a band of inwoven red near ends? This had about entirely disappeared. Quantity of salt and a few plant seeds. Under body, inside wrappings, 2 palms sticks and 1 "sont" tied together at ends. Remains of 2 shirts. Hardly anything of woven shirt remaining. Large rosettes of dark cloth with decoration of original thread. Outer shirt (i). Width from seam to seam 72. Apparently same width all way down. Edges of neck hole turned over and down. Bottom of shirt plain. Bottom of sleeves like neck. Shirt made of 2 pieces of cloth. Straight join all round middle. Side seams overlapped and sewn together. Sleeves left open to wrist, then sewn ornamentation in red thread (inwoven) pattern being left in original thread. Band up front 


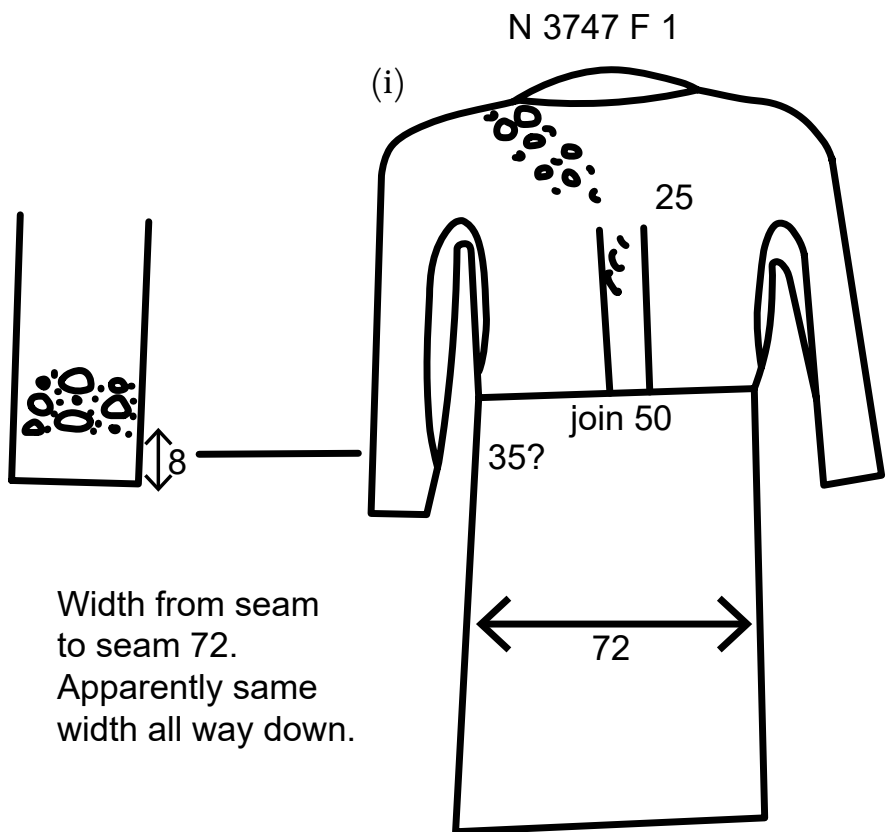

N 3747 F 2

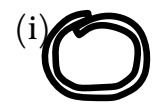

(ii)

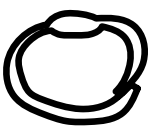

(iii)

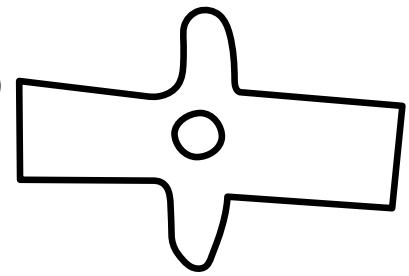

(iv)
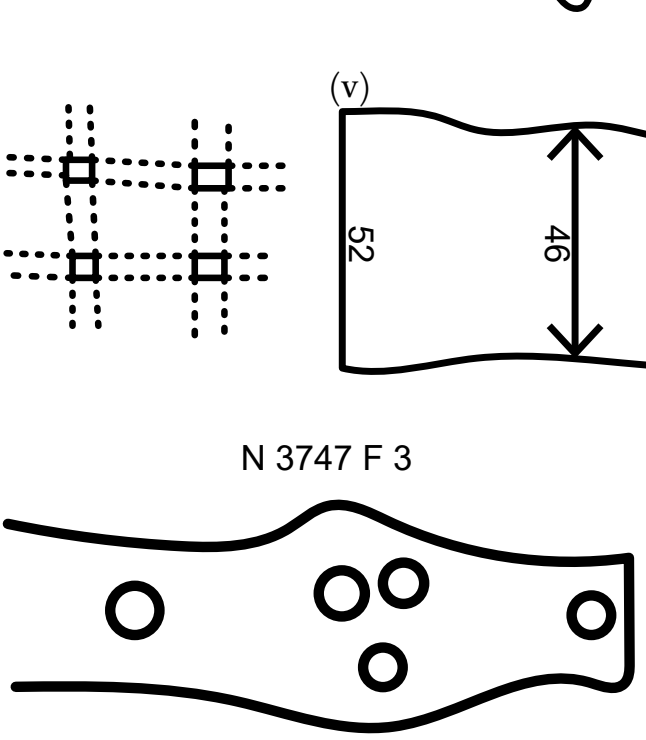
from join dividing on breast and going over shoulder and part of the way down back. Another band down center of back to join. Another band 8 from ends of sleeves.

2. Child aged approx. 7. Wrapped first in a piece of sackcloth. This was a long shawl c. 200 long and c. 100 wide with fringed ends. The large excess was left at gut, which was thrown back and reached almost to chin. Then excess at head was thrown back, sides thrown over, and the whole tied round with fiber cord. Number of [ed.: blank] seeds on body. 1 palm stick and 1 [ed.: rubbok?] under body. Inside shirt, fastened together at either end, the cord which tied end running down stick to fasten other end. Salt on body. On left arm, iron bracelet (i). On right arm, 2 iron bracelets (ii). First shirt was used as a wrapping merely and not worn. It was opened out so (iii), and body was laid upon it. This shirt was plain, save for a slight frilling to sleeve. Underneath, remains of a more elaborate shirt with a large check pattern of open work (iv) and remains of elaborate embroidery. Sleeves and bottom? had a narrow band of red cloth sewn on with embroidery of yellow thread. First shirt (v). On right shoulder, a knob of cloth with a cord loop on other side for fastening. An extra piece 10 wide sewn on to each sleeve and join being apparently hidden by a band of embroidery sewn on. From this another band probably ran from shoulder to neck, but embroidery all gone. There had also been a narrow band round bottom of sleeves and round neck. Bottom of shirt plain.

photo C 8473

3. Child aged approx. 10-12. Lying on stomach. Wrapped first in sackcloth and tied round with 2 kinds of cord, one of coarse 2 -stranded fiber, the other fine of 2 strands, each of which was made by 3 strands. Under body, between sackcloth and shirt, 2 palm sticks of which the ends were tied together, a groove being cut in one to hold cord. Quantity of salt on body and several plant seeds. Bronze bracelet on right wrist, at join (i). On left, a similar bracelet, but without ornamentation. Round neck, a string of green glass beads and also a few green glaze disc beads, not on same string? Over head, remains of a net cap with tassel. Shirt had a narrow band of blue cloth with yellow thread decoration sewn on round neck and bottom of sleeves in band running over shoulders and down sleeves? Bottom of shirt had a fringed end and some distance above it, a line of drawn work with rosettes at intervals. Very little of the wool insertion left. Shirt made of 1 piece without seam. 


\section{N 3747 F 4}

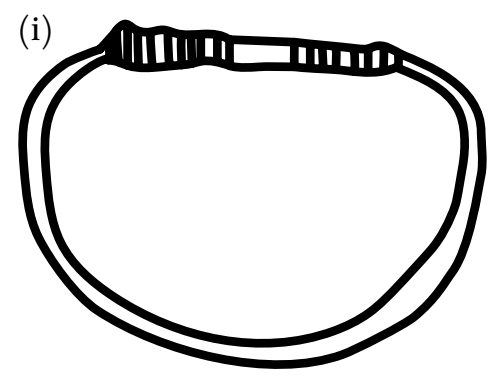

(ii)
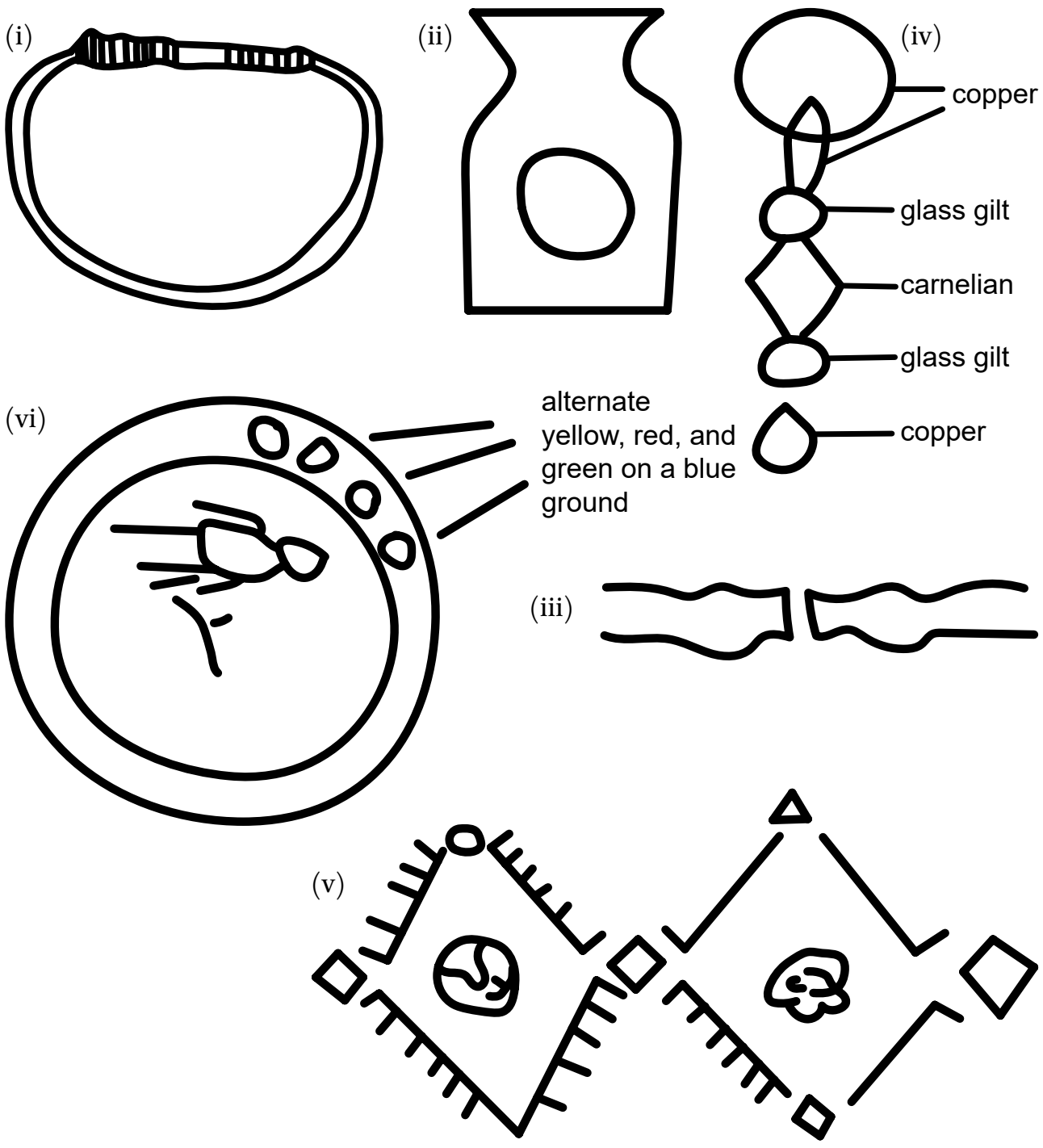

(vii)

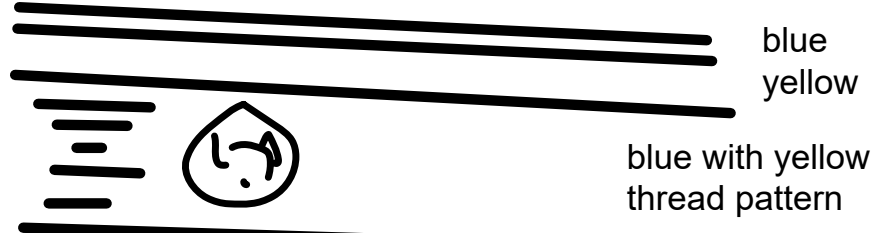

yellow blue 
photos C 8451 , C 8456 , C 8457 , C 8472

4. Female aged approx. $25^{-28}$ : bones only recently ossified. Tied round first with a rough network of horizontal 2-strand fiber cord. Above it, 2 bindings of vertical cords, 2 in each. Also tied round feet with a number of thin strips of cloth. Wrapped in 2 shawls which completely covered body of fairly coarse cloth with fringed edges and a line of embroidery near each edge. Outer shawl: 14 from fringe, a line of wool work 4.5 wide. Various patterns worked in red, green, yellow, and blue. The wool was worked onto warp of original cloth. These patterns were bounded by lines of the cloth thread. At head, end rolled up into a tight roll to rest on top of the head. At either end, there were 3 bands of coarser woof thread. Inner shawl: Much smaller, only covered top of body and halfway underneath. Similar band of wool work, but less elaborate and apparently only yellow and blue wool used. This shawl was wrapped round feet, but only came up to neck. Head fallen out of position. By it, out of position, there was a circlet (i) made by crossing ends and then twisting round so that circlet could be enlarged and contracted. This was made of copper. Under body, 3 palm sticks between wrappings and shirt. These were tied together at either end. One had a groove cut at the end for cord. Between wrappings and shirt, there was a regular layer of salt. A few plant seeds also on body. Round neck, a string of shells and glass beads, strung apparently with a string of shells together with 3 glass at intervals. Also strung on it, a silver ? cross. Remains of dark straight brown hair. By head, inside wrappings, a small glass bottle (ii) with an indentation each side and at bottom (MFA 47.1685). By head, remains of a hood of red cloth and black net work. On left forearm, 1 copper ? bracelet with ends (iii) and 1 of twisted palm? On right forearm, a similar copper? and 2 palm? On right arm above elbow, 2 ? bracelets. On left arm above elbow, 3 ? bracelets, 1 with key attached. By head, 2 earrings (iv). By right hand, plain copper ring. By left hand, 2 rings of twisted hair. Remains of 2 shirts. Outer: Round bottom, a band of blue cloth 5 wide sewn on exactly at bottom. On the blue, a pattern in white thread (v). At sides, where seams joined, this band extended up for about 6 . Seams were corded. Near bottom, 2 on front and 2 on back, 4 large rosettes (vi), on 2 sides woven in, on 2 sides sewn. Edges corded. Alternate yellow, red, and green on a blue ground. Inside red ground. On this, 2 very rough figures picked out in blue thread with green dresses. Inner shirt, which was a good deal darned, had a somewhat similar blue strip sewn on bottom, but projected considerably below bottom of cloth (vii). Seams at sides corded. Like other shirt, had apparently 4 rosettes near bottom designs? Also, from top of shirt, there were bands of red cloth, some showing lions? in blue and green, some alternate hares and flowers. Sleeves had double rows of hares and flowers. 
N 3747 F 5
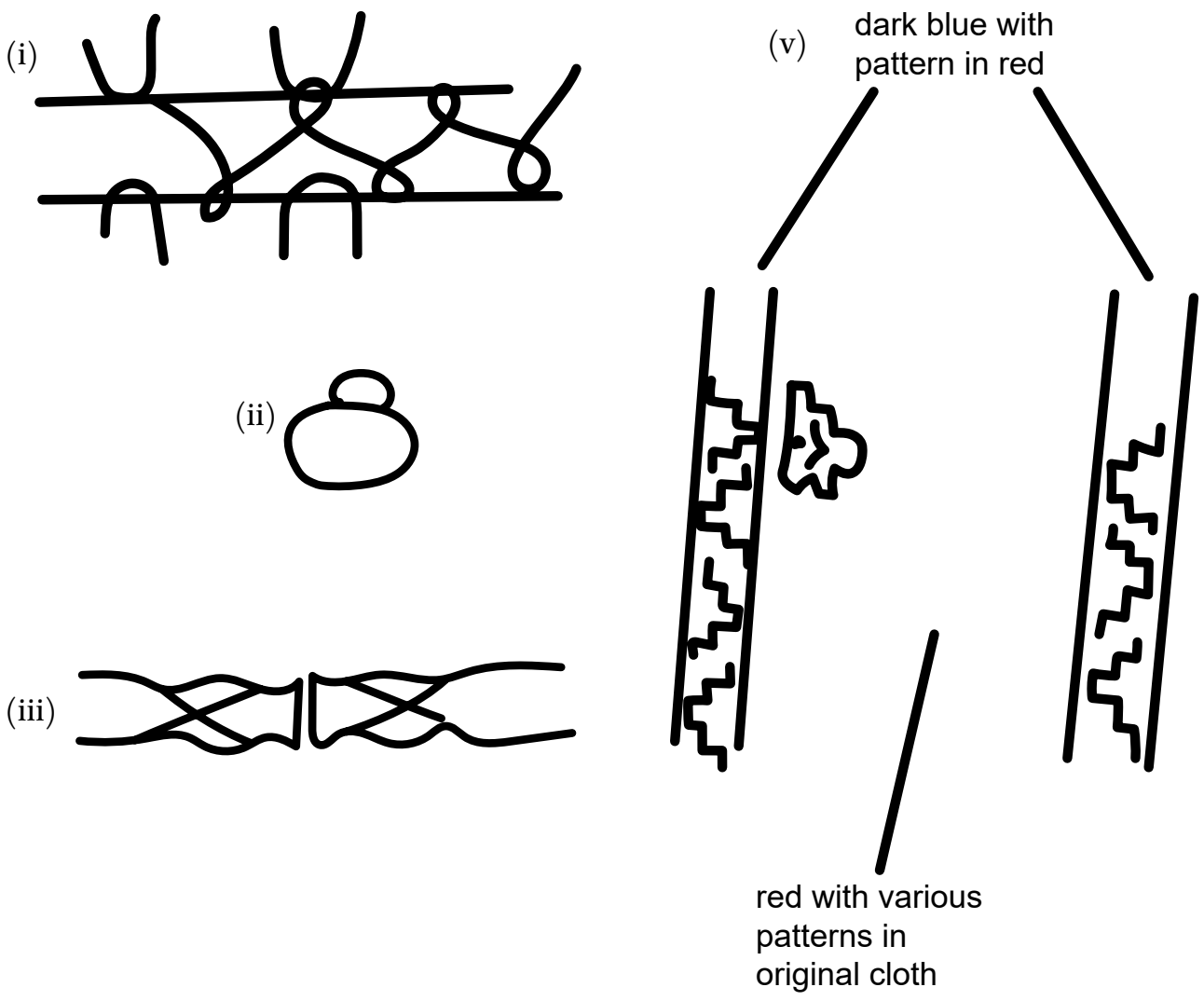

(iv)

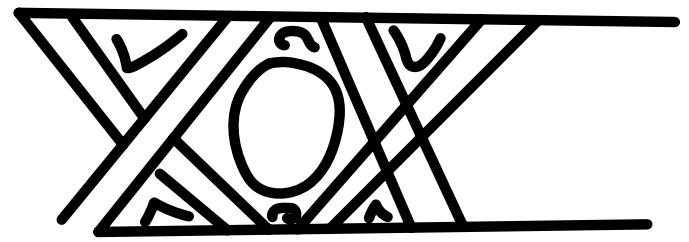

(vi)

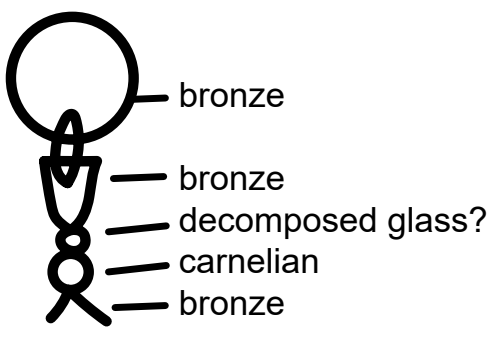


photo C 8451, C 8477

5. Female aged approx. 20-23. Most of bones just ossified. Tied first with horizontal bindings of coarse 2 -strand fiber cords. Then above with 2 vertical bindings of 4 and 3 cords respectively of fine 2 -strand fiber cords. These were bound as usual (i). Wrapped in a single wrapping of sackcloth folded over in usual way, flaps on body being sewn together with thin fiber cord. Quantity of salt on body. On finger of right hand, 4 rings, 2 of bone and 2 of bronze or copper, with small bezel (ii). On left wrist, bracelet of copper? Ends (iii). On left finger, bone ring. At either side of body, not underneath, a palm stick that on right side being outside and on left side inside shirt. Upper part of body disturbed and much damaged. Over skull, an additional pad of cloth. This consisted of an older shirt, which had once been embroidered. Two shirts on body. The outer one was of thin yellow cloth. Round bottom, a strip of blue cloth was sewn on, 13 wide, with decoration in white and yellow thread (iv). Down front and back, 2 broad lines of colored cloth inwoven (v). Thin lines of original cloth left between the lines. By head, 2 earrings (vi). Skeleton of fetus within. Bones fully formed. Between the shirts, round stomach, a belt of cloth 6 wide or folded up to that width. This was tied at the back. Similar band round sleeves and also a thin band of blue sewn on at cuff. Ends of sleeves corded. Inner shirt almost all destroyed. Sewn on to bottom of skirt, a band of blue 13 wide with patterns in yellow.

6. Adult male. Tied first with coarse 2-strand fiber rope. Above, bound vertically and horizontally with strong cord with additional horizontal bindings of finer cord. Wrapped on outside in a single wrapping of sackcloth folded over in usual way. Underneath, a wrapping of ordinary, rather coarse, cloth. This enveloped body completely and was tied round neck with strong cord. (After second photograph, body was turned on back.) This wrapping was turned back over body. Round feet, it was wound round and tied by ends of the fringing. On chest, the ends were sewn together with cord. Round neck, it was tied and also bound by a corner of the cloth wound round. Ends of this wrapping were fringed and starting at 19 in from fringe at either end, there were 5 lines of wool patterns sewn onto cloth. Underneath remains of an embroidered shirt, but only just enough to show that there had been one. Number of plant seeds on body and a quantity of salt. Under body, inside both wrappings, 2 palm sticks and 1 "sont." These were tied together at either end. Remains of dark brown straight hair. 
N 3747 F 7

(i)

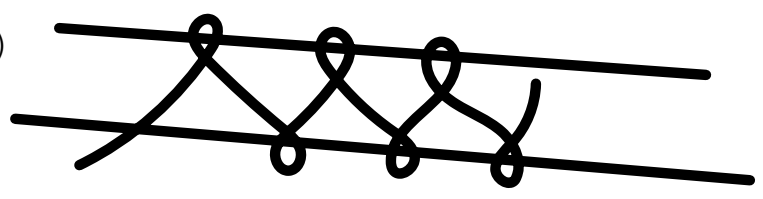

N 3747 F 8

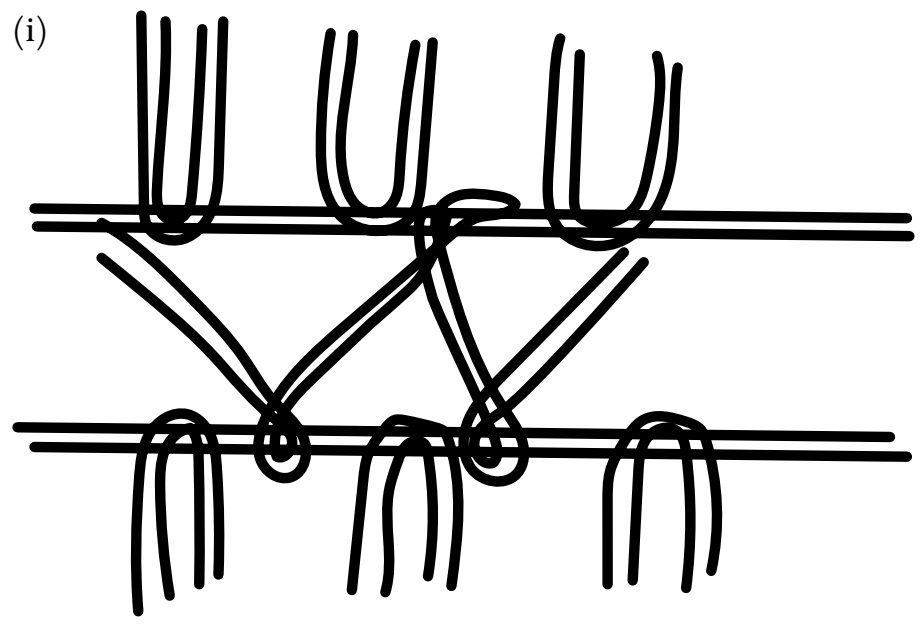

N 3747 F 9

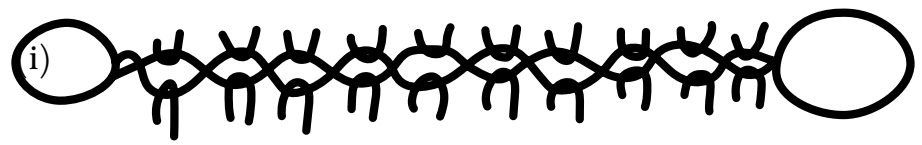


7. Adult. Female? Tied first with a rough horizontal network of 2-strand fiber cord. Then 2 vertical bindings of 3 and 4 cords respectively. These were fastened by cords, which went under body, and by separate crossing cords between them (i). Near feet, 1 strip of palm leaf bound round. Wrapped in a single shawl of sackcloth with plain edges and a line of open work near each end. Sides and ends folded over in usual way. Inside, a wrapping of fine black cloth. Quantity of salt. Several seeds on body. On right side of body, not underneath, 3 palm sticks tied together at ends. These were inside black wrapping. Below, a wrapping of coarse cloth. Below, remains of a very thin cloth shirt with corded edges. Skin remaining on upper part of body. Hands resting in front of pelvis.

8. Wrapped round on outside with rough sackcloth with fringed edges. Body was laid on this. Sides were thrown over and join on top of body. Sewn together with thin fiber cord. Ends thrown back over head and feet. Then tied round with coarse 2-strand fiber cords horizontally in a rough network. Then tied with 2 double cords down front of body going round head and feet. To each of them were attached tape bindings, which went underneath body, a network of similar tapes joining the 2 double cords inside (i). These tapes were made of alternate coarse red and white threads on a warp of smaller double brown threads, (the latter) being 2 at a time at wide intervals. Sent away whole.

9. Adult female. No back teeth in lower jaw. Tied first with 2 vertical bindings of 2-strand fiber cord tied round head and feet. To these were attached thin cords, which went round body (i). A single wrapping of sackcloth turned over in usual way. Salt and plant seeds on body. Below remains of a cloth wrapping, which completely covered body? By head, remains of a hood or veil of black cloth. Only traces left. Below, remains of a cloth shirt apparently plain. Nose of skull extraordinarily turned up. Under body, inside wrappings, 2 palm sticks fastened together at ends. These were bent to a bow shape. Shirt reached to about halfway between knees and ankles.

10. Adult female. Bindings of 2-strand fiber cord. 3 vertical bindings first down front and round head and feet. Then horizontal bindings of 3 or 4 ends each fastened round each other and around vertical bindings in a rough network (i). Wrapped in 2 rough sackcloth shawls with fringed edges and a band of drawn work near each end. Under body, between sackcloth and shirt, 2 palm sticks. These were fastened together at either end. Quantity of salt on body. Over head and face, a covering of fine black cloth. At top, coarse net. Below, closely woven. Few plant seeds scattered on body inside wrappings. On left hand, a 
N 3747 F 10

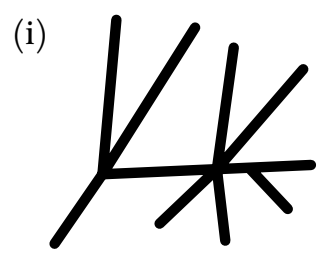

(ii)<smiles>[Os]</smiles>

(iii)

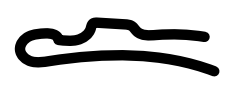

(iv)

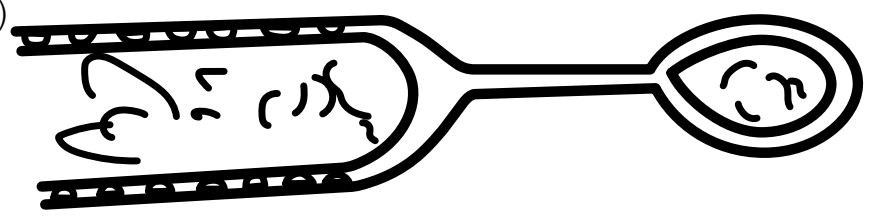

(i)

N 3747 F 12

OH⿻ 
ring of [ed.: material not given here; in manuscript, it is bronze] with seal. On right wrist, bronze bracelet (ii).Right arm at any rate was not in sleeve of shirt. On left wrist, a similar bracelet. On left elbow, an iron bracelet. On right elbow, an iron bracelet, end overlapping, both ends so (iii). One pierced shell inside wrappings. Remains of shirt with 2 bands of colored cloth and embroidery down front. Edges corded (iv). Border blue with red semicircles. Inside red with patterns in original cloth. Remains of sleeves with a similar band.

11. Female? Very old. No teeth left in either jaw. Tied round with vertical and horizontal single-strand cord. Tied in with cords on top. 3 or 4 rough balls of cord. Wrapped round on outside with coarse cloth, not sackcloth, with fringed edges. Edges of cloth turned over in usual way. Below, a second similar wrapping, also tied round. Over head, a mass of dark, finer cloth. Bones were considerably disarrayed. Remains of a shirt, but almost entirely rotted away. Corded edges. 2 palm sticks under body. Right humerus had been broken. 2 parts had receded and were worn down to points. Ball of left femur also broken off and decayed. Few plant seeds scattered on body. Quantity of salt on body. By left hand, a ball of cord containing a piece of pottery. Remains of another wrapping? with a wide check pattern of dark red or black thread.

12. Female? Old. Hardly any teeth. Tied first with a few horizontal bindings, then with 2 vertical bindings of 3 cords each. These were fastened round head and feet and crossed each other in zigzag down body, being held in position by cords, which caught the loops amd passed round back (i). The cords were of fiber, 2 strand. Outside cords, remains of a cloth wrapping? This may have belonged to another burial. Covered with a single wrapping of sackcloth with fringed ends and a band of open work near each end. The ends were rolled up in usual way over head and feet. Sides were turned over and fastened together with cord. Below, wrapped in a double wrapping of cloth, which reached to knees. Ends of this were folded over in such a way that they did not meet over body. Below, another wrapping, which covered whole body including feet. Below, remains of a plain shirt with corded edges. Under body, outside shirt, 2 palm sticks. These were fastened together at either end, notches being cut to keep cords in place. Quantity of salt on body and a few plant seeds. Remains of a fine cloth veil or cap by head.

13. Adult male. On outside, tied round with 2-strand fiber cords horizontally, then with a vertical tying of 8 cords running down middle of body and tying round feet and head. Wrapped outside in a covering of sackcloth with fringed 


\section{N 3747 F 14}

(i)

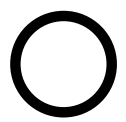

(ii)

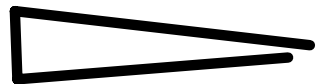

N 3747 F 15

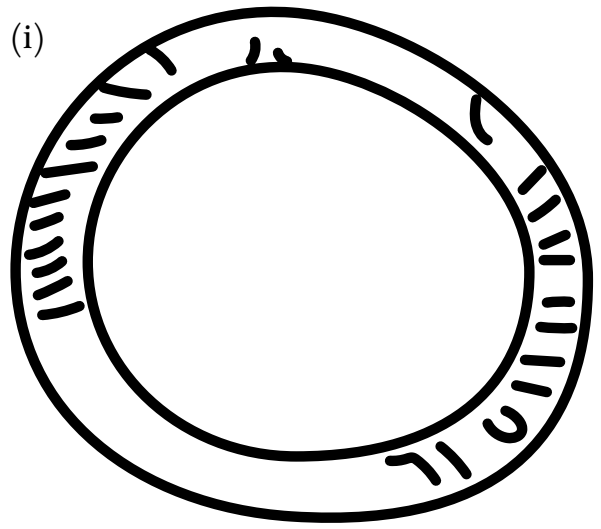

N 3747 F 16
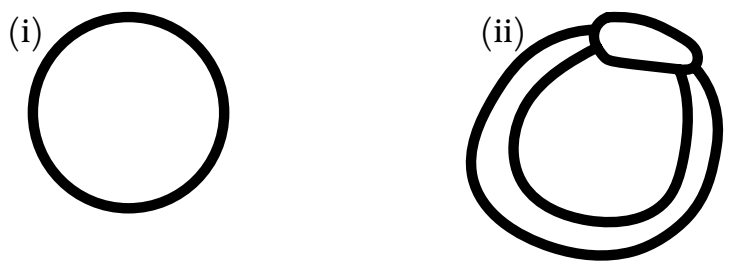

N 3747 F 17

(i)

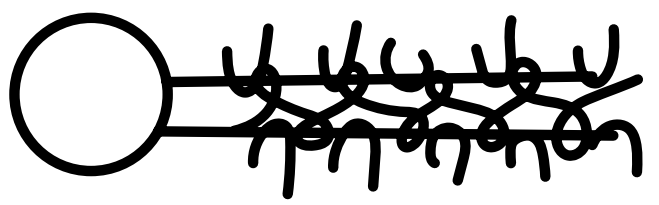

(ii)

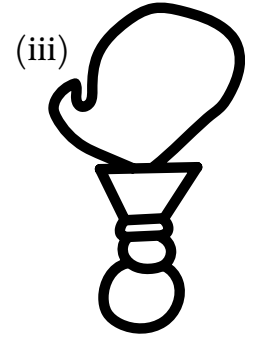


edges. Under this, body was tied round leg and by neck only. Below, more sackcloth shawl wrappings. 4 in all. Quantity of salt on body. Between sackcloth and shirt, 1 on each side of body, not below, 2 thick sticks, 1 "sont" and other sesaban? Near end of latter, head end, a pierced dom nut transfixed. Remains of 2 shirts? Outer had almost all decayed away. Had been elaborately embroidered, but only cord enclosing work left. Over head, a pad of fine cloth. This had been apparently a fringed shawl with an elaborate line of embroidery at either end, possibly only in corners. Right ulna had been broken near elbow, radius not. Upper shirt was of somewhat coarser dark cloth. Under shirt was of fine, soft, white cloth with remains of embroidery. Round sleeve from end, 2 narrow bands of red cloth with patterns in black and original cloth (all inwoven). A similar band went down front of shirt? There were also 2 rosettes of similar designs, but these were sewn onto cloth.

14. Child aged approx. 4. Wrapped first in sackcloth and tied round. Underneath, remains of a plain linen shirt. 2 palm sticks under body, inside sackcloth. On left arm, bronze bracelet of (i) type, ends widening out (ii).

15. Child aged approx. 5. Wrapped first in sackcloth and tied round with 2 -strand fiber cord. This cloth was made of 2 pieces sewn together. Body was laid upon it, sides thrown over and excess at head and feet thrown over and tied round. Below, remains of a coarse linen shirt. This had been embroidered, but color almost all gone. Round neck, narrow red border with yellow thread decoration. Under body, between sackcloth and shirt, 2 palm sticks. Quantity of salt on body. On right arm, a bracelet of bronze, bound round and round with a strip of copper? wire (i). Similar bracelet on left arm.

photos $\mathrm{C} 7787, \mathrm{C} 8475$

16. Small child aged approx. 3. Wrapped first in a rough cloth and tied round with fiber cord. Under this, a second wrapping of cloth with remains of embroidery, apparently a shirt. On each arm, 2 iron bracelets (i), 2 with (ii) [ed.: i.e., bezel] (MFA Eg.Inv. 1541). On breast, a cross of lead or decomposed silver. Also, a bronze bird amulet. Body covered with salt. Inner shirt apparently of usual pattern with 2 seams at each side. 1 sleeve left. Sewn for 11 up from wrist. Above open. Round bottom, a band of red cloth sewn over, and a second similar band at top of sewn part of sleeve. Bottom of shirt plain. Top? 2 or 3 corded frames of rosettes for working left, but wool almost entirely gone.

photo C 8451

17. Adult female. Tied first with horizontal 2-strand fiber cords. Above, 2 vertical bindings of 6 cords, bound as usual (i). Round neck, an additional binding 
N 3747 F 19

(i)

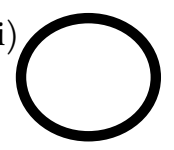

(ii)

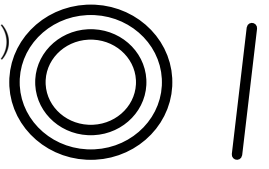

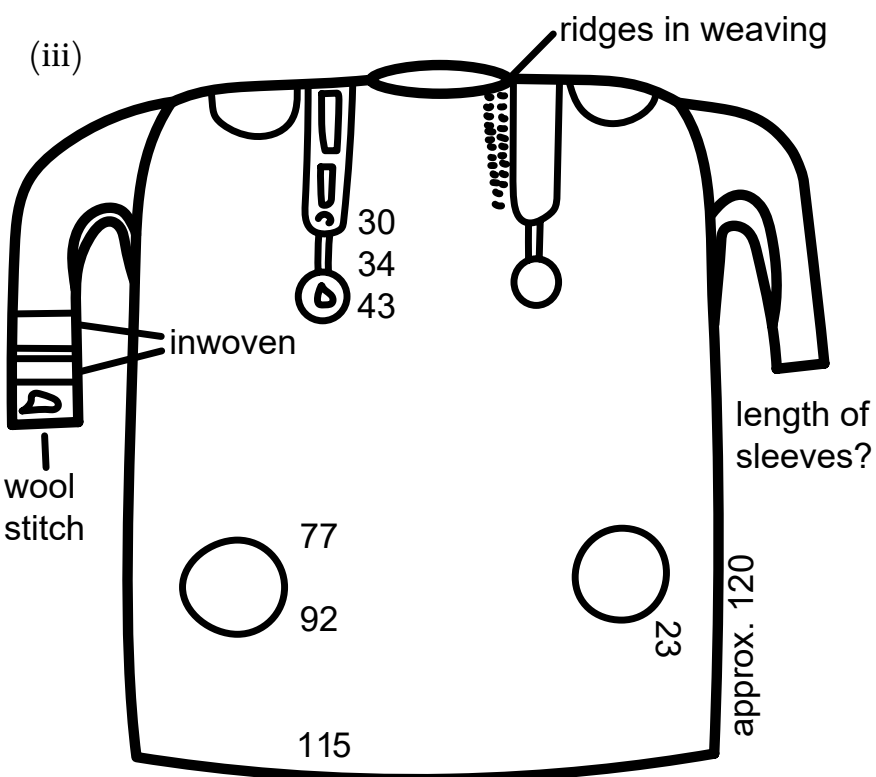

sleeve

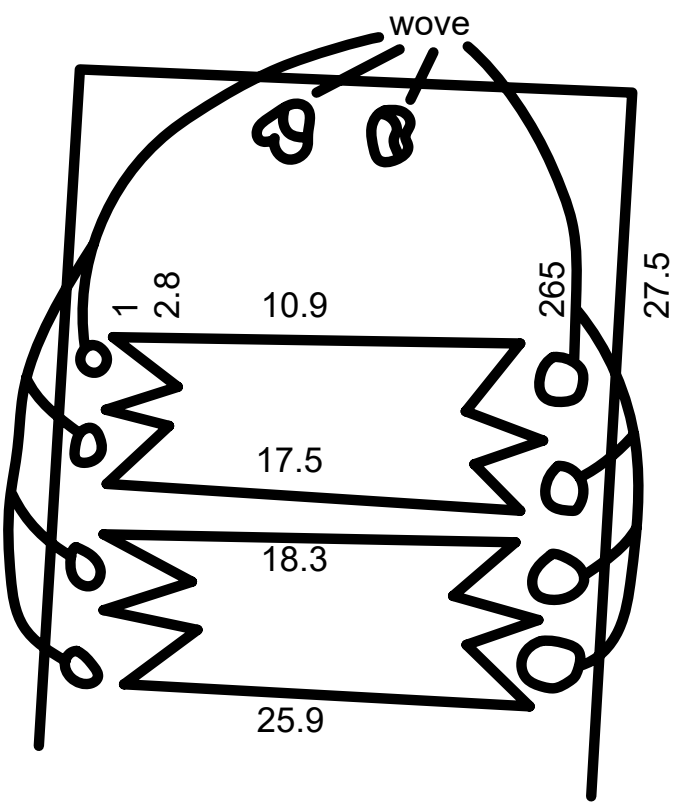


of strips of cloth. Tied in with this at neck, a quantity of loose palm fiber. Wrapped outside in a covering of sackcloth. Edges thrown over in usual way and fastened together with cord. Under this wrapping, over head, remains of black cloth. Below, wrapped in a covering of coarse cloth. This enveloped head and came down to ankles, round which it was fastened by the 2 cords. Quantity of salt between this wrapper and the shirt. Also, a few plant seeds. Skull had fallen out of position. On it, there was the remains of a net hood or veil by head, but all folded up and not in position. Also, apparently round neck, tight rolls of cloth covered with red cloth worked diagonally (ii). This was apparently attached to a thick cord. By left ear, silver? earring (iii) (MFA Eg.Inv. 1544). Right one had gone. Remains of elaborate embroidery by neck of shirt, but only outlines of patterns left. There may have been a third wrapping above shirt.

18. Outside wrapping consisted of a cloth wrapping with fringed edges. This was a shawl on which body was laid, sides and ends being thrown over. Tied round with horizontal and vertical cords (2-stranded) of fiber. Quantity of salt. Under body, between shirt and wrapping, 1 thick "shawm" and 2 "sont" sticks. By left hand, a large twist of fiber. Remains of shirt with elaborate work, which had almost all rotted away. Over head, roll of cloth with rows of white thread inwoven. This was end of outside wrapping.

\section{photo C 8477}

19. Adult male. Tied first with a network of 2-strand fiber horizontal bindings. Above, a few horizontal bindings of 4 strips of sackcloth down center of body and joining round head and feet. To these were also attached fiber cords, which went round body. Wrapped in a shawl of plain cloth (not sackcloth) with fringed edges folded over in usual way, ends tied round feet. Quantity of salt on body. Also, a few plant seeds. Under body on left side, but not by hand, 4 iron? rings with bezels and 2 of bronze?, 1 of usual pattern (i), other cut from a thin disc (ii). These were probably all tied together, as there was a wisp of thread by them. They were all surrounded by salt. Under body, between wrapping and shirt, 2 palm sticks. One of these was notched at the end for end, but they were not tied together nor was there any cord visible. Remains of an elaborate shirt of yellow cloth ornamented with green cloth (inwoven) with yellow stitched patterns. Wide band over each shoulder. Large rosette on either breast and on either side near bottom. This shirt reached to the knees (iii). Neck turned over and hemmed. Sides corded. Bottom finished off thick in weaving. Bottom of sleeves corded. Ornamentation in green cloth, worked in on warp, sides sewn. Pattern worked in in yellow thread. Shirt cut from one piece of cloth. Long, very curly hair. 
N 3747 F 21

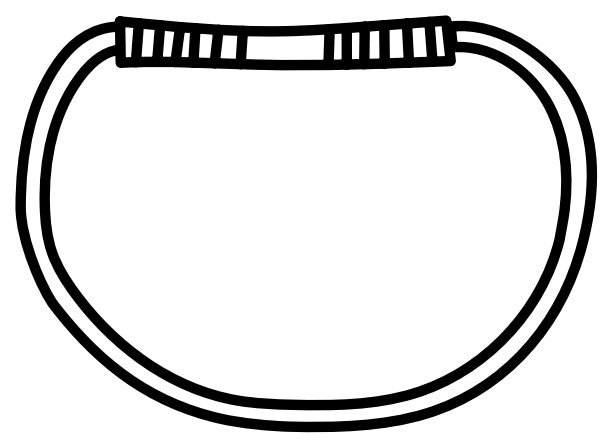

N 3747 F 22

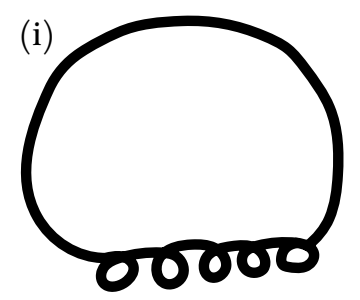

(ii) $\mathbf{0}$

(iii)

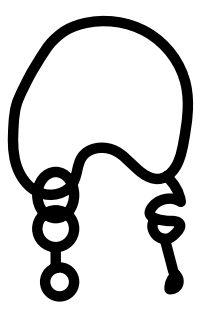

(iv)

(v)<smiles>c1ccccc1</smiles> 
2o. Adult. Male? Back teeth worn away. Outside wrapping of plain cloth (almost all gone) tied round with a few cords. Below, wrapping of sackcloth with numerous horizontal bindings of fiber cord and a vertical binding of 9 cords running down center of body and dividing to go round feet and head. Sticks at sides, not underneath, between sackcloth and shirt. At right side, 1 long palm, and 1 short palm, and short piece of "sont." On left side, a long "sont." Over head, several bunches of soft palm fiber. Quantity of salt on body. Remains of shirt with corded edges.

photo C 8472

21. Adult female. Remains of 2-strand fiber cords, 2 thickness. Type of tying? By feet, a bunch of cloth strips in very bad condition covered with a single wrapping(?) of plain cloth. Under body, apparently inside shirt, 4 palm sticks. Over head, remains of a net veil of twisted yellow and black cloth. Round neck, a circlet of bronze? of (i) type. Remains of shirt with a border of green or dark blue with yellow geometrical patterns sewn on to bottom. Also, remains of a large rosette near bottom with yellow, red, and blue wool embroidery. Outer shawl had a fringe and occasional lines of open work filled in with red thread.

\section{photos C 8451, C 8474}

22. Child aged approx. 10-12. Cloth very much decayed. Apparently, wrapped first in rough cloth with a large pad over head (see below). Underneath this, tied round in all directions most carefully with 2 -strand fiber cord. Over head, a handmade network of coarse threads and dark green wool. Under this, a net cap or hood with knob top. On both ears, elaborate earrings (i) made of a single bronze wire by twisting. From loops hung bronze chains (ii), 2 links being made by twisting a simple wire. These differed in length. At end of each, a glass bead, but on left in one case instead of chain (iii). Fastened to main ring above a small ring (iv). On right forearm, a bronze bracelet (v). On left forearm, 2 iron bracelets. At left elbow, bracelet made by bending to a circle a thin strip of palm and binding it round and round with fiber? Round neck, a necklace consisting of a few shells, 3 small bronze crosses, a bone button, and 2 or 3 green glass beads threaded on cloth twist. Under body, between shirts and outer wrappings, 2 palm sticks. Quantity of salt on body. On 1 finger of left hand, 3 bronze rings and 2 bone. Remains of straight, dark brown hair. Few plant seeds on body. Underneath, apparently 2 shirts, both in very bad condition and stiff with salt. Head pad consisted of a shawl $144 \times 6$ o with fringed edge and 2 small bands of drawn work at each end filled with green wool. 
N 3747 F X

(i)
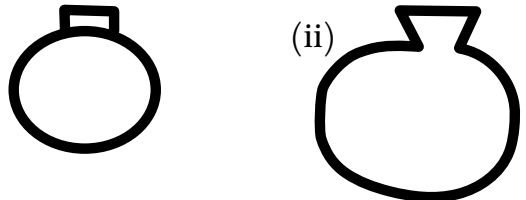

(iii)

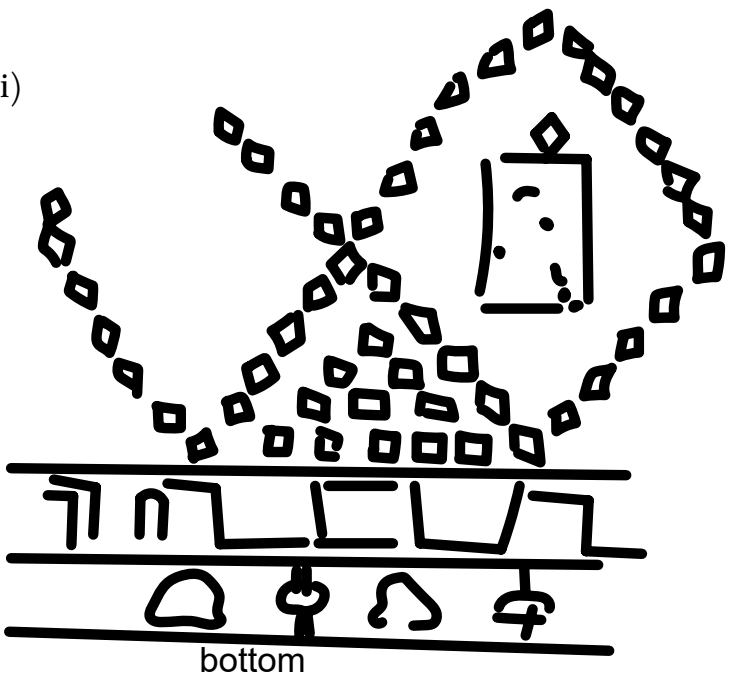

drawn

tasselled
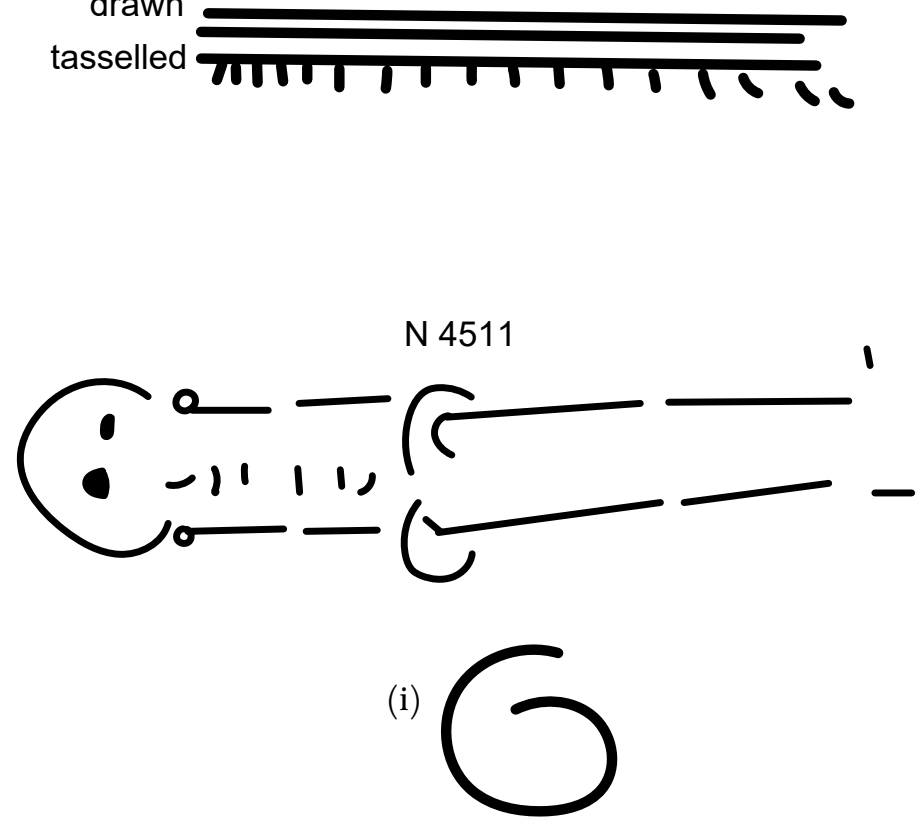
23. Adult female. Remains of 3-strand fiber cord. Not enough left to show type. Wrapped in 2 or possibly 3 shawls of cloth, the 2 outer being fine, the inner coarse. The middle one of these had fringed ends, and near ends, a band of drawn work with decoration in dark blue and red wool. Skull had fallen away out of position. Remains of an embroidered shirt, but very little left. Under body, 1 on each side, 2 palm sticks. Quantity of salt with body. Remains of an extra pad of cloth, which had gone over head. 2 small bronze rings by body ? ? earrings.

\section{photo $\mathrm{C} 8478$}

? number X

[ed.: The " $\mathrm{X}$ " designation was apparently an official one. In the draft of his manuscript, Mace refers to this burial as 3747 F X.]

Tied first with horizontal 2-strand fiber cord bindings. Then with double vertical bindings, which were fastened together and round body. By feet, a ball of extra cord. Below, wrapped in a sackcloth, ends of which did not meet on top, but underneath. Band of open work near ends. Under this, over head, 5 rolls of halfa grass tied round separately with cord. These contained a small palm stick in center as core. These rested on a bed of loose fiber, the whole being fastened to head by bindings of cord. Below, bound with additional horizontal bindings of cord. Below, a second wrapping of sackcloth similar to first, but without line of open work. Sides of this fastened together with cord. Skull fallen out of position. Vertebrae beginning to join together. 7 lightly joined in one place. On little finger of left hand, an iron ring (i). On third finger of left hand, bronze ring (ii). Round neck, remains of a leather collar? with small pendant leather bag. Remains of 2 shirts? Upper: Practically nothing left but pieces of the embroidery. Lower: Apparently nothing but a shirt reaching to breast, but possibly upper part had disappeared. This had been covered with embroidery sewn straight on to cloth without drawn work. Pattern was something of this sort, etc. (iii)

24. Small child. Remains of a net veil over head.

[ed.: According to Hearst Museum records, 6-1712 (wooden staff) and the ceramics 6-1713-6-1722 and 6-2863 are from this burial.]

\section{N 4511 (TC) Not on map; photos C 8479, C 8571}

Copt. Small child. Covered with rough sackcloth. On both wrists, elbows, and ankles, gilt bronze rings, all of (i) pattern. Round head, circlet of palm wood, surrounded on outside with with paste and straw. Round neck, strings of shell and blue and green glass beads. The glass beads were all on left side. On other 
side, only one blue bead fastened to a thick cord of leather. Above left shoulder, copper disc, possibly coin, dated 4th year of Justinian (MFA Eg.Inv. 1545). On left ear, bronze earring.

\section{Other objects}

[ed.: According to Hearst Museum records, the following objects are attributed to tombs that do not exist in the original excavators' records.]

6-12504, jar, N 2567

6-12505, hoe handle, $\mathrm{N} 2606$

6-12514, incomplete jar, $\mathrm{N} 2747$

6-14349, ovoid jar, $\mathrm{N} 2051$ [ed.: Note that the original excavators' notes tentatively label $\mathrm{N} 2051$ as $\mathrm{N} \mathrm{2114}$, but there is no record of this object in that burial.] 6-14350, broken jar, $\mathrm{N} 2064$

6-1446o, jar, $\mathrm{N} 2265$

6-14467, jar, N 2379

\section{Bibliography}

Reisner, G. A. 1932. A Provincial Cemetery of the Pyramid Age, Naga-ed-Dêr Part III. University of California Publications, Egyptian Archaeology, vol. vi. Berkeley. 


\section{Plates}

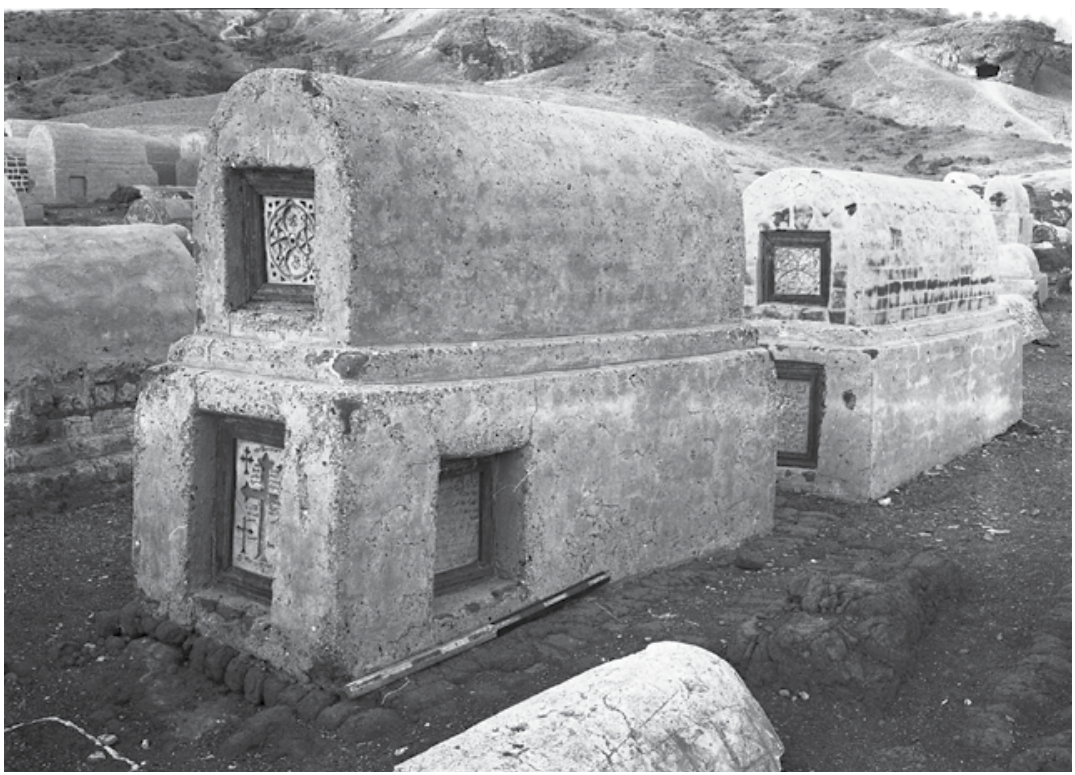

FIGURE 1.1 Modern Coptic graves with plaques (NED-C-8552)

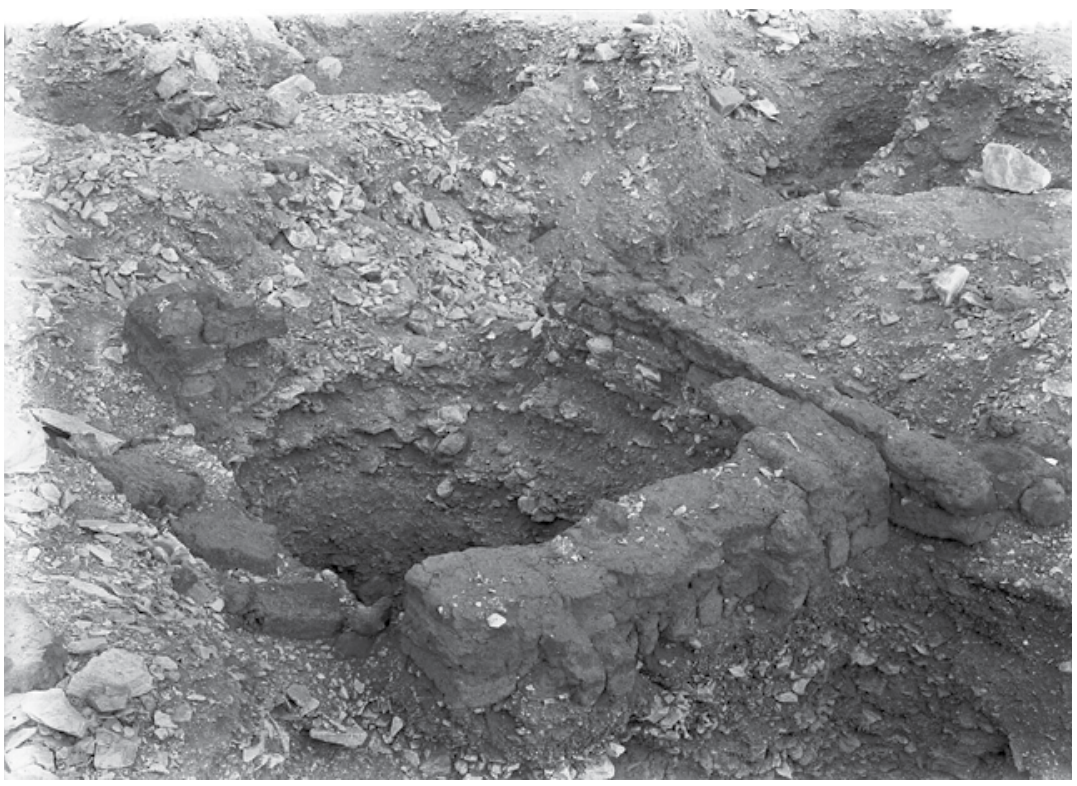

FIGURE 1.2 Superstructure of N 2049 (NED-C-8506) 


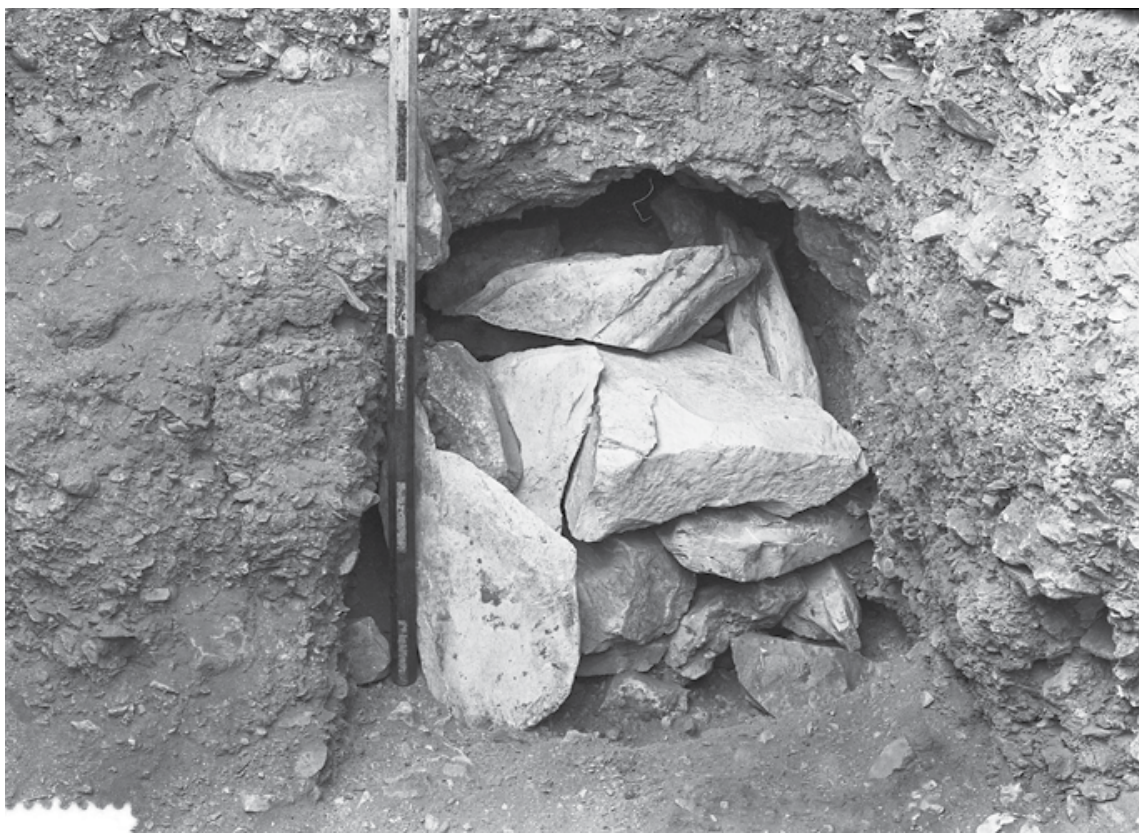

FIGURE 1.3 Blocked door of N 2114 (NED-C-8518)

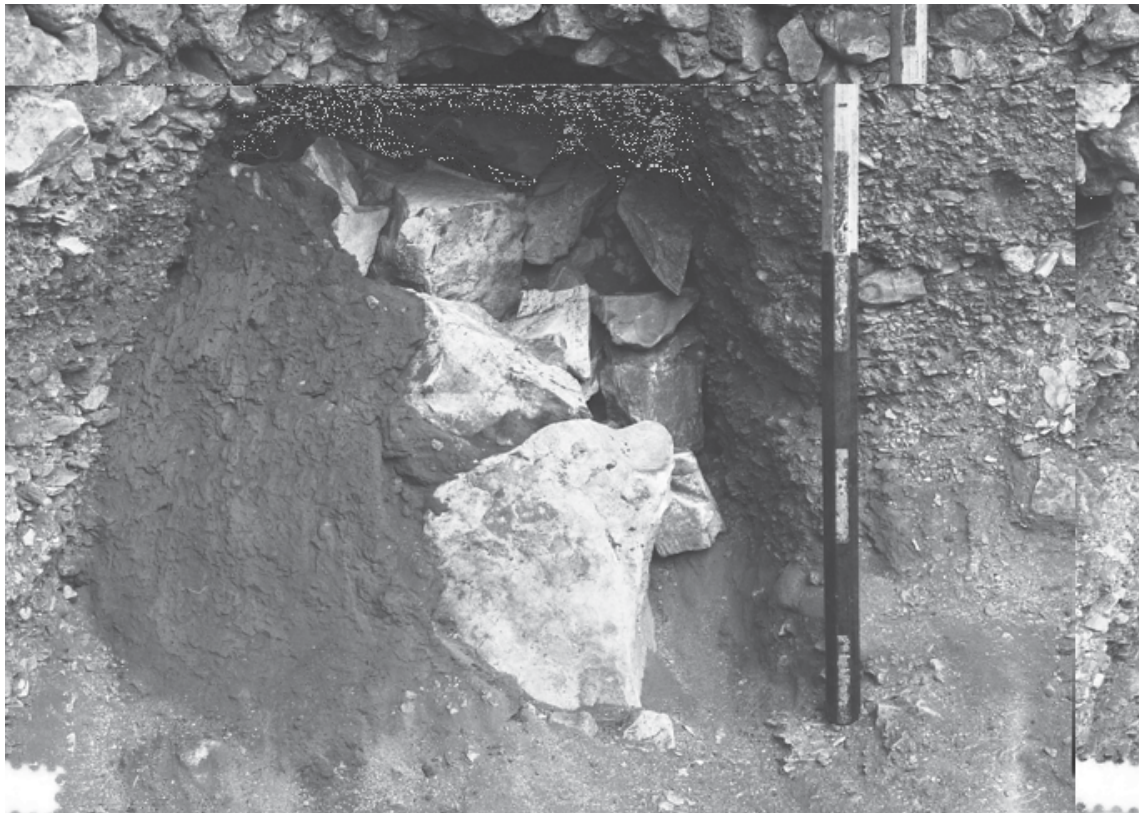

FIGURE 1.4 Blocked door of N 2119 (NED-C-8516) 


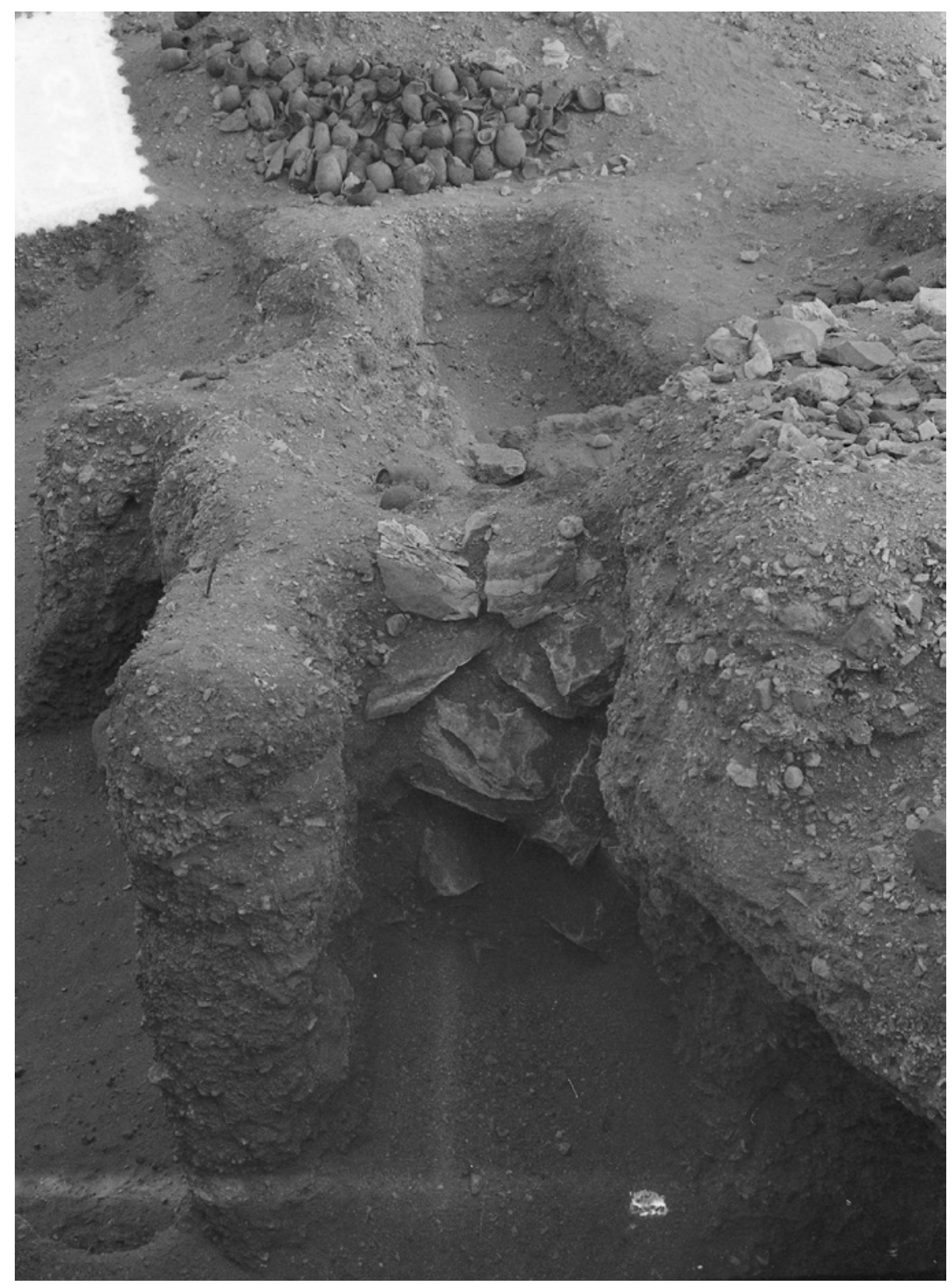

FIGURE 1.5 Blocked door of N 2442 (NED-C-7473) 


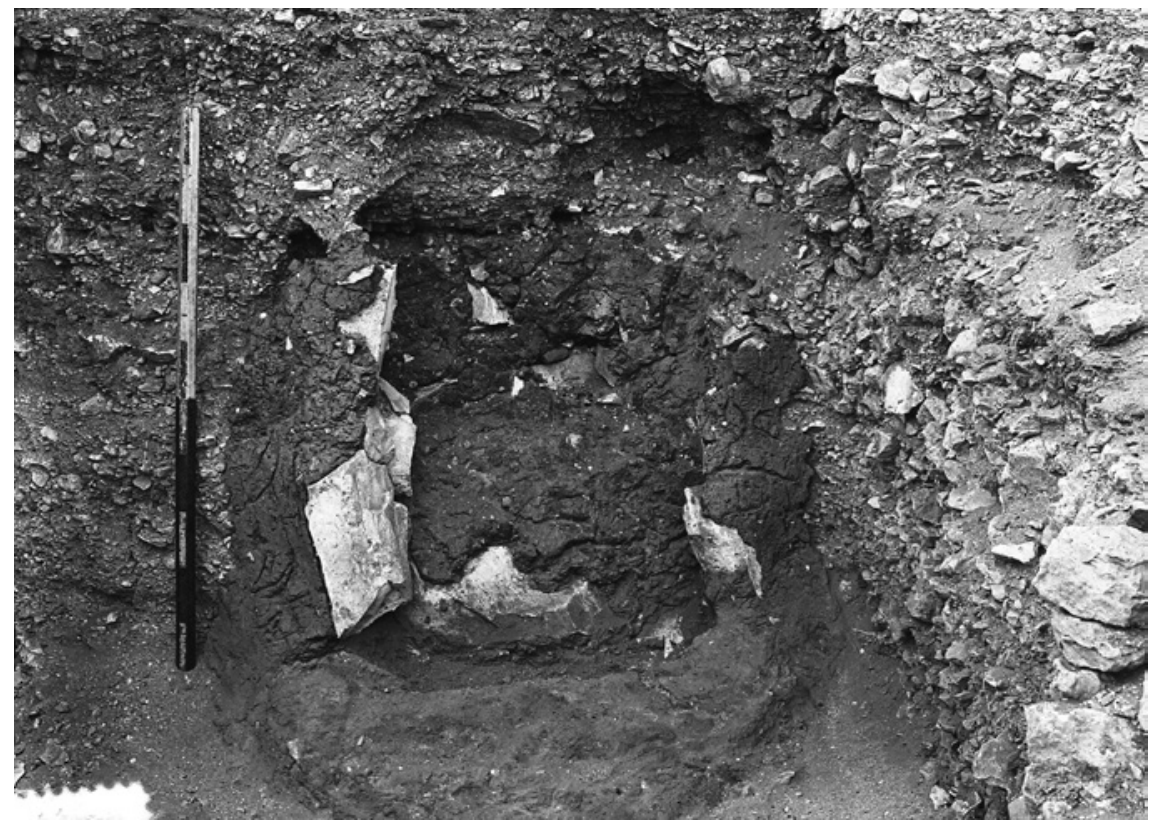

FIGURE 1.6 Blocked door of N 2507 (NED-C-8522)

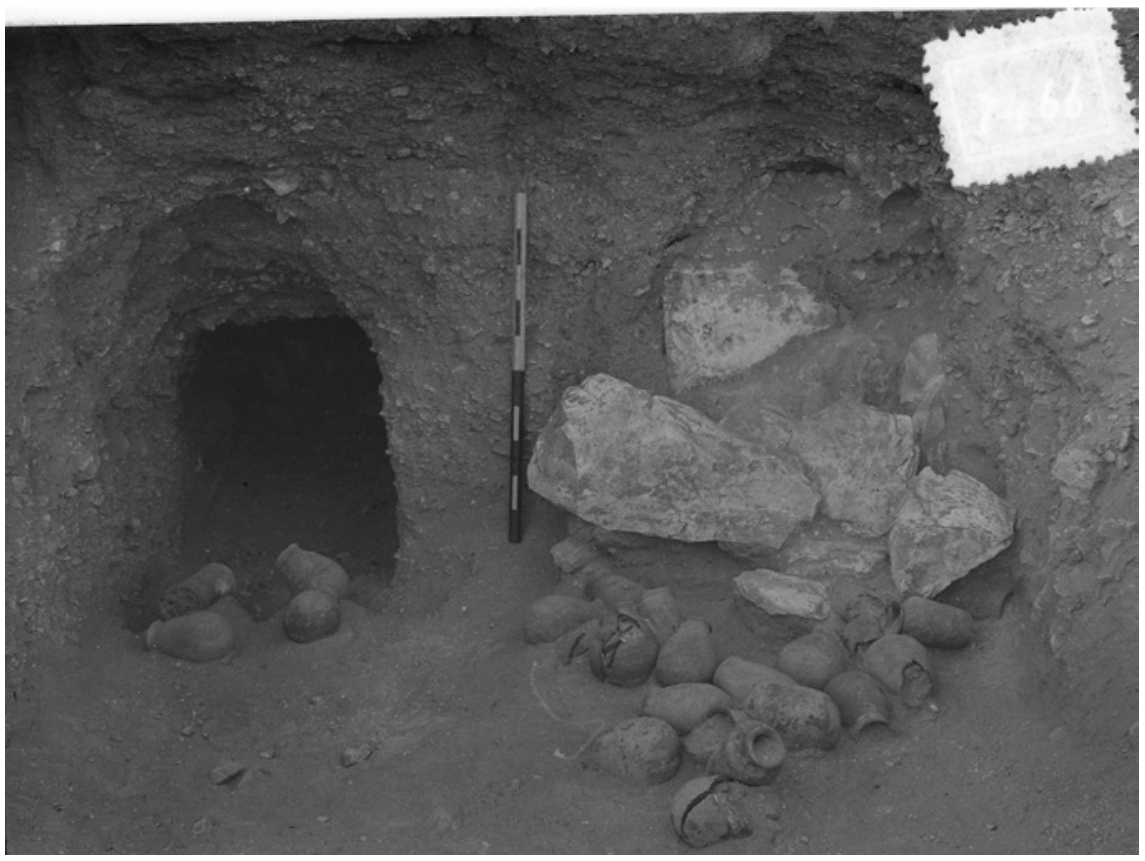

FIGURE 1.7 Blocking in front of stela in N 2507 (NED-C-7466) 


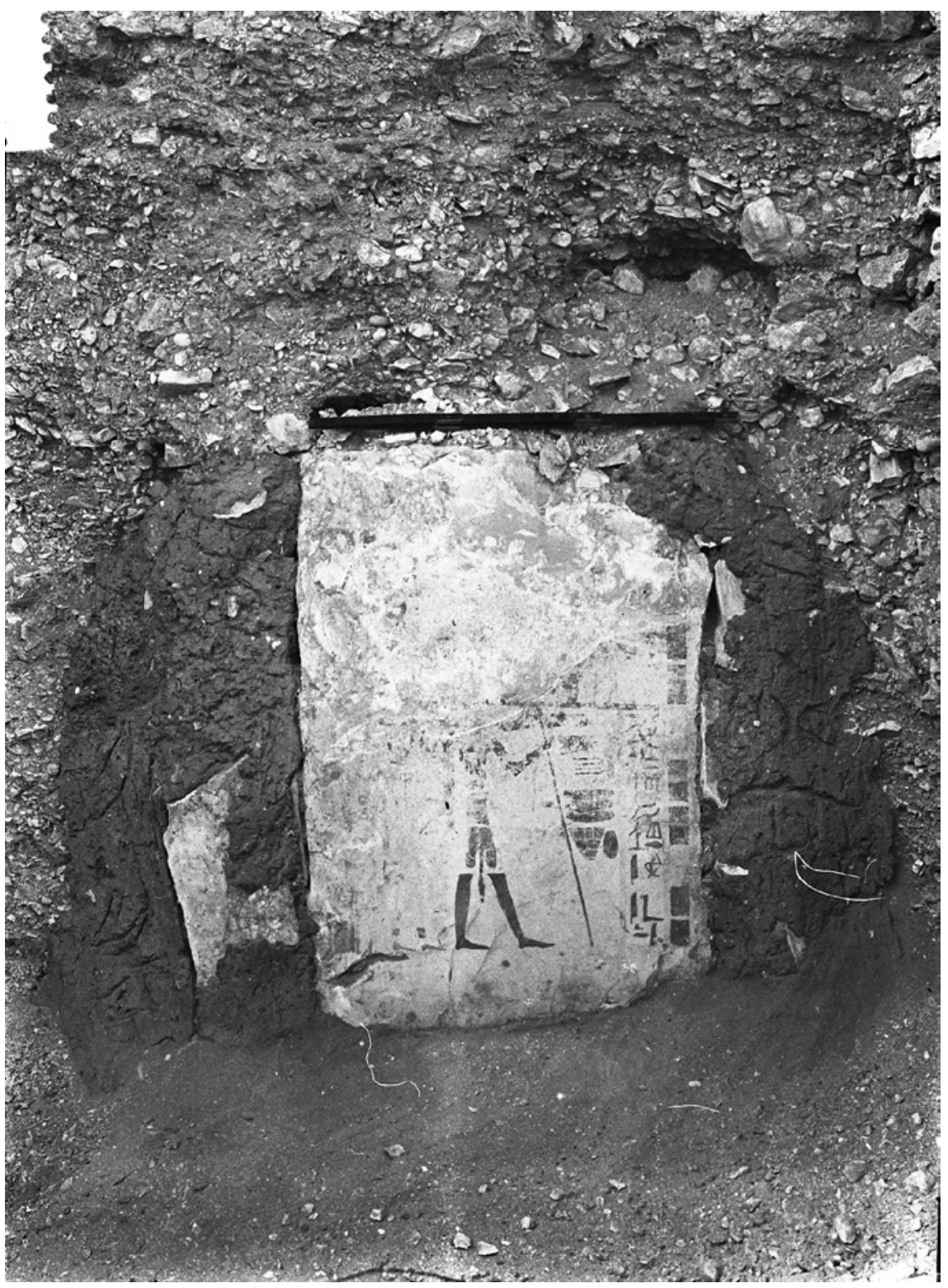

FIGURE 1.8 Stela in position N 2507 (NED-C-7770) 


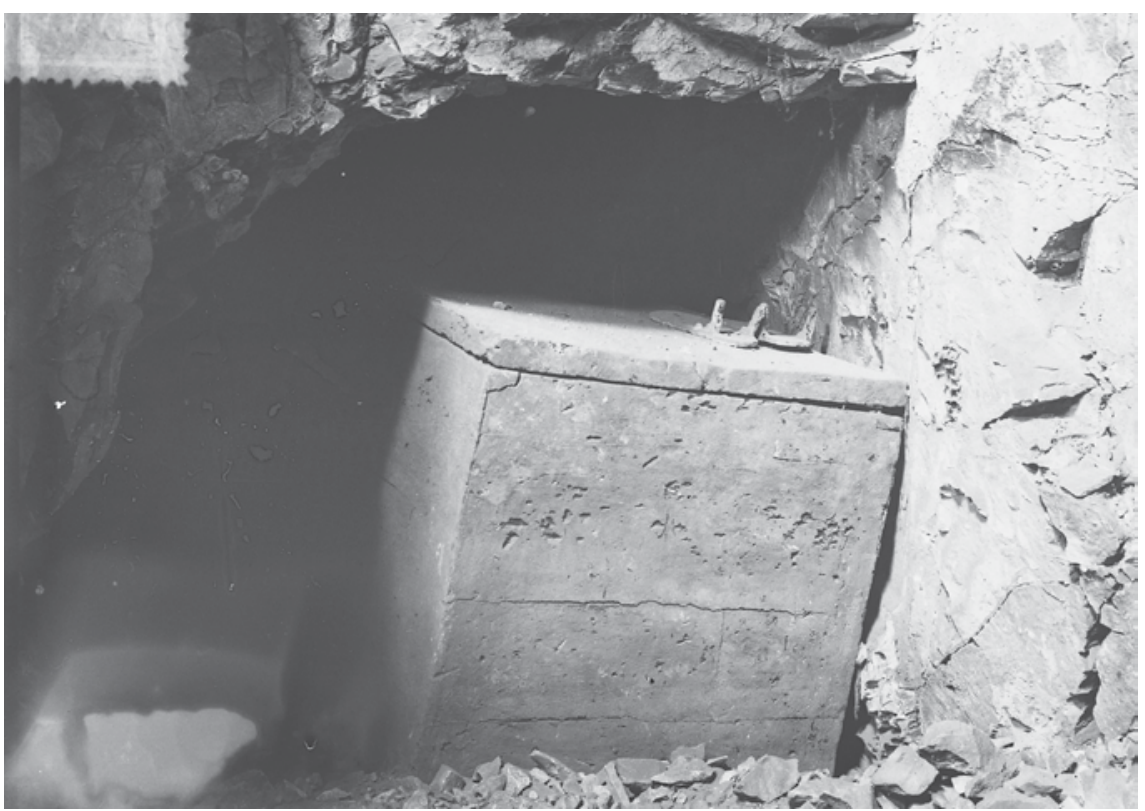

FIGURE 1.9 Coffin with sandals on top N 2511 (NED-C-2112)

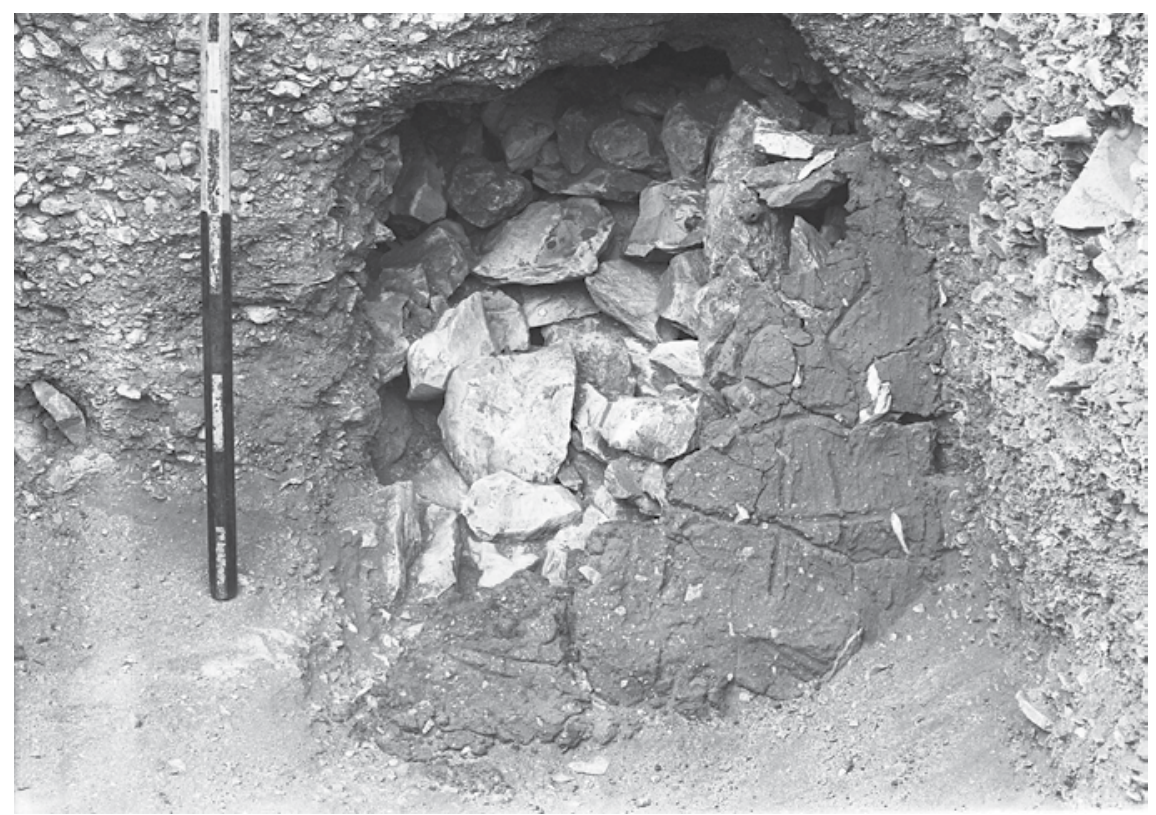

FIGURE 1.10 Blocked door of N 2618 (NED-C-8520) 


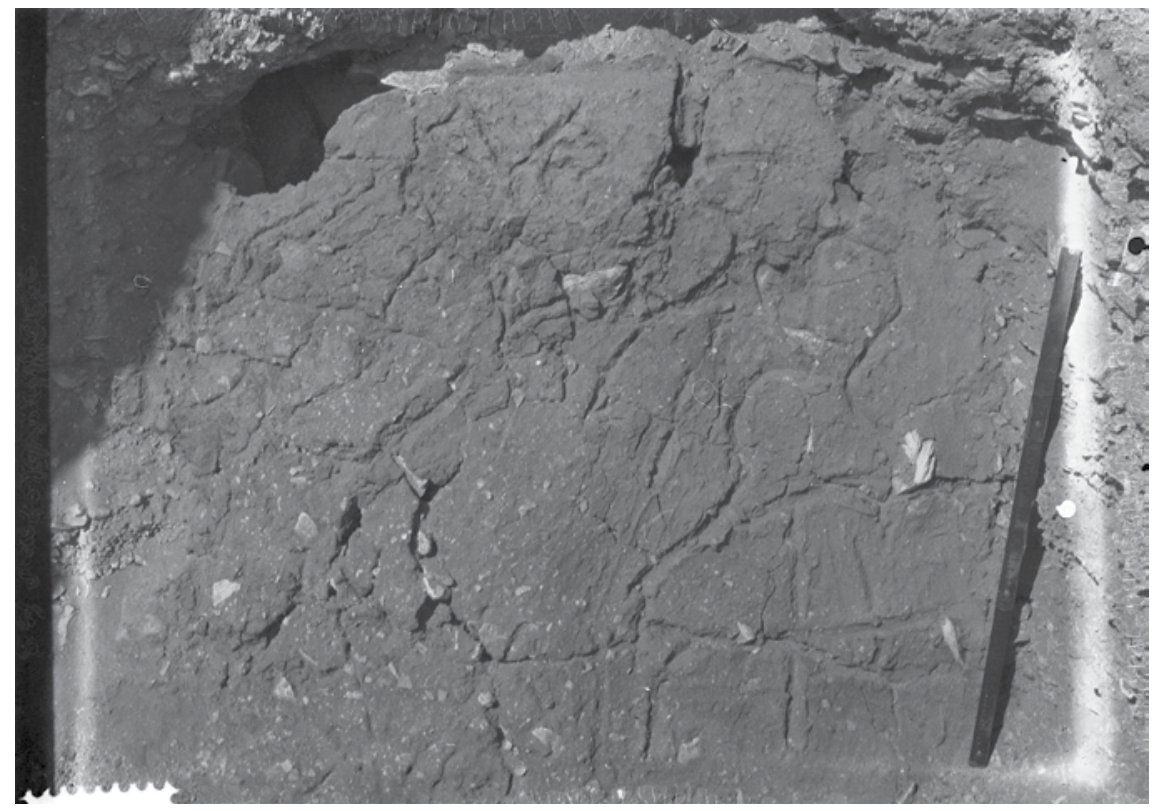

FIGURE 1.11 Detail of scratchings on door of N 2618 (NED-C-8594)

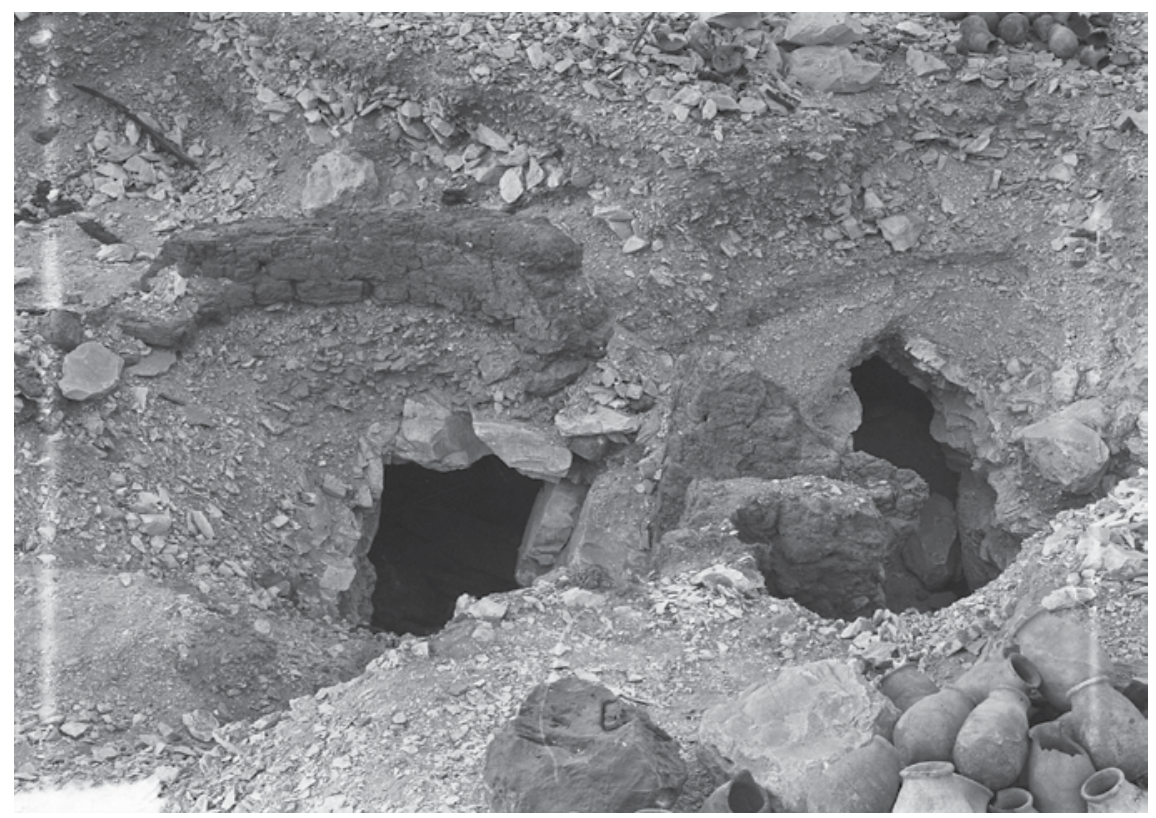

FIGURE $1.12 \quad$ N 2640 and N 3747 with superstructure (NED-C-8503) 


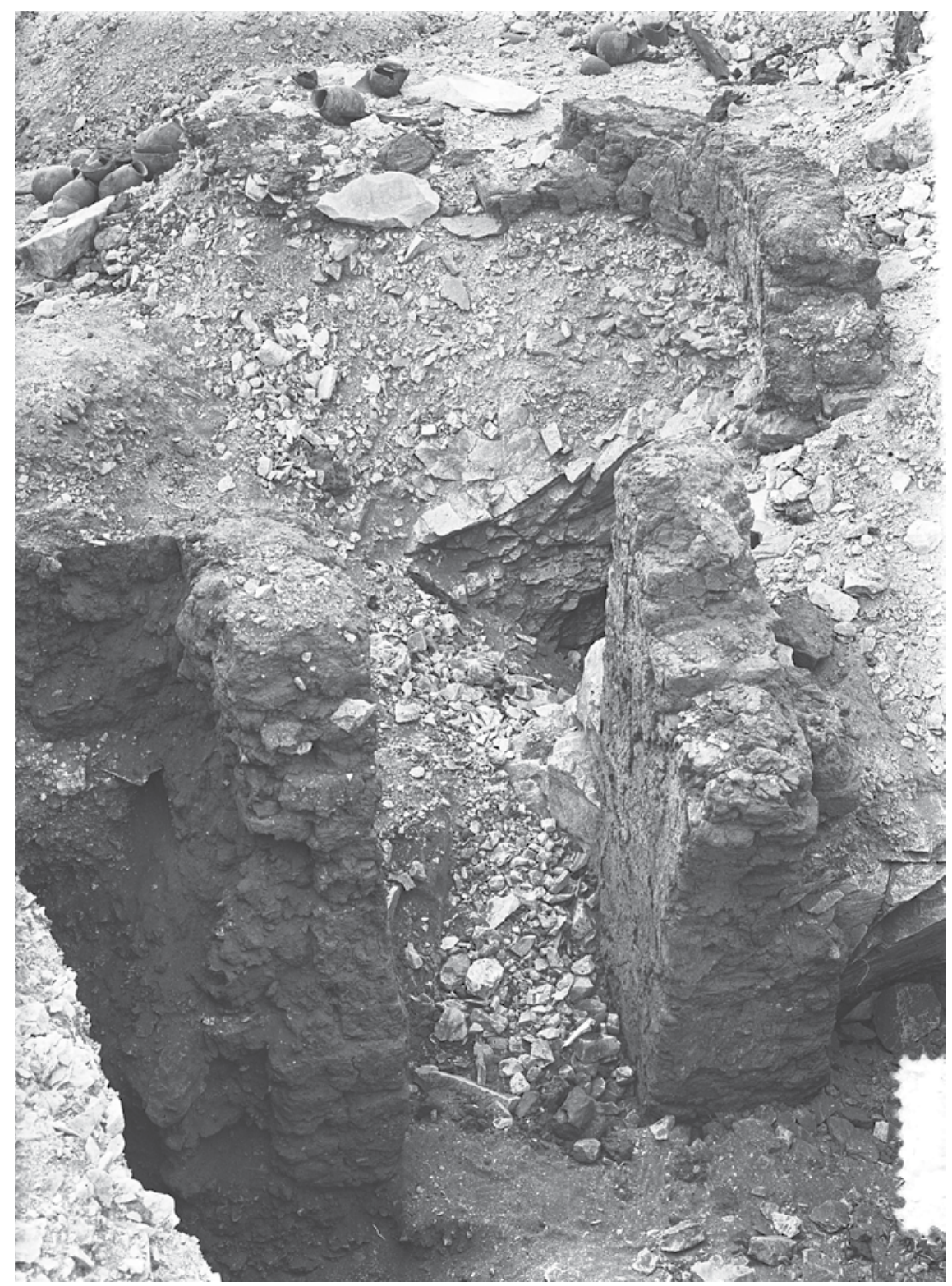

Figure 1.13 Doorway of N 3747 (NED-C-8504) 


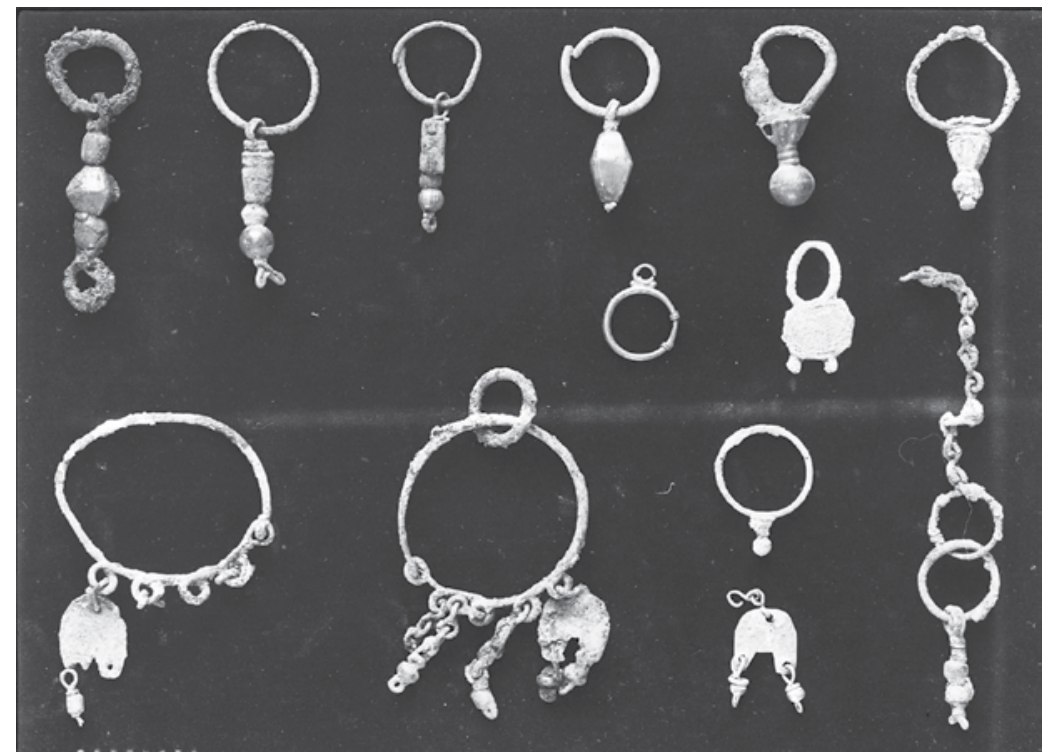

FIGURE 1.14 (Upper): 1. earring ( $\mathrm{N}_{3747}$, 4, iv), 2. earring $\left(\mathrm{N}_{3747}, 5\right.$, vi), 5. earring (N 3747, 17, iii); (middle): 1. gold earring (N 2812, ii); (bottom): 1-2. earring $(\mathrm{N} 3747,22, \mathrm{i}-\mathrm{iv}), 5$. copper earring with glass bead pendants (N 2002, ii) (NED-C-8451)

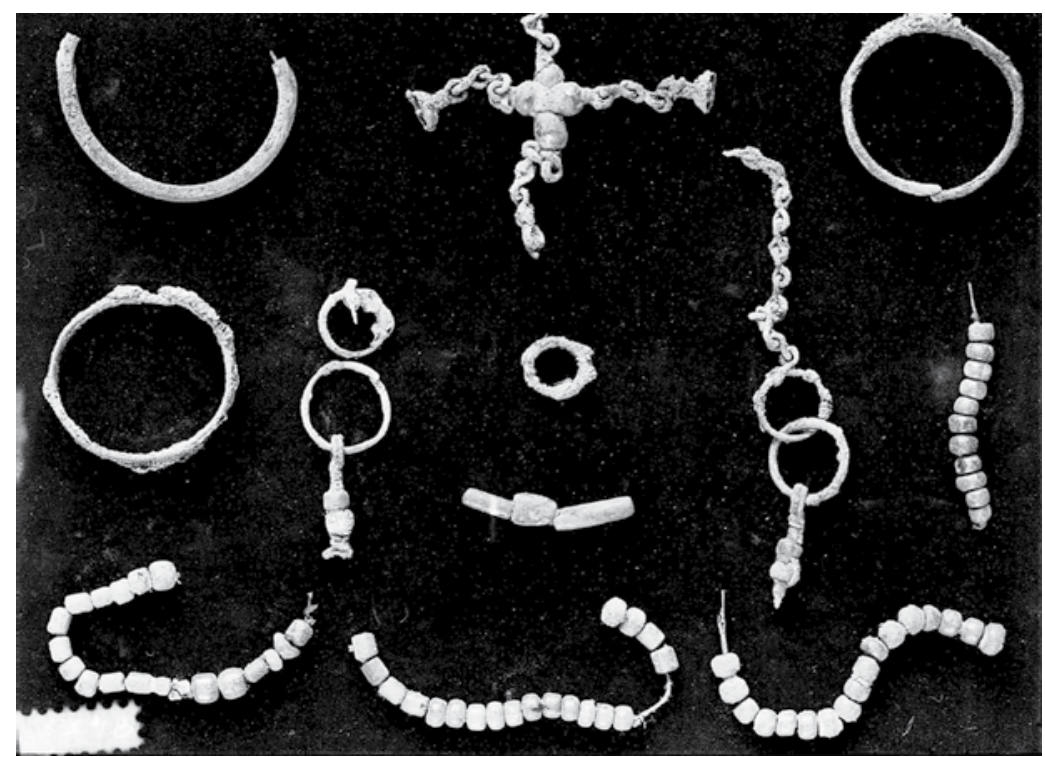

FIGURE 1.15 (Upper): 2. cross of glass beads and copper wire (N 2002, i); (middle): 5. copper earring with glass bead pendants ( $\mathrm{N} 2002$, ii) (NED-C-8455) 


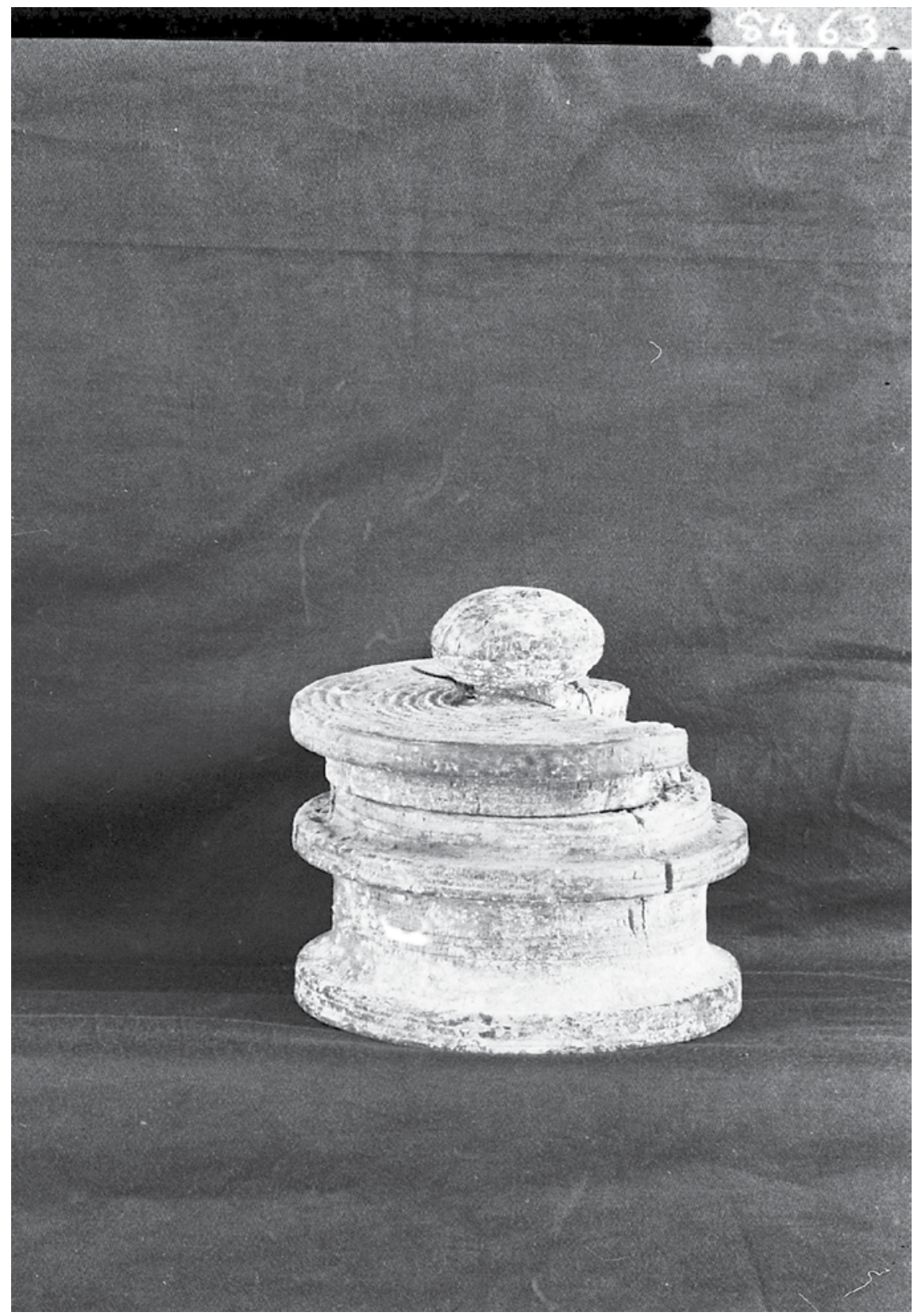

FIGURE 1.16 Wooden box found in filling on west side (N 2007) (NED-C-8463) 


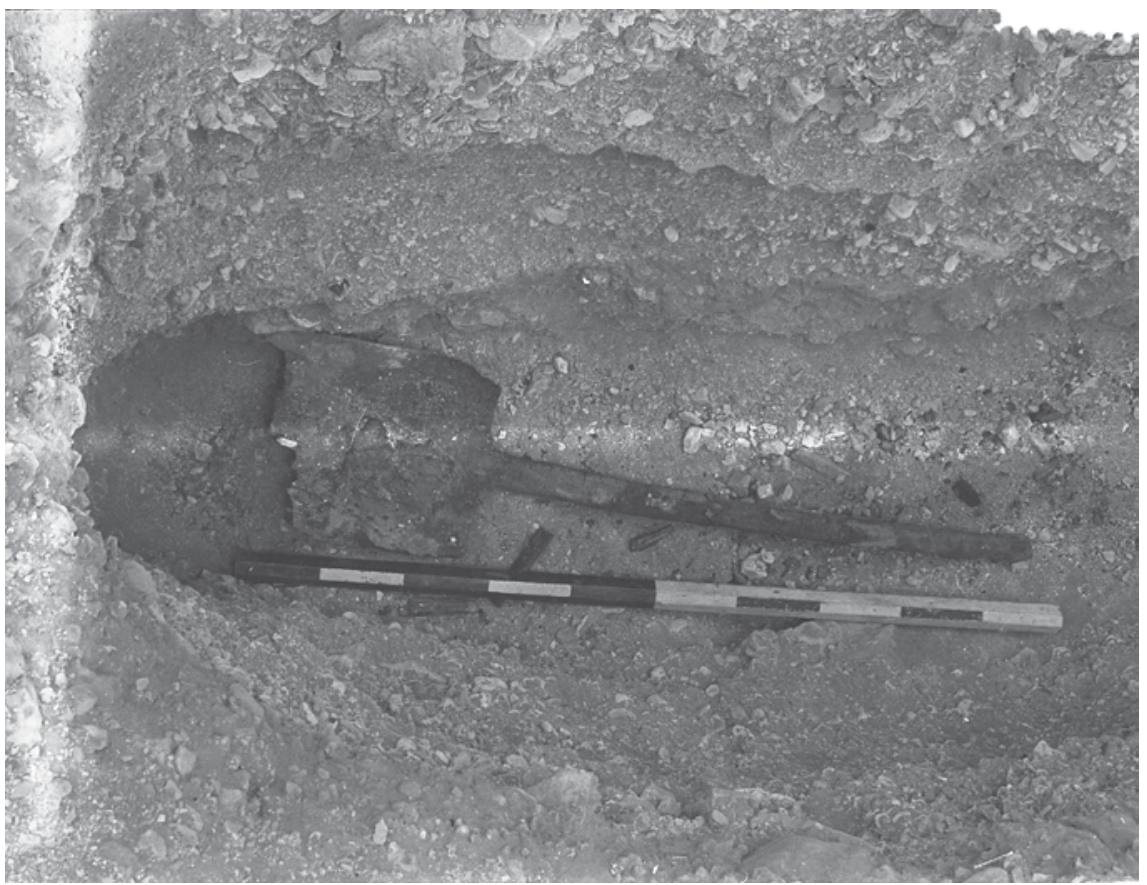

FIGURE 1.17 Broken wooden spade as found under the body in N 2219 (NED-C-7709)

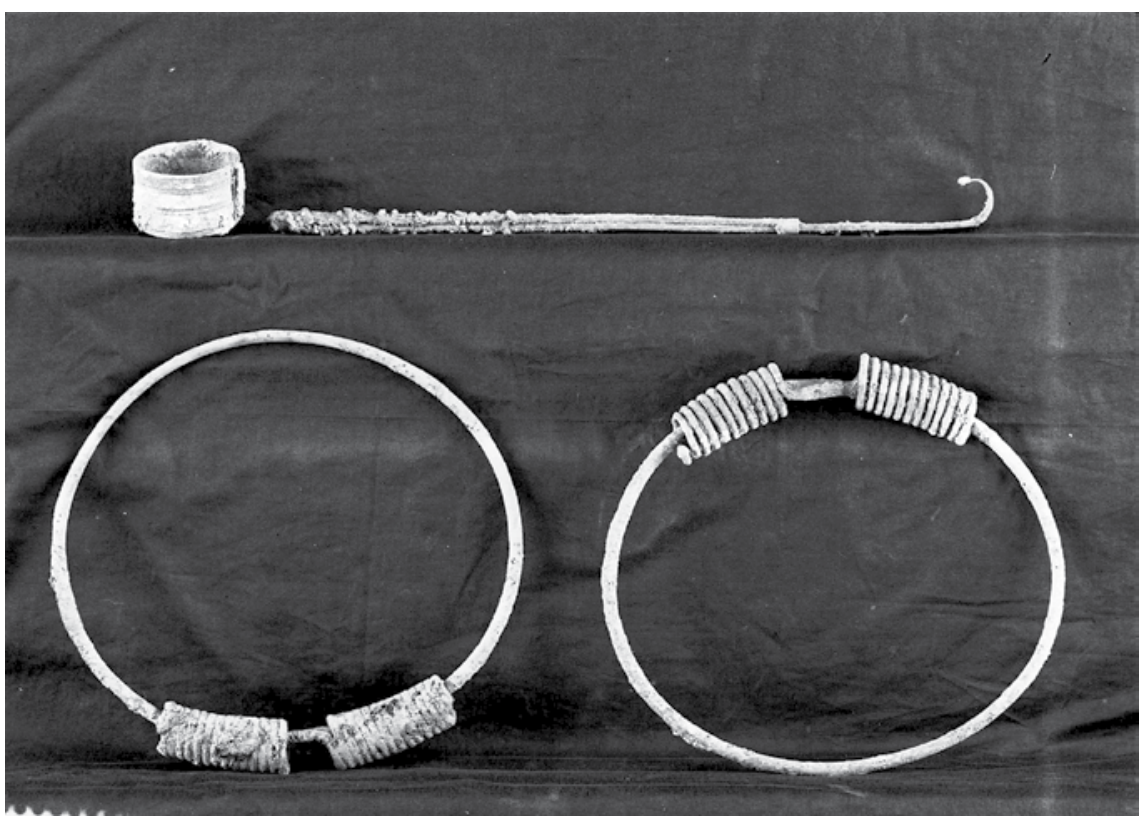

FIGURE 1.18 Copper dipper and handle (N 2417) and bracelets/circlets (as in N 2102, N 3747, 4, i, 21, i) (NED-C-8472) 


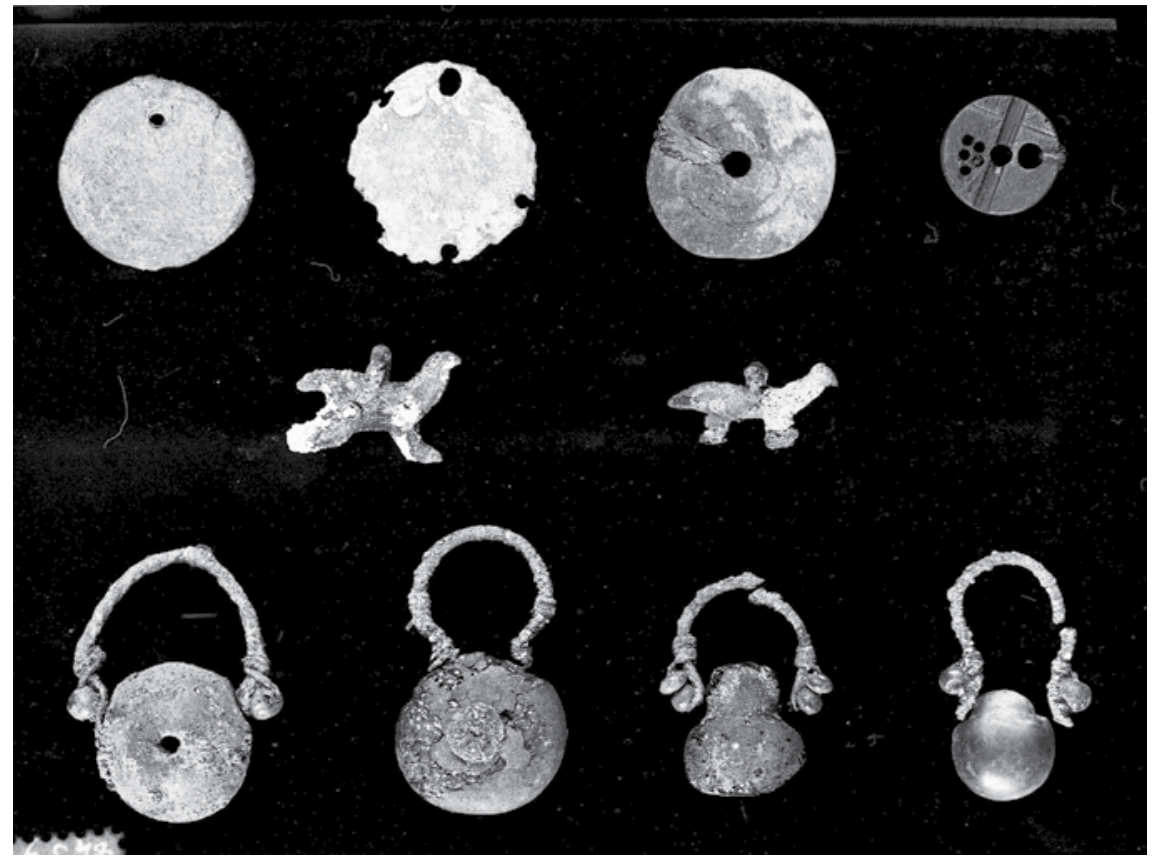

FIGURE 1.19 Jewelry from Coptic tombs. (Middle left): Tentatively identified by excavator as bronze earring (N 2813) (NED-C-8459)

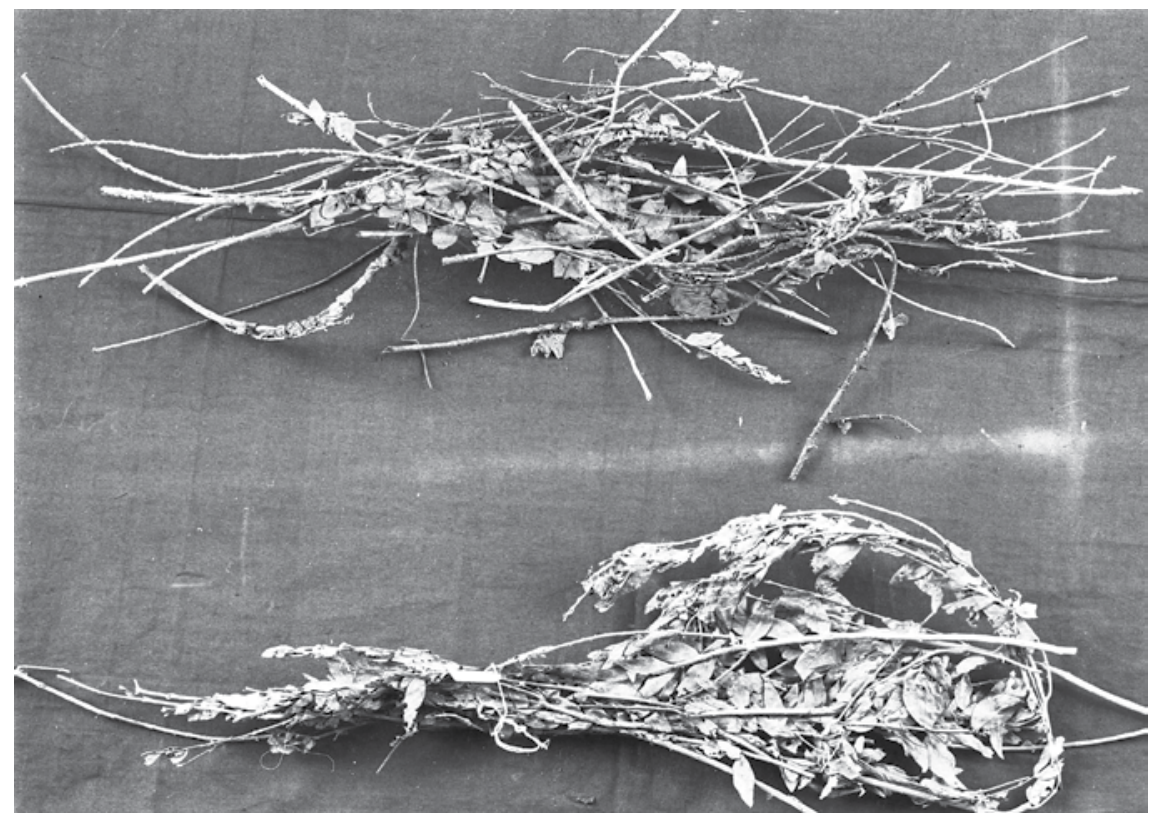

FIGURE 1.20 Dried plant bundles (N 2812, N 2439) (NED-C-8559) 